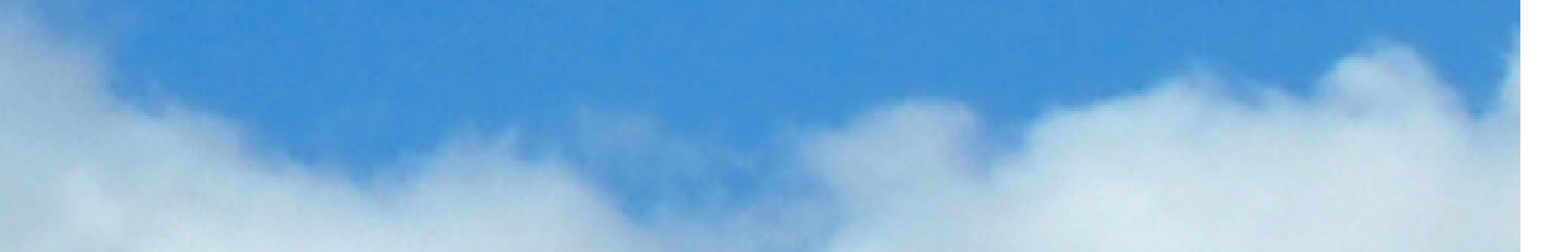

\title{
CIÊNCIAS AGRÁRIAS: A MULTIDISCIPLINARIDADE DOS RECURSOS NATURAIS
}

VOLUME II

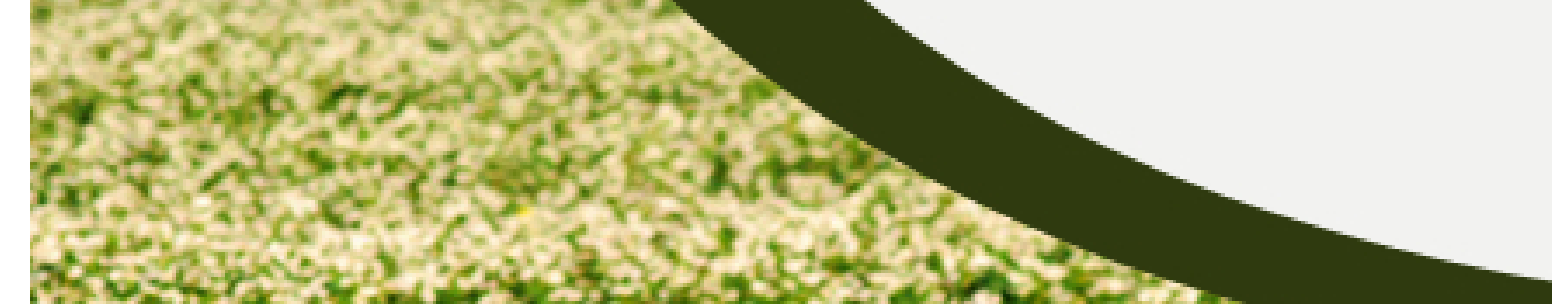

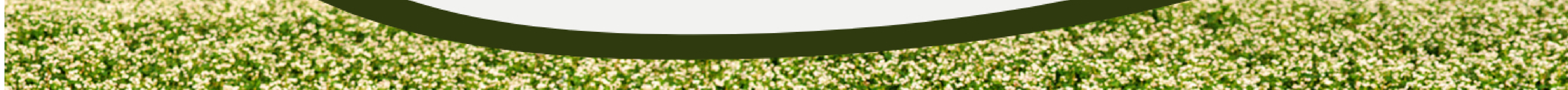

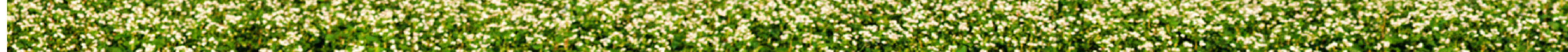

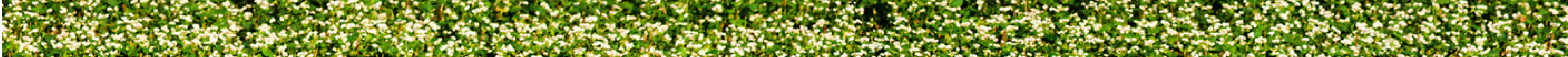

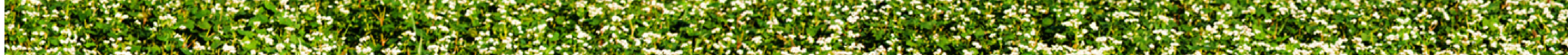

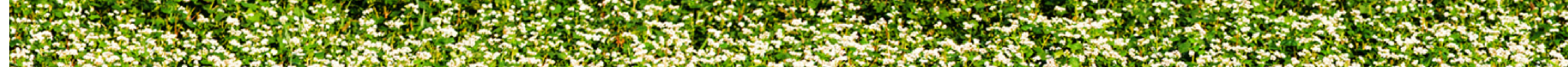
17.

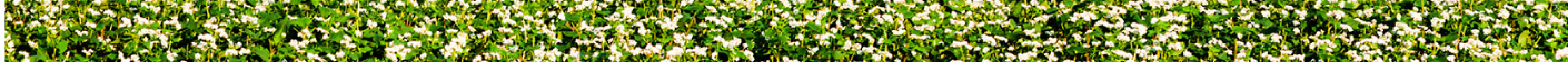

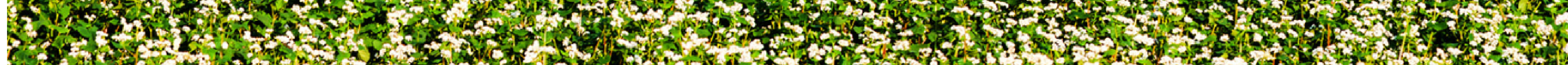

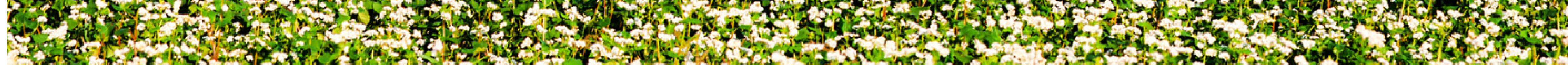

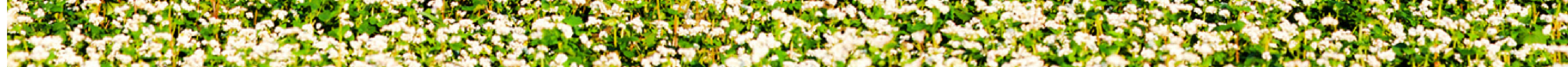

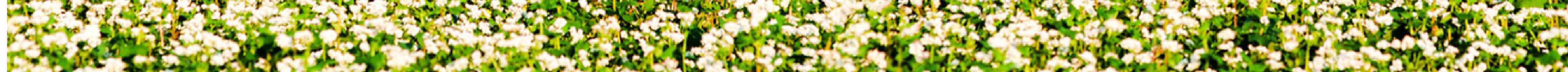

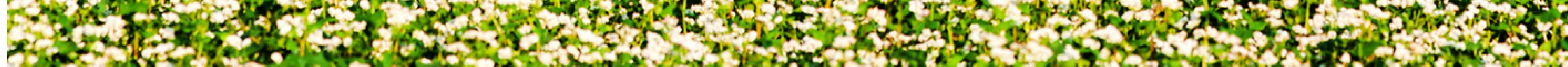

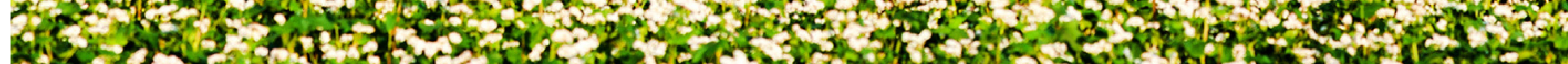

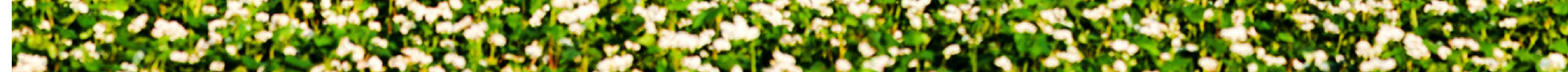

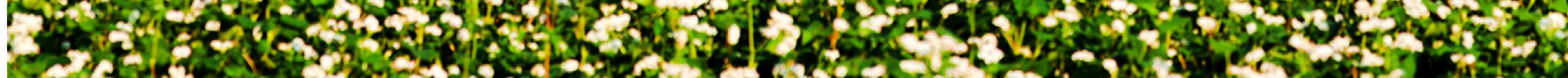

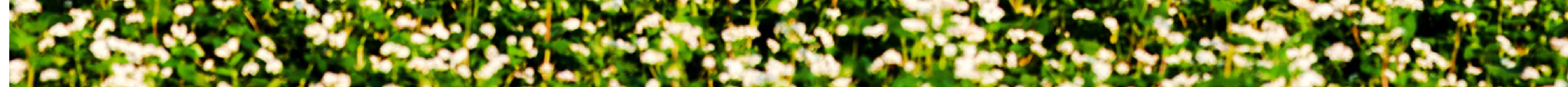
(1)

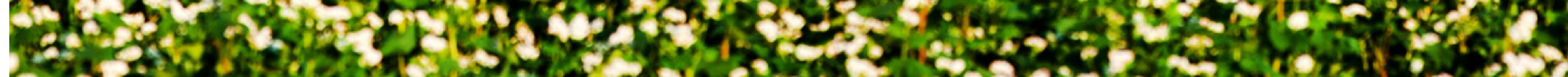

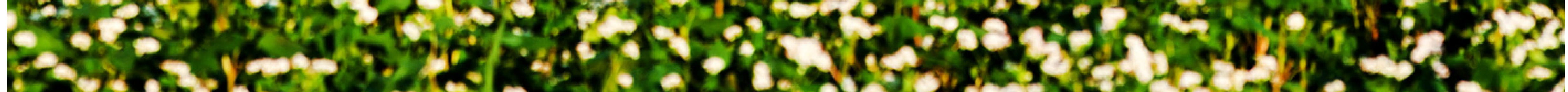

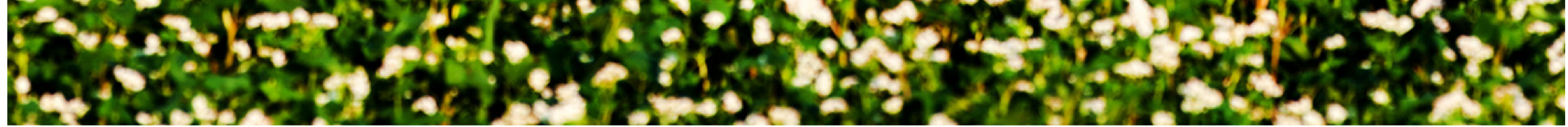


Frederico Celestino Barbosa

Ciências agrárias: a multidisciplinaridade dos recursos naturais

$2^{\mathrm{a}} \mathrm{ed}$.

Piracanjuba-GO

Editora Conhecimento Livre

Piracanjuba-GO 
$2^{\mathrm{a}} \mathrm{ed}$

\section{Dados Internacionais de Catalogação na Publicação (CIP)}

Barbosa, Frederico Celestino
B238C Ciências agrárias: a multidisciplinaridade dos recursos naturais
/ Frederico Celestino Barbosa. - Piracanjuba-GO

Editora Conhecimento Livre, 2021

293 f.: il

DOI: $10.37423 / 2021$. edcl297

ISBN: 978-65-89955-52-8

Modo de acesso: World Wide Web

Incluir Bibliografia

1. agronomia 2. engenharia-florestal 3. engenharia-agrícola 4. medicina-veterinária 5. engenhariade-pesca I. Barbosa, Frederico Celestino II. Título

CDU: 630

https://doi.org/10.37423/2021.edc1297

O conteúdo dos artigos e sua correção ortográfica são de responsabilidade exclusiva dos seus respectivos autores. 


\title{
EDITORA CONHECIMENTO LIVRE
}

\section{Corpo Editorial}

\author{
Dr. João Luís Ribeiro Ulhôa \\ Dra. Eyde Cristianne Saraiva-Bonatto \\ Dr. Anderson Reis de Sousa \\ MSc. Frederico Celestino Barbosa \\ MSc. Carlos Eduardo de Oliveira Gontijo
}

$\underline{\text { MSc. Plínio Ferreira Pires }}$

Editora Conhecimento Livre

Piracanjuba-GO 


\section{SUMÁRIO}

CAPÍTULO 1 8 A RELAÇÃO ENTRE COMUNICAÇÃO DE RISCOS E EXTENSÃO RURAL EM TEMPOS DE PANDEMIA DA COVID-19

Daniela de Ulysséa Leal Ivonete da Silva Lopes Miriam do Carmo Lima DOI 10.37423/210704464

CAPÍTULO 2

NOVAS TECNOLOGIAS PARA APLICAÇÃO OU SUBSTITUIÇÃO DOS AGROTÓXICOS: UM ENFOQUE OCUPACIONAL

Priscila Souza Pereira

Alexandre da Silva Adão

Cleonice Campos Teixeira

Jéssica Pontes Rangel

Zenil Ricardo Cunha Rodrigues de Oliveira

DOI 10.37423/210704486

CAPÍTULO 3

CARACTERIZAÇÃO DO POTENCIAL GERMINATIVO DE TRÊS CULTIVARES DE PIMENTA MALAGUETA SUBMETIDAS AO SUBSTRATO AUTOCLAVADO E NÃO AUTOCLAVADO

Juliano Milhomem Ribeiro

Cide Moreira da Silva

Luís Henrique Froés Michelin

Diniz Didier Dias

Lúcio Mário Quirino do Nascimento

Thiago Magalhães de Lázari

Cid Tacaoca Muraishi

DOI 10.37423/210704525

CAPÍTULO 4

ANÁLISE FITOQUÍMICA E ESTRUTURAL DA MUCILAGEM DE ALOE BARBADENSIS MILLER

Beatriz da Silva Batista

Walajhone Oliveira Pereira

Dágyla Mayara Oliveira Dias

Ana Raquel Araújo da Silva

Fernando José Figueiredo Agostinho D’Abreu Mendes

Ana Angélica Mathias Macêdo

DOI 10.37423/210704533 
METABÓLITOS SECUNDÁRIOS E CONSTITUINTES QUÍMICOS DAS FOLHAS DE CROTON

RHAMNIFOLIOIDES (QUEBRA-FACA)

Dayseane Sales Bernardo Campelo

Suzana Moreira de Lima

Fabíola Soraia Vital Campos Barbosa da Silva

Sofia Suely Ferreira Brandão Rodrigues

Cláudia de Albuquerque Maranhão

DOI 10.37423/210704535

\section{CAPÍTULO 6}

A GESTÃO AMBIENTAL DAS EMBALAGENS DE AGROQUÍMICOS REALIZADA PELOS

PEQUENOS PRODUTORES NO POLO IRRIGADO DE PETROLINA-PE

Mary Ann Saraiva Bezerra Fornelos Pereira

Melina Fernanda Silva Costa

Janete Rodrigues Matias

Maria Aline de Lima Silva

DOI 10.37423/210704538

CAPÍTULO 7

CARACTERIZAÇÃO E AVALIAÇÃO DO POTENCIAL POLUIDOR DA ÁGUA RESIDUÁRIA

PROVENIENTE DO PROCESSAMENTO DO FRUTO DO AÇAIZEIRO

RENATO AUGUSTO PAMPLONA PEREIRA

FERNANDA LAMEDE FERREIRA DE JESUS

RAFAELA FERREIRA CARVALHO

LUCIANA YUMIE SASAKI BORGES

ADRIANO BICIONI PACHECO

JHENIFER COSTA DE OLIVEIRA

ARTHUR CARNIATO SANCHES

CRISTIANE FERNANDES LISBOA

JANNAYLTON EVERTON OLIVEIRA SANTOS

DOI 10.37423/210704543

CAPÍTULO 8

PESCA, AQUICULTURA E QUALIDADE DE VIDA: UM ESTUDO DE CASO NAS ILHAS DE

ANANINDEUA, PARÁ.

PÂMELA MELO COSTA

FRANCISCA NARA CONCEIÇÃO MOREIRA

ANA RACHEL BRONI DE JESUS

EVERTON SILVA TEIXEIRA

DOI 10.37423/210804555 
SUPERAÇÃO DA DORMÊNCIA DE SEMENTES DE QUALEA PARVIFLORA MART. (PAU-

TERRA)
LARISSA DA SILVA CINTRA
GILBERTO IRIS SOUZA DE OLIVEIRA
HYGOR GOMES DE ALMEIDA SOUSA
DALTON HENRIQUE ÂNGELO
FLÁVIA BEZERRA SOUZA
MILLENA OLIVEIRA XAVIER
VALERIA CARDOSO LOPES
DANIEL RAMOS DE SOUZA
JOÃO PEDRO NOLETO BARBOSA
PRISCILA BEZERRA DE SOUZA
DOI 10.37423/210804561

CAPÍTULO 10

ANÁLISE DAS CONCENTRAÇÕES DE BIOGÁS EM LIXÃO DESATIVADO NO MUNICÍPIO DE JUAZEIRO DO NORTE-CE

Érika Romana Gomes

Perboyre Barbosa Alcântara

Francisco Gleson dos Santos Moreira

Jéssica Bezerra de Sousa

DOI 10.37423/210804562

\section{CAPÍTULO 11}

A REFLECTÂNCIA DO MATERIAL PLÁSTICO EM PROL DA GERAÇÃO DE TECNOLOGIAS LIMPAS

Sebastião Leandro de Souza

Juliana Verçosa Batinga

Vicente Rodolfo Santos Cezar

Renato de Mei Romero

José Aparecido da Silva Gama

Adelmo Lima Bastos

DOI 10.37423/210804566

CAPÍTULO 12

AVALIAÇÃO DO CURSO TÉCNICO EM COOPERATIVISMO: LIMITES E PERSPECTIVAS A PARTIR DOS OLHARES DOS DISCENTES.

DENISE CÁSSIA DA SILVA

Lúcia de Fátima Lúcio da Costa

DOI 10.37423/210804567 
FITOSSOCIOLOGIA E USO MÚLTIPLO DE ESPÉCIES ARBUSTIVAS-ARBÓREAS DE UM

FRAGMENTO DE CERRADO, REGIÃO NORTE DA AMAZONIA LEGAL

MARCOS VINICIUS DE MELO AMORIM

HYGOR GOMES DE ALMEIDA SOUSA

FLÁVIA BEZERRA SOUZA

MILLENA OLIVEIRA XAVIER

VALERIA CARDOSO LOPES

RENATA CARVALHO DA SILVA

HELOISA ARAÚJO DANTAS

DANIEL RAMOS DE SOUZA

JOÃO PEDRO NOLETO BARBOSA

PRISCILA BEZERRA DE SOUZA

DOI 10.37423/210804569

CAPÍTULO 14

DIAGNÓSTICO DO DESTINO FINAL DAS LÂMPADAS FLUORESCENTESPÓS- CONSUMO

UTILIZADAS NA ILUMINAÇÃO PÚBLICA DOMUNICÍPIO DE BOA VISTA-RR

Daniela Cristina da Silva Melo

Antonia Raniely Vieira da Silva

Leovergildo Rodrigues Farias

Jozilene de Souza

DOI 10.37423/210804570

CAPÍTULO 15

AVALIAÇÃO DAS CARACTERÍSTICAS FÍSICO-QUÍMICAS DE FRUTOS DO NONI (MORINDA

CITRIFOLIA LINN.)

Wellkens David da Silva Praxedes

Lucas Figueira da Silva

Mateus Madruga da Silva

José Carlos da Silva

José Marcílio da Silva

Amanda Reges de Sena

DOI 10.37423/210804573

CAPÍTULO 16

ESTRATÉGIAS PARA O DESENVOLVIMENTO DE UMA COMUNIDADE MARGEADA PELO RIO IPANEMA E O CANAL DO SERTÃO EM SANTANA DO IPANEMA/AL

VAGNA DA SILVA TORRES

DOI 10.37423/210804574 
AVALIAÇÃO DA POTENCIALIDADE DE TRÊS CULTIVARES DE MANDIOCA PARA A

PRODUÇÃO DE ETANOL NA REGIÃO CENTRAL DO ESTADO DO TOCANTINS

Kallyana Moraes Carvalho Dominices

Valdira Dias Pereira de Carvalho

Tarso da Costa Alvim

DOI 10.37423/210804579

CAPÍTULO 18

A REGIÃO MERCOESTE E O FUTURO DA PRODUÇÃO DE BIODIESEL NO BRASIL

Vinícius Souza Ribeiro

José Eustáquio Canguçú Leal

DOI 10.37423/210804586

CAPÍTULO 19

234

PROGRAMA NACIONAL DE PRODUÇÃO E USO DE BIODIESEL (PNPB): REFLEXÕES

ACERCA DA AGRICULTURA FAMILIAR, DESENVOLVIMENTO SUSTENTÁVEL E GESTÃO

SOCIAL

Vinícius Souza Ribeiro

José Eustáquio Canguçú Leal

DOI 10.37423/210804587

CAPÍTULO 20

ELABORAÇÃO E ACEITABILIDADE DE IOGURTE TIPO LÍQUIDO COM ARATICUM (ANNONA

CRASSIFLORA)

AFRA MARIA DO CARMO BANDEIRA DO NASCIMENTO

MELINA DA CONCEIÇÃO MACEDO DA SILVA

SUYANNE DO ESPIRITO SANTO DE S. FEITOSA

DOI 10.37423/210804598

CAPÍTULO 21

ECONOMIA DO MEIO AMBIENTE E DESENVOLVIMENTO SUSTENTÁVEL: PRINCÍPIOS E

FUNDAMENTOS TEÓRICOS

José Nilton de Melo

DOI 10.37423/210804599

CAPÍTULO 22

CINZA VEGETAL COMO FONTE ALTERNATIVA DE POTÁSSIO NA NUTRIÇÃO DA CULTURA

DE ALFACE (LACTUCA SATIVA)

Ruy Borges da Silva

Roberta de Freitas Souza

FERNANDA BORGES MARTINS

DOI 10.37423/210804601 


\section{Capítulo 1}

doi) $10.37423 / 210704464$

\section{A RELAÇÃO ENTRE COMUNICAÇÃO DE RISCOS E EXTENSÃO RURAL EM TEMPOS DE PANDEMIA DA COVID-19}


Resumo: O novo coronavírus se disseminou rapidamente pelas cidades do interior e no meio rural, onde a população é mais vulnerável, pela ausência e/ou distância dos aparatos de saúde. O objetivo deste artigo é analisar como a extensão rural tem contribuído para comunicar os riscos da Covid-19. Estuda-se as estratégias comunicacionais utilizadas durante a pandemia pela Empresa de Assistência Técnica e Extensão Rural do Estado de Minas Gerais (Emater-MG), que atende aproximadamente 400 mil agricultores. Baseado na análise de conteúdo do material produzidos pela Emater, observou-se a ampliação do uso das mídias digitais, pois muitas dessas peças empregam o humor e expressam em inglês o que pode comprometer a compreensão por parte do público. O estudo também aponta a necessidade de capacitação destes agentes para situações de risco.

Palavras-chave: Comunicação de Risco; Extensão Rural; Covid-19. 


\section{INTRODUÇÃO}

Este texto é escrito no momento em que o novo coronavírus faz 500 mil vítimas no Brasil, entre metrópoles e cidades do interior, atingindo até as localidades mais remotas. Em Minas Gerais, a Covid19 está em quase todas as 853 cidades, a grande maioria tem menos de 10 mil habitantes, onde os leitos de terapia intensiva são escassos ou inexistentes (PEIXOTO, 2020). Nesses pequenos municípios residem a população rural, estimada em cerca de 3 milhões entre os 19,5 milhões de mineiros $(\text { IBGE,2010) })^{2}$.

O fato é preocupante principalmente porque o público rural apresenta significativo contexto de vulnerabilidade social, como baixa escolaridade, pois $16,7 \%$ nunca frequentaram a escola, $53,1 \%$ possuem o Ensino Fundamental incompleto e possuem condições precárias de moradia: 30,4\% dos rurais não possuem água encanada e $67,4 \%$ das casas não possuem nenhum tipo de esgotamento sanitário (BRAGA, 2015). Esta fragilidade se reflete também no acesso à informação e à saúde, em especial pela indisponibilidade de serviços de saúde públicos nessas áreas acesso e pela falta do hábito de saúde como prevenção (ARRUDA, MAIA, ALVES, 2018). A situação vivenciada de vulnerabilidade é agravada durante a pandemia pelas condições socioeconômicas e pela falta de informação adequada (GOMES, 2020).

Diante deste contexto, o serviço de extensão rural e assistência técnica (ATER) se vê diante de um novo desafio: como continuar a dar suporte ao produtor em tempos de distanciamento social, visto que as criações e lavouras não obedecem a dinâmicas sociais, e como orientar os agricultores sobre os riscos perante uma questão de saúde pública tão séria como a pandemia do novo coronavirus? Será que as perspectivas propostas pela nova ATER Digital conseguirão atender as reais demandas do homem do campo?

O objetivo deste artigo é analisar como a extensão rural tem contribuído com a comunicação dos riscos do novo coronavírus, para tanto vamos nos debruçar sobre as estratégias comunicacionais utilizadas durante a pandemia pela Empresa a de Assistência Técnica e Extensão Rural do Estado de Minas Gerais (Emater-MG). A empresa estudada é vinculada à Secretaria de Estado de Agricultura, Pecuária e Abastecimento de Minas Gerais (SEAPA) e está presente em cerca de 790 municípios mineiros, atendendo aproximadamente 400 mil agricultores. Pela abrangência da empresa no interior do estado, percebe-se seu potencial como agente comunicador na prevenção contra o novo coronavírus. 
O presente artigo se divide em cinco seções, além desta introdução, onde são apresentadas o histórico da extensão rural no Brasil, o aporte teórico da comunicação de riscos, a metodologia da pesquisa, análise dos conteúdos, bem como as considerações finais.

\section{A EXTENSÃO RURAL E O USO DA COMUNICAÇÃO COMO FERRAMENTA DE MODERNIZAÇÃO}

A comunicação foi uma ferramenta crucial para a implementação de um projeto de modernização do meio rural brasileiro e seu papel "como gerador de divisas e para suprir as necessidades das classes urbanas, sem onerar o capital industrial" (FONSECA, 1985, p. 61). Na primeira metade do século XX, a ciência e a tecnologia passaram a ser a "promessa de uma vida melhor" (SILVA, 2009, p. 23), dando início, a convênios entre governos latino-americanos e agências estadunidenses para a difusão de conteúdo técnico-científico com o intuito de informar e persuadir os agricultores a adotarem novas práticas em suas atividades. Para fomentar este paradigma, lançava-se mão de um pacote de ferramentas que incluiam crédito agrícola, extensão rural, reforma agrária, informação nutricional e estradas de acesso, de modo a acelerar a passagem da sociedade "tradicional" para a "moderna".

Com este objetivo, em 1948 foi assinado um convênio entre agência de fomento estadunidense e o Governo do Estado de Minas Gerais, criando assim a Associação de Crédito e Assistência Rural (ACAR), atual Empresa de Assistência Técnica e Extensão Rural (Emater), impulsionando pela primeira vez no Brasil a Extensão Rural enquanto política pública. A ACAR, então, se expande, aumentando o número de escritórios no estado, baseados em um modelo de equipe formada por um supervisor agrícola, uma supervisora doméstica, para prestar assistência às esposas dos agricultores no tocante à alimentação e saúde da família,_um auxiliar administrativo e um Jipe Willys para ajudar no transporte dos profissionais (FONSECA, 1985).

Este período de transformação no meio rural é caracterizado pelo aspecto humanista-assistencialista do serviço de extensão rural (1948-1960), quando, em geral, os extensionistas não "problematizavam" com os agricultores, apenas procuravam induzir mudanças de comportamento por meio de metodologias pré-estabelecidas (FONSECA, 1985), as quais não favoreciam o florescimento da consciência crítica nos indivíduos, atendendo apenas as suas necessidades imediatas.

Para se difundir, então, o modelo agropecuário idealizado, lançou-se mão de um suporte técnico vindo diretamente dos Estados Unidos, que consistia em cartazes, folhetos, cartilhas, audiovisuais, programas de rádio e de vídeos, introduzidos nos contextos histórico, cultural e político do Brasil. Esta metodologia se caracteriza por ser uma ação domesticadora, pela persuasão sobre os sujeitos rurais 
para que estes apliquem novas possibilidades técnicas e econômicas e se difere de uma ação educadora dentro da visão de Paulo Freire (1977). Segundo o autor, persuadir implica em um sujeito (que persuade) e um objeto (que é persuadido), corroborando para uma ideia de objetificação dos sujeitos rurais.

Todavia, segundo Fonseca (1985, p. 41), “a utilização intensiva do mass media não resultou como esperado". Não é difícil perceber que o material, produzido nos Estados Unidos, baseado na cultura e lógica estadunidense, tenha encontrado obstáculos ao se fazer compreender por parte do homem rural brasileiro pós-guerra. Particularidades locais e culturais interferem no entendimento da mensagem, sendo complicado reproduzir um modelo que se aplique a públicos distintos. Outra limitação deste modelo difusionista é a verticalidade, pois a população rural é classificada apenas como aberta ao progresso ou tradicional, ignorando outras inúmeras contradições, visto que, geralmente, as inovações não refletiam as necessidades dos receptores.

Sustentando o discurso ideológico de aumentar a produção de alimentos para acabar com a fome no mundo, foi iniciada nos anos 1940 nos Estados Unidos, a denominada Revolução Verde, que significou uma mudança profunda no processo de produção agrícola (LIMA; AZEVEDO, 2013). Tinha em sua essência o uso de agrotóxicos e insumos de origem industrial como: sementes de alto rendimento, fertilizantes, pesticidas, herbicidas e fungicidas, além de sistemas de irrigação mecanizados. No Brasil, já sob o regime militar, esta revolução teve a participação de agências e instituições internacionais privadas voltadas ao desenvolvimento da agricultura, que via na produção em larga escala, com uso de tecnologia, a solução encontrada para combater a fome no mundo (ALVES; TEDESCO, 2015), privilegiando médios e grandes agricultores do Sul e Sudeste, que davam ênfase à produção para o comércio exterior (GRISA; SCHNEIDER, 2014).

Os serviços de assistência técnica e extensão rural (ATER) serviam como instrumento para a introdução do homem do campo na dinâmica da economia de mercado e passaram, inclusive, a contar com especialistas por produtos. Esses profissionais tinham a atribuição de difundir a transferência de tecnologias, fortalecendo, assim, a ideia de uma extensão rural voltada a técnicas de venda e ao marketing. Os serviços eram focados na aquisição, por parte dos produtores, de pacotes tecnológicos modernizantes e uso intensivo de capital (máquinas e insumos industrializados), devido à abundância de crédito agrícola subsidiado (FONSECA, 1985). 
Buscando corrigir as inadequações do modelo difusionista clássico ao mundo "subdesenvolvido", como a América Latina, o sociólogo estadunidense Everett Rogers desenvolveu o modelo difusionista produtivista ou inovador, propondo que a mudança da estrutura se dê por meio da difusão e adoção de ideias novas (FONSECA, 1985). Este período (entre 1964 - 1980) se caracterizou pela abordagem "difusionista produtivista" dos serviços de ATER, que tinha por objetivo incorporar inovações junto aos agricultores chamados progressistas, ou seja, aqueles mais abertos às mudanças. Gerando, desta forma, uma reação em cadeia e encurtando o tempo intermediário entre uma inovação pelos centros de pesquisa e sua adoção generalizada pelos agricultores (BORDENAVE, 1983).

Este modelo difusionista subdivide-se em difusão de conhecimento (difusão através dos meios de comunicação e instâncias impessoais) e difusão de convicção (se dá através de canais interpessoais). Esta segunda etapa tem significativa importância no processo visto que é o momento da tomada de decisão, destacando a importância dos agricultores progressistas e seus exemplos nas práticas de adoção de inovações (ROGERS, 1974). Segundo o autor, o processo de transformação de um sistema social (cambio social), é dividido em duas categorias: cambio inmanente (intrínseco), quando os membros de um sistema social buscam desenvolver uma inovação sem influência externa, e cambio por contato, quando se introduz num sistema social uma ideia nova originada em fontes externas, como foi o caso da Revolução Verde no Brasil e demais países da América Latina.

Este modelo de desenvolvimento comprometeu a autonomia produtiva no campo e colaborou com o agravamento da concentração de terras, da poluição, do êxodo rural, empobrecimento do meio rural e exclusão social dos agricultores de autoconsumo ou que acessavam apenas os mercados locais de comercialização (FONSECA, 1985).

Na década de 1990 é lançado o Programa Nacional de Fortalecimento da Agricultura Familiar (Pronaf), com intuito de ser um instrumento capaz de aumentar as possibilidades de investimento dos agricultores familiares e promover a mudança da base técnica da agricultura no Brasil (AQUINO; SCHNEIDER, 2015), pautando o serviço de ATER num direcionamento burocrático.

Na mesma década, a capacidade de explicar a nova perspectiva do meio rural fez com que o termo agronegócio se popularizasse, caracterizado pelo crescimento das exportações de produtos agrícolas e agroindustriais, e traduz a complexa integração do setor, apoiada pelas inovações tecnológicas, uso de maquinários, insumos químicos e assistência de cientistas, pesquisadores e especialistas. Novas relações de trocas são estabelecidas por esta integração entre setores da economia, configurando um 
meio rural dependente da indústria, desde a compra de sementes (geralmente híbridas, o que fortalece a dependência), compra de insumos e máquinas, até o beneficiamento e transporte. Desta maneira, muitos agricultores estabelecem uma relação de dependência também com o sistema financeiro, já que para conseguir acessar esta modernização agrícola, recorreram a financiamentos e, tomados por dívidas, precisam produzir em maior quantidade para quitar seus débitos (CAPORAL, 1998).

No início do século XXI a prática de ATER no Brasil passa a ser direcionada para a construção de um modelo de desenvolvimento socialmente includente e ambientalmente sustentável (GRISA; SCHNEIDER, 2014) com políticas de reforma e reordenamento agrário, fortalecimento de ampliação do crédito rural, inclusão produtiva e criação e ampliação dos mercados institucionais. Adota-se a concepção das metodologias participativas, nas quais os agricultores são inseridos no processo "desde os atos da problematização até os atos de decisão" (COELHO, 2005, p 87). Difere-se, portanto da unilateralidade presente em processos comunicacionais sustentados pelo paradigma hegemônico. Nesse processo caberia aos técnicos e extensionistas a tarefa de trazer o uso de metodologias educacionais ativas e o diálogo para o processo de se fazer extensão (OLIVEIRA, 2017). Neste contexto, se ratifica a proposta na qual o agricultor não está desassociado de sua realidade concreta e histórica, considerando os sentidos e significados que estes dão a sua realidade, e se adotando uma perspectiva mais dialógica (FREIRE, 1977).

O serviço de extensão rural foi, desta forma, estimulado a adotar uma abordagem humanista crítica, que vai contra a domesticação do sujeito rural, numa busca pela transformação constante da realidade, na qual tanto o técnico quanto o agricultor podem ser agentes de mudança. Esta visão de mundo demanda uma temporalidade maior para que os efeitos venham à tona, o que se choca com os prazos e a lógica produtivista, muitas vezes desmotivando ações institucionais com esta ótica. Ainda segundo Freire (1977), nas práticas de extensão mais "libertadoras", o extensionista pode exercer seu papel de educador, visto que não há nenhuma categoria de persuasão que tenha cunho justificável. Neste campo educacional, o objeto da extensão se torna sujeito pela sua postura "curiosa face ao mundo", diferentemente de uma visão autoritária, onde objeto e sujeito se polarizam enquanto invadido e invasor cultural

No ano de 2013, a criação da Agência Nacional de Assistência Técnica e Extensão Rural (Anater) passa a orientar novamente o serviço de ATER no sentido do difusionismo tecnológico voltado ao mercado e à agricultura moderna, novamente interpretando o meio rural brasileiro apenas como espaço de 
produção agrícola. A partir de 2016, com o início do governo Michel Temer (2016-2019) e a extinção do Ministério do Desenvolvimento Agrário, a autonomia da prática extensionista é desfavorecida de apoios federais, culminando com a extinção, em 20/02/2020, do Departamento de Assistência Técnica e Extensão Rural pelo presidente Jair Bolsonaro (2019 - atual).

Além disso, segundo o documento "Mexpar 4.0: ATER Digital Conectando Pessoas", produzido pela Emater, pelo Ministério de Agricultura, Pecuária e Desenvolvimento e pelo Governo de Minas Gerais, com o novo governo e o agravamento da pandemia da COVID-19, intensificaram-se as discussões sobre a nova ATER, que se propõe em agir com uma nova forma de trabalho com base na Mexpar (Metodologia Participativa de Extensão Rural), que tem como intuito dar mais agilidade aos processos de extensão rural, gerando uma comunicação mais efetiva entre os extensionistas e o público da ATER, contribuindo para a inclusão digital dos produtores rurais.

Todavia, deve-se refletir sobre como essas novas metodologias participativas atingem de fato a população do campo. Em uma sociedade capitalista e extremamente desigual vivenciam-se processos de desconhecimento da população rural frente às TICs (Tecnologias de Informação e Comunicação), devido à falta de infraestrutura e de distanciamento geográfico, o que faz com que o acesso dessa população, frente as informações sobre a pandemia, se torne mais escasso (NOVO-CORTI et al., 2014).

Desta forma, diante do pluralismo atribuído ao serviço de extensão rural no Brasil, a conjuntura da pandemia do novo coronavírus vem reforçar os aspectos humanísticos da prática e atribuir novos papéis aos seus agentes, demonstrando a importância de uma ATER presencial e humanística (CAPORAL, 2005). Em um cenário de emergência de saúde coletiva, o extensionista tem um papel relevante, desde que sua estratégia de comunicação tenha uma interface com a comunicação de riscos, conceito descrito no próximo tópico.

\section{A COMUNICAÇÃO DE RISCOS}

A prática extensionista demanda que o prestador do serviço tenha habilidades em comunicação (DEL CASTELLO e BRAUN, 2006), todavia, quando as ações se desenham num cenário de riscos à saúde pública, estas habilidades precisam ser mais específicas para promover benefícios e segurança ao público visado. Informações sobre riscos sanitários e medidas de proteção necessitam ser acessadas no devido tempo e frequência (OMS, 2018), o que constatamos com a alta velocidade de contágio do novo coronavírus. 
Então é preciso estabelecer estratégias e mecanismos que facilitem a percepção dos riscos da pandemia pelos agricultores, além de protocolos de prevenção, lançando mão de um processo comunicativo que incorpore as dimensões da aprendizagem e da interpretação, bem como o uso de linguagem adequada. Caso o processo apresente falhas, pode-se incorrer na não compreensão destes riscos, o que pode levar a ações que afetam a saúde destes atores e a contaminação de outros.

Neste sentido, destaca-se o evento do desastre nuclear de Chernobyl, em 1986, quando evidenciouse o despreparo, em todos os níveis, para se enfrentar tal situação de crise, tanto na tomada de medidas emergenciais quanto na comunicação com a população (SORIANO, 2016). A partir de então, os estudos sobre comunicação de risco $(C R)$ se intensificaram e passaram a considerar desde a elaboração de mensagens acerca da natureza do risco, bem como preocupações, opiniões e reações resultantes da divulgação das mensagens.

Desta forma, para que o extensionista consiga comunicar os riscos de maneira eficiente ao seu público atendido, é preciso, além de informar, promover seu envolvimento com a prevenção do risco (COVELLO, 1993). No caso de uma pandemia, este aspecto é especialmente relevante, visto que o engajamento popular na prevenção do novo coronavírus, como a adoção do distanciamento social e uso de máscaras, é a medida mais eficiente, já que as vacinas ainda não estão disponíveis a toda a população.

Estratégias de CR bem-sucedidas tem como base a troca de percepções e opiniões entre os vários atores sociais envolvidos e um alinhamento entre a percepção do risco por parte da fonte da mensagem e do público. Deste modo, deve se considerar que a percepção pública do risco é influenciada por dimensões culturais e sociais. Além disso, diante de um risco, a razão humana pode ficar prejudicada, comprometendo o poder de decisão, devido a fatores que afetam os aspectos emocionais dos indivíduos, como o medo. Segundo Batista (2007, p. 105), “a percepção do risco é moderada pela capacidade percebida do indivíduo em lidar com o problema". O autor afirma que o indivíduo racional passa por diferentes fases ante seu processo decisório: saber da existência do risco, ter conhecimento suficiente do problema para avaliar as alternativas disponíveis, compreender a importância da informação e o impacto em sua vida, ter capacidade de incorporar a informação em seu processo decisório.

Caso o indivíduo que receba a informação inicialmente não tenha habilidade para absorver a informação, o extensionista pode optar pela simplificação da mensagem, pela alternativa mais fácil e 
rápida, não necessariamente a melhor, de modo que as informações compartilhadas sejam compreensíveis por todos os membros envolvidos no processo comunicacional. Desta forma, por saber-se da existência de problemas ligados à percepção do público com relação ao risco, "a mensagem a ser transmitida sobre um evento crítico tem de ser realista e precisa", visto que cada mensagem é interpretada e filtrada de acordo com as experiências individuais (MELO, 2007, p. 130). Percebe-se assim o importante papel do agente comunicador de riscos, no sentido de transpor estas barreiras cognitivas ao levar uma mensagem efetiva.

Lofstedt (2012) destaca o papel da confiança na amplificação social do risco, o fenômeno pelo qual a experiência social do risco é moldada pelos processos de informação, pelas estruturas institucionais, pelo comportamento do grupo social e pelas respostas individuais. Desta maneira, para que a população aceite os protocolos de enfrentamento da Covid-19, ou a existência do risco, é preciso que haja confiança em quem gerencia a comunicação. Neste ponto reforça-se o papel que o extensionista pode desempenhar, visto que a prestação de serviços e assistência técnica de forma continuada tende a construir uma relação de confiança com seu público atendido.

\section{METODOLOGIA}

Esta pesquisa teve como base metodológica a Análise de Conteúdo, procedimento sistemático para levantamento de indicadores que permitam a realização de inferência sobre determinado texto (BARDIN, 1977) do Relatório de Ações da Assessoria de Comunicação da Emater-MG durante o enfrentamento a Covid-19, do mês de março de 2020. Este relatório traz as ações realizadas pela empresa voltadas ao público interno, à imprensa, ações de design e um conjunto de ações voltadas ao público externo, mais especificamente, à sociedade. Durante a primeira etapa da análise de conteúdo, a leitura flutuante ou pré-análise (BARDIN, 1977), foram excluídas as ações que não fazem parte do escopo desta pesquisa, ou seja, as ações que não foram voltadas à sociedade.

As ações de comunicação para o público externo que constam no relatório estão subdivididas em Mídias Sociais, Relações Públicas, o programa televisivo Minas Rural e o programa de rádio Estação Rural. A análise desta pesquisa se concentrou em oito peças comunicacionais da Emater-MG voltadas ao público externo que constam no relatório, nas seções de Mídias Sociais e Relações Públicas. Devido ao tamanho do trabalho aqui proposto, não nos debruçamos sobre a os episódios dos programas de TV e Rádio, indicando lacunas que podem ser preenchidas por futuros estudos. 
Para realizar esta análise de conteúdo adotamos as categorias de Lopes e Leal (2020) criadas com base na discussão teórica sobre comunicação de riscos (COVELLO, 1993; BATISTA, 2007; LOFSTEDT, 2012) e no guia Comunicação de riscos em emergências de saúde pública (OMS, 2018), sendo elas:

a) Temporalidade - diz respeito ao dinamismo da comunicação de risco na incorporação de componentes dos diferentes estágios da pandemia. Essa é uma característica que tem sua relevância acentuada especialmente porque as pesquisas sobre a Covid-19 estão acontecendo simultaneamente a sua ampliação global, ao acompanhamento dos estágios da doença e descobertas sobre o comportamento do vírus. Isso significa que procedimentos de proteção e enfrentamento indicados, principalmente pela OMS, estão sendo adaptados de acordo com as descobertas científicas.

b) Riscos - envolve informações sobre os riscos sanitários que a população corre de contrair o novo coronavírus, as medidas que deverão ser adotadas para o enfrentamento à pandemia e proteção à vida;

c) Adequação - concerne à adaptação das mensagens para diferentes grupos, considerando as distintas estruturas sociais, culturas, estilos de vida, educação, classe social e outros aspectos demográficos como gênero e pertencimento racial.

A pesquisa também lançou mão de análise documental deste relatório e uma entrevista com a gerente de Comunicação da Unidade Central da empresa. Esta unidade concentra os setores administrativos da empresa e dá suporte a 35 unidades regionais e aproximadamente 750 escritórios locais.

\section{O PAPEL DA EXTENSÃO RURAL EM MEIO A PANDEMIA DA COVID-19}

Buscando compreender como a extensão rural tem contribuído com a comunicação dos riscos do novo coronavírus, as oito peças comunicacionais voltadas ao público externo presentes no Relatório de Ações da Assessoria de Comunicação da Emater-MG durante o enfrentamento a Covid-19 foram analisadas segundo as categorias de análise da CR desenvolvida por Lopes e Leal (2020). Apresentamos abaixo os resultados e discussão.

\section{a) Temporalidade}

A situação da pandemia do novo coronavírus se apresentou de maneira surpreendente para todos, segundo a gerente Assessoria de Comunicação (Ascom) da Emater-MG, as soluções foram sendo construídas de forma emergencial, adaptando-as conforme a realidade se impõe. A empresa tomou iniciativas em nível local, regional e estadual, bem como ações voltadas ao público interno e externo. 
Para colaborar com esclarecimentos sobre o Covid-19 para o público externo, a empresa buscou apoio nos meios digitais de comunicação de forma a passar informações de maneira rápida. Contudo, evidencia-se que devido à dificuldade de acesso à internet e às TICs, muitas dessas populações rurais não conseguiram se apropriar das informações repassadas pela empresa (NOVO-CORTI et al., 2014). No site da empresa, na barra principal, encontra-se o menu Covid-19, com todo o conteúdo específico produzido relacionado ao tema, inclusive relatórios de monitoramento junto aos municípios, como questões de abastecimento e comercialização de produtos agropecuários, entre outras.

Além disso, desde o início da pandemia, a empresa lançou mão do WhatsApp, ${ }^{3}$ para se comunicar diretamente com o público. Contudo, também não é preciso o número de agricultores envolvidos nesta rede de comunicação, visto que a empresa envia as peças de comunicação para seus mais de 600 técnicos que capilarizam as mensagens, enviando-as para seus atendidos. Desse modo, os dados de percepção e, consequentemente, o conhecimento dos riscos não se tornam precisos.

\section{b) Riscos}

Depois de categorizado o corpus, interessa-nos entender mais profundamente como os riscos da Covid-19 foram comunicados à sociedade, principalmente devido à dificuldade de acesso da população rural à uma internet de qualidade.

No primeiro mês da pandemia, segundo o Relatório de Ações da Assessoria de Comunicação da Emater-MG, peças comunicacionais "com uma leve pegada de humor", e com foco na prevenção foram enviadas via WhatsApp e por e-mail institucional para o público rural, conforme figura abaixo.
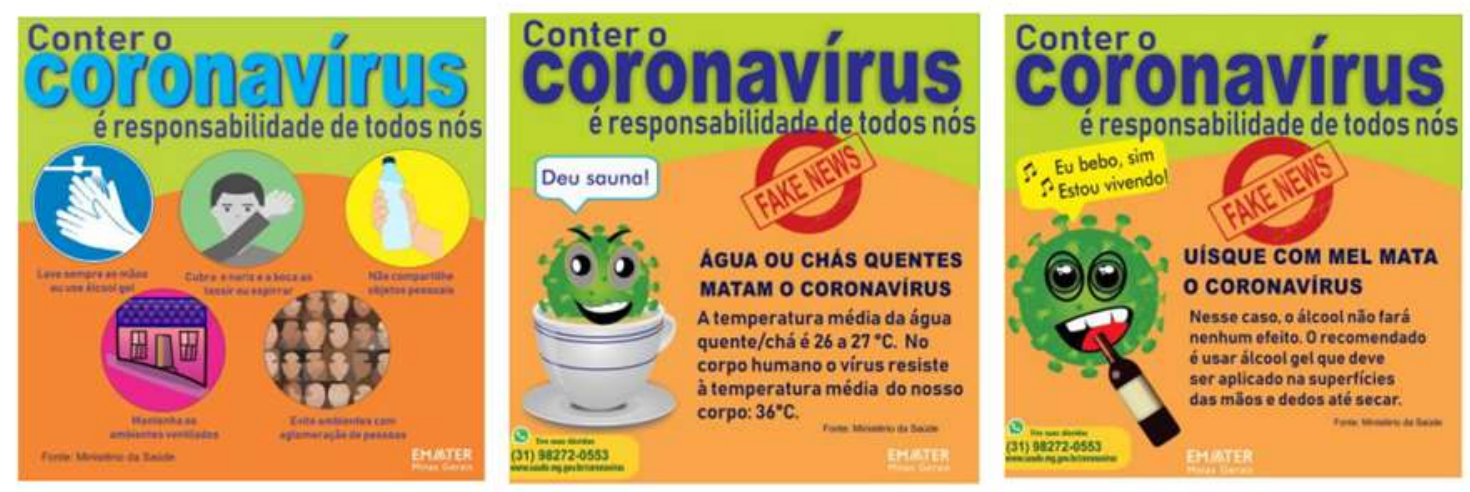

Figura 1, 2 e 3: Peças de comunicação Emater-MG. Fonte: Relatório de ações da Assessoria de Comunicação da Emater-MG durante o enfrentamento à Covid-19 
A opção estratégica de usar o humor para elucidar o público sobre notícias falsas (fake news), que circulam mais intensamente em redes sociais,${ }^{4}$ dentro do escopo da comunicação de riscos não parece apropriado. Nas peças acima apresentadas, as notícias falsas, inclusive, se destacam, já que estão no centro das figuras e o aviso alertando sobre a falsidade da informação vem escrito em inglês. Estratégia que pode limitar o entendimento do dito "humor" pelo homem do campo e se distanciar do autêntico objetivo de alertar sobre os riscos e promover a prevenção ao vírus. Considera-se que a percepção de cada indivíduo com relação ao risco depende de seu referencial interno (BATISTA, 2007) e que o Covid19 é um vírus pouco conhecido pela ciência e sociedade e seus danos são imensos, assim, não há espaço para ambiguidade na comunicação, que pode desencadear uma interpretação errônea por parte do público. Diante disto, reflete-se que desenvolver estratégias de comunicação de riscos requer conhecimentos e preparações específicas, com mensagens claras, objetivas e de fácil entendimento. Como a situação da pandemia é nova, imagina-se que a Ascom-Emater precise buscar referencial que oriente os passos para uma CR eficiente e leve as informações sobre os cuidados durante a pandemia para as populações mais vulneráveis.

Entre as ações de prevenção à Covid-19, a Emater-MG lançou, no início de abril de 2020, uma cartilha para o agricultor familiar com medidas a serem adotadas durante a comercialização nas feiras livres ${ }^{5}$. A cartilha foi uma demanda dos próprios técnicos de campo para fornecer orientações aos agricultores feirantes, sendo divulgada pelos meios eletrônicos, como o site da Emater-MG, e, principalmente, pelo WhatsApp e e-mail. A cartilha conta com as seguintes orientações:

- Montagem das barracas com uma distância mínima de três metros entre elas;

- Necessidade do uso de máscara por todos os feirantes;

- Disponibilização de álcool gel para higienização das mãos;

- Os consumidores devem ser orientados a não tocar em nenhum produto;

- Somente o feirante pode coletar e embalar a mercadoria exposta nas bancas;

- As feiras devem ser realizadas em espaço público, aberto e arejado;

- A participação de feirantes enquadrados no grupo de risco de contaminação da Covid-19 é proibida;

- Comerciantes, funcionários e ajudantes com sintomas respiratórios (tosse, coriza, espirros, falta de ar e febre) não devem permanecer no local

Quadro 01- Medidas Estratégicas para Feiras Livres da Agricultura Familiar na prevenção de contágio do novo coronavírus

Fonte: Cartilha de Medidas Estratégicas para Feiras Livres Emater-MG

Na observação dos itens do Quadro 01 percebe-se a importância do papel da empresa ao detalhar medidas relevantes de prevenção num contexto tão específico. Aproximar as dimensões dos cuidados com a pandemia do agricultor, que tem que escoar sua produção e ter contato com a sociedade, 
reforça um novo aspecto da extensão rural, que é o de comunicar riscos e realizar ações que de fato auxiliem nos cuidados que o agricultor deve ter ao realizar suas atividades. Neste sentido, a EmaterMG também produziu um material digital visando orientar produtores de leite e queijo sobre como amenizar impactos da pandemia, bem como uma cartilha orientando agricultores na colheita de café em tempos de coronavírus, entre outras, a fim de garantir o sustento desses agricultores familiares de uma forma segura e eficiente.

\section{c) Adequação}
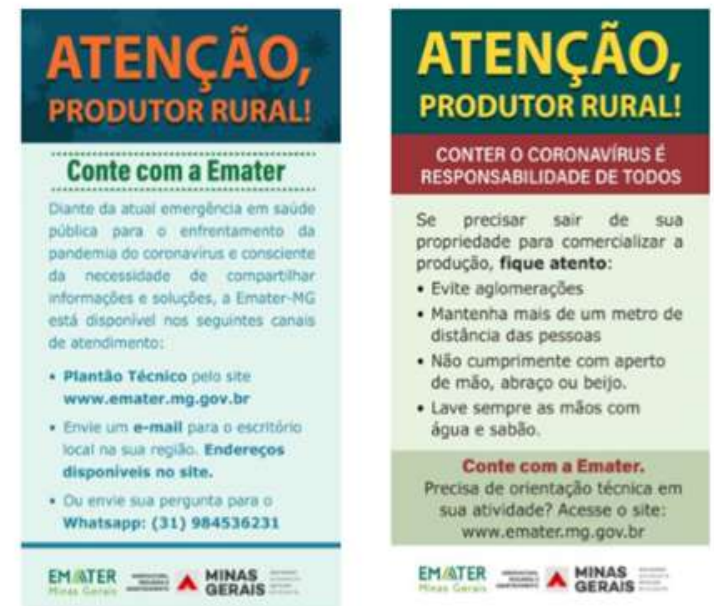

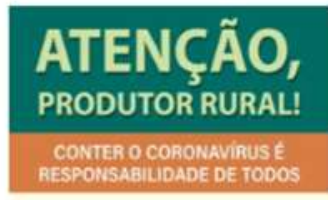

Após ter contato com dinheiro, embalagens, volantes, macanetas de veiculos e outros objetos no momento de comercializar sua produçăo, lembre-se de lavar as måos com água e sabào ou use alcool gel.

Nunca toque o rosto antes de fazer a limpeza das mass.

Conte com a Emater.

Precisa de orientação técnica em sua atividade? Acesse o site:
www.emater.mp.gov.br

EMATER $\equiv \Lambda$ MINAS

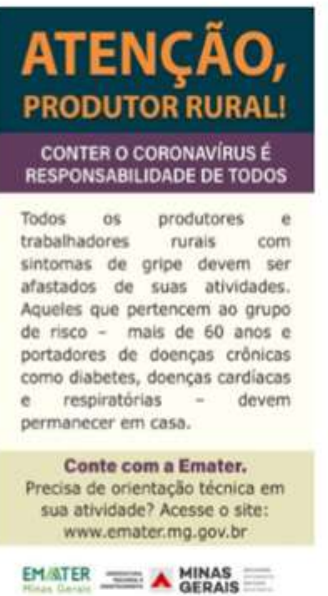

EMATER $=\mathbf{\Lambda}$ MINAS

Figura 4 - Peças de comunicação Emater-MG. Fonte: Relatório de ações da Assessoria de Comunicação da Emater-MG durante o enfrentamento à Covid-19

A empresa disseminou informações chamando a atenção do produtor rural sobre prevenção, de forma mais detalhada, e sintomas, de forma superficial, não mencionando detalhes que podem ser associados à Covid -19. A falta de ilustrações para dar suporte à comunicação dificulta o entendimento pela parcela do público mais vulnerável e de baixa escolaridade e analfabetos.

Pode-se considerar, também, que o disparo de uma mesma mensagem via WhatsApp para vários usuários ao mesmo tempo remete ao modelo difusionista de comunicação rural, fazendo com que a ATER ao intensificar uma perspectiva mais digital, não leve em conta as particularidades dos indivíduos. Desta forma, quando a comunicação rural tem interfaces com a comunicação de riscos é importante que as estratégias considerem a dimensão interpretativa, peculiar de cada sujeito, o que se alinha mais com o escopo da comunicação rural dialógica.

No período de isolamento social devido ao Covid-19, além de contribuir com a comunicação dos riscos, o WhatsApp possibilitou novas iniciativas, como a mobilização os produtores de alguns municípios em 
estratégias inovadoras como a organização de feiras online e a retomada de compras do Programa de Aquisição de Alimentos (PAA) e do Programa Nacional de Alimentação Escolar (PNAE). De acordo com o $5^{\circ}$ Relatório de Monitoramento Situação Emergencial de Saúde Pública da Emater-MG, realizado no início de maio de 2020, a venda por meio de telefone e redes sociais, com entregas em domicílio dos consumidores, é registrada em $56,1 \%$ dos municípios consultados.

Entre os canais virtuais utilizados para atendimento aos produtores pela Emater-MG está o Plantão Técnico, que pode ser acessado pelo site da empresa para tirar dúvidas e obter orientações. Além disso, duas vezes por semana, a empresa está fazendo transmissões ao vivo pelo Instagram (@ematerminas), conhecidas como lives, que chegam a ter, segundo a Ascom, entre 250 e 400 visualizações e contam com a participação de técnicos da Emater-MG de diferentes áreas, abordando assuntos de interesse dos produtores rurais. Segundo a Ascom, o número de seguidores na conta do Instagram tem aumentado durante o período de isolamento, sendo que antes da pandemia estes somavam 9.800 e em 22 de junho de 2021 já chegam a 17.800 seguidores. A empresa ofereceu, também, oficina online no início de maio de 2020 sobre comercialização por plataformas digitais para os extensionistas, bem como noções de marketing digital.

Todavia, deve-se levar em consideração que apesar do aumento do número de seguidores nas redes sociais, o acesso à internet e às TICs ainda é escasso no meio rural, com baixa conectividade estrutural e com redes ainda limitadas. Além disso, atenta-se ao fato de que muitos desses agricultores, devido ao baixo nível de escolaridade, tem dificuldade de conhecimento do manuseio dessas TICs, o que faz com que a implementação de uma ATER Digital, apesar de intensificada com o advento da pandemia da COVID-19, ainda seja em sua totalidade ineficiente (NOVO-CORTI et al., 2014). A pesquisa TIC Domicílios 2019 indica que o acesso à internet na área rural ocorre principalmente pelo telefone celular (97\%) em detrimento do computador (23\%). Além disso, apenas $44 \%$ dos domicílios rurais possuem conexão, percentual que alcança $70 \%$ em áreas urbanas. A falta de internet na zona rural ocorre porque os moradores não chegam sequer a ter disponibilidade de internet (44\%); não sabem usar a internet (44\%); não se sentem seguros com ela (45\%); ou porque acham caro adquirir um plano (65\%). A empresa lançou mão também do formato programas de rádio, chamados podcast, disponibilizados no site da empresa e em plataformas como Spotify e Soundcloud. Entre os temas abordados nos podcasts estão: "Como higienizar corretamente frutas, legumes, verduras e embalagens", "Impactos do Coronavírus afetam mercado do leite e do queijo e produtores", "Procedimentos necessários para evitar contaminação pelo coronavírus durante a colheita do café", 
entre outros. Contudo, a empresa explorou muito pouco o rádio como mídia de apoio nas ações de extensão rural e na comunicação de riscos, apesar deste ser um veículo de grande alcance no meio rural. Em seu relatório contam apenas duas entrevistas de seus técnicos em rádios locais durante o período estudado.

Percebe-se aqui uma nova faceta da extensão rural, que promove as ações através das mídias digitais, pautando-se cada vez nas metodologias de extensão provenientes da nova ATER Digital. Embora apenas $58 \%$ dos domicílios rurais tenham acesso à internet, o uso do celular se faz presente em $85 \%$ dos lares rurais e através destes aparelhos (CETIC, 2018), muitas vezes em pontos específicos da propriedade pela dificuldade de obter sinal, os usuários conseguem se conectar pelo 3G (ou 4G). De qualquer maneira, a necessidade de ter um aparelho para ser atendido pelo serviço não deixa de excluir uma parcela de produtores de autoconsumo, devido não são aos preços dos aparelhos, mas também a dificuldade de conexão com uma internet de boa qualidade.

Como a recomendação do distanciamento social vem para a prevenção da saúde pública, desenvolver ferramentas digitais torna-se imprescindível para a continuidade dos serviços neste momento e se apresenta como uma via num futuro permeado de incertezas. Contudo, tais iniciativas devem ser pensadas de forma humanizada, avaliando as especificidades dos agricultores e usando tal recurso como uma complementação das atividades exensionistas. Neste intuito, a empresa está elaborando um documento sobre Ferramentas Digitais de Apoio aos Serviços de ATER, dentro da perspectiva da Metodologia Participativa de Extensão Rural para o Desenvolvimento Sustentável (Mexpar), documento referencial de orientação pedagógica e metodológica para a ação extensionista, desenvolvido pela Emater-MG. Nota-se aqui a opção pelas metodologias participativas como norte em algumas estratégias, que se fortalecem pelo caráter interativo que as mídias digitais podem apresentar.

\section{CONSIDERAÇÕES FINAIS}

O desconhecido e inesperado acontecimento da pandemia do novo coronavírus fez com que o serviço de extensão rural, devido à sua relevância, precisasse se renovar e se reinventar para manter sua presença junto aos produtores rurais de Minas Gerais. Para tal, ampliou o uso das mídias digitais, não apenas para dar continuidade a ações como assistência técnica e extensão rural, mas também para comunicar seu público sobre os riscos da Covid-19 e como se prevenirem. Embora saiba-se que com o uso destas mídias não se alcança a totalidade do público que é atingido presencialmente, há uma 
tendência de que estas ferramentas se tornem cada vez mais usuais, principalmente com o fortalecimento da ATER Digital e, espera-se assim, um esforço de políticas públicas que favoreçam a inclusão digital do meio rural.

Pode-se notar que muitas ações comunicacionais da empresa durante a pandemia da Covid-19 se basearam em estratégias difusionistas, o que pode gerar falhas de interpretação, principalmente quando a mensagem é sobre um risco. Todavia, as diferentes funções e aplicativos das mídias digitais permitem diversas formas de interação, o que deve ser explorado para a complementação de uma plena comunicação de riscos, visto a importância do engajamento por parte do público nesta área.

Ainda existem muitas lacunas para se compreender melhor como comunicar riscos a comunidades em zonas rurais, quais os veículos mais eficientes e os gargalos nas percepções de risco. Da mesma forma, há lacunas entre o que um extensionista aprende durante sua formação e os desafios inesperados que podem assolar o meio rural, exigindo deste novas habilidades, se adaptando aos processos comunicativos rurais e compartilhando conhecimentos com o auxílio das novas ferramentas digitais.

Como o contexto da pandemia é novo, os serviços de extensão rural ainda estão adequando seus modos de operar, entre erros e acertos. Abre-se, assim, uma porta para se aprofundar este aspecto de interação entre o técnico e o meio rural, que não visa a produção, mas a saúde do agricultor. Pela velocidade de contagio do novo coronavírus podemos ter noção da importância de ações de comunicação de riscos que acontecem no tempo certo e em lugares mais afastados dos postos de saúde. Todavia, deve-se atentar que para uma comunicação de riscos efetiva deve-se levar em consideração a multiplicidade de identidades rurais, produzindo assim, não somente uma extensão digital, mas sim, uma extensão que promova a equidade de informações sobre a pandemia e sobre os riscos que ela promove para a população. 


\section{REFERÊNCIAS}

ALVES, Clovis; TEDESCO, João. A revolução verde e a modernização agrícola na mesorregião noroeste do Rio Grande do Sul - 1960/1970. In: Teoria e Evidência Econômica - Ano 21, n. 45, p. 257-281, jul./dez. 2015;

AQUINO, Joacir; SCHNEIDER, Sérgio. Pronaf e o desenvolvimento rural brasileiro: avanços, contradições e desafios para o futuro. In: Políticas públicas de desenvolvimento rural no Brasil. Porto Alegre: Ed. da UFRGS, 53-81, 2015;

ARRUDA, N. M.; MAIA, A.G.; ALVES, L.C. Desigualdade no acesso à saúde entre as áreas urbanas e rurais do Brasil: uma decomposição de fatores entre 1998 a 2008. Cad. Saúde Pública. V.34, n6, 2018;

BARAM, Mi. Risk Communication: Moving from Theory to Law to Practice. In: Effective Risk Communication: The Role and Responsibility of Government and Nongovernment Organizations. Contemporary issues in risk analysis Vol. IV. New York: Plenum Press, 1989;

BARDIN, L. Análise de conteúdo. Lisboa: Edições 70 Ltda, 1977;

BATISTA, L. A comunicacao dos riscos no mundo corporativo e o conteúdo da mensagem. In: Organicom, Ano IV n.06. 2007;

BECK, Ulrich. Sociedade de risco: rumo a uma nova modernidade. São Paulo: Ed. 34, 2010;

BORDENAVE, J.E.D. O que é Comunicação Rural? São Paulo: Editora Brasiliense, 1983;

BRAGA, G. B..Por uma caracterização dos territórios segundo o modo de vida rural e/ou urbano . Tese (Programa de Pós-Graduação em Extensão Rural). UFV: Viçosa, MG, 2015;

BRASIL. Ministério da Saúde. Coronavirus Brasil. Disponível em https://covid.saude.gov.br/. Acessado em 10/05/2020;

CAPORAL, F. R. La extensión agraria del sector público ante los desafíos del desarrollo ostenible: el caso de Rio Grande do Sul, Brasil. Córdoba, 1998. 517p. (Tese de Doutorado) Programa de Doutorado em Agroecología, Campesinado e Historia, ISEC-ETSIAN, Universidade de Córdoba, Espanha, 1998;

CAPORAL, Francisco Roberto. Política Nacional de Ater: primeiros passos de sua implementação e alguns obstáculos e desafios a serem enfrentados. Brasília, agosto/2005.

CETIC, Centro Regional de Estudos para o Desenvolvimento da Sociedade da Informação. TIC Domicílios - 2018 Indivíduos. Disponível em

https://www.cetic.br/tics/domicilios/2018/individuos/C2A/. 2018. Acessado em 10/05/2020;

COELHO, F. M. G. A arte das orientações técnicas no campo. 1. ed. Viçosa: UFV, 2005;

COVELLO, V. T. Communicating risk information: a guide to environmental communication in crisis and noncrisis situations. In: RAO, V. K. (Ed.) Environmental strategies handbook: a guide to effective policies and practices. New York, 1993; 
DEL CASTELLO, Riccardo; BRAUN, Paul Mathias. Framework on effective rural communication for development. Roma: Food and Agriculture Organization of the United Nations, 2006;

EMATER-MG. Cartilha: Medidas Estratégicas para Feiras Livres da Agricultura Familiar na prevenção de contágio do novo coronavírus. Disponível em

http://www.emater.mg.gov.br/download.do?id=42538. Acesso em 05/05/2020;

EMATER. Mexpar 4.0: Ater Digita Conectando Pessoas. Belo Horizonte, jul. 2020.

Relatório Ações da Assessoria de Comunicação da Emater-MG durante o enfrentamento a Covid-19. Belo Horizonte, 2020;

FISCHHOFF, B. Risk perception and communication unplugged: twenty years of process. Risk Anal ,13745. 1995;

FONSECA, Maria Teresa L. A Extensão Rural no Brasil, um projeto educativo para o capital. São Paulo: Edições Loyola, Coleção Educação Popular n 3, 1985;

FREIRE, Paulo. Extensão ou Comunicação. São Paulo: Ed Paz e Terra, 1977;

GOMES, Nilma Lino. Questão racial e o novo coronavírus o Brasil. São Paulo: Fiedrich Ebert Stifung, 2020;

GRISA, C.; SCHINEIDER, S. Três gerações de políticas públicas para agricultura familiar e interação entre Estado e Sociedade Civil no Brasil. RESR, v. 52, n. Supl. 1, p. S125-S146, 2014;

IBGE - Instituto Brasileiro de Geografia e Estatística. Pesquisa Nacional por Amostra de Domicílios. Síntese dos Indicadores de 2009. Rio de Janeiro: IBGE; 2010. Acesso em 10/06/2020 Disponível em: https://www.ibge.gov.br/estatisticas/sociais/educacao/9662-censo-demografico-

2010.html?t=publicacoes

LIMA, Andrezza M.; AZEVEDO Camila F.; Impactos culturais e socioambientais deixados pela Revolução Verde na região do brejo paraibano - Brasil. Revista Verde de Agroecologia e Desenvolvimento Sustentável, v. 8, n. 5, p. 116 - 123, (Edição Especial) Mossoró, 2013. Disponível em: http://revista.gvaa.com.br ISSN 1981;

LOFSTEDT, R. Risk Management in Post-Trust Societies. Londres: Ed. Routledge, 2012;

LOPES, Ivonete; Leal, Daniela. Entre a pandemia e o negacionismo: a comunicação de riscos da Covid19 pelo Ministério da Saúde do Brasil. Chasqui. Revista Latinoamericana de Comunicación N.ㅇ 145, diciembre 2020 - marzo 2021 (Sección Diálogo de saberes, pp. 261-280) ISSN 1390-1079 / e-ISSN 1390$924 X$

MELO, W. Comunicação de risco: ação obrigatória das organizações que trabalham com produtos perigosos. In: Organicom, Ano 4, número 6. 2007;

NOVO-CORTI, Isabel. et al. Breaking the walls of social exclusion of women rural by means of ICTs: The case of 'digital divides' in Galician. I. Novo-Corti et al. / Computers in Human Behavior 30 (2014) 497507 ; 
OLIVEIRA, Pedro C.F. Semeando consenso com adubo e dedal: dominação e lutas de classe na extensão rural no Brasil (1974 -1990). Tese de Doutorado, Programa de Pós-graduação em História Social, Universidade Federal Fluminense. Niterói, 2017;

ORGANIZAÇÃO MUNDIAL DA SAÚDE. Comunicação de riscos em emergências de saúde pública: um guia da OMS para políticas e práticas em comunicação de risco de emergência. Genebra: WHO, 2018;

SANTOS, Isabel. Comunicação e governância de risco - Construção de um modelo de capacitação social. Dissertação de Doutorado em Ambiente e Sustentabilidade, Faculdade de Ciência e Tecnologia, Universidade Nova de Lisboa, 2016;

SETTELE, J., DIAZ, S., BRONDIZIO, E. \& DASZAK, Peter. COVID-19 Stimulus Measures Must Save Lives, Protect Livelihoods, and Safeguard Nature to Reduce the Risk of Future Pandemics. In: IPBES Expert Guest Article, 2020.

SILVA, Claiton. Agricultura e cooperação internacional: a atuação da American International Association for Economic and Social Development (AIA) e os programas de modernização no brasil (1946-1961). Tese de Doutorado, Curso de Pós-Graduação em História das Ciências e da Saúde, Casa de Oswaldo Cruz-Fiocruz, Área de Concentração: História das Ciências. Rio de Janeiro, 2009;

SORIANO, E. A identificação e análise da comunicação do risco de desastres naturais em municípios do estado de São Paulo. Centro Nacional de Monitoramento e Alertas de Desastres Naturais. CEMADEN, Universidade Federal de São Carlos- UFSCar, 2016. Revista da Associação Nacional de Pósgraduação e Pesquisa em Geografia (Anpege). p.390-408, V.12, n.19, jul-dez.2016; 


\section{NOTAS}

\section{Nota 1}

Os autores agradecem à Coordenação de Aperfeiçoamento de Pessoal de Nível Superior - Brasil (CAPES), pelo apoio na realização dessa Pesquisa. Código de Financiamento 001.

\section{Nota 2}

A Pesquisa Nacional por Amostra de Domicílios Contínua - (PNAD, 2019) estimou a população de Minas Gerais em 21 milhões. Usamos os dados do Censo 2010 por ser disponibilizado a porcentagem de rurais nos dados de 2019.

\section{Nota 3}

Whatsapp é aplicativo mais utilizado no Brasil (e no mundo), com 120 milhões de usuários ativos que correspondem a $57,6 \%$ da população brasileira.

\section{Nota 4}

Durante o período eleitoral, o aplicativo Whatsapp se tornou protagonista na disseminação de fake news, como apontam os resultados preliminares da investigação realizada pelo grupo de pesquisa em Tecnologias da Comunicação e Política (TCP) na Universidade do Estado do Rio de Janeiro (UERJ).

\section{Nota 5}

O funcionamento das feiras municipais foi autorizado pelo Governo de Minas Gerais, desde que as prefeituras e outros órgãos responsáveis pela organização e gestão desses pontos de venda adotem medidas para garantir a segurança dos feirantes e consumidores. As orientações valem durante vigência do Decreto de Situação de Emergência em Saúde Pública e de Estado de Calamidade Pública (Decreto no 47.891, de 20 de março de 2020), do Governo de Minas Gerais. 


\section{Capítulo 2}

doi) $10.37423 / 210704486$

\section{NOVAS TECNOLOGIAS PARA APLICAÇÃO OU SUBSTITUIÇÃO DOS AGROTÓXICOS: UM ENFOQUE OCUPACIONAL}


Resumo: A demanda por alimentos cresceu consideravelmente ao longo dos anos e com ela, a utilização de defensivos agrícolas que visam à minimização dos prejuízos causados pela ação danosa de insetos, fungos, plantas daninhas, dentre outros. Por outro lado, ainda que existam pesquisadores e movimentos populares contra o emprego desses insumos, a realidade é que os defensivos agrícolas ainda serão muito utilizados no modelo de desenvolvimento da agricultura no país. Assim, sob a ótica ocupacional, é preciso buscar meios de promover a utilização desses agentes químicos sem impactos à saúde dos trabalhadores. Nesse sentido, o presente trabalho aborda as formas de aplicação tradicionais dos defensivos agrícolas, bem como as novas tecnologias e o envolvimento da agricultura de precisão. A partir dessa temática, também foi realizada uma correlação entre os assuntos abordados e a ótica ocupacional de exposição e proteção dos trabalhadores. Dessa forma, foi realizada uma revisão bibliográfica envolvendo a análise de artigos científicos, boletins técnicos, livros e sites relevantes sobre o assunto. Finalmente, foi apresentada a importância na utilização das novas tecnologias para a proteção coletiva dos trabalhadores e consequente diminuição dos impactos ocupacionais.

Palavras-Chave: Defensivos agrícolas, aplicação de defensivos, tecnologias. 


\section{INTRODUÇÃO}

Segundo as Nações Unidas no Brasil - ONUBR (1), por duas décadas a demanda global por alimentos aumentou de forma constante, associada com o crescimento mundial da população, safras recordes, melhorias na renda e com a diversificação das dietas. Nesse mesmo sentido, de acordo com o Ministério da Cultura, Pecuária e Abastecimento (MAPA), a renda dos brasileiros aumentou nos últimos cinco anos em 8,6\% e, como consequência, houve o crescimento da demanda por alimentos, uma vez que a população está consumindo mais alimentos e com maior valor agregado, tais como carnes e derivados do leite, além de bebidas, como cerveja e vinho (2).

Nesse contexto, para que o aumento da produção de alimentos atendesse à demanda nacional e global, tornou-se necessário o aumento da produtividade, já que a incorporação de terras produtivas tem sido cada vez mais difícil. Assim, surge a necessidade de investimento em: mecanização, irrigação, otimização das matérias primas e das áreas plantadas, capitais humanos mais qualificados e aplicação de defensivos agrícolas.

Segundo Silva et al. (4), os químicos usados na agricultura, independente do nome dado aos mesmos, agroquímicos, agrotóxicos, produtos fitossanitários ou outro qualquer, são em sua maioria substâncias criadas e desenvolvidas para serem utilizadas no ambiente como uma ferramenta que dispõe o agricultor para minimizar o prejuízo causado pela ação danosa de insetos, fungos, plantas daninhas, dentre outros.

De acordo com o Ministério do Meio Ambiente (5), os defensivos agrícolas são considerados extremamente relevantes no modelo de desenvolvimento da agricultura no país, colocando o Brasil como o maior consumidor de produtos agrotóxicos no mundo.

Miguela e Cunha (7) afirmaram que a proteção das lavouras é incipiente a própria cultura, sendo uma criação que surgiu para satisfazer muitas necessidades de maneira estável, pois precisa proporcionar alimentos e também produtos de uso comercial e industrial, mas, sobretudo no primeiro caso, em quantidade e qualidade adequadas. Portanto, ainda segundo esses mesmos autores, nada disso seria possível sem uma proteção contínua das lavouras, dentro da qual o emprego dos produtos fitossanitários ocupa um papel muito importante.

Guimarães (4) apontou que apesar do avanço progressivo de formas alternativas na produção de alimentos, os produtos químicos ainda serão utilizados por muito tempo na agricultura, porém foram criadas novas formulações, mais seguras e ambientalmente menos agressivas. 
Ainda segundo Vital (8), a liderança brasileira em volume pode ser explicada pelo clima tropical, que por um lado permite o plantio nas quatro estações do ano e a colheita de três safras anuais, mas por outro propicia o desenvolvimento das pragas. Pois com temperaturas elevadas, chuvas e comida disponível o ano todo, os invasores se multiplicam com facilidade e os agroquímicos passam a ser utilizados para diminuir o crescimento dessas populações e assim, evitar danos significativos às lavouras.

Por outro lado, Papini et al. (9) citaram que o uso intensivo de agrotóxicos tem acarretado inúmeros impactos negativos ao ambiente. Dentre eles, alegaram que o aumento do número de pragas e que a resistência dos insetos aos produtos utilizados no seu controle vem aumentando, obrigando também o aumento no volume de produto aplicado e no número de vezes que são aplicados, mesmo com a criação de novas moléculas. Esses mesmos autores também destacam que são urgentes e necessárias alternativas que mudem o enfoque do modo de produção e que busquem a máxima eficiência, mantendo a estabilidade do meio ambiente, a qualidade dos alimentos e promovendo a saúde dos trabalhadores e consumidores. Pois o uso excessivo de produtos químicos causa riscos à saúde do trabalhador, impactos negativos no ambiente e na produtividade.

No entanto, independente da linha de defesa, a ampla maioria dos autores sobre o assunto concorda que em relação aos trabalhadores, os defensivos agrícolas oferecem riscos à saúde. Portanto, a utilização de equipamentos de proteção individual e a busca por métodos de aplicação e manuseio mais seguros são de extrema importância para minimização dos casos de intoxicação e outras doenças relacionadas.

Com vistas às formas de aplicação e à otimização no uso dos defensivos agrícolas, abordaremos no presente trabalho o envolvimento da Agricultura de Precisão, que segundo o Ministério da Agricultura, Pecuária e Abastecimento (MAPA) (13) existem relatos de trabalhos realizados desde o início do século XX. No entanto, segundo esse mesmo ministério, o surgimento do GPS (Sistema Posicionamento Global por satélites), em torno de 1990 foi o passo determinante para a sua implantação.

O objetivo da Agricultura de Precisão é principalmente resolver os problemas relacionados à desuniformidade das lavouras, envolvendo práticas que podem ser desenvolvidas em diferentes níveis de complexidade e com diferentes objetivos. No Brasil, as soluções existentes têm como foco principal a aplicação de fertilizantes e corretivos em taxa variável, porém deve-se considerar que Agricultura de Precisão é um sistema de gestão que pondera a variabilidade espacial das lavouras em todos seus aspectos: produtividade, solo, infestação de ervas daninhas, doenças e pragas (13). 
Nesse sentido, ao longo do presente trabalho, além de serem abordados aspetos gerais da aplicação de defensivos agrícolas, serão apresentadas algumas tecnologias de aplicação envolvendo a Agricultura de Precisão, também com o objetivo de associá-las à minimização dos danos causados aos trabalhadores.

\section{METODOLOGIA}

O presente trabalho foi desenvolvido a partir de uma revisão bibliográfica sobre a aplicação tradicional de defensivos agrícolas e as novas tecnologias utilizadas, incluindo a Agricultura de Precisão. Para tal, foram analisados artigos científicos, boletins técnicos, normas regulamentadoras da Secretaria de Trabalho, bem como livros e sites relevantes ao assunto.

Após uma ampla pesquisa, foram relacionadas as formas tradicionais de aplicação dos defensivos agrícolas e posteriormente, as novas tecnologias e o envolvimento da agricultura de precisão. Ao longo do trabalho, fez-se uma correlação de como cada as práticas ou tecnologias envolvidas podem influenciar as questões ocupacionais referentes à saúde e segurança dos trabalhadores.

\section{APLICAÇÃO DE DEFENSIVOS AGRÍCOLAS}

Segundo Braibante e Zappe (14) existem mais de mil formulações diferentes de agrotóxicos, incluindo: inseticidas, herbicidas, fungicidas, nematicidas, fumigantes e outros compostos orgânicos, bem como outras substâncias usadas como reguladores de crescimento, dissecantes e desfoliantes. As formulações são constituídas de princípios ativos, que são os compostos responsáveis pela atividade biológica desejada. No entanto, o mesmo princípio ativo pode ser vendido em diferentes formulações e distintos nomes comerciais. Também é possível encontrar produtos com mais de um princípio ativo. Balastreire (15) citou que à medida que os métodos culturais foram se desenvolvendo, e as áreas cultivadas aumentando, a quantidade de produtos químicos utilizados no controle de pragas e doenças das plantas cultivadas também cresceu. No entanto, ele também ressaltou que a falta de treinamento dos operadores e usuários desses produtos e o desconhecimento da ação dos mesmos sobre o organismo humano e sobre o meio ambiente têm resultado no aumento dos riscos desnecessários para o controle das pragas e moléstias, além da agressão ao meio ambiente. Nesse sentido, o autor também expõe que devem ser observados alguns fatores principais que afetam a utilização dos defensivos agrícolas:

- clima: pluviosidade, temperatura, umidade relativa e ocorrência de ventos; 
- solo: cobertura, topografia e textura;

- hospedeiro (vegetal ou anima): seleção, melhoramento, ciclo biológico, características fisiológicas e morfológicas;

- patógeno: tamanho e mobilidade;

- princípio ativo: seleção, dosagem e técnica de aplicação;

- veículo: líquido, pó ou grânulo;

- operador: treinamento e proteção;

- máquina: regulagem, manutenção e características operacionais.

No que se refere à segurança dos trabalhadores, cabe ressaltar que o risco aumenta em função do vento e da temperatura. O vento auxilia na manutenção das partículas em suspensão no ambiente e no transporte dessas para outros locais, enquanto a elevação da temperatura aumenta o risco de volatilização e reduz o tamanho das gostas, dificultando assim, a deposição do produto (7).

Em relação aos treinamentos dos trabalhadores, a Norma Regulamentadora no 31 (NR-31) da Secretaria de Trabalho (16), estabelece, dentre outros itens, o seguinte:

31.8.7 o empregador rural ou equiparado, deve fornecer instruções suficientes aos que manipulam agrotóxicos, adjuvantes e afins, e aos que desenvolvam qualquer atividade em áreas onde possa haver exposição direta ou indireta a esses produtos, garantindo os requisitos de segurança previstos nesta norma.

31.8.8 O empregador rural ou equiparado, deve proporcionar capacitação sobre prevenção de acidentes com agrotóxicos a todos os trabalhadores expostos diretamente.

31.8.8.1 A capacitação prevista nesta norma deve ser proporcionada aos trabalhadores em exposição direta mediante programa, com carga horária mínima de vinte horas, distribuídas em no máximo oito horas diárias, durante o expediente normal de trabalho, com o seguinte conteúdo mínimo:

a) conhecimento das formas de exposição direta e indireta aos agrotóxicos;

b) conhecimento de sinais e sintomas de intoxicação e medidas de primeiros socorros;

c) rotulagem e sinalização de segurança;

d) medidas higiênicas durante e após o trabalho;

e) uso de vestimentas e equipamentos de proteção pessoal;

f) limpeza e manutenção das roupas, vestimentas e equipamentos de proteção pessoal. 
31.8.8.2 O programa de capacitação deve ser desenvolvido a partir de materiais escritos ou audiovisuais e apresentado em linguagem adequada aos trabalhadores e assegurada a atualização de conhecimentos para os trabalhadores já capacitados.

Portanto, além do adequado treinamento dos trabalhadores influenciar diretamente na qualidade da aplicação e, por consequencia, no resultado final da cadeia produtiva, ele é fundamental para a proteção da integridade física dos trabalhadores Além disso, conforme demonstrado anteriormente, os treinamentos são obrigatórios legalmente. Portanto, o não cumprimento legal poderá implicar na aplicação de penalidades previstas na legislação pertinente.

No que tange o fornecimento de equipamentos de proteção individual (EPIs), a NR-31 regulamenta, dentre outros itens, que o empregador rural ou equiparado deverá fornecer os EPIs e vestimentas adequadas aos riscos, que não gerem desconforto térmico prejudicial ao trabalhador, bem como fornecê-los em perfeitas condições de uso e devidamente higienizados. Além do exposto, o empregador rural ou equiparado também é o responsável pela descontaminação dos mesmos ao final de cada jornada de trabalho e substituição sempre que necessário.

A seguir, serão abordados os métodos de aplicação mais utilizados para os defensivos agrícolas. No entanto, cabe ressaltar, que em geral as aplicações mecanizadas são mais seguras do que as aplicações manuais para os trabalhadores. Isso, porque no segundo caso o contato com o produto é mais fácil, além das aplicações manuais gerarem a fadiga dos trabalhadores, levando-os por consequência à pressa e às falhas com segurança (7).

\subsection{MÉTODOS DE APLICAÇÃO DE DEFENSIVOS AGRÍCOLAS}

Os métodos de aplicação atualmente em uso podem ser agrupados em aplicações por via sólida, líquida ou gasosa, em função do estado físico do material a ser aplicado. O método predominante é o que utiliza a água como diluente. Todavia, em algumas condições, as dificuldades na obtenção e no transporte de água podem conduzir às demais alternativas, como a aplicação por via sólida ou por via líquida sem o uso de água (17).

\subsubsection{APLICAÇÃO VIA SÓLIDA}

Os defensivos agrícolas aplicados em forma sólida são basicamente de três tipos: pó, microgrânulos e grânulos. A técnica de distribuição dos produtos pulverulentos é denominada genericamente de polvilhamento e as máquinas de distribuição recebem o nome de polvilhadores para os produtos pulverulentos e aplicadores de grânulos para grânulos (7). 
Cabe ressaltar, que quanto mais pulverulento for o produto, maior será o risco de intoxicação do trabalhador por inalação. Portanto, a temperatura, a umidade relativa do ar, a velocidade e a direção do vento também serão aspectos importantes a serem observados durante a aplicação. Pois quanto maior a temperatura, a velocidade do vento e menor a umidade relativa do ar, maior será a chance de deriva do produto e por mais tempo ele irá permanecer em suspensão na atmosfera. Já em relação à direção do vento, se este estiver no mesmo sentido da aplicação, maior será a incidência de partículas sobre o trabalhador.

Nesse contexto, deve-se ter atenção à utilização dos EPIs, e em especial à seleção e uso dos equipamentos de proteção respiratória adequados, de forma a serem adquiridos máscaras e/ou filtros compatíveis com o material que está sendo aplicado.

\subsubsection{APLICAÇÃO VIA LÍQUIDA}

Segundo Spadotto (18), a aplicação por via líquida é o método predominante, onde uma formulação é geralmente diluída em água, formando a calda que, salvo algumas exceções, é aplicada na forma de gotas através de pulverização. Ainda de acordo com esse mesmo autor, existem casos em que a aplicação é feita através de nebulização, com gotas muito pequenas que formam uma neblina.

Já Miguela e Cunha (7) explicaram, que os tratamentos fitossanitários por via líquida são aqueles em que se aplica sobre o alvo uma calda fitossanitária, cuja composição se dá pelo produto comercial original puro ou, na maioria das vezes, adicionando um diluente que, quase sempre, é a água. De acordo com eles, a uniformidade da calda e sua distribuição homogênea sobre o objeto são requisitos fundamentais para o controle do problema, portanto, os dispositivos das máquinas de aplicação são desenvolvidos para conseguir uma população de gostas o mais homogênea possível e com a possibilidade de ajustamento do diâmetro.

Azzevedo e Freire (17) citaram que existe uma grande diversidade de máquinas pulverizadoras que podem ser agrupadas em função do sistema de pulverização do líquido, ou seja, pelo sistema utilizado para transformar uma massa líquida em pequenas gotas, dependendo do tipo de bico. Esses sistemas são classificados de acordo com a forma de energia utilizada em: hidráulicos, pneumáticos, centrífugos, eletrostáticos e térmicos.

Do ponto de vista da segurança do trabalho, quanto menor o tamanho das gotas, maior a chance de deriva e de evaporação. Portanto, aumenta também a possibilidade de contato do produto com o operador, de inalação e por consequência, de intoxicação. Conforme citado no item anterior, a 
temperatura, a umidade relativa do ar, a velocidade e a direção do vento também serão aspectos importantes a serem observados durante a aplicação, pelos mesmos motivos já mencionados.

\subsubsection{APLICAÇÃO VIA GASOSA (FUMIGAÇÃO)}

Nesse tipo de aplicação, o produto preparado na forma líquida ou sólida (pastilhas ou pasta), ao entrar em contato com o ar volatiliza, liberando um gás fumigante. Os produtos mais utilizados são o fosfeto de alumínio ou fosfina e o brometo de metila, estando esse último atualmente com a comercialização proibida (17).

No Brasil, são amplamente utilizados os inseticidas fumigantes para o tratamento curativo de grãos armazenados, com uso da técnica de fumigação ou expurgo. O brometo de metila está atualmente com o uso proibido por ser um depletor da camada de ozônio. Já o uso da fosfina tem sido limitado devido à possibilidade de seleção de populações de insetos-praga resistentes (19).

Sob a ótica ocupacional, o produto volatizado oferece maior risco de intoxicação por inalação ao trabalhador. No entanto, de acordo com o Anexo no 11 da Norma Regulamentadora no 15 (NR-15) (20), o brometo de metila é um agente químico que também oferece risco de absorção pela pele e possui limite de tolerância máximo para absorção por via respiratória $\left(12 \mathrm{ppm}\right.$ ou $\left.47 \mathrm{mg} / \mathrm{m}^{3}\right)$. Assim, a exposição acima dos limites mencionados gera insalubridade de grau máximo. Logo, além de ser um agente químico que oferece danos à camada de ozônio, também proporciona riscos à saúde do trabalhador.

Nesse sentido, é importante a proteção não somente das vias respiratórias, mas também das vias cutâneas, exigindo na sua manipulação o uso de luvas adequadas, além dos EPIs necessários à proteção de outras partes do corpo.

Já em relação ao fosfeto de alumínio ou fosfina, esse também é um agente químico que possui limite de tolerância máximo para absorção por via respiratória $\left(0,23 \mathrm{ppm}\right.$ ou $\left.0,3 \mathrm{mg} / \mathrm{m}^{3}\right)$. No entanto, de acordo com o Quadro no 1 do Anexo no 11 da NR-15 (20), esse é um agente que não está assinalado como

"Absorção também pela pele". Logo, apesar de ser um agente químico cuja exposição acima dos limites de tolerância mencionados gera direito à insalubridade de grau máximo, não existe risco iminente de contaminação cutânea. Assim, deve-se ter atenção principal à seleção e uso dos equipamentos de proteção respiratória, de forma a serem adquiridos máscaras e/ou filtros compatíveis com a neutralização desse produto. 


\subsection{MÁQUINAS E FORMAS DE APLICAÇÃO DE DEFENSIVOS AGRÍCOLAS}

Segundo Balastreire (15), as máquinas para aplicação de defensivos agrícolas podem ser classificadas utilizando diversos critérios. Portanto, quanto à fonte de potência para acionamento e transporte, pode-se classificá-las em: manuais, de tração animal, motorizadas, tratorizadas, atopropelidas ou aéreas.

No que se refere à segurança do trabalhador, quanto menor o contato deste com os produtos, mais segura é a operação. Portanto, as máquinas manuais e de tração animal oferecem menor segurança, pois durante as aplicações o trabalhador possui maior contato com os agentes químicos. Por outro lado, para as máquinas tratorizadas e autopropelidas, deve-se dar prioridade à utilização de máquinas com cabines adequadas ao isolamento do trabalhador em relação aos agentes químicos. Por fim, no que tange à utilização de máquinas aéreas, deve-se atentar para a guarda correta dos produtos no interior da aeronave. No entanto, considerando aeronaves devidamente isoladas e produtos adequadamente estocados, tem-se baixa probabilidade de intoxicação do operador da aeronave durante o processo de aplicação. Em contra partida, deve-se atentar para a necessidade de não haver pessoas na área de manejo, a fim de que essas não sejam contaminadas durante o sobrevôo de aplicação da aeronave.

\section{TECNOLOGIAS DE APLICAÇÃO DE DEFENSIVOS AGRÍCOLAS NA AGRICULTURA DE PRECISÃO}

A tecnologia de aplicação de defensivos agrícolas envolve o emprego de conhecimentos científicos que proporcionem a correta colocação do produto biologicamente ativo no alvo, em quantidade necessária, de forma econômica e visando a mínima contaminação de outras áreas (28).

Nesse sentido, novas tecnologias têm sido desenvolvidas para a aplicação de defensivos agrícolas, visando proporcionar a redução da quantidade de produtos aplicados além de melhores resultados de produtividade. Dentre essas novas tecnologias têm-se: GPS associado aos mapas de aplicação digitais; computadores de bordo capazes de controlar o sistema de pulverização; sensores de alvos biológicos; piloto automático; robôs e outros (29).

Em conjunto com essas tecnologias, é importante ressaltar a implantação da Agricultura de Precisão (AP), que lida com o manejo aprimorado dos insumos da agricultura, incluindo: sementes, fertilizantes, água, defensivos agrícolas e energia.

Segundo Say et al. (30), a Agricultura de Precisão visa: gerar a economia dos insumos, aumentar o rendimento, conservar o meio ambiente e aumentar a rentabilidade. Nesse contexto, as tecnologias 
da AP incluem: mapeamento do solo, aplicação de taxa variável (preparo do solo, semeadura, adubação, irrigação e aplicação de defensivos agrícolas), mapeamento da produção, orientação automática e veículos.

No entanto, muitos fatores afetam a adoção de tecnologias da AP, incluindo: recursos das fazendas, acessibilidade e rentabilidade do equipamento, características das tecnologias como complexidade e compatibilidade, personalidade e estrutura familiar do agricultor, assuntos jurídicos e instituições que oferecem suporte a essas tecnologias. Assim, o nível de adoção da AP é variável em diferentes países, bem como em diferentes regiões de um mesmo país (30).

Segundo Umezu (31) As etapas da agricultura de precisão constituem-se um ciclo que é repetido à cada safra. Portanto, em cada uma das etapas deve ser realizada uma cautelosa avaliação dos resultados, reavaliando a estratégia utilizada e permitindo um refinamento de todo o processo.

A etapa de coleta dos dados tem a finalidade de identificar a variabilidade existente em um campo da produção e dos diversos fatores de produção. Nesta etapa, uma ampla coleta de dados da própria produção e dos fatores de produção deve ser feita, com informações suficientes para evidenciar a variabilidade espacial em campo. Para isso, diversos equipamentos são utilizados: coletores de dados e amostradores de solo (automáticos ou manuais), imagens de satélite, fotos aéreas, dentre outros (33).

De acordo com Swinton e Lowenberg-Deboer (34), a agricultura de precisão compreende um conjunto de quatro tecnologias: determinação de localização (GPS), sistema de informações geográficas (SIG), controle de aplicação de insumos a taxas variáveis e automação da coleta e atualização dos dados da cultura.

\subsection{APLICAÇÃO A TAXA VARIÁVEL}

Associados ao ciclo da agricultura de precisão são necessários equipamentos com capacidade de aplicar, de forma precisa, insumos a taxas variáveis. Deste modo, o desenvolvimento da denominada "Tecnologia de Aplicação Variável” (VRT) requer pesquisas na área de gerenciamento de dados e projeto de equipamentos destinados a essa finalidade (31).

Segundo Saraiva et al. (33), muitos dos novos equipamentos devem possuir uma característica importante que é a capacidade de aplicar os insumos à taxa variáveis (sementes, defensivos, fertilizantes, dentre outros), o que vem estimulando muitas empresas a realizar pesquisa e desenvolver produtos para atender a essa demanda. 
Para uma máquina ser capaz de fazer a aplicação de produtos em taxa variável é necessário que exista um controle externo do seu mecanismo dosador. Seja ele através de um comando de vazão associado a um controle eletrônico, ou através de um mecanismo dosador onde o controle externo ocorrerá por conta de um atuador linear com controle eletrônico que irá abrir e fechar o orifício, definindo então as vazões requeridas. Nesse sentido, existe uma variedade de equipamentos dessa natureza no mercado e são normalmente denominados de controladores para aplicação em taxa variável (13).

De acordo com Sudduth (35), as decisões de controle para aplicação de taxa variável podem ser tomadas "on-line" ou "off-line". Na abordagem "on-line" ou baseada em sensores, o equipamento controlado possui sensores de bordo e os dados do sensor são usados de forma imediata para o controle automático.

Já na abordagem "off-line" ou baseada em mapas, os dados são coletados e armazenados em uma operação, e o equipamento controlado usa as informações em uma operação de campo separada. A abordagem baseada em mapas permite mais flexibilidade na manipulação de dados e préprocessamento, mas exige que a localização do equipamento no campo seja definida com precisão.

Ainda segundo Sudduth (35), a maioria dos sistemas atualmente disponíveis são baseados em mapas, no entanto, mais sistemas "on-line" provavelmente se tornarão disponíveis quando as tecnologias de detecção em tempo real estiverem mais desenvolvidas.

\subsection{ZONAS DE MANEJO}

Muitos produtores optam por fazer a aplicação dos insumos por "zonas de manejo". Tal método de aplicação consiste na definição e delimitação em campo de divisas para setores do talhão onde serão aplicadas doses diferenciadas de produtos. No entanto, o conceito de "zonas de manejo" ou unidades de gerenciamento, subentende que todos os tratamentos sejam feitos uniformemente dentro de cada unidade (13).

Por outro lado, segundo Rodrigues Júnior et al. (36) uma zona de manejo pode ser definida como uma sub-região do campo que apresenta uma combinação de fatores limitantes de produtividade e de qualidade onde se pode aplicar uma dose uniforme de insumos. Ainda de acordo com esses mesmos autores, a definição de zonas de manejo torna mais fácil a aplicação das técnicas de AP uma vez que é possível empregar os mesmos sistemas utilizados na agricultura convencional, no manejo das culturas.

De acordo com Alves et al. (37), entender como funciona a distribuição espacial dos atributos (químicos e físicos dos solos, condições da cultura, do terreno, da produtividade e localização) é 
importante para o estabelecimento de práticas de manejo adequadas, não somente para a otimização da produtividade agrícola, mas também para a minimização de possíveis impactos ambientais. Nesse sentido, o uso da geoestatística permite a modelagem e visualização da estrutura de dependência espacial (38).

Nesse contexto, no que se refere à aplicação de defensivos agrícolas, é possível definir e delimitar os locais onde haja efetiva necessidade de aplicação, bem como determinar doses diferenciadas a serem aplicadas em cada zona de manejo. Assim, tem-se a possibilidade de otimização dos produtos, beneficiando não só a cultura e o meio ambiente, mas também a exposição do trabalhador aos agentes químicos.

\subsection{SENSORES}

Com exceção da produtividade de grãos, a maior parte da coleta de dados espaciais feita comercialmente na agricultura de precisão é através de análises de amostras coletadas. Há uma grande necessidade e oportunidade para o desenvolvimento de tecnologias de sensoriamento que permitam a coleta automatizada de solo, colheita e dados de pragas. No entanto, vários sensores estão em desenvolvimento. Algumas das variáveis do solo para as quais os sensores estão sendo desenvolvidos incluem: matéria orgânica do solo (importante para a aplicação de herbicidas e fertilizantes), nível de nutrientes (para aplicação de fertilizantes), pH (para taxa de calagem e aplicação de herbicidas), umidade (para profundidade de semeadura) e profundidade superficial e taxas de aplicação de fertilizantes) (35).

Em relação à aplicação de defensivos agrícolas, existem sensores ópticos que realizam a detecção das plantas daninhas e ao reconhecer o local onde deve ser aplicado o defensivo, mandam um sinal para válvula do bico que automaticamente abre a vazão da calda no local especificado pelo sensor. Esse tipo de sensor dá uma resposta rápida para a válvula que está diretamente relacionada ao deslocamento da máquina de pulverização. Os sensores ópticos ficam localizados na barra de pulverização e são capazes de diferenciar as plantas daninhas da cultura através da análise de refletância, fazendo a aplicação dos defensivos em taxa variável (39).

O uso de sensores ópticos na dita catação química automatizada, pode reduzir o custo com o uso de defensivos agrícolas em até $80 \%$, minimizando os gastos de tempo, trabalho e dinheiro, bem como os impactos ambientais. Isto, porque as plantas daninhas não se distribuem de maneira uniforme na área. 
Logo, a aplicação de defensivos é realizada através dos sensores, que atuam com base nas refletâncias, utilizando os comprimentos das ondas eletromagnéticas dos raios vermelho e infravermelho (40).

Também já existem sensores pendulares de biomassa que podem ser utilizados para cobrir o vegetal com defensivo. O cobrimento ocorre de acordo com o tamanho do vegetal, sendo possível a prevenção contra pragas e doenças. O sensor pendular fica localizado na frente do trator, assim, quando ele faz o deslocamento ao longo do vegetal, é possível fazer a movimentação e verificação do ângulo. A aplicação em taxa variável é feita através da medida desse ângulo, sendo possível aplicar a calda com maior ou menor intensidade (39).

Do ponto de vista ocupacional, a utilização dos sensores também pode minimizar os impactos relacionados à saúde dos trabalhadores durante o processo de aplicação, uma vez que irão promover a aplicação otimizada e pontual do produto. Assim, tem-se também a redução da concentração dos agentes químicos na atmosfera, minimizando o risco de intoxicação dos operadores.

\subsection{SENSORIAMENTO REMOTO}

Segundo Veras (41), a técnica de sensoriamento remoto pode ser melhor compreentendida, em um primeiro instante, traduzindo-se o próprio termo. Onde remoto significa "sem contato direto" e sensoriamento remete ao uso de sensores para detectar dados variáveis de uma superfície, como temperatura, distribuição de cores, relevo, dentre outros. Através do uso de tais sensores e suas combinações, é possível registrar variáveis de grande interesse: localização e dimensões planares, localização topográfica, cores, temperatura de superfícies, textura, umidade e tipo de vegetação.

Atualmente, as imagens são amplamente obtidas por satélites com missões específicas de observação da terra. No que se refere ao Brasil, dados de sensoriamento remoto são coletados a partir de inúmeras plataformas satelitais. O Instituto Nacional de Pesquisas Espaciais (INPE) mantém um banco de imagens, incluindo, por exemplo os seguintes satélites: LANDSAT1, LANDSAT2, LANDSAT3, LANDSAT4, LANDSAT5, LANDSAT7 (EUA), CBERS-2 (China-Brasil), CBERS-2B (China-Brasil), RESOURCESAT-1 (Índia), TERRA (EUA) e AQUA (EUA) (41).

Segundo o Ministério da Agricultura, Pecuária e Abastecimento (MAPA) (13), o sensoriamento remoto tem sido utilizado a fim de avaliar as condições das culturas em relação ao nitrogênio, incidência de pragas, invasoras e doenças. Tradicionalmente tem-se trabalhado com a obtenção de imagens multiespectrais, por satélite ou avião, para a geração de diagnósticos e recomendações. No entanto, ainda existem desafios, pois a iluminação natural não está disponível a todo o momento e coaduna 
com a presença de nuvens, que podem ocasionar variação da intensidade e das características espectrais dos alvos.

A vegetação é considerada um alvo complexo do sensoriamento remoto, pois apresenta propriedades de reflexão foliar que variam numa mesma planta, múltiplos componentes refletores, nãouniformidade de estrutura inter e intraplantas. Além disso, a vegetação encontra-se sobre um substrato constituído de solo e restos de vegetais que apresentam propriedades de reflexão próprias (42).

Por outro lado, de acordo com Rudorff e Moreira (43), a tecnologia de sensoriamento remoto apresenta um grande potencial para ser utilizada na agricultura, pois através dela é possível obter informações sobre a estimativa de área plantada, a produção agrícola e vigor vegetativo das culturas, além de fornecer subsídios para o manejo agrícola em nível de país, estado, município, microbacia hidrográfica ou fazenda.

A partir do exposto, é possível compreender que o sensoriamento remoto permite tomadas de decisão envolvendo também a aplicação dos defensivos agrícolas. Pois, através das imagens obtidas podemse verificar inconsistências em relação a massa verde e, após a investigação do fator impactante na massa verde, providenciar as devidas aplicações.

No que tange os impactos ocupacionais, a utilização do sensoriamento remoto para a aplicação dos defensivos agrícolas, assim como os sensores, também é capaz de minimizar a utilização dos agentes químicos, diminuindo os riscos relacionados à saúde dos trabalhadores durante o processo de aplicação.

\subsection{UTILIZAÇÃO DE SISTEMAS AUTÔNOMOS, ROBÔS E VANTS NA APLICAÇÃO DE DEFENSIVOS AGRÍCOLAS}

Conforme já citado anteriormente, novas tecnologias têm sido desenvolvidas para a aplicação de defensivos agrícolas. Dentre essas novas tecnologias iremos destacar algumas que têm relação com a agricultura de precisão e que contribuem significativamente para a minimização dos risos à saúde dos trabalhadores, já que têm como finalidade a operação autônoma ou remota.

\subsubsection{SISTEMAS AUTÔNOMOS}

Na chamada Agricultura 4.0, baseada na tecnologia digital, os fabricantes de insumos e ferramentas estão trabalhando veementemente para ofertar soluções que ofereçam maior competitividade aos 
produtores. Nesse cenário, sistemas autônomos serão cada vez mais comuns e viáveis. Dentre as vantagens dessa tecnologia que dispensa boa parte da intervenção humana estão a (44):

- habilidade de reimplantação do trabalho em tarefas de valor agregado;

- capacidade de superar a falta de trabalho qualificado;

- possibilidade de 24 horas de trabalho sem variação de produtividade;

- perspectiva de produzir mais em um espaço de tempo menor e;

- possibilidade de aperfeiçoamento de todo o resultado.

Atualmente existem pesquisas, protótipos e testes de máquinas agrícolas autônomas que dispensam o tratorista. Tais projetos, não incluem apenas os tratores agrícolas, mas também pulverizadores autônomos.

Em abril de 2017, foi apresentado na Agrishow em Ribeirão Preto, o modelo de trator sem cabine e operado totalmente à distância. O modelo foi trazido pela primeira vez ao Brasil após ter passado pela Farm Progress Show, nos Estados Unidos, e pelo Salão Internacional de Máquinas Agrícolas (Sima), na França. O trator autônomo apresentado é controlado através de um tablet e agrega tecnologias como: telemetria, sensores, radares, câmeras, aplicativo de controle remoto e sistemas de comunicação com outras máquinas e implementos (45). O trator autônomo também para imediatamente se o sinal do GPS ou dados de posição forem perdidos, bem como se o botão de parada manual for acionado. Cada um dos sistemas de detecção e percepção tem um sistema auxiliar interno, que entra em operação se o sensor principal falhar. No entanto, se ambos os sistemas falharem, a máquina para imediatamente (44).

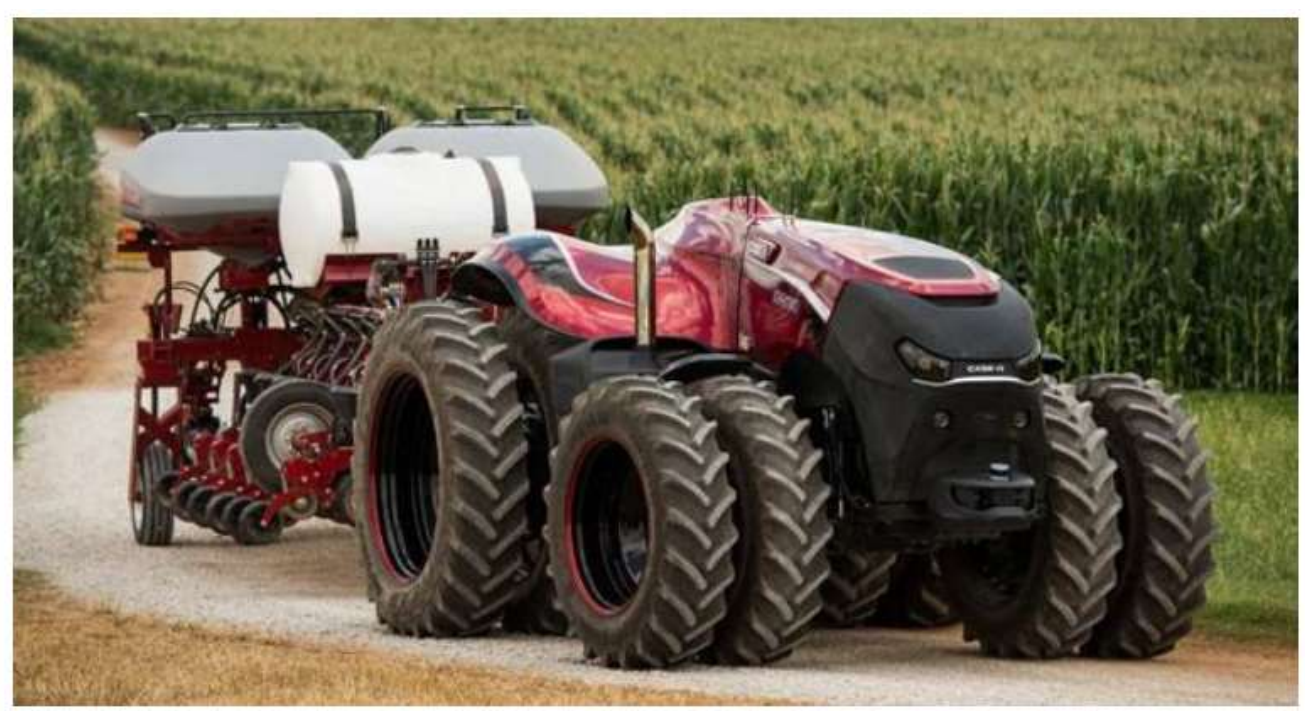

Figura 1: Trator autônomo (46) 
Já em relação ao pulverizador autônomo, Rocha (47) cita que essa máquina está apta a trabalhar individualmente ou como membro de um comboio que realiza trabalho cooperativo. Além disso, o pulverizador é dotado de sensores que monitoram todas as atividades na área e o guiam por uma rota pré-estabelecida, mas também é capaz de identificar obstáculos fixos ou móveis, fazendo paradas em casos de emergência e informando a sua base de controle.

O sistema de pulverização dessa máquina também identifica as plantas permitindo o acionamento preciso, bem como a economia de insumos e a proteção do meio ambiente. A máquina também está dotada de sensores que monitoram continuamente as condições meteorológicas e decidem, de forma autônoma, se devem ou não realizar a pulverização (47).

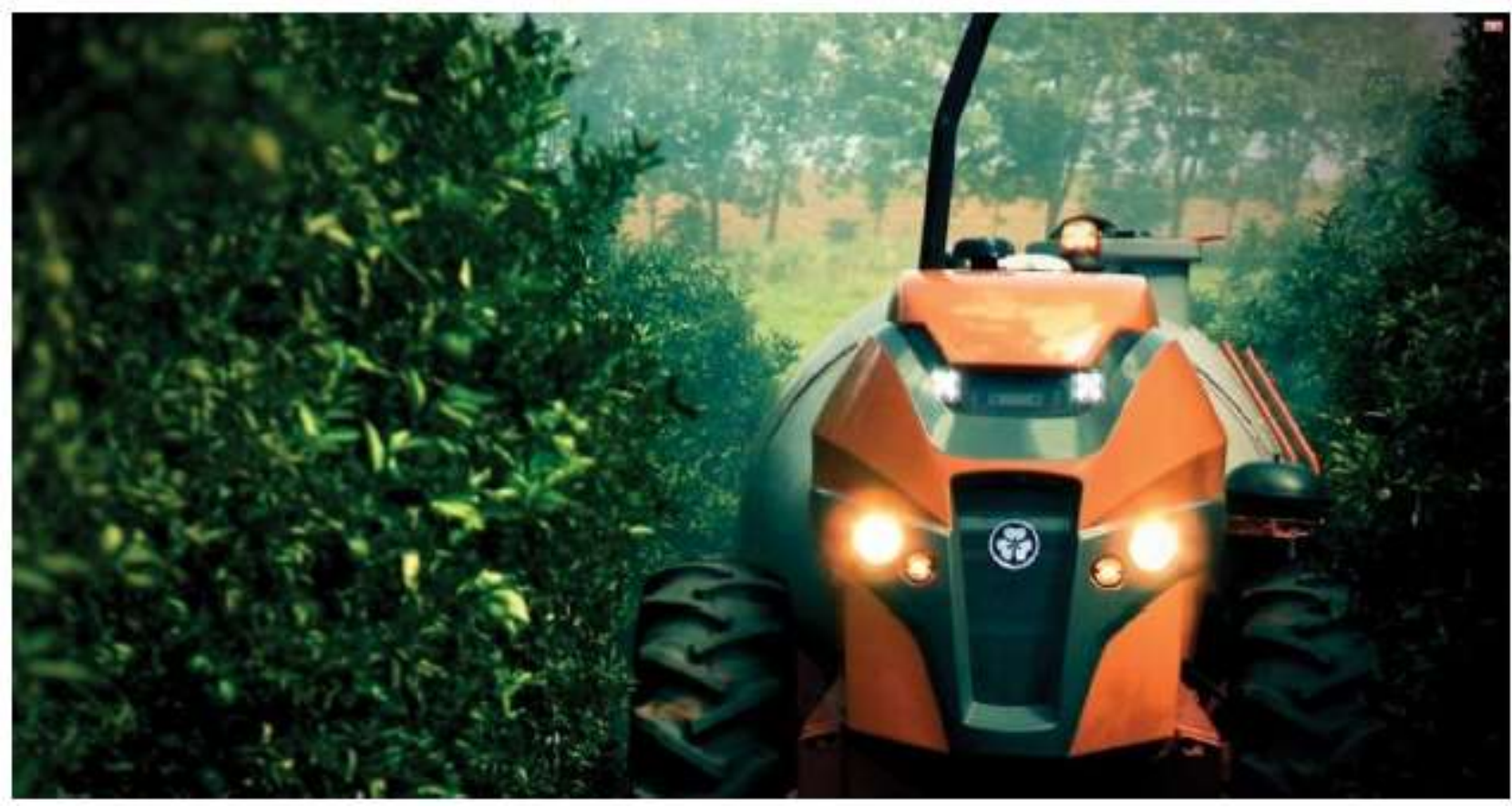

Figura 2: Pulverizador autônomo (48)

Assim, percebe-se que os tratores e pulverizadores autônomos serão alternativas à aplicação de defensivos agrícolas, minimizando significativamente a exposição dos trabalhadores aos agentes químicos. No entanto, ressalta-se que ainda haverá contato com os produtos durante o preparo da calda e inserção dessa no equipamento. Portanto, as medidas de prevenção não estarão dispensadas.

\subsubsection{VANT (VEÍCULO AÉREO NÃO TRIPULADO)}

O uso de aeronaves na aplicação de defensivos agrícolas tem sido cada vez mais comum devido à sua velocidade e eficácia na pulverização. No entanto, alguns fatores podem reduzir o rendimento, ou mesmo causar danos, como por exemplo, áreas de culturas não cobertas no processo de pulverização, 
a sobreposição de pulverização de áreas de cultivo e as falhas na aplicação de pesticidas na borda externa da cultura. Alguns fatores também geram mais complexidade ao sistema de controle, tais como as condições climáticas, como a intensidade e direção do vento durante a pulverização. Nesse sentido, visando minimizar esses problemas e também os custos, surgem os veículos aéreos não tripulados (VANTs) que também podem ser utilizados para pulverização de produtos químicos nas culturas (49).

Um dos tipos de VANTs muito utilizados são os "drones". Nos últimos anos, agricultores de vários países visualizaram nos "drones" uma oportunidade para aplicar no campo os conceitos da agricultura de precisão. A vantagem dos "drones" sobre outros sistemas de monitoramento é que eles são capazes de fazer sobrevôos semanais, a baixo custo, durante todo o período de produção (50).

Segundo Yang et al. (51), os parâmetros de trabalhos ideais dos VANTs para uma pulverização aérea precisa devem envolver: dosagem das gotas de pulverização, áreas de deposição, posicionamento, navegação e tecnologia de pulverização de taxa variável. Ainda de acordo com esses mesmos autores, aplicações aéreas, especialmente para proteção de cultivos, constituem o principal uso dos VANTs na agricultura chinesa.

Já existem projetos para que a aeronave e demais sensores funcionem de modo autônomo, com uma estação de controle e um técnico apenas com a função de monitorar o andamento do processo (50).

Portanto, a utilização de VANTs para a aplicação de defensivos agrícolas também é capaz de minimizar significativamente a exposição dos trabalhadores aos agentes químicos durante o processo de aplicação. No entanto, assim como para os sistemas autônomos citados anteriormente, ainda haverá contato com os produtos durante o preparo da calda e inserção dessa no equipamento. Também devese estar atento à localização do controlador do VANT ou do técnico responsável por monitorar o trabalho dos equipamentos autônomos, para que esse não seja atingido pelo produto durante o sobrevôo da aeronave na área de aplicação. 


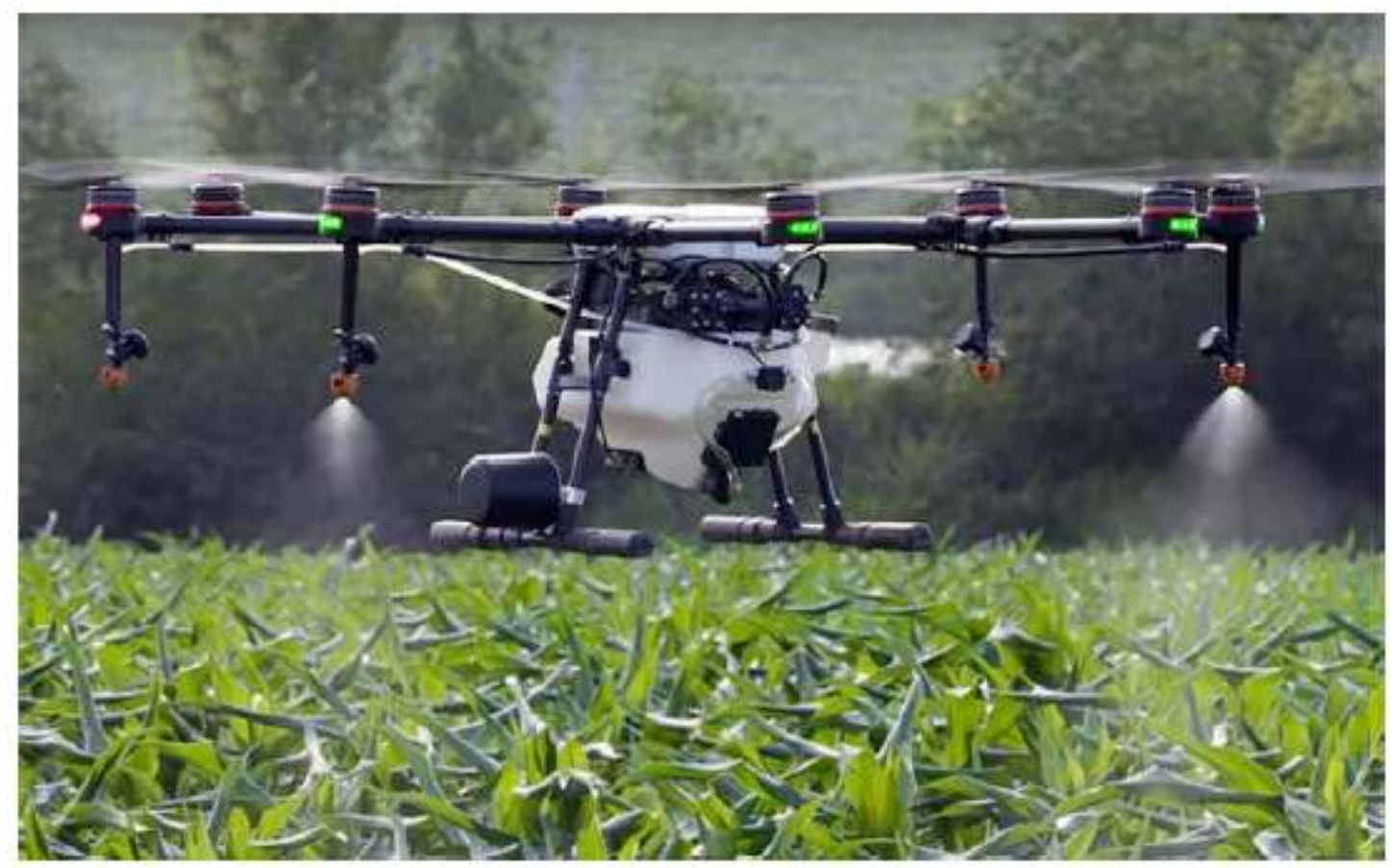

Figura 3: VANT para pulverização de defensivos (52)

\subsubsection{ROBÔS}

A agroindústria está defasada no uso de robôs em suas atividades e processos, se comparada à indústria, onde a utilização de robôs é presente em vários estágios da produção. Uma dificuldade é a adaptação de robôs para uso em ambientes mais rústicos e ao ar livre. No entanto, a evolução tecnológica, assim como o desenvolvimento dos sensores, da inteligência artifical, dos agentes autônomos inteligentes, da precisão do Global Positioning System (GPS), dos equipamentos de telemática e da mecânica de movimentação de máquinas, permitiu que se vislumbre a utilização de robôs para atividades no campo (53)

Atualmente vários países e empresas ao redor do mundo investem uma significativa quantidade de recursos na área da robótica móvel aplicada à agricultura. Isso ocorre principalmente visando o aumento da produção de alimentos, bem como a redução dos custos. Nesse sentido, os robôs agrícolas podem ser empregados na otimização das atividades de: colheita, pulverização, semeação e preparo do solo. Porém, existem vários desafios que precisam ser superados para que seja produzido um robô agrícola economicamente viável (54).

Hackenhaar et al. (55) fizeram uma revisão bibliográfica sobre a utilização da robótica na agricultura de precisão e apontaram que os robôs têm sido projetados e usados principalmente em situações onde há necessidade de energia relativamente baixa. Como por exemplo, cita-se a capina, na qual as 
ervas daninhas podem ser tratadas com uma pequena quantidade de produto químico, altamente concentrado ou através do controle de plantas daninhas de forma mecânica.

Nesse contexto, em relação à aplicação de defensivos agrícolas, já existem projetos de robôs para a realização de pulverização de forma semiautomática (FIG. 6) e automática (FIG. 7), eliminando assim, a exposição dos trabalhadores aos agentes químicos durante o processo de aplicação.

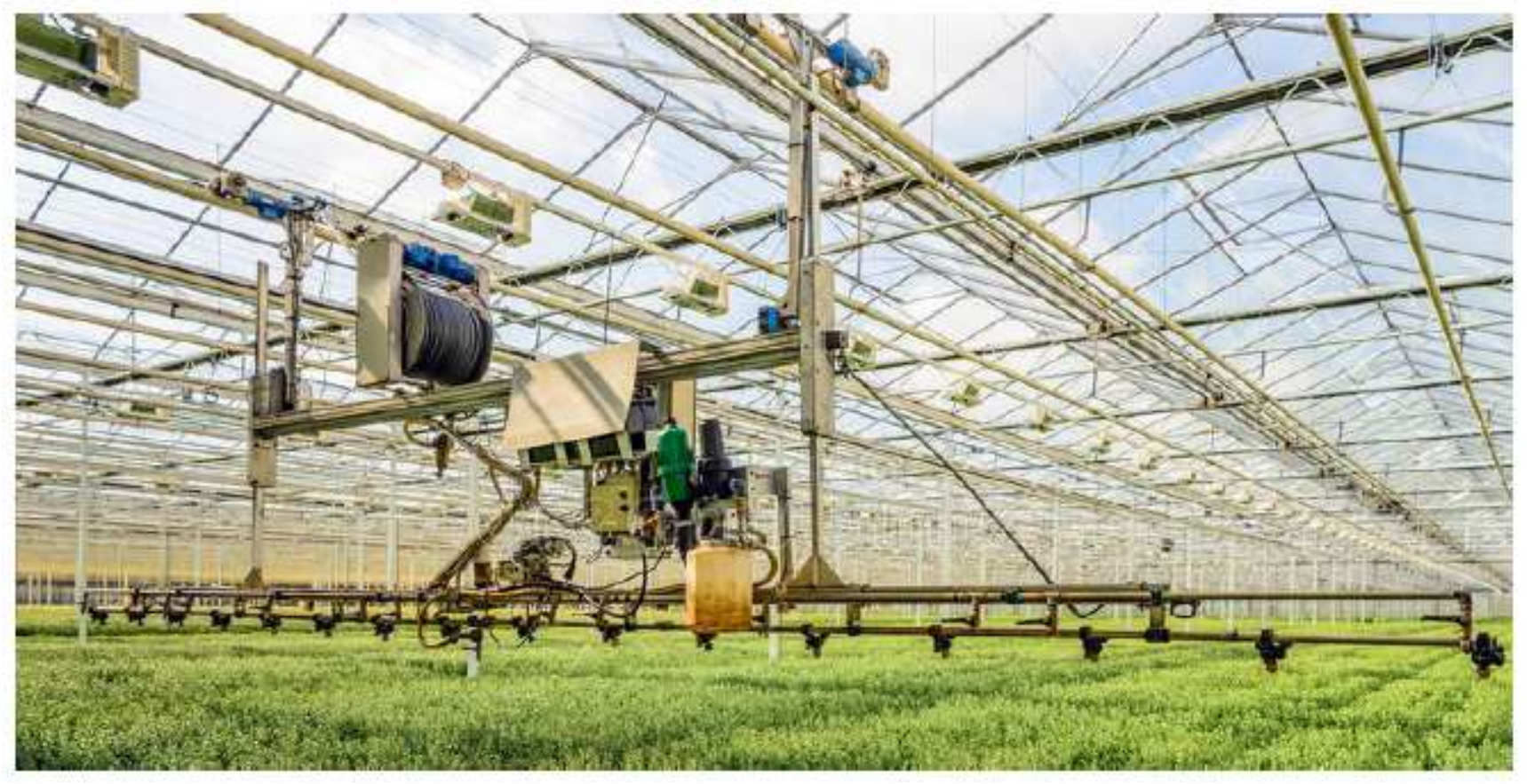

Figura 4: Robô de pulverização semiautomático (56)

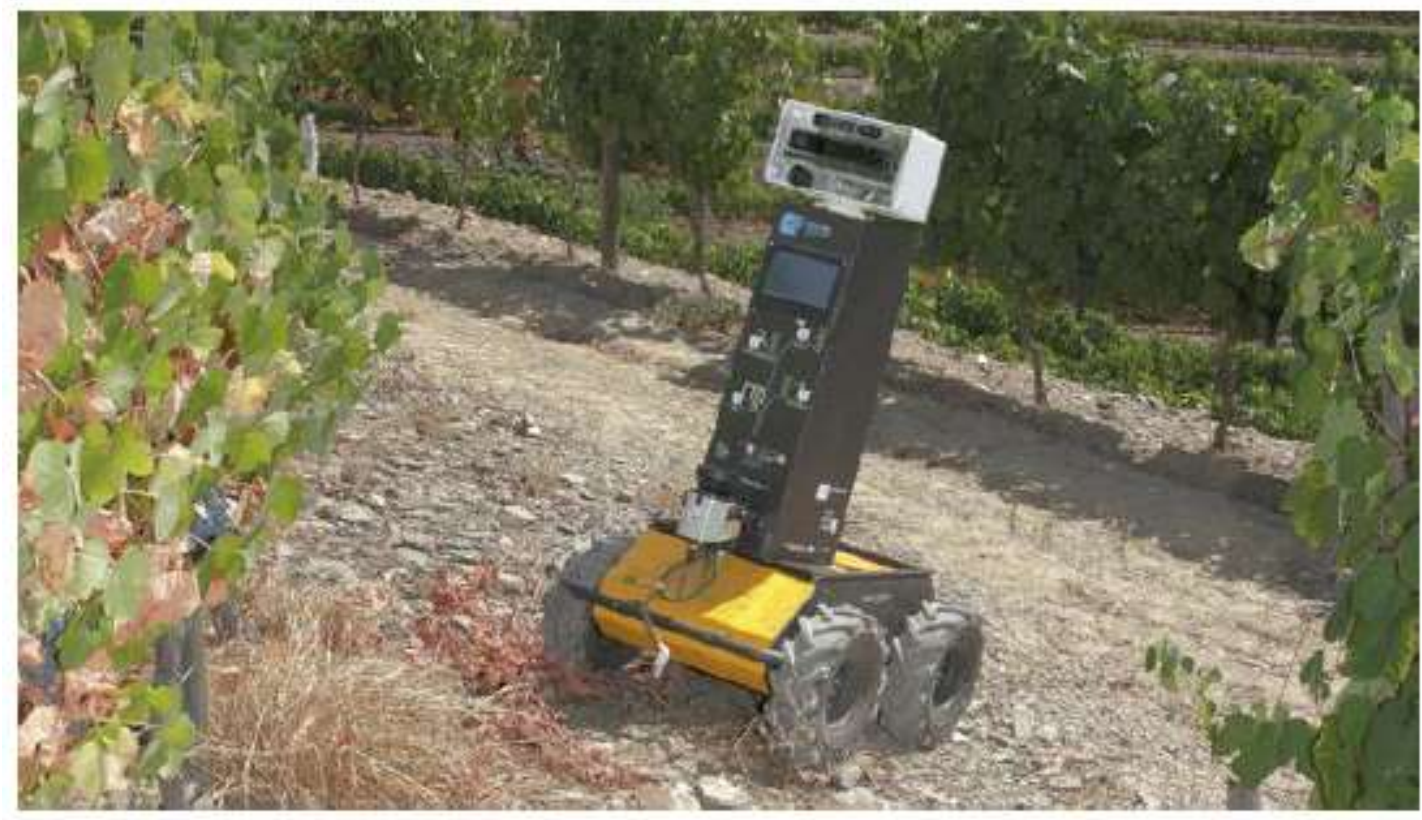

Figura 5: Robô automático (57) 
No entanto, cabe ressaltar que também está em desenvolvimento máquinas/robôs para exterminação de plantas daninhas e outros invasores que dispensam a utilização de defensivos agrícolas. Sob a ótica ocupacional, tais sistemas oferecem a eliminação dos agentes químicos, favorecendo a saúde dos trabalhadores.

Nesse sentido, um projeto da Bosh em parceria com Universidade de Osnabrück (Alemanha), criou um robô capaz de identificar plantas saudáveis, doentes e ervas daninhas para eliminar as invasoras sem o uso de herbicidas. A tecnologia, denominada de BoniRob, utiliza algorítimos, redes neurais, e inteligência artificial, assim, ao identificar uma planta invasora, o BoniRob aciona um dispositivo (de cerca de um centímetro de largura) que destrói o vegetal não desejado de maneira definitiva, arrancando pela estrutura. Embora seja do tamanho de um carro popular e pese cerca de meia tonelada, o robô é ágil, eliminando quase duas ervas daninhas por segundo (58).

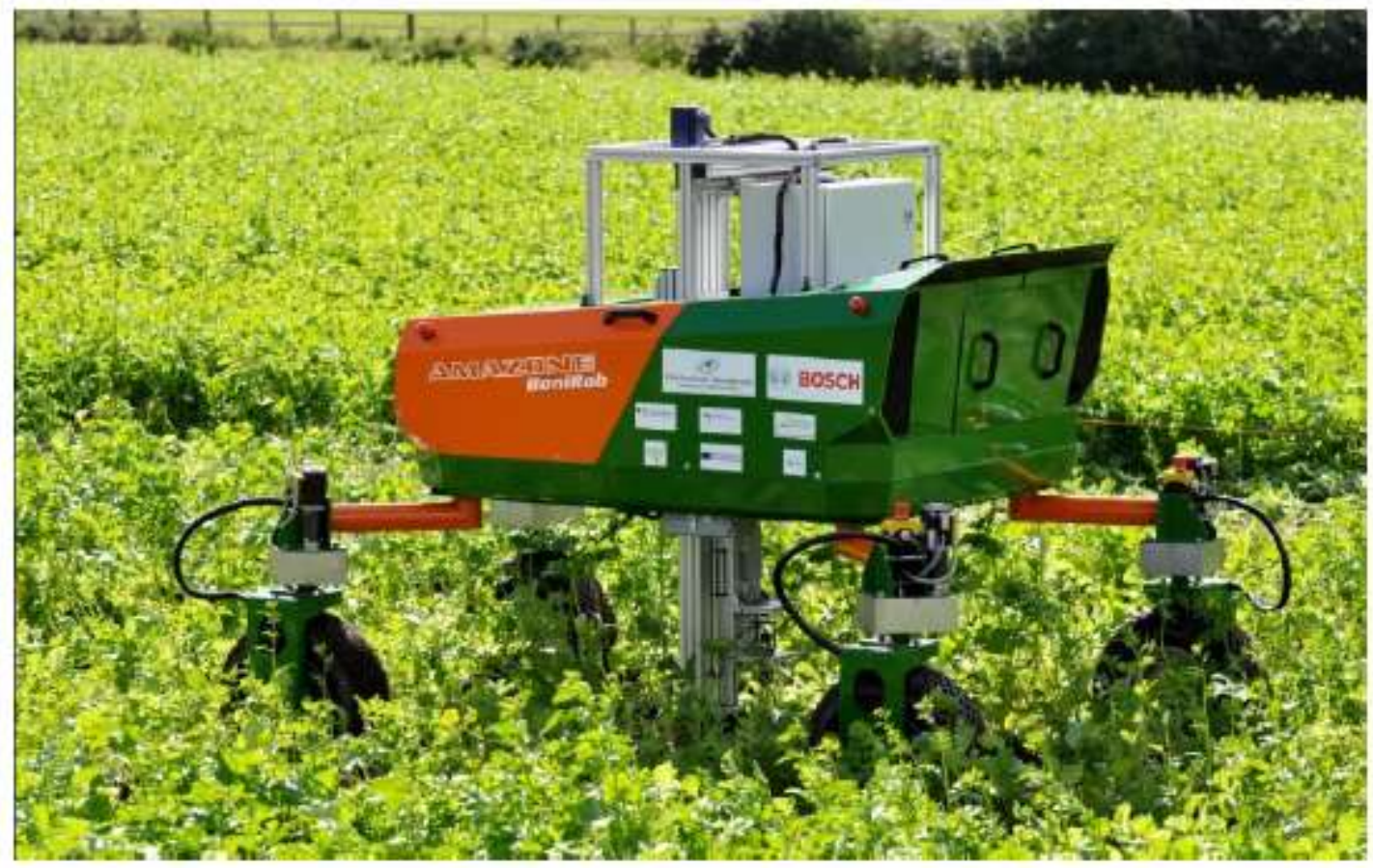

Figura 6: BoniRob (59)

As empresas também têm buscado outras formas de extinção dos organismos indesejáveis em substituição aos defensivos agrícolas. Empresas alemãs, por exemplo, também desenvolveram um robô que destrói tais organismos com a utilização de lasers. O denominado Jäti é um rastreador autônomo movido a bateria que é projetado para identificar ervas daninhas e destruí-las com feixes de laser (60). 
Destaca-se ainda a utilização de equipamentos que produzem choques elétricos para o controle de ervas daninhas. Nesse tipo de equipamento que pode ser acoplado aos tratores, as ervas daninhas são eliminadas por meio de descargas elétricas. De acordo com a fabricante, a empresa Sayyou Brasil, o implemento passa sobre a terra um aplicador com eletrodos disparando choque elétrico de 5 mil volts, que paralisa a condução da seiva e causa a morte da planta em até uma semana (61).

Por fim, ressalta-se que as alternativas em desenvolvimento para a substituição na utilização dos defensivos agrícolas são importantes não somente para a economia no uso de insumos e para a minimização dos impactos ambientais, mas também para a redução dos riscos à saúde dos trabalhadores gerados pela preparação da calda, abastecimento dos equipamentos e aplicação nas culturas.

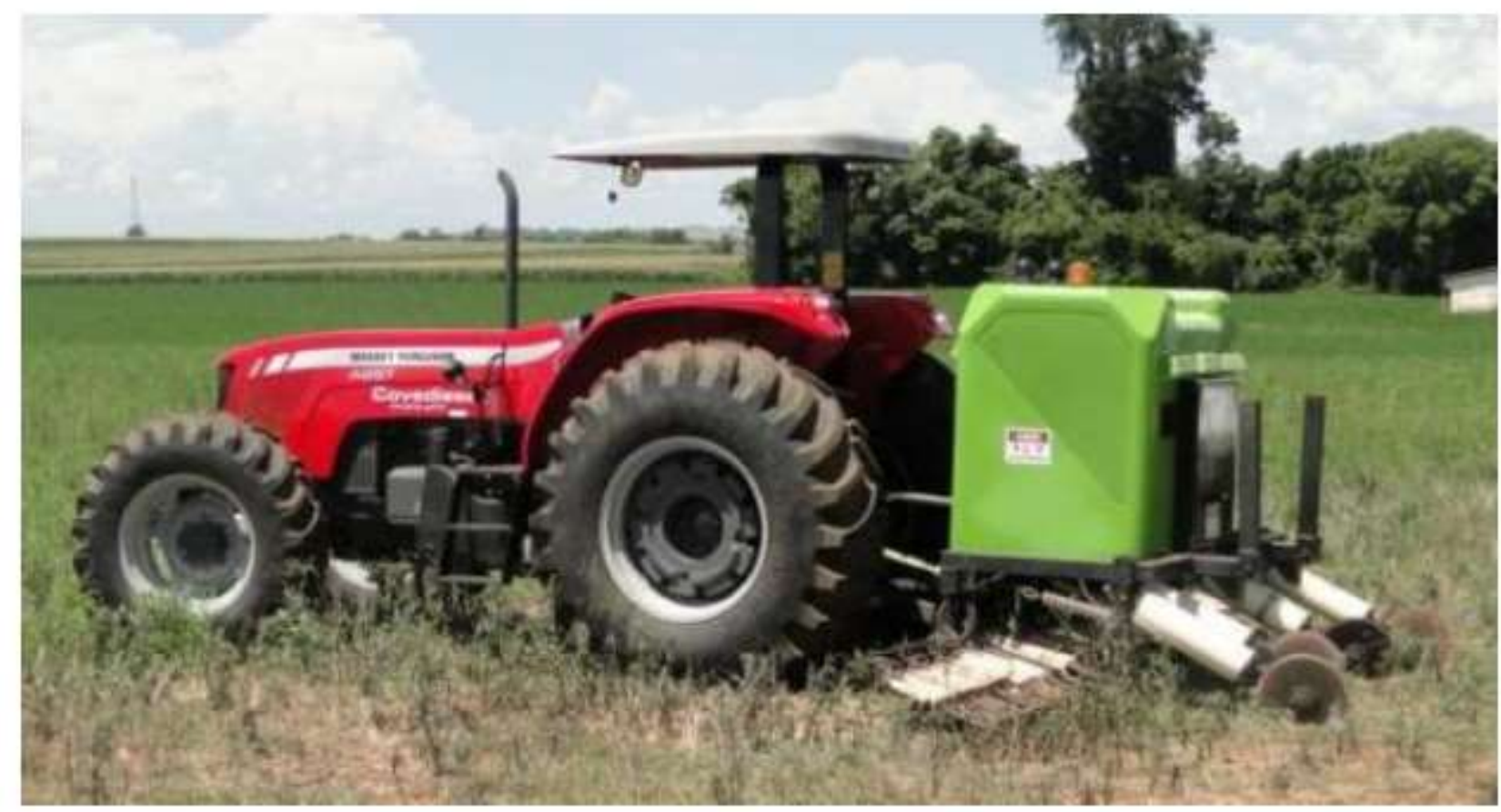

Figura 7: Aplicador com eletrodos disparando choque elétrico de 5 mil volts (62)

\section{CONCLUSÕES}

Apesar dos avanços tecnológicos em relação à aplicação de defensivos agrícolas, os agrotóxicos ainda serão amplamente utilizados no modelo de produção brasileiro. Portanto, a adequada instrução e proteção dos trabalhadores são fundamentais para a minimização dos riscos à saúde e consequentemente para a redução dos casos de intoxicação ocupacional e outras doenças associadas envolvendo tais agentes químicos. 
Em relação aos métodos tradicionais de aplicação de defensivos, por via sólida, líquida ou gasosa, todos oferecem riscos ao trabalhador, seja durante a aplicação ou no preparo da calda e abastecimento dos equipamentos.

Por outro lado, em relação às máquinas e formas de aplicação, é possível perceber que as aplicações realizadas manualmente ou através da utilização de tração animal oferecem riscos mais acentuados à segurança dos trabalhadores, já que durante essa etapa, o trabalhador possui maior contato com os agentes químicos.

No entanto, para que as máquinas tratorizadas e autopropelidas também sejam mais seguras no tocante ao processo de aplicação, é importante priorizar a utilização de máquinas com cabines adequadamente isoladas em relação aos agentes químicos. Contudo, tal medida não evita o contato do trabalhador durante o preparo da calda e abastecimento das máquinas.

No que se refere à aplicação com a utilização de aeronaves, desde que os produtos estejam adequadamente isolados do piloto, bem como a aeronave esteja também devidamente isolada, minimizam-se os riscos à saúde dos trabalhadores.

Já em relação à agricultura de precisão e as tecnologias aplicadas a essa forma de gerenciamento: sensores, aplicação à taxa variável, sensoriamento remoto e definição de zonas de manejo; há um consenso entre os pesquisadores sobre a redução da quantidade de produtos aplicados, além da promoção de resultados mais eficazes. Logo, em relação à aplicação de defensivos agrícolas através da agricultura de precisão, a minimização no emprego dos produtos, bem como a maior precisão nos processos de aplicação, impacta positivamente na segurança dos trabalhadores. Isso, porque há uma significativa redução no manuseio de produtos e na dissipação desses na atmosfera (deriva).

Nesse sentido, percebe-se que a agricultura de precisão pode ser utilizada como uma ferramenta de gerenciamento não apenas para a minimização dos gastos com insumos, ensaios de campo e impactos ao meio ambiente, mas também como uma forma de redução dos impactos ocasionados à saúde dos trabalhadores no campo.

Em relação às novas tecnologias de aplicação, são muitas as pesquisas de máquinas e implementos em desenvolvimento. Portanto, quanto mais autônomos ou mais remotos o controle dos aplicadores de defensivos, menores são os riscos à saúde dos operadores durante a etapa de aplicação. 
Por outro lado, as novas tecnologias que dispensam a utilização dos produtos químicos são alternativas ainda melhores para a eliminação dos agentes causadores de intoxicações e outras doenças ocupacionais relacionadas aos defensivos agrícolas.

Por fim, considerando que a utilização de EPIs não deve ser a única, mas sim a última, forma de proteção do trabalhador, a utilização das novas tecnologias abordadas no presente trabalho precisam ser avaliadas e desenvolvidas para que se tornem economicamente mais viáveis e possam propiciar benefícios à segurança dos trabalhadores. 


\section{REFERÊNCIAS}

1. ONUBR - Nações Unidas no Brasil. A ONU e a alimentação. Disponível em:

<https://nacoesunidas.org/acao/alimentacao/>. Acesso em: 08 abr. 2018.

2. Governo do Brasil. Crescimento da renda aumenta demanda por alimentos. Disponível em: <http://www.brasil.gov.br/economia-e-emprego/2013/10/crescimento-da-renda-aumentademanda-por-alimentos>. Acesso em: 08 abr. 2018.

3. Planalto. LEI № 7.802, DE 11 DE JULHO DE 1989. Disponível em:

<http://www.planalto.gov.br/ccivil_03/Leis/L7802.htm>. Acesso em: 10 abr. 2018.

4. DA SILVA, A. A., et al. Critérios Toxicológicos e Ambientais para Registro de Produtos Fitossanitários. [A. do livro] L. ZAMBOLIM; A. A. da SILVA e M. C. PICANÇO. O que Engenheiros Agrônomos devem saber para orientar o uso de Produtos Fitossanitários. Viçosa : Universidade Federal de Viçosa, 4a Edição, 2014.

5. Ministério do Meio Ambiente. Agrotóxicos. Disponível em: <http://www.mma.gov.br/segurancaquimica/agrotoxicos>. Acesso em: 06 abr. 2018.

6. IBAMA. Relatórios de comercialização de agrotóxicos. Disponível em:

<http://www.ibama.gov.br/phocadownload/qualidadeambiental/relatorios/2016/grafico-consumoagrotoxicos-2000-2016.pdf>. Acesso em: 08 abr. 2018.

7. MIGUELA, J. V. e DA CUNHA, J. P. A. R. Manual de Aplicação de Produtos Fitossanitários. Viçosa: Aprenda Fácil, 1a Edição, 2017. 588p.

8. VITAL, N. Agradeça aos agrotóxicos por estar vivo. Rio de Janeiro: Record, 1a Edição, 2017. 251p.

9. PAPINI, S., DE ANDREA, M. M. e LUCHINI, L. C. Segurança ambiental no controle químico de pragas e vetores. São Paulo: Atheneu, 1a Edição, 2014. 290p.

10. DASUS. Intoxicação exógena - Notificações registradas no SINAN NET - Brasil. Disponível em:

<http://tabnet.datasus.gov.br/cgi/tabcgi.exe?sinannet/cnv/Intoxbr.def>. Acesso em: 09 abr. 2018.

11. DIVE - Diretoria de Vigilância Epidemiológica. Intoxicação Exógena. Disponível em: <http://www.dive.sc.gov.br/index.php/d-a/item/intoxicacao-exogena>. Acesso em: 09 abr. 2018.

12. DATASUS. Notificações por Exposição trabalho segundo Agente Tóxico. Disponível em: <http://tabnet.datasus.gov.br/cgi/tabcgi.exe?sinannet/cnv/Intoxbr.def>. Acesso em: 09 abr. 2018.

13. Ministério da Agricultura, Pecuária e Abastecimento - MAPA. Boletim Técnico - Agricultura de Precisão. Ministério da Agricultura, Pecuária e Abastecimento. 3a Edição, 2013. 31p. Disponível em: <http://www.agricultura.gov.br/assuntos/sustentabilidade/tecnologia-agropecuaria/agricultura-deprecisao-1/arquivos-de-agricultura-de-precisao/boletim-tecnico-agricultura-de-precisao2013.pdf/view>. Acesso em: 22 mar. 2018. 
14. BRAIBANTE, M. E. F. e ZAPPE, J. A. A Química dos Agrotóxicos. $n^{\circ}$ 1: Química Nova na Escola, fev.2012, vol. 34 , p. 10-15.

15. BALASTREIRE, L. A. Máquinas Agrícolas. Piracicaba, SP: 2005. 310p.

16. Secretaria de Trabalho. NR 31 - Segurança e saúde no trabalho na agricultura, pecuária, silvicultura, exploração florestal e aquicultura. Disponível em: <https://www.gov.br/trabalho/pt$\mathrm{br} /$ inspecao/seguranca-e-saude-no-trabalho/normas-regulamentadoras/nr-31.pdf $>$. Acesso em: 20 jul. 2021.

17. AZEVEDO, F. R. de; FREIRE, F. das C. O. Tecnologia de Aplicação de Defensivos Agrícolas. Fortaleza, CE: Embrapa Agroindústria Tropical, 2006. 47p.

18. SPADOTTO, C. A. Influência das condições meteorológicas no transporte de agrotóxicos no ambiente. Boletim SBMET, abr. 2016. p. 15-20.

19. PIMENTEL, M. A. G., et al. Phosphine resistance, respiration rate and fitness consequences in stored-product insects. Pest Management Science, 2007, vol. 63. p.876-881.

20. Secretaria de Trabalho . NR 15 - Atividades e operações insalubres. Disponível em: <https://www.gov.br/trabalho/pt-br/inspecao/seguranca-e-saude-no-trabalho/normasregulamentadoras/nr-15.pdf>. Acesso em: 20 jul. 2021.

21. A granja. Pulverização eletrostática, a química a serviço da eficiência. Disponível em: <http://edcentaurus.com.br/agranja/edicao/776/materia/5398>. Acesso em: 12 abr. 2018.

22. Canal Agrícola. Pulverizador de Tração Animal Tipo Burrojet com 2 hastes e tanque 100 Litros. Disponível em: <https://www.canalagricola.com.br/pulverizador-tracao-animal-tipo-burrojet2hastes-100litros>. Acesso em: 12 abr. 2018.

23. Youtube. Atomizador Costal Motorizado Vulcan VAT-20L Durabilidade e Eficiência Garantida! Disponível em: <https://www.youtube.com/watch?v=2MEjwSGPNEw>. Acesso em: 12 abr. 2018.

24. Sindicato Rural Amambai - MS. REGULAGEM E OPERAÇÃO DE PULVERIZADOR ELETRONICO TRATORIZADO. Disponível em: <http://www.sramambai.com.br/agenda.php?cdMateria=486>. Acesso em: 12 abr. 2018.

25. Panegossi. Pulverizador 2500 SP Defensor da New Holland. Disponível em:

<https://www.panegossi.com.br/pulverizador-2500-sp-defensor-mais-um-lancamento-da-newholland-em-2017/>. Acesso em: 12 abr. 2018.

26. Brasquímica. Benefícios da pulverização aérea. Disponível em:

<http://brasquimica.ind.br/beneficios-da-pulverizacao-aerea/>. Acesso em: 12 abr. 2018.

27. JUSTINIANO, W. Tecnologia de Aplicação. Agronômico - Informativo de desenvolvimento tecnológico. Ano 3, n. 9, set. 2014. 
28. PICANÇO, M. C., et al. Controle Químico de Pragas. [A. do livro] L. ZAMBOLIM; A. A. da SILVA e M. C. PICANÇO. O que Engenheiros Agrônomos devem saber para orientar o uso de Produtos Fitossanitários. Viçosa : Universidade Federal de Viçosa, 4a Edição, 2014.

29. Portal São Francisco. Pulverização com precisão. Disponível em: <https://www.portalsaofrancisco.com.br/biologia/pulverizacao-com-precisao>. Acesso em: 22 mar. 2018.

30. SAY, S. M.; KESKIN, M.; SEHRI, M.; SEKERLI, Y. E. Adoption of precision agriculture technologies in developed and developing countries. Disponível em:

<https://www.tojsat.net/journals/tojsat/articles/v08i01/v08i01-02.pdf>. Accesso em: 23 mar. 2018.

31. UMEZU, C. K. Sistema de controle de um equipamento de formulação, dosagem e aplicação de fertilizantes sólidos a taxas variáveis. Tese de doutorado. Disponível em: <http://repositorio.unicamp.br/bitstream/REPOSIP/257579/1/Umezu_ClaudioKiyoshi_D.pdf>. Acesso em: 10 abr. 2018.

32. STAFFORD, J. V. Spatially variable field operations. Computers and Electronics in Agriculture. n.23, fev. 1996, vol. 14. p.99-100.

33. SARAIVA, A. M., et al. O problema da padronização e integração de sistemas na Agricultura de Precisão. Curitiba: GIS BRASIL, 1998.

34. SWINTON, S. M. e LOWENBERG-DEBOER, J. Global Adoption of Precision Agriculture Technologies: Who, When and Why?. Montpellier: Agro Montpellier (ENSAM): European Conference on Precision Agriculture, vol. 3., 2001. p.557-562.

35. SUDDUTH, K. A. Engineering Technologies for Precision Farming. 1999. Disponível em: <https://pdfs.semanticscholar.org/c81f/739bf0208f20a85bc58446c8119311b7d8cb.pdf>. Acesso em: 23 mar. 2018.

36. RODRIGUES JÚNIOR, F. A., et al. Geração de zonas de manejo para cafeicultura empregando-se sensor SPAD e análise foliar. n.8., Campina Grande, PB. : Revista Brasileira de Engenharia Agrícola e Ambiental, 2011, vol. 15. p.778-787.

37. ALVES, S. M. de F., et al. Definição de zonas de manejo a partir de mapas de condutividade elétrica e matéria orgânica. n. 1, Uberlândia: Biosci. J., Jan./Feb. 2013, vol. 29. p. 104-114.

38. MENDES, A. M. S., FONTES, R. L. F.; OLIVEIRA, M. Variabilidade espacial da textura de dois solos do Deserto Salino, no Estado do Rio Grande do Norte. Revista Ciência Agronômica., 2008, vol. 39. p. 1927.

39. MOLIN, J. P., AMARAL, L. de R.; COLAÇO, A. F. Agricultura de Precisão. Edição 1, 2015.

40. universoagro. A tecnologia no controle às plantas invasoras. Disponível em: <http://www.uagro.com.br/editorias/tecnologia/agricultura-de-precisao/2013/10/02/a-tecnologiano-controle-as-plantas-invasoras.html>. Acesso em: 15 abr. 2018. 
41. VERAS, C. A. G. Agência Espacial Brasileira. Sensoriamento remoto no Brasil. Disponível em: < http://www.aeb.gov.br/sensoriamento-remoto-no-brasil/>. Acesso em: 09 abr. 2018.

42. EPIPHANIO, J. C. N., et al. Índices de vegetação no sensoriamento remoto da cultura do feijão. Pesquisa agropecuária brasileira, Brasília, jun. 1996, vol. 31. p. 445-454.

43. MOEREIRA, M. A.; RUDORFF, B. F. T. INSTITUTO NACIONAL DE PESQUISAS ESPACIAIS-INPE . Sensoriamento remoto aplicado à agricultura. Disponível em: <http://mtcm12.sid.inpe.br/col/sid.inpe.br/sergio/2005/06.14.13.14/doc/CAP9_MAMoreira.pdf>. Acesso em: 10 abr. 2018.

44. AGRISHOW DIGITAL. Ferramentas com sistemas autônomos são tendências da Agricultura 4.0. Disponível em: <http://digital.agrishow.com.br/ferramentas-com-sistemas-autonomos-saotendencias-da-agricultura-4-0/>. Acesso em: 23 mar. 2018.

45. SALOMÃO, R. GLOBO RURAL. Case apresenta trator autônomo e sem cabine no Brasil. Disponível em: $\quad<$ https://revistagloborural.globo.com/Noticias/Empresas-e-Negocios/noticia/2017/04/caseapresenta-trator-autonomo-e-sem-cabine-no-brasil.html>. Acesso em: 22 de mar. 2018.

46. AUTO ESPORTE. Case IH apresenta trator autônomo no brasil. Disponível em: <https://revistaautoesporte.globo.com/Noticias/noticia/2017/05/case-ih-apresenta-tratorautonomo-no-brasil.html>. Acesso em: 22 mar. 2018.

47. ROCHA, R. G. O. Cultivar. Jacto apresenta conceito de veículo autônomo JAV. Disponível em: <http://www.grupocultivar.com.br/noticias/jacto-apresenta-conceito-de-veiculo-autonomo-jav>. Acesso em: 16 abr. 2018.

48. Jacto. Linha do tempo. Disponível em: <https://www.jacto.com.br/brasil/company/linha-dotempo>. Acesso em: 12 abr. 2018.

49. COSTA, F. G., et al. The use of unmanned aerial vehicles and wireless sensor network in agricultural applications. Geoscience and Remote Sensing Symposium (IGARSS), 2012. p. 5045-5048.

50. Pesquisa FAPESP. Drones sobre o campo. Disponível em:

<http://revistapesquisa.fapesp.br/2016/01/12/drones-sobre-o-campo/>. Acesso em: 22 mar. 2018.

51. YANG, S.; YANG, X.; MO, J. The application of unmanned aircraft systems to plant protection in China. v.19. abr. 2018, p. 278-292. Disponível em:

<https://link.springer.com/article/10.1007\%2Fs11119-017-9516-7>. Acesso em: 15 abr. 2018.

52. INDIAN DRONE STORE. DJI AGRAS MG-1 Pesticide Spray UAV. Disponível em: <http://www.indiandronestore.in/product/dji-agras-mg-1-pesticide-spray-uav/>. Acesso em: 16 abr. 2018.

53. ZAPPA, M. Business Insider. Emerging agriculture technologies that will change the world. Disponível em: <http://www.businessinsider.com/15-emerging-agriculture-technologies-2014-4>. Acesso em: 15 abr. 2018. 
54. ABRAHÃO, G. Q. S., MEgDA, P. T. e BECKER, M. O Uso de Algoritmos A* e Field A* em Robôs Agrícolas. Disponível em: <http://www.abcm.org.br/anais/conem/2010/PDF/CON10-0451.pdf>. Acesso em: 15 abr. 2018.

55. HACKENHAAR, N. M., HACKENHAAR, C. e ABREU, Y. V. de. Robótica na agricultura. vol. 16, n.1, Campo Grande, 2015. Disponível em: <http://dx.doi.org/10.1590/1518-70122015110>. Acesso em: 15 abr. 2018.

56. Dreamstime. O robô de pulverização semiautomático em uma estufa especializou-se no. Moderno, hothouse. Disponível em:

<https://pt.dreamstime.com/foto-de-stock-o-rob-de-pulveriza\%C3\%A7\%C3\%A3o semiautom\%C3\%A1tico-em-uma-estufa-especializou-se-no-image89875275>. Acesso em: 12 abr. 2018.

57. ResearchGate. Path Planning for Automatic Recharging System for Steep-Slope Vineyard Robots. Disponível em:

<https://www.researchgate.net/publication/321019630_Path_Planning_for_Automatic_Recharging_ System_for_Steep-Slope_Vineyard_Robots>. Acesso em: 12 abr. 2018.

58. AGROLINK. Bosch cria robô que identifica e elimina erva daninha sem herbicida. Disponível em: <https://www.agrolink.com.br/noticias/bosch-cria-robo-que-identifica-e-elimina-erva-daninha-semherbicida_344233.html>. Acesso em: 13 abr. 2018.

59. Field Robot Event. Field Robot Demo. Disponível em:

<http://www.fieldrobot.com/event/index.php/demo/>. Acesso em: 12 abr. 2018.

60. realagriculture. This robot kills weeds with lasers. Disponível em:

<https://www.realagriculture.com/2017/11/this-robot-kills-weeds-with-lasers/>. Acesso em: 13 abr. 2018.

61. Portal Biossistemas Brasil. Uso de choques elétricos como controle de ervas daninhas. Disponível em: <http://www.usp.br/portalbiossistemas/?p=6424>. Acesso em: 22 mar. 2018.

62. GAUCHAZH. Máquina que elimina ervas daninhas com choques elétricos vira atração no Interior. Disponível em: <https:/gauchazh.clicrbs.com.br/geral/noticia/2013/12/maquina-que-elimina-ervasdaninhas-com-choques-eletricos-vira-atracao-no-interior-4374260.html>. Acesso em: 12 abr. 2018.

63. Ministério do Trabalho e Emprego - MTE. NR 9 - PROGRAMA DE PREVENÇÃO DE RISCOS AMBIENTAIS. Disponível em: <http://trabalho.gov.br/images/Documentos/SST/NR/NR09/NR-092016.pdf>. Acesso em: 22 mar.de 2018. 


\section{Capítulo 3}

doi) $10.37423 / 210704525$

\section{CARACTERIZAÇÃO DO POTENCIAL GERMINATIVO DE TRÊS CULTIVARES DE PIMENTA MALAGUETA SUBMETIDAS AO SUBSTRATO AUTOCLAVADO E NÃO AUTOCLAVADO}

Juliano Milhomem Ribeiro

Cide Moreira da Silva

\section{Luís Henrique Froés Michelin}

\section{Diniz Didier Dias}

\section{Lúcio Mário Quirino do Nascimento}

\section{Thiago Magalhães de Lázari}

\section{Cid Tacaoca Muraishi}

Agência de Defesa Agropecuária do Estado do Tocantins

Agência de Defesa Agropecuária do Estado do Tocantins

Agência de Defesa Agropecuária do Estado do Tocantins

Agência de Defesa Agropecuária do Estado do Tocantins

Uniggel Sementes

Universidade Estadual do Tocantins

Universidade Estadual do Tocantins 
Resumo: O trabalho foi desenvolvido em casa de vegetação no Campus de Ciências Agrárias e Ambientais da Faculdade Católica do Tocantins, com o objetivo de avaliar três cultivares de pimenta malagueta (Capsicum frutescens) em relação ao seu potencial de germinação. As sementes foram semeadas em um mesmo substrato a base de vermiculita, porém um deles foi autoclavado para a eliminação de fitopatógenos e o outro não passou por nenhum tratamento, mantendo suas características físico-químicas-biológicas originais. As cultivares utilizadas foram a pimenta malagueta comum, pimenta malagueta vulcão e pimenta malaguetinha. As sementes foram cultivadas em bandeja contendo substrato comercial de matéria orgânica diversificada. O delineamento experimental utilizado foi inteiramente casualizado, sendo adotado um esquema fatorial (3x2), 32 repetições e um total de 192 parcelas. Foi avaliado o índice germinativo das cultivares em diferentes condições de substrato.

Palavras-chave: autoclave, capsicum frutescens, germinação. 


\section{INTRODUÇÃO}

A pimenta malagueta (Capsicum frutecens) é uma espécie vegetal pertencente à família das solanáceas, sendo originária das regiões tropicais americanas. Capsicum L. é o gênero botânico da família Solanaceae, que abrange as pimentas e os pimentões, hortícolas originários da América Central e do Sul. Acredita-se que a exploração de tais pimentas se deu desde o início do povoamento humano nas Américas, supostamente há cerca de 12.000 anos (BOSLAND e VOTAVA, 2000).

É uma planta semi perene, arbustiva e possui caule medianamente lignificado. É cultivada principalmente nos estados de MG, BA e GO, ocupando lugar de destaque entre as espécies condimentares mais utilizadas, superada apenas pelo alho e cebola. Apresentam teores de vitamina A e C superiores aos encontrados no pimentão e demais olerícolas produzidas no Brasil (DIAS, 2008; FILGUEIRA, 2000; FILGUEIRA, 2003; ARAÚJO, 2005).

O Brasil é o segundo maior produtor de pimenta no mundo (RISTORI et al., 2002) e centro da diversidade do gênero Capsicum (REIFSCHNEIDER, 2000). Essa hortaliça está difundida em todas as regiões do Brasil, sendo que as principais áreas de cultivo são as regiões Sudeste e Centro-Oeste.

Para que haja a germinação é necessário que ocorra uma sequência de reações metabólicas até a emergência da plântula. Segundo CARVALHO e NAKAGAWA (2000), os principais fatores que influenciam a germinação das sementes são a umidade, a luz, a disponibilidade de oxigênio e a temperatura. Quando todos estes fatores são expressos em condições ótimas, então as sementes expressam seu potencial máximo de germinação, que por sua vez torna-se uma característica de suprema importância para que haja uniformidade e rápida formação das plântulas.

O objetivo desse trabalho foi avaliar o potencial germinativo de três cultivares de pimenta malagueta (Malaguetinha, Malagueta comum e Malagueta vulcão) em substrato autoclavado e não autoclavado em um ambiente controlado.

\section{MATERIAL E MÉTODOS}

O presente trabalho foi realizado no Campus de Ciências Agrárias e Ambientais da Faculdade Católica do Tocantins em Palmas-TO, com coordenadas geográficas $48^{\circ} 16^{\prime} 34^{\prime \prime}$ W e $10^{\circ} 32^{\prime} 45^{\prime \prime} \mathrm{S}$ e altitude de 230m, localizando-se na Rodovia TO 050, Loteamento Coqueirinho, Lote 7.

O experimento foi conduzido em um delineamento inteiramente casualizado em casa de vegetação, com as sementes dispostas em bandeja. O estudo adotou um esquema fatorial (3x2) sendo 192 
parcelas e 32 repetições por cultivar de pimenta. As sementes apresentavam 99\% de potencial germinativo e $100 \%$ de pureza até a data da semeadura. As sementes de pimenta malagueta foram semeadas em substratos de composição físico-químicas iguais a base de vermiculita, porém uma dessas amostras foi submetida à autoclave por 40 minutos a uma temperatura de 120 ㅇ. C. Os turnos de regas foram divididos em três turnos por dia, com cerca de 1 hora por turno.

As sementes foram depositas nas respectivas parcelas com o mesmo posicionamento em relação ao substrato, ou seja, com o híleo voltado para baixo, favorecendo assim o geotropismo positivo.

A germinação (\%) foi determinada através da contagem do número de sementes que emitiram radículas e em seguida plântulas normais ao longo de 15 dias após a semeadura, quando o processo germinativo apresentava-se estabilizado.

\section{RESULTADOS E DISCUSSÃO}

No decorrer de 15 dias foi avaliado o potencial germinativo das cultivares de pimenta malagueta em substratos que passaram por diferentes tratamentos, que neste caso foi a autoclavagem em um deles.

\begin{tabular}{|l|l|l|l|}
\hline \multicolumn{1}{|c|}{ Substrato } & \multicolumn{3}{|c|}{ Genótipos } \\
\hline & Malaguetinha & M. Comum & M. Vulcão \\
\hline \multicolumn{5}{|c|}{$18.200 \mathrm{aA}$} & $17.200 \mathrm{aA}$ & $6.800 \mathrm{aB}$ \\
\hline Ñ autoclavado & $12.600 \mathrm{aA}$ & $11.600 \mathrm{aA}$ & $3.600 \mathrm{aB}$ \\
\hline \multicolumn{5}{|l|}{}
\end{tabular}

As plântulas apresentaram os seguintes resultados: a cultivar malaguetinha, das 32 sementes que foram semeadas, todas germinaram no substrato não autoclavado e apenas 24 germinaram no substrato autoclavado; a cultivar malagueta comum obteve um bom desempenho no substrato não autoclavado com 100\% de germinação e apenas 23 germinaram das 32 sementes semeadas em substrato autoclavado; a cultivar vulcão, que apresentou desempenho insatisfatório em detrimento das demais. Em ambos os substratos foi notado que apenas 15 sementes germinaram das 32 que foram semeadas, sendo que no substrato autoclavado seu desempenho foi ainda mais inferior, apenas 09 sementes germinaram. 
Classificação com letras minúsculas para colunas e com letras maiúsculas para linhas. As médias seguidas de mesma não diferem entre pelo teste de Tukey à $5 \%$ de probabilidade.

Varela et. al (2005) observaram em um estudo sobre a influência do substrato na germinação das sementes de itaubarana (Acosmium nitens) que esse fator afetou sensivelmente a germinação das sementes de Acosmium nitens, conforme constatada pela análise dos resultados. É provável que além da capacidade de retenção dos substratos, as características intrínsecas que regulam o fluxo de água das sementes possam ter influenciado os resultados. A variação na disponibilidade de água dos substratos.

Talvez isso explique o motivo de a cultivar Vulcão não ter obtido resultados satisfatórios, uma vez que características genotípicas intrínsecas à essa variedade não tolerem condições de déficit hídrico pelo rápido fluxo de água percolado através do substrato, uma vez o que mesmo apresenta grande quantidade de macroporos.

Para Popinigis (1977), o substrato utilizado nos testes de germinação apresenta grande influência no processo germinativo, uma vez que fatores como estrutura, aeração, capacidade de retenção de água, grau de infestação de patógenos, etc, os quais podem variar de acordo com o tipo de material utilizado. Neste sentido, percebe-se que quando um substrato possui a presença de um patógeno, isso poderá interferir no processo germinativo.

O processo de autoclavagem permite a eliminação de pragas de solo que poderão comprometer desde o início do desenvolvimento da plântula, até a fase adulta.

\section{CONCLUSÃO}

O substrato autoclavado não afeta diretamente a germinação da semente.

O processo de autoclavagem, quando acessível, garante a eliminação de diversos tipos de patógenos de solo, que em um dado momento poderá comprometer a sanidade da planta e consequentemente a produtividade. 


\section{REFERÊNCIAS BIBLIOGRÁFICAS}

ARAUJO, N. C. Formulário de Resposta Técnica Padrão (SBRT). CETEC - Fundação Centro Tecnológico de Minas Gerais. Publicado em 23/03/2005. Disponível em: <http://sbrt.ibict.br/upload/sbrt475.pdf > Acesso em: 25/05/2011.

BOSLAND, P. W.; VOTAVA, E. J. Peppers: vegetable and spice Capsicums. Wallingford: CABI Publishing, 2000. (Crops Production Science in Horticulture, 22). 224 p.

CARVALHO, N. M. e NAKAGAWA, J. Sementes: ciências, tecnologia e produção. 2.ed. Campinas: Fundação Cargill, 2000. 565p.

DIAS, M. A.; LOPES, J.C.; CORREA, N.B.; DIAS, D.C.F.S. Germinação e desenvolvimento de plantas de pimenta malagueta em função do substrato e da lâmina de água. Revista Brasileira de Sementes, vol. 30, no 3, p.115-121, 2008.

FILGUEIRA, F. A. R. Novo manual de olericultura: agrotecnologia moderna na produção e comercialização de hortaliças. Viçosa: UFV, 2000. 402p.

FILGUEIRA, F. A. R. Solanáceas: agrotecnologia moderna na produção de tomate, batata, pimentão, pimenta, berinjela e jiló. Lavras: UFLA, 2003.333p.

REIFSCHNEIDER, F. J. B. (Org.) Capsicum: pimentas e pimentões no Brasil. Brasília: Embrapa Comunicação para Transferência de Tecnologia/Embrapa Hortaliças, 2000.

RISTORI, C. A.; PEREIRA, M. A. S.; GELLI, D. S. O efeito da pimenta do reino moída frente a contaminação in vitro com Salminella Rubslaw. Rev. Inst. Adolfo Lutz, v. 62, n. 2, p. 131-133, 2002

POPINIGIS, F. Fisiologia da semente. AGIPLAN. Brasília. 209pp. 1977.

VARELA, P.V.; COSTA, S.S.; RAMOS, M.B.P. Influência da temperatura e do substrato na germinação de sementes de itaubarana (Acosmium nitens (vog.) Yakovlev) - leguminosae, caesalpinoideae. Acata Amazonica. vol. 35(1) 35 - 39. 2005. 


\section{Capitulo 4}

doi $10.37423 / 210704533$

\section{ANÁLISE FITOQUÍMICA E ESTRUTURAL DA MUCILAGEM DE ALOE BARBADENSIS MILLER}

Beatriz da Silva Batista

Walajhone Oliveira Pereira

Dágyla Mayara Oliveira Dias

Ana Raquel Araújo da Silva
Universidade Federal do Maranhão / Campus Avançado

Universidade Federal do Maranhão / Campus Avançado

Instituto Federal do Ceará / Campus Quixadá

Instituto Federal do Ceará

Fernando José Figueiredo Agostinho D’Abreu Mendes Escola Superior de Tecnologia da Saúde de Coimbra / Instituto Politécnico de Coimbra

Instituto Federal do Maranhão / Campus Imperatriz 
Resumo: Aloe barbadensis Miller, conhecida por Aloe Vera ou Babosa, utilizada há séculos na medicina popular por suas propriedades terapêuticas, por este motivo a necessidade de aumentar a pesquisa com plantas medicinais a fim de contribuir com a sociedade validando o saber popular adquirido ao longo dos anos. Pensando nisso, objetivou-se investigar os constituintes químicos e a estrutura do extrato etanólico da mucilagem da Aloe barbadensis Miller por meio de análises fitoquímicas e difração de raios X (DRX), respectivamente. A mucilagem foi obtida de folhas da Aloe barbadensis Miller e realizada a extração etanólica a 96\%. A análise fitoquímica foi realizada por meio de ensaios clássicos para identificação de fenóis, taninos, antocianinas, antocianidinas, flavonóides, leucoantocianidinas, flavonas e saponinas, enquanto a análise estrutural foi por DRX. O extrato etanólico da mucilagem da Aloe barbadensis Miller reagiu positivamente para os constituintes químicos: catequinas, fenóis, flavanóis, flavanonas, saponinas, taninos flabobênicos e xantonas apresentou padrão de DRX típico de materiais amorfos. Os metabólitos secundários presentes na mucilagem das folhas da Aloe barbadensis Miller podem ser úteis em várias aplicações industriais devido as atividades biológicas. Sugere-se a avaliação da atividade antioxidante da mucilagem e do exsudado da Aloe barbadensis Miller para avaliar seu potencial de aplicação.

Palavras-chave: Aloe barbadensis Miller; Difração de raios X; Fitoquímica. 


\section{INTRODUÇÃO}

Planta medicinal é uma espécie vegetal, cultivada ou não, utilizada com propósitos terapêuticos, enquanto a droga vegetal é definida como a planta medicinal ou partes que contenham substâncias responsáveis por ação terapêutica após processos de coleta, colheita, estabilização e secagem, nas formas: íntegra, rasurada, triturada ou pulverizada (SAÚDE, 2014). O uso se apoia nas descobertas empíricas de milhares de anos (GURIB-FAKIM, 2006), havendo necessidade em validar seu potencial das plantas, bem como os efeitos colaterais. Essas plantas formaram à base de sofisticados sistemas da medicina tradicional, tornando-se parte integrante no desenvolvimento de novos fármacos.

As plantas medicinais são constituídas por unidades terapêuticas, nas quais todos os princípios ativos formam juntos um fitocomplexo que interage entre si e com outras moléculas aparentemente inativas, representando a unidade farmacológica integral da planta medicinal (MATOS, 2007). Como exemplo: alecrim (Rosmarinus officinalis Linnaeus) (GAUCH et al., 2014), babosa (Aloe barbadensis Miller) (CHANDAN et al., 2007), boldo (Peumus boldus Molina) (PAYDAR et al., 2014), citronela (Cymbopogon nardus Linnaeus) (MAHALWAL; ALI, 2003), coentro (Coriandrum sativum Linnaeus) (NIKHAT; KHAN; AHMAD, 2012), a sálvia (Salvia officinalis Linnaeus) (GRDIŠA et al., 2015), dentre outras.

Das diversas plantas medicinais que há no território brasileiro, a babosa ou alóes, que tem por nome científico de Aloe barbadensis Miller, conhecida como Aloe vera (Aloe - substância amarga e brilhante; Vera - verdadeira), é utilizada há séculos na medicina popular devido suas propriedades, tendo seu primeiro registro de uso datado em 1.750 anos a.C. (SHELTON, 1991).

Nativa da África Austral e Oriental ao longo do alto Nilo no Sudão, posteriormente introduzida no norte da África e naturalizada na região do Mediterrâneo e em outros países do mundo. Trata-se de uma planta suculenta com altura de 80 a $100 \mathrm{~cm}$, possui folhas com três camadas: a externa protetora (casca), a intermediária (exudado ou látex de cor amarelada) e a interna incolor (gel ou mucilagem), amadurece de 4 a 6 anos e sobrevive por quase 50 anos em condições favoráveis (SAHU et al., 2013). $\mathrm{Na}$ mucilagem, encontram-se os princípios ativos constituídos de: tecidos orgânicos, enzimas, vitaminas, sais minerais, aminoácidos (LANKA, 2018; MATOS, 2007; SHELTON, 1991), dentre outros.

Destacam-se pelas propriedades terapêuticas: cicatrização de feridas (YADAV et al., 2012), cicatrização de ferimentos térmicos (RODRÍGUEZ-BIGAS; CRUZ; SUÁREZ, 1988), imunoestimuladora (LISSONI et al., 2009), antioxidante (ABO-YOUSSEF; MESSIHA, 2013; PANDEY et al., 2011), antitumoral (TOMASIN; GOMES-MARCONDES, 2011) e antidiabética/hipoglicemiante (ABO-YOUSSEF; MESSIHA, 2013; 
MISAWA et al., 2008; RAJASEKARAN et al., 2004). Além disso, o uso da mucilagem reduz o nível plasmático de colesterol e triglicerídeos em ratos com síndrome do ovário policístico (MAHARJAN; NAGAR; NAMPOOTHIRI, 2010), mas também que a administração oral da mucilagem em camundongo com diabetes reduz significativamente os níveis de triglicerídeos no fígado e no plasma (KIM et al., 2009), além de melhorar a integridade da pele, diminuir o aparecimento de rugas da acne e diminui o eritema (WEST; ZHU, 2003), dentre outros.

A investigação fitoquímica é um processo fundamental no estudo de plantas com atividade biológica, pois tem por objetivo constatar a presença de grupos metabólitos secundários, bem como caracterizar os constituintes químicos presentes. Os grupos metabólicos secundários apresentam em geral estrutura complexa, dentre outras características, atividades biológicas importantes, como os flavonoides, as saponinas e os taninos. Para a caracterização dos principais grupos de metabólitos secundários, ensaios clássicos baseados em reações químicas resultando em surgimento de cor e/ou precipitados são utilizados (SIMÕES et al., 2017).

Além dos ensaios clássicos, processos cromatográficos e espectroscópicos para identificação de metabólitos primários e/ou secundários, há o incentivo para o uso da técnica de difração de raios $\mathrm{X}$ (MARTINS et al., 2011; SIMÕES et al., 2017). Nesta caracterização é possível conhecer a estrutura cristalina do material baseando-se na incidência da radiação sobre a amostra e na detecção do feixe difratado por um conjunto de átomos ordenados. É uma técnica utilizada, principalmente na determinação estrutural, mas também pode ser empregada na caracterização e quantificação de substâncias em misturas sólidas (NÉMET et al., 2009) como materiais de fontes naturais (ARAKAWAKOBAYASHI et al., 2004; MAULNY; BECKETT; MACKENZIE, 2005).

Pensando nisso, este capítulo apresenta o estudo do extrato etanólico da mucilagem da Aloe barbadensis Miller por análise fitoquímica qualitativa e por Difração de raios $\mathrm{X}$.

\section{METODOLOGIA}

As folhas da Aloe barbadensis Miller (Figura 1) foram coletadas no horto medicinal do Instituto Federal de Educação, Ciência e Tecnologia do Ceará - campus Quixadá. 


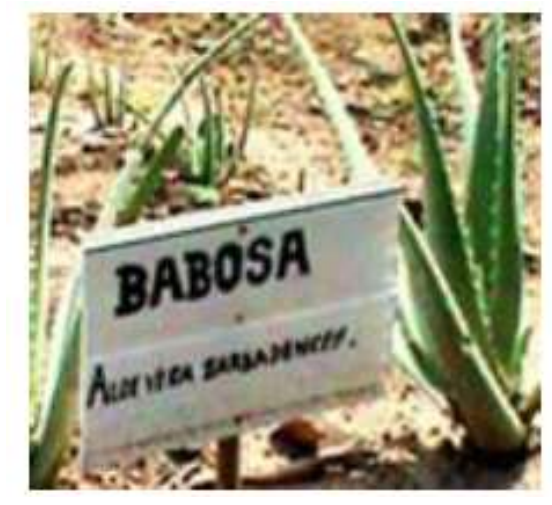

Figura 1. Babosa (Aloe barbadensis Miller).

Após coleta, as folhas de Aloe barbadensis Miller foram higienizadas, encortadas, descartando a casca e o exsudato amarelado. Em seguida, a mucilagem obtida foi triturada, peneirada, desidratada e pulverizada. O pó da mucilagem foi submetido à extração etanólica (96\%), por sete dias, a temperatura ambiente por 24 horas. A solução resultante foi filtrada e evaporada a $65^{\circ} \mathrm{C}$ em banho Maria (Figura 2).

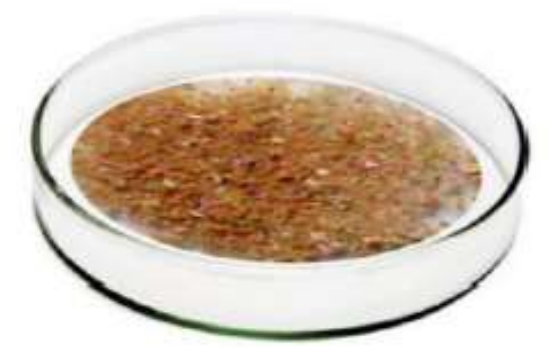

Figura 2. Extrato etanólico da mucilagem da Aloe barbadensis Miller.

A metodologia dos testes fitoquímicos foram realizados para identificação de: fenóis, taninos, antocianinas, antocianidinas, flavonóides, leucoantocianidinas, flavonas e saponinas, proposta por Matos (2009) (MATOS, 2009), baseada na observação visual da coloração e/ou formação de precipitado.

Teste de fenóis e taninos: adicionou-se três gotas de solução alcoólica de cloreto férrico (FeCl3) em um tubo de ensaio contendo extrato etanólico; logo após agitou-o lentamente e observando a variação de coloração.

Teste de antocianinas, antocianidinas e flavonoides: utilizaram-se três tubos de ensaio com extrato etanólico. O primeiro tubo foi acidificado a $\mathrm{pH} 3,0$, os outros dois tubos foram alcalinizados a pH 8,5 e $\mathrm{pH} 11$, respectivamente. Em seguida, foi observado se aconteceu mudança na cor. 
Teste de leucoantocianidinas, catequinas e flavanonas: utilizaram-se dois tubos de ensaio com extrato etanólico. O primeiro tubo foi acidificado com $\mathrm{HCl}$ até $\mathrm{pH}$ 1-3 e o outro tubo alcalinizado com $\mathrm{NaOH}$ pH 11, sendo que ambos foram aquecidos em uma lâmpada a álcool por 2 minutos, posteriormente foi verificado se houve mudança de cor.

Teste de saponinas: dissolveu-se uma alíquota de extrato bruto em água destilada. Agitou-se o tubo com a solução e averigou se ocorria a formação de espumas para teste positivo.

A difração de raios $X$ é a técnica utilizada para identificação da estrutura cristalina dos materiais, capaz de fornecer um perfil amorfo, semicristalino ou cristalino do material analisado. O difratograma de raios $\mathrm{X}$ foi obtido fazendo uso da mucilagem da Aloe barbadensis Miller pulverizada. A medida foi realizada em um difratômetro da marca Rigaku, modelo Miniflex II, radiação $\mathrm{Cu} K \propto(\lambda=1,5418 \AA$ ), tensão $30 \mathrm{kV}$ e corrente de $15 \mathrm{~mA}$, em intervalo $(2 \theta)$ de 5ㅇ a 70으, em passo angular de 0,02으 e tempo de contagem 0,5 s por passo.

\section{RESULTADOS E DISCUSSÃO}

Na Tabela 1, observam-se os constituintes químicos presentes no extrato etanólico da mucilagem da Aloe barbadensis Miller. Os resultados obtidos das análises químicos, apresentaram reações positivas para: catequinas, fenóis, flavanóis, flavanonas, saponinas, taninos flabobênicos e xantonas.

Tabela 1. Resultado fitoquímico do extrato etanólico da mucilagem da Aloe barbadensis Miller.

\begin{tabular}{|c|c|c|}
\hline Teste Fitoquímico & Reação & Literatura \\
\hline Antocianidinas & \multirow{5}{*}{ Negativa } & \multirow[t]{5}{*}{ 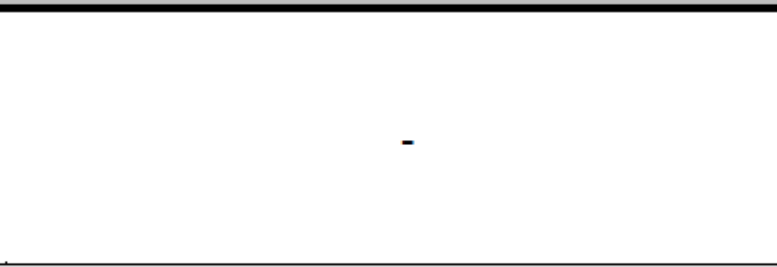 } \\
\hline Antocianinas & & \\
\hline Auronas & & \\
\hline Chaconas & & \\
\hline Leucoantocianidinas & & \\
\hline $\begin{array}{l}\text { Catequinas } \\
\text { (ou Flavanóis) }\end{array}$ & \multirow{7}{*}{ Positiva } & \multirow{6}{*}{$\begin{array}{l}\text { (ARUNKUMAR; MUTHUSELVAM, 2009; } \\
\text { MARIAPPAN; SHANTHI, 2012; } \\
\text { MARIUTTI; BRAGAGNOLO, 2007) }\end{array}$} \\
\hline Fenóis & & \\
\hline Flavonóis & & \\
\hline Flavanonas & & \\
\hline Saponinas & & \\
\hline Taninos Flobabênicos & & \\
\hline Xantonas & & (MARIUTTI; BRAGAGNOLO, 2007) \\
\hline
\end{tabular}

Fenóis e taninos foram identificados pela formação de precipitado de cor verde e mudança de coloração. Para o teste de antocianinas, antocianidinas e flavonóides ocorreu a mudança de coloração incolor para amarelo, em pH 11, indicando a presença de flavanonas, flavonóis e xantonas. Para os 
testes de leucoantocianinas, catequinas e flavonas, foi observado o aparecimento da cor pardoamarelado em meio ácido e, vermelho alaranjado em básico. Por fim, o teste para saponinas apresentou espuma persistente e abundante confirmando a presença saponinas (heterósides saponínicos).

Os compostos extraídos da mucilagem da Aloe barbadensis Miller pertencem aos compostos fenólicos, exceto pela saponina. Dados que corroboram com a literatura (MARIUTTI; BRAGAGNOLO, 2007), em que a maioria das espécies da família Lamiaceae, a qual pertence à Aloe vera, apresentam compostos fenólicos responsáveis por seu caráter antioxidante. Estes resultados estão de acordo com pesquisas realizadas com a Aloe vera L. (ARUNKUMAR; MUTHUSELVAM, 2009; MARIAPPAN; SHANTHI, 2012).

Enquanto isso, as saponinas, quando em soluções aquosas, são responsáveis pela ação detergente e emulsificante segundo suas estruturas características lipofílica e hidrofílica (SIMÕES et al., 2017).

As estruturas químicas dos constituintes químicos catequina, fenol, flavonóis, flavanona, saponinas, taninos flobabênicos e xantonas, identificados no extrato da mucilagem da Aloe barbadensis Miller, são apresentadas na Figura 3.

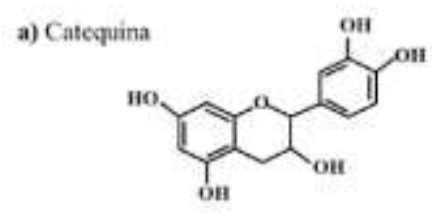

b) Fenol<smiles>Oc1ccccc1</smiles>

c) Flavonóis<smiles>O=C1c2ccccc2OC(c2ccccc2)C1O</smiles>

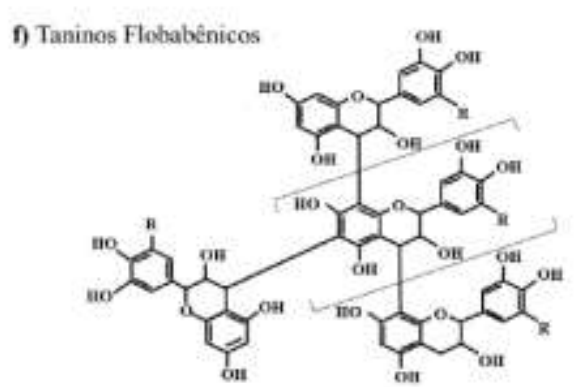

g) Xantonas

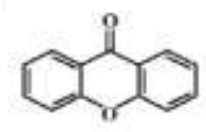

d) Flavanona<smiles>O=C1CC(c2ccccc2)Oc2ccccc21</smiles>

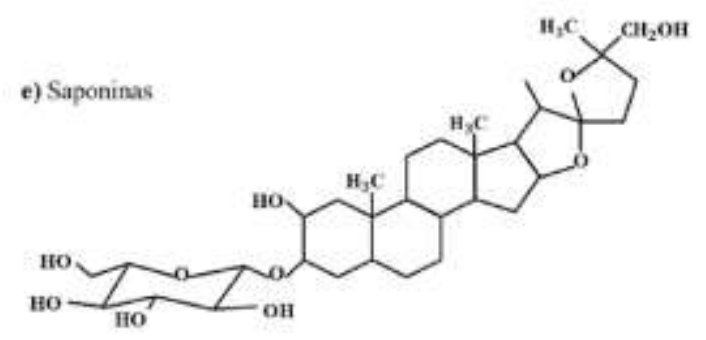

Figura 3. Estruturas químicas dos compostos extraídos da mucilagem da Aloe barbadensis Miller: a) catequina, b) fenol, c) flavonóis, d) flavanona, e) saponinas, f) taninos flobabênicos e g) xantonas. 
A Figura 4 mostra o padrão de difração de raios $X$ obtido para o extrato etanólico da mucilagem da Aloe barbadensis Miller revelando a presença de halo amorfo característico de regiões desordenadas do material e sem picos de fases cristalinas, perfil típico de estrutura amorfa.

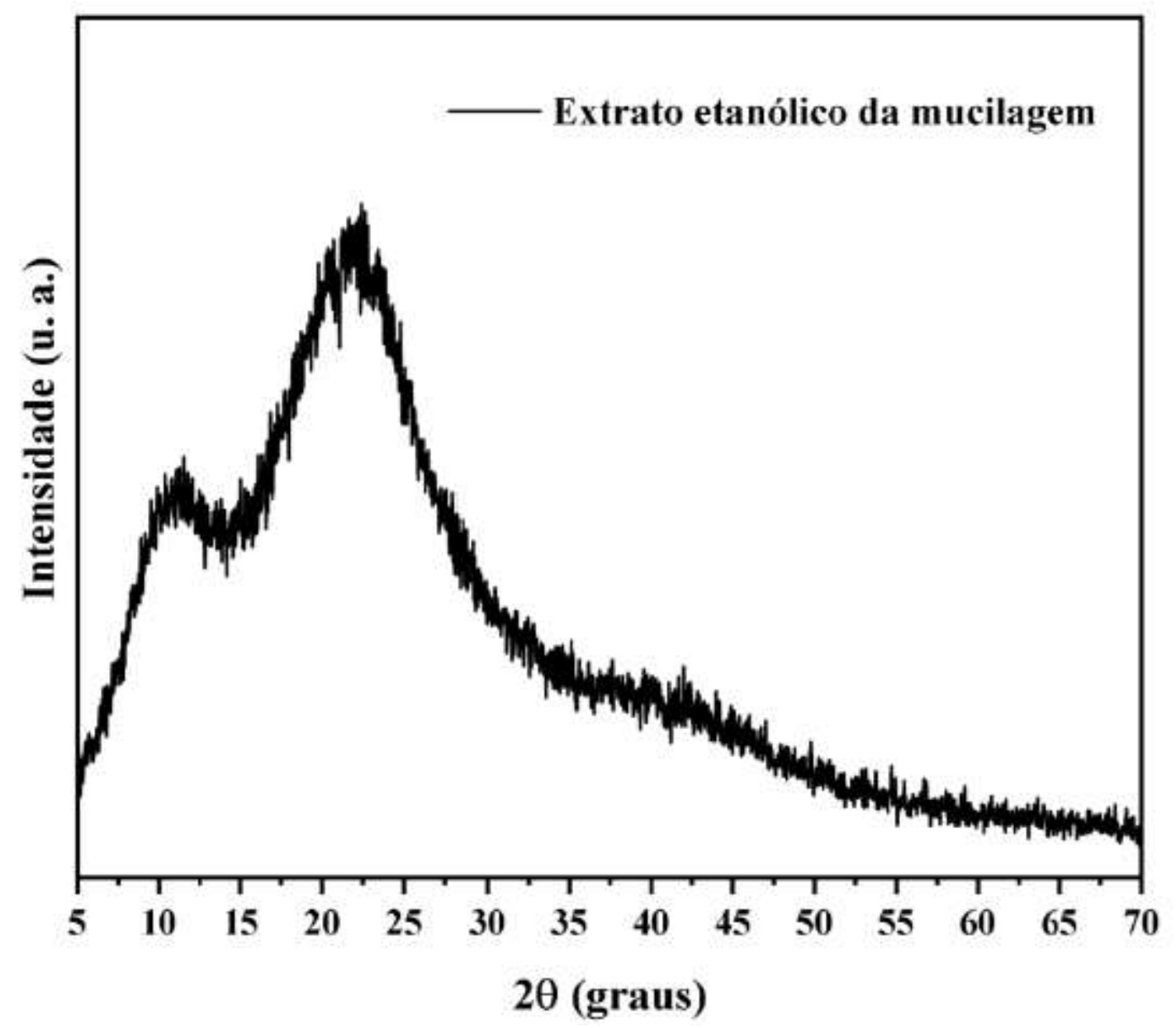

Figura 4. Padrão de difração de raios X do extrato etanólico mucilagem da Aloe barbadensis Miller.

Padrões de difração de raios X semelhantes, com certo grau de cristalinidade, relatados na literatura podem ser observados para outras mucilagens extraídas da Aloe arborescens M. (SANTOS, 2017), do feno-grego (MISHRA et al., 2006), da jaracatiá (HEIDEMANN et al., 2014) e do cladódio (BRANCO, 2011).

\section{CONCLUSÃO}

O método de extração utilizado permitiu a identificação dos metabólitos secundários presentes na mucilagem das folhas da Aloe barbadensis Miller podem ser úteis em várias aplicações devido as atividades biológicas. E, no extrato etanólico da mucilagem da Aloe barbadensis Miller há complexidade de ordenação das cadeias moleculares, devido as características de material amorfo. 
Sugere-se a avaliação da atividade antioxidante da mucilagem e do exsudado da Aloe barbadensis Miller para avaliar o potencial de aplicação. 


\section{REFERÊNCIAS}

ABO-YOUSSEF, A. M. H.; MESSIHA, B. A. S. Beneficial effects of Aloe vera in treatment of diabetes: Comparative in vivo and in vitro studies. Bulletin of Faculty of Pharmacy, Cairo University, vol. 51, no. 1, p. 7-11, 2013. https://doi.org/10.1016/j.bfopcu.2012.03.002.

ARAKAWA-KOBAYASHI, S.; KOBAYASHI, T.; HASEBE, M.; KANASEKI, T. Identification of crystalline material found in the thallus of the lichen, Myelochroa leucotyliza. Journal of Structural Biology, vol. 146, p. 393-400, 2004. https://doi.org/10.1016/j.jsb.2004.01.015.

ARUNKUMAR, S.; MUTHUSELVAM, M. Analysis of phytochemical constituents and antimicrobial activities of Aloe vera L. against clinical pathogens. World Journal of Agricultural Sciences, vol. 5, no. 5, p. 572-576, 2009.

BRANCO, N. B. C. B. Mucilagem do cladódio de Cereus hildmaniannus K. Schum: caracterização física, química e reológica. 2011. 95 f. Universidade Federal de Santa Catarina, Florianópolis, 2011.

CHANDAN, B. K.; SAXENA, A. K.; SHUKLA, S.; SHARMA, N.; GUPTA, D. K.; SURI, K. A.; SURI, J.; BHADAURIA, M.; SINGH, B. Hepatoprotective potential of Aloe barbadensis Mill. against carbon tetrachloride induced hepatotoxicity. Journal of Ethnopharmacology, vol. 111, no. 3, p. 560-566, 2007. https://doi.org/10.1016/j.jep.2007.01.008.

GAUCH, L. M. R.; PEDROSA, S. S.; ESTEVES, R. A.; SILVEIRA-GOMES, F.; GURGEL, E. S. C.; ARRUDA, A. C.; MARQUES-DA-SILVA, S. H. Antifungal activity of Rosmarinus officinalis Linn. essential oil against Candida albicans, Candida dubliniensis, Candida parapsilosis and Candida krusei. Revista PanAmazônica de Saúde, vol. 5, no. 1, p. 61-66, 2014. https://doi.org/10.5123/s217662232014000100007.

GRDIŠA, M.; JUG-DUJAKOVIĆ, M.; LONČARIĆ, M.; CAROVIĆ-STANKO, K.; NINČEVIĆ, T.; LIBER, Z.; RADOSAVLEVIĆ, I.; ŠATOVIĆ, Z. Dalmatian sage (Salvia officinalis L.): A review of biochemical contents, medical properties and genetic diversity. Agriculturae Conspectus Scientificus, vol. 80, no. 2, p. 69-78, 2015.

GURIB-FAKIM, A. Medicinal plants: Traditions of yesterday and drugs of tomorrow. Molecular Aspects of Medicine, vol. 27, no. 1, p. 1-93, 2006. https://doi.org/10.1016/j.mam.2005.07.008.

HEIDEMANN, H. M.; FACCIO, C.; QUADRI, M. G. N.; SIMÃO, U.; ZOLDAN, S. R. Caracterização da mucilagem de jaracatiá (Carica quercifolia (A. ST.-HIL) Hieron liofilizada para uso em processo de separação. Florianópolis - SC, p. 1-8, 2014.

KIM, K.; KIM, H.; KWON, J.; LEE, S.; KONG, H.; IM, S. A.; LEE, Y. H.; LEE, Y. R.; OH, S. T.; JO, T. H.; PARK, Y. I.; LEE, C. K.; KIM, K. Hypoglycemic and hypolipidemic effects of processed Aloe vera gel in a mouse model of non-insulin-dependent diabetes mellitus. Phytomedicine, vol. 16, no. 9, p. 856-863, 2009. https://doi.org/10.1016/j.phymed.2009.02.014.

LANKA, S. a Review on Aloe Vera-the Wonder Medicinal Plant. Journal of Drug Delivery and Therapeutics, vol. 8, no. 5-s, p. 94-99, 2018. https://doi.org/10.22270/jddt.v8i5-s.1962.

LISSONI, P.; ROVELLI, F.; BRIVIO, F.; ZAGO, R.; COLCIAGO, M.; MESSINA, G.; MORA, A.; PORRO, G. A randomized study of chemotherapy versus biochemistry with 
chemotherapy plus aloe arborescens in patients with metastatic cancer. In Vivo, vol. 23, no. 1, p. 171176, 2009.

MAHALWAL, V. S.; ALI, M. Volatile constituents of Cymbopogon nardus (Linn.) Rendle. Flavour and Fragrance Journal, vol. 18, no. 1, p. 73-76, 2003. https://doi.org/10.1002/ffj.1144.

MAHARJAN, R.; NAGAR, P.; NAMPOOTHIRI, L. Effect of Aloe barbadensis Mill. Formulation on Letrozole induced polycystic ovarian syndrome rat model. Journal of Ayurveda and Integrative Medicine, vol. 1, no. 4, p. 273-279, 2010. https://doi.org/10.4103/0975-9476.74090.

MARIAPPAN, V.; SHANTHI, G. Antimicrobial and Phytochemical Analysis of Aloe Vera L. International Research Journal of Pharmacy, vol. 3, no. 10, p. 158-161, 2012. .

MARIUTTI, L. R. B.; BRAGAGNOLO, N. Revisão: antioxidantes naturais família Lamiaceae. Aplicação em produtos alimentícios. Brazilian Journal of Food Technology, vol. 10, no. 2, p. 96-103, 2007.

MARTINS, F. T.; MARCELO, H.; COELHO, C. P.; BARBOSA, L. C. A.; DIAS, G. C.; FRACCA, M. P.; NEVES, P. P.; STRINGHETA, P. C.; DORIGUETTO, A. C. A powder X-ray diffraction method for detection of polyprenylated benzophenones in plant extracts associated with HPLC for quantitative analysis. Journal of Pharmaceutical and Biomedical Analysis, vol. 54, no. 3, p. 451-457, 2011. DOI 10.1016/j.jpba.2010.09.010.

MATOS, F. J. A. Introdução à fitoquímica experimental. 3rd ed. [S. I.]: Fortaleza: UFC, 2009.

MATOS, F. J. A. Plantas Medicinais: Guia de seleção e emprego de plantas usadas em fitoterapia no nordeste do Brasil. 3rd ed. [S. I.]: Fortaleza: UFC, 2007.

MAULNY, A. P. E.; BECKETT, S. T.; MACKENZIE, G. Physical Properties of Co-crystalline Sugar and Honey. E : Food Engineering and Physical Properties, vol. 70, no. 9, p. 567-572, 2005.

MISAWA, E.; TANAKA, M.; NOMAGUCHI, K.; YAMADA, M.; TOIDA, T.; TAKASE, M.; IWATSUKI, K.; KAWADA, T. Administration of phytosterols isolated from Aloe vera gel reduce visceral fat mass and improve hyperglycemia in Zucker diabetic fatty (ZDF) rats. Obesity Research and Clinical Practice, vol. 2, no. 4, p. 239-245, 2008. https://doi.org/10.1016/j.orcp.2008.06.002.

MISHRA, A.; YADAV, A.; PAL, S.; SINGH, A. Biodegradable graft copolymers of fenugreek mucilage and polyacrylamide: A renewable reservoir to biomaterials. Carbohydrate Polymers, vol. 65 , no. 1, p. 5863, 2006. https://doi.org/10.1016/j.carbpol.2005.12.015.

NÉMET, Z.; KIS, G. C.; POKOL, G.; DEMETER, A. Quantitative determination of famotidine polymorphs : X-ray powder diffractometric and Raman spectrometric study. Journal of Pharmaceutical and Biomedical Analysis, vol. 49, p. 338-346, 2009. https://doi.org/10.1016/j.jpba.2008.11.033.

NIKHAT, S.; KHAN, J. A.; AHMAD, G. Seeds of Coriandrum Sativum Linn : A Review. International Pharmaceutica Sciencia, vol. 2, no. 4, 2012.

PANDEY, M.; SARAF, S.; OJHA, S.; SONKER, K. Aloe vera gel: A potent nutraceutical. Journal of Natural Pharmaceuticals, vol. 2, no. 1, p. 36-39, 2011. https://doi.org/10.4103/2229-5119.78496. 
PAYDAR, M.; KAMALIDEHGHAN, B.; WONG, Y. L.; WONG, W. F.; LOOI, C. Y.; MUSTAFA, M. R. Evaluation of cytotoxic and chemotherapeutic properties of boldine in breast cancer using in vitro and in vivo models. Drug Design, Development and Therapy, vol. 8, p. 719-733, 2014. https://doi.org/10.2147/DDDT.S58178.

RAJASEKARAN, S.; SIVAGNANAM, K.; RAVI, K.; SUBRAMANIAN, S. Hypoglycemic Effect of Aloe vera Gel on Streptozotocin-Induced. Journal of Medicinal Food, vol. 7, no. July 2003, p. 61-66, 2004.

RODRÍGUEZ-BIGAS, M.; CRUZ, N. I.; SUÁREZ, A. Comparative evaluation of aloe vera in the management of burn wounds in guinea pigs. Plastic and Reconstructive Surgery, vol. 81, no. 3, p. 386389, 1988.

SAHU, P. K.; GIRI, D. D.; SINGH, R.; PANDEY, P.; GUPTA, S.; SHRIVASTAVA, A. K.; KUMAR, A.; PANDEY, K. D. Therapeutic and Medicinal Uses of Aloe vera: A Review. Pharmacology \&amp; Pharmacy, vol. 04, no. 08, p. 599-610, 2013. https://doi.org/10.4236/pp.2013.48086.

SANTOS, W. S. Caracterização de biopolímeros extraídos da babosa (Aloe arborescens) e avaliação no processo de floculação e coagulação no tratamento de água. 2017. 1-41 f. Universidade Tecnológica Federal do Paraná, Pato Branco, 2017.

SAÚDE, B. M. da. Dispõe sobre o registro de medicamentos fitoterápicos e o registro e a notificação de produtos tradicionais fitoterápicos, junto à Agência Nacional de Vigilância Sanitária. Diário Oficial da União, p. 52-58, 2014.

SHELTON, R. M. Aloe vera, its chemical and therapeutic properties. International Journal of Dermatology, vol. 30, p. 679-683, 1991.

SIMÕES, C. M. O.; SCHENKEL, E. P.; MELLO, J. C. P.; MENTZ, L. A.; PETROVICK, P. R. Farmacognosia: do produto natural ao medicamento. Porto Alegre: Artmed, 2017.

TOMASIN, R.; GOMES-MARCONDES, M. C. C. Oral administration of Aloe vera and honey reduces walker tumour growth by decreasing cell proliferation and increasing apoptosis in tumour tissue. Phytotherapy Research, vol. 25, no. 4, p. 619-623, 2011. https://doi.org/10.1002/ptr.3293.

WEST, D. P.; ZHU, Y. F. Evaluation of aloe vera gel gloves in the treatment of dry skin associated with occupational exposure. American Journal of Infection Control, vol. 31, no. 1, p. 40-42, 2003. https://doi.org/10.1067/mic.2003.12.

YADAV, K. C. H.; KUMAR, J. R.; BASHA, I. I.; DESHMUKH, G. R.; GUJJULA, R.; SANTHAMMA, B. Wound healing activity of topical application of Aloe vera gel in experimental animal models. International Journal of Pharma and Bio Sciences, vol. 3, no. 2, 2012. . 


\section{Capítulo 5}

doi) $10.37423 / 210704535$

\section{METABÓLITOS SECUNDÁRIOS E CONSTITUINTES QUÍMICOS DAS FOLHAS DE CROTON RHAMNIFOLIOIDES (QUEBRA-FACA)}

Dayseane Sales Bernardo Campelo

Suzana Moreira de Lima

Fabiola Soraia Vital Campos Barbosa da Silva

\section{Sofia Suely Ferreira Brandấo Rodrigues}

Cláudia de Albuquerque Maranhão
Instituto Federal de Educação, Ciência e Tecnologia de Pernambuco

Instituto Federal de Educação, Ciência e Tecnologia de Pernambuco

Instituto Federal de Educação, Ciência e Tecnologia de Pernámbuco

Institutito Federal de Educação, Ciência e Techologia de Pernambuco

Instituto Federal de Educação, Ciência e Tecnologia de Pernambuco 
Resumo: Croton rhamnifolioides Pax e Hoffm é conhecida popularmente por quebra-faca e pertence à família Euphorbiaceae com 300 gêneros e 8000 espécies. O gênero a qual pertence possui ampla representação no nordeste brasileiro devido às várias espécies que apresentam óleos essenciais e substâncias ativas como alcaloides, terpenoides e flavonoides. Também apresenta importantes ações farmacológicas úteis contra dor de estômago, mal-estar gástrico, vômito, diarreia com sangue e para diminuir a febre. Neste trabalho, objetivou-se realizar o "screening" fitoquímico e identificar os constituintes químicos de Croton rhamnifolioides, extraídos através da técnica por refluxo/Soxhlet e hidrodestilação. Os extratos foram obtidos usando os solventes: hexano, acetato de etila e álcool etílico. O extrato em álcool etílico apresentou maior rendimento $(19,78 \%)$. Entre os compostos identificados no óleo essencial estão sesquicineol (16,79\%) como composto majoritário seguido de $\alpha$ felandreno $(12,83 \%)$ e 1,8 -cineol $(7,24 \%)$. Nas folhas de quebra-faca confirmou-se a presença de terpenoides, esteroides, flavonoides, taninos e alcaloides.

Palavras-chave: Euphorbiaceae, Croton rhamnifolioides, quebra-faca, "screening" fitoquímico. 


\section{INTRODUÇÃO}

A família Euphorbiaceae é uma das mais extensas famílias de fanerógamos, com cerca de 300 gêneros e 8000 espécies e tem como segundo maior representante o gênero Croton com aproximadamente 700 espécies. (MACIEL et al., 2006). Este gênero tem grande importância econômica devido às várias espécies que apresentam óleos essenciais e diversas substâncias ativas como alcaloides, terpenoides e flavonoides. Essas substâncias orgânicas e voláteis são as responsáveis pelo agradável aroma dessas plantas (Randau et al., 2004) e estão associadas a várias funções necessárias à sobrevivência do vegetal, como: defesa contra microrganismos, predadores, para atrair insetos e outros agentes fecundadores.

As espécies desse gênero são empregadas com frequência na medicina popular e algumas delas demonstram propriedades terapêuticas comprovadas (Randau et al., 2004). Tem-se estudos existentes sobre as espécies de Croton nas áreas de fitoquímica e farmacologia.

Entre as várias espécies de Croton já estudadas, encontram-se: Croton cajucara - cujas atividades antifúngica, antimicrobiana e antiprotozoários foram estudadas, sendo ainda isolado o 7-hidróxicalameneno, que é um sesquiterpeno hidroxilado e potente agente antiprotozoários (RODRIGUES et al, 2010); Croton pullei Var. Glabrior - onde os extratos foram obtidos das cascas do caule da planta seca e moída, e foram isoladas substâncias como julocrotina, diterpeno ribenona, ácido caurenóico, lupeol e ésteres graxos do sitosterol (ABREU et al, 2001); Croton grevioides Baill. - obteve-se óleo essencial das folhas e do caule, e foi testado seu efeito fumigante, sendo a classe química predominante o fenilpropanoide, que tem como principal representante o $E$-anetol (GOMES, C., 2007); Os extratos das folhas e do caule de Croton jacobinensis Baill, Croton micans Muell. ,Croton sellowii Baill e Croton rhamnifolius H.B.K apresentaram potenciais inseticidas e acaricidas (GOMES, C., 2007).

A fim de contribuir com os estudos fitoquímicos, foi escolhido para este trabalho a espécie Croton rhamnifolioides Pax e Hoffm, popularmente conhecida por quebra-faca ou catinga branca, o primeiro nome faz referência à rigidez de seu tronco e o outro devido ao seu aroma e coloração do caule, tal espécie é geralmente encontrada no nordeste brasileiro. Possui ação farmacológica, útil para dor de estômago, mal-estar gástrico, vômitos, diarreia e para diminuir a febre (Randau, 2001).

A referida planta foi coletada no município de Serra Talhada - PE e está catalogada no Herbário professor Vasconcelos Sobrinho do Departamento de Biologia da Universidade Federal Rural de 
Pernambuco (PEUFR). Este trabalho tem como objetivo identificar os metabólitos secundários e os constituintes químicos das folhas de quebra-faca.

\section{MATERIAL E MÉTODOS}

\section{1 - MATERIAL BOTÂNICO}

A planta foi coletada no município de Serra Talhada - PE (2011) e catalogada no Herbário professor Vasconcelos Sobrinho do Departamento de Biologia da Universidade Federal Rural de Pernambuco (PEUFR), onde foram depositadas exsicatas com no 49.855 (exsicata 1) e $n$ o 49.854 (exsicata 2). As folhas foram secas a temperatura ambiente e trituradas. Em seguida, foram submetidas a "screening" fitoquímico (COSTA, 1982) e extração dos constituintes.

\section{2 - EXTRAÇÃO DOS CONSTITUINTES QUÍMICOS}

Foi realizada por meio da técnica por refluxo/soxhlet e hidrodestilação. Para a técnica por soxhlet foi utilizado aproximadamente $5 \mathrm{~g}$ de planta e $250 \mathrm{~mL}$ de cada solvente por $8 \mathrm{~h}$, e os solventes: hexano, acetato de etila e etanol seguindo a ordem de polaridade. Posteriormente, realizou-se a rotaevaporação para concentração dos extratos. Para a técnica de hidrodestilação foi utilizado aproximadamente $100 \mathrm{~g}$ de planta em $2500 \mathrm{~mL}$ de água por $6 \mathrm{~h}$. Em seguida, o óleo essencial extraído foi submetido a análise por Cromatografia Gasosa acoplada à espectrometria de massas (GC-MS).

\section{3 - "SCREENING" FITOQUÍMICO}

O material vegetal triturado foi submetido a análises de "screening" fitoquímico (Tabela 1).

Tabela 1 - Testes que identificam as classes de compostos presentes nas plantas.

\begin{tabular}{c|c}
\hline Classes de compostos & Testes \\
\hline Alcaloides & Dragendorf e Mayer \\
\hline Terpenos e esteroides & Liebermann-Buchard \\
\hline Flavonoides & Shinoda, oxalo-bórica \\
\hline Saponinas & Espuma \\
\hline Taninos & Cloreto férrico \\
\hline
\end{tabular}

\section{- Alcaloides}


Foram adicionados a $1 \mathrm{~g}$ de planta $10 \mathrm{~mL}$ de ácido sulfúrico $\left(\mathrm{H}_{2} \mathrm{SO}_{4}\right)$ a $1 \%$ e em seguida a mistura foi aquecida em banho-maria a $100^{\circ} \mathrm{C}$ por 2 minutos e posteriormente filtrada. Alíquotas do filtrado foram testadas com os reagentes de Dragendorff e Mayer. Assim, na presença de alcaloides o reagente de Dragendorff forma um precipitado laranja-avermelhado, enquanto o reagente de Mayer origina um precipitado branco.

\section{- Terpenos e esteroides}

Foram adicionados a $1 \mathrm{~g}$ de planta $10 \mathrm{~mL}$ de clorofórmio e em seguida a mistura foi submetida à filtração. No filtrado foi acrescentado $4 \mathrm{~mL}$ de anidro acético e agitado vagarosamente. Posteriormente foi adicionado 10 gotas de $\mathrm{H}_{2} \mathrm{SO}_{4}$ concentrado à solução obtida. $\mathrm{O}$ aparecimento sucessivo de cores rosa ao azul e verde caracteriza a presença de terpenos e esteroides.

\section{- Flavonoides}

Para constatar a presença de flavonoides utilizou os seguintes testes:

Teste de Shinoda - Foram adicionados $10 \mathrm{~mL}$ de metanol a $1 \mathrm{~g}$ de planta; a solução obtida foi filtrada e em seguida, adicionado $2 \mathrm{~mL}$ de ácido clorídrico concentrado. Esta solução foi deixada reagir com $1 \mathrm{~cm}$ de fita de magnésio. O aparecimento de uma coloração rosa caracteriza a presença de flavonoides.

Reação oxalo-bórica - Foram adicionados $10 \mathrm{~mL}$ de acetona a $1 \mathrm{~g}$ de planta, a solução obtida foi filtrada e concentrada em banho-maria até $0,5 \mathrm{~mL}$. Foi adicionado ao concentrado 0,05 $\mathrm{mg}$ de ácido oxálico e a mesma quantidade de ácido bórico, esta solução foi então aquecida em banho-maria durante 5 minutos e adicionada a ela $10 \mathrm{~mL}$ de éter etílico. O aparecimento de fluorescência na luz UV indica a presença de flavonoides.

\section{- Saponinas}

Foi utilizado o teste de espuma para verificar a presença de saponinas. Para isto, adicionou $10 \mathrm{~mL}$ de água destilada a $1 \mathrm{~g}$ de planta. Em seguida esta mistura foi agitada vigorosamente por cerca de 5 minutos. A formação de espuma persistente por 30 minutos evidencia a presença de saponinas.

\section{- Taninos}

Para determinar a presença de taninos foram adicionados $10 \mathrm{~mL}$ de água destilada a $1 \mathrm{~g}$ de planta. Posteriormente a mistura foi filtrada e ao filtrado foi gotejada lentamente uma solução de cloreto 
férrico a 1\%. O surgimento de uma coloração ou precipitado verde ou azul indica reação positiva para taninos.

\section{4 - ANÁLISE CROMATOGRÁFICA - GC/MS}

A análise cromatográfica do óleo de Croton rhamnifolioides foi feita na Central Analítica do Departamento de Química da Universidade Federal de Pernambuco (UFPE). Foi realizada em um Hewlett Packard 5890 SERIES equipado com detector de ionização (FID) e com coluna DB-5 (J \& W) capilar $(30 \mathrm{~m} \times 0,25 \mathrm{~mm} \times 0,25 \mu \mathrm{m})$. A temperatura da coluna foi programada para $40^{\circ} \mathrm{C}$ por $2 \mathrm{~min}$, variando de $220^{\circ} \mathrm{C}$ à $4^{\circ} \mathrm{C} \mathrm{min}-1$, aumentando para $280^{\circ} \mathrm{C}$ à $20^{\circ} \mathrm{C} \mathrm{min}^{-1}$ para integração. As temperaturas do injetor e detector foram de $250^{\circ} \mathrm{C}$ e $280^{\circ} \mathrm{C}$, respectivamente. O hidrogênio foi usado como carreador gasoso, com um fluxo de $1,5 \mathrm{~mL} \mathrm{~min}^{-1}$ (1:10). Uma solução de $1,5 \mu \mathrm{L}$ de aproximadamente 10 mg do óleo e acetato de etila foram ministradas. A análise do óleo foi feita usando GC/MS Shimadzu QP5050 quadrupole utilizando-se a mesma coluna e temperaturas utilizadas no experimento com GC. $O$ carreador gasoso foi o hélio, fluxo de $1,5 \mathrm{~mL} \mathrm{~min}^{-1}$ (1:50). Aplicou-se $1 \mu \mathrm{L}$ de $1 / 100$ da solução diluída em acetato de etila. $\mathrm{O}$ espectro de massa foi obtido à $70 \mathrm{eV}$. A velocidade de leitura foi $0.5 \mathrm{scan} \mathrm{s}^{-1} \mathrm{de}$ $\mathrm{m} / \mathrm{z} 40$ à 650. O óleo essencial foi analisado por GC e GC/MS, e a identificação foi feita com base na comparação dos índices de retenção (Van Den Doll \& Kratz 1963), bem como por comparação computadorizada do espectro de massas obtido com aqueles contidos na biblioteca de espectro de massas do National Institute of Standards and Technology's (NIST) na GC-MS (NIST) do banco de dados GC/MS (Adams 2007).

\section{RESULTADOS E DISCUSSÃO}

O screening fitoquímico das folhas de quebra-faca indicou a presença de alcaloides, flavonoides, taninos, terpenos e esteroides. Tal resultado condiz com dados da literatura referente a outras espécies de Croton que apresentam alcaloides, terpenoides, flavonoides e taninos (SALATINO, et al 2007). Rodrigues e colaboradores, em 2010, isolaram terpenoides de Croton cajucara. Do Croton grevioides Baill. foram isoladas substâncias derivadas dos fenilpropanoides (GOMES, C. 2007).

A presença de alcaloides e terpenos indica a atividade terapêutica, já que essas classes de compostos conferem ação anestésica, analgésica, psicoestimulantes. Taninos e flavonoides conferem ações biológicas como antioxidantes. $E$ a ausência de saponina leva a conclusão de que está planta não tem propriedades detergentes e surfactantes. Os metabólitos secundários são responsáveis pelo 
mecanismo de defesa das plantas e de grande importância para pesquisa científica, devido a diversas atividades biológicas que possuem.

O extrato em hexano teve rendimento de $8,82 \%$; em acetato de etila 4,95\% e em etanol $19,78 \%$. Acredita-se que as folhas de quebra-faca possuem grande quantidade de substâncias polares, justificando o extrato em etanol ter maior rendimento. Não foi possível a tempo, isolar e identificar os constituintes químicos presente nos extratos. Mas os constituintes químicos presente no óleo essencial de quebra-faca foram identificados.

O óleo apresentou um rendimento de 1,99\%, valor superior ao encontrado por Costa (2011) que foi de 1,40\%. Tal variação pode ocorrer devido a época de colheita, ao método e tempo de destilação.

Após a análise cromatográfica por GC-MS obtive-se 57 constituintes (Tabela 2) que corresponde a $92,47 \%$ do óleo. Entre os compostos identificados estão sesquicineol (16,79\%) como composto majoritário seguido de $\alpha$-felandreno (12,83\%) e 1,8-cineol (7,24\%), esses percentuais podem variar em função de alguns fatores, como, por exemplo, horário de coleta e condições climáticas. Os compostos identificados possuem atividade antibacteriana, antifúngica, anti-inflamatória e são compatíveis com já encontrados em outras espécies de Croton (SANTOS et al., 2005; COSTA, 2011).

Tabela 2 - Constituintes químicos identificados no óleo essencial das folhas de $C$. rhamnifolioides

\begin{tabular}{c|c|c|c}
\hline Compostos & I.R.C & I.R.L & \% \\
\hline tricicleno & 920 & 921 & 0,16 \\
\hline$\alpha$-tujeno & 926 & 924 & 1,49 \\
\hline$\alpha$-pineno & 932 & 932 & 4,74 \\
\hline canfeno & 946 & 946 & 0,65 \\
\hline sabineno & 972 & 969 & 3,04 \\
\hline$\beta$-pineno & 974 & 974 & 0,55 \\
\hline mirceno & 991 & 988 & 0,36 \\
\hline $\boldsymbol{\alpha}$-felandreno & $\mathbf{1 0 0 3}$ & $\mathbf{1 0 0 2}$ & $\mathbf{1 2 , 8 3}$ \\
\hline$\alpha$-Terpineno & 1016 & 1014 & 0,31 \\
\hline$o$-cimeno & 1023 & 1022 & 4,60 \\
\hline silvestreno & 1027 & 1025 & 3,62 \\
\hline $\mathbf{1 , 8}$-cineol & $\mathbf{1 0 3 0}$ & $\mathbf{1 0 2 6}$ & $\mathbf{7 , 2 4}$ \\
\hline
\end{tabular}




\begin{tabular}{|c|c|c|c|}
\hline álcool benzílico & 1033 & 1026 & 0,20 \\
\hline$\beta$-(E)-ocimeno & 1048 & 1044 & 0,75 \\
\hline$\gamma$-terpineno & 1058 & 1054 & 1,09 \\
\hline terpinoleno & 1088 & 1086 & 0,24 \\
\hline linalol & 1100 & 1095 & 1,32 \\
\hline Dehidro sabina cetona & 1120 & 1117 & 0,16 \\
\hline$\beta$ - $(Z)$-terpineol & 1139 & 1140 & 0,08 \\
\hline cânfora & 1144 & 1141 & 0,06 \\
\hline pinocarvona & 1162 & 1160 & 0,02 \\
\hline borneol & 1165 & 1165 & 0,83 \\
\hline terpinen-4-ol & 1177 & 1174 & 1,90 \\
\hline$\alpha$-terpineol & 1190 & 1186 & 1,91 \\
\hline mirtenol & 1196 & 1194 & 0,31 \\
\hline metil chavicol & 1198 & 1195 & 0,06 \\
\hline timol metil éter & 1235 & 1232 & 0,03 \\
\hline bornil acetato & 1286 & 1284 & 0,33 \\
\hline timol & 1292 & 1289 & 0,05 \\
\hline carvacrol & 1301 & 1298 & 0,20 \\
\hline mirtenil acetato & 1326 & 1324 & 0,02 \\
\hline$\delta$-elemeno & 1338 & 1335 & 0,03 \\
\hline$\alpha$-copaeno & 1377 & 1374 & 0,19 \\
\hline$\beta$-bourboneno & 1386 & 1387 & 0,07 \\
\hline$\beta$-elemeno & 1393 & 1389 & 0,35 \\
\hline$\alpha$-(Z)-bergamoteno & 1417 & 1411 & 0,05 \\
\hline (E)-cariofileno & 1422 & 1417 & 6,33 \\
\hline$\alpha$-(E)-bergamoteno & 1438 & 1432 & 0,14 \\
\hline$\beta$-(Z)-farneseno & 1445 & 1440 & 0,04 \\
\hline$\alpha$-humuleno & 1457 & 1452 & 1,17 \\
\hline cariofileno-9-Epi-E & 1465 & 1464 & 0,80 \\
\hline$\delta$-muuroleno & 1481 & 1478 & 0,04 \\
\hline
\end{tabular}




\begin{tabular}{c|c|c|c}
\hline germacreno D & 1485 & 1484 & 0,99 \\
\hline viridifloreno & 1490 & 1496 & 0,14 \\
\hline biciclogermacreno & 1501 & 1500 & 4,59 \\
\hline$\beta$-(E)-guaieno & 1504 & 1502 & 0,10 \\
\hline$\alpha$-buneseno & 1506 & 1509 & 0,05 \\
\hline germacreno A & 1510 & 1508 & 0,21 \\
\hline sesquicineol & $\mathbf{1 5 1 8}$ & $\mathbf{1 5 1 5}$ & $\mathbf{1 6 , 7 9}$ \\
\hline$\delta$-cadineno & 1527 & 1522 & 0,45 \\
\hline germacreno B & 1556 & 1559 & 0,06 \\
\hline espatulenol & 1580 & 1577 & 4,14 \\
\hline óxido de cariofileno & 1586 & 1582 & 3,22 \\
\hline viridiflorol & 1596 & 1592 & 0,09 \\
\hline epi- $\alpha$-cadinol & 1643 & 1638 & 2,33 \\
\hline$\alpha-b i s a b o l o l$ & 1685 & 1685 & 0,72 \\
\hline Total do óleo identificado & 1688 & 1687 & 0,23 \\
\hline eudesma-4(15),7-dien-1 $\beta-o l$ & $\mathbf{9 2 , 4 7 \%}$ & \\
\hline
\end{tabular}

I.R.L= índice de retenção de Kratz da literatura (Adams, 2007); I.R.C= índice de retenção de Kratz calculado.

\section{CONCLUSÕES}

- As folhas de Croton rhamnifolioides possuem alcaloides, terpenoides, esteroides, taninos e flavonoides;

- As folhas de quebra-faca concentram substâncias polares, uma vez que o extrato em etanol apresentou maior rendimento $(19,78 \%)$;

- O óleo essencial apresentou rendimento de 1,99\%;

- Os constituintes majoritários presente no óleo são: sesquicineol (16,79\%), $\alpha$-felandreno $(12,83 \%)$ e 1,8 -cineol $(7,24 \%)$. 


\section{REFERÊNCIAS}

ABREU, A. S.; BARBOSA, P. S.; MÜLLER, A. H.; GUILHON, G. M. S. P. Constituintes Químicos do Caule e das Cascas do Caule de Croton pullet var.glabrior (Euphorbiaceae). Revista Científica da UFPA - Belém - PA. 2a edição, outubro 2001.

ADAMS, R.P. Identification of Essential Oil Components by Gas Chromatography/Mass Spectrometry, 4a ed. Allured Publishing Corporation, Carol Stream. 2007.

COSTA, A.F. Farmacognosia. v.III, 2a. edição. Lisboa: Fundação Calouste Gulbenkian, 1982.

COSTA, A.C.V. Perfil Químico e atividade antibacteriana in vitro e em matriz alimentar do óleo essencial de Croton rhamnifolioides Pax \& Hoffm. Dissertação (Mestrado) - Departamento de Ciência e Tecnologia de Alimentos. Universidade Federal da Paraíba. João Pessoa, 2011.

MACIEL, M. A. M.; CORTEZ, J. K. P. C.; GOMES, F. E. S. O gênero Croton e Aspectos e Aspectos Relevantes de Diterpenos Clerodanos. Revista Fitos, v.2 n.3 dezembro 2006.

RANDAU, K.P. Estudo farmacognóstico (farmacobotânico e farmacoquímico) e atividade biológica do Croton rhamnifolius H.B.K. e Croton rhamnifolioides Pax \& Hoffm. (Euphorbiaceae). Dissertação (Mestrado) - Departamento de Ciências Farmacêuticas, Universidade Federal de Pernambuco. Recife, 2001.

RANDAU, K. P.; FLORÊNCIO, D. C.; FERREIRA, C. P.; XAVIER, H. S. Estudo farmacognóstico de Croton rhamnifolius H.B.K. e Croton rhamnifolioides Pax \& Hoffm (Euphorbiaceae). Revista Brasileira de Farmacognosia, v. 14, n.2, 89-96, 2004.

GOMES, C. Bioatividade de extratos etanólicos de Croton sobre Plutella xylostella (L.) e ação fumigante e composição química de óleos essenciais de Croton grevioides (Baill.) sobre Zabrotes subfasciatus (Boheman). Dissertação (Mestrado) - Programa de Pós-Graduação em Entomologia Agrícola, Universidade Federal Rural de Pernambuco. Recife, 2007.

RODRIGUES, I.A.; AZEVEDO M.M.B.; ROSA M.S.S.; CHAVES F.C.M.; BIZZO H.R.; ALVIANO D.S.; ALVIANO C.S. Atividade antiprotozoários de Croton cajucara Benth. e do 7-hidroxi-calameneno. In: CONGRESO LATINOAMERICANO DE MICROBIOLOGIA, XX; ENCUENTRO NACIONAL DE MICROBIÓLOGOS, IX. LbrO de resúmenes. Montevideo: Sociedad Uruguaya de Microbiología, p. 189, ref. J_057. 2010.

SALATINO, A.; SALATINO, M. L. F.; NEGRI, G. Traditional uses, Chemistry and Pharmacology of Croton species (Euphorbiaceae). Journal of the Brazilian Chemical Society, v.18, n.1, 11-33, 2007.

SANTOS, F.A.; JEFERSON, F.A.; SANTOS, C.C.; SILVEIRA, E.R.; RAO, V.S.N. Antinociceptive effect of leaf essential oil from Croton sonderianus in mice. Life Sciences 77, 2953-2963, 2005.

VAN DEN DOOL, H.; KRATZ, P. D. A generalization of the retention index system including linear temperature programmed gas-liquid partition chromatography. Journal of Chromatography A, v. 11, p. 463-471, 1963. 


\section{Capítulo 6}

doi) $10.37423 / 210704538$

\section{A GESTÃO AMBIENTAL DAS EMBALAGENS DE AGROQUÍMICOS REALIZADA PELOS PEQUENOS PRODUTORES NO POLO IRRIGADO DE PETROLINA-PE}

Mary Ann Saraiva Bezerra Fornelos Pereira

Melina Fernanda Silva Costa

Janete Rodrigues Matias

Maria Aline de Lima Silva
Instituto Federal Do Sertão Pernambucano Campus Petrolina Zona Rural

Instituto Federal Do Sertão Pernambucano Campus Petrolina Zona Rural

\section{Universidade do Estado da Bahia}

Instituto Federal Do Sertão Pernambucano Campus Petrolina Zona Rural 
Resumo: O uso contínuo e em grande escala dos agroquímicos, o crescimento do número de produtos utilizados e a falta de conscientização, tanto no uso como na comercialização, feita sem receituário e controle, contribuem para a geração de grande quantidade de embalagens vazias contaminadas desses produtos. Os agricultores devem ser conscientes do seu papel, e os revendedores assumirem sua participação no contexto socioambiental da gestão dos resíduos de agroquímicos, conforme dispõe a Política Nacional de Resíduos Sólidos. O presente trabalho objetivou analisar a gestão das embalagens de agroquímicos usados em áreas agrícolas dos perímetros irrigados de Petrolina-PE. Foram visitados 7 núcleos de irrigação e aplicados 30 questionários para pequenos agricultores, abordando o manejo das embalagens usadas com ênfase no destino final de tais recipientes. Identificou-se que 30\% agricultores não sabe a quantidade de resíduos de embalagens que gera ao mês, embora $80 \%$ receba orientações quanto ao uso e destino final dessas embalagens no ato da compra. Dos agricultores que quantificam os resíduos gerados por mês, detectou-se que, para cada hectare de cultivo irrigado, gerou-se 4,84 embalagens de agroquímico, o que é indício do uso em larga escala de tais produtos na agricultura irrigada do polo Petrolina(PE)-Juazeiro(BA).

Palavras-chave: agroquímicos, gestão ambiental, reciclagem 


\section{INTRODUÇÃO}

A ampla utilização de agrotóxicos nas áreas agrícolas é um grave problema para a saúde e para o ambiente, por contaminarem o solo, a água e o ar. Estima-se que ocorram no mundo cerca de três milhões de intoxicações agudas por agrotóxico com 220 mil mortes, sendo 70\% dessas provenientes dos países em desenvolvimento (WHO, 1995).

A cidade de Petrolina(PE) é um polo de fruticultura irrigada, sendo o uso de agroquímicos frequente. Todavia, para ser possível exportar frutos, o uso de agroquímicos deve ser reduzido e cuidados adicionais de proteção ao homem e ao meio ambiente têm sido exigidos pelos órgãos governamentais e pelas empresas exportadoras. Neste contexto, os produtores devem ser conscientes do seu papel enquanto promotores do desenvolvimento sustentável, na realização da gestão ambiental nas atividades rurais.

Uma das consequências do uso intensivo de agrotóxicos é a geração de grande quantidade de embalagens vazias contaminadas desses produtos. Devido a esse problema, foi promulgada a Lei Federal no 9.974/2000, que disciplina o recolhimento e a destinação final das embalagens vazias de agrotóxicos. A partir dessa lei, foi criado o programa de destinação final de embalagens vazias de agrotóxicos, de grande importância para a saúde e o meio ambiente. Em 2010, a gestão de resíduos de agroquímicos também foi contemplada na Lei 12.305/2010, que institui a Política Nacional de Resíduos Sólidos (BRASIL, 2010)

Estima-se que cerca de 135 milhões de embalagens desses produtos são vendidas por ano no Brasil. Essas embalagens têm de ser recolhidas, incineradas ou recicladas de forma segura, uma vez que constituem resíduos potencialmente perigosos (INPEV, 2007). No polo irrigado de Petrolina (PE)Juazeiro (BA), a ACAVASF - Associação do comércio Agropecuário do Vale do São Francisco - é empresa responsável pela coleta das embalagens utilizadas. O presente trabalho analisou a gestão das embalagens dos agroquímicos usados nos projetos de irrigação do polo Petrolina (PE).

\section{MATERIAL E MÉTODOS}

O estudo foi desenvolvido na cidade de Petrolina-PE (921'01"S e 4033'45"O), localizada no sertão pernambucano, as margens do Rio São Francisco. Petrolina possui uma população de aproximadamente 294 mil habitantes (estimativa IBGE/2010). Ainda, segundo o IBGE, em 2010 a cidade produziu: banana (cacho) - 45.900t em 2.700 ha plantados; Coco - 45.000 frutos em 1.500 ha; 
Goiaba - 71.400t em 2.300 ha; manga 150.000 t em 7.500 ha; Uva $106.000 t$ em 3.800 ha; tendo sua economia concentrada na agricultura irrigada.

Dos projetos de Irrigação existentes em Petrolina, destacam-se: o Perímetro Irrigado Senador Nilo Coelho (PISNC), o Perímetro Irrigado Bebedouro e o Perímetro Irrigado Maria Teresa, sendo o PISNC o maior, tendo 11 núcleos. Os questionários foram aplicados em 7 núcleos do PISNC: N-1, N-2, N-4, $\mathrm{N}-5, \mathrm{~N}-6, \mathrm{~N}-7$ e $\mathrm{N}-9$, sendo aplicados 30 questionários, para pequenos produtores encontrados aleatoriamente, cujos lotes agrícolas eram de até 12 ha. Os questionários foram aplicados entre fevereiro e março de 2012. De acordo com Leite et al. (2004), a maior parte da manga (mais de 70\%) e das uvas de mesa (mais de 60\%) do Vale do São Francisco são produzidas pelos pequenos produtores (área irrigável menor que 12 ha) que são, em grande parte, empresas familiares.

Através do questionário e de visitas às áreas agrícolas, identificou-se, para cada produtor entrevistado: as culturas, o controle do uso dos agroquímicos nas referidas propriedades, o nível de conscientização sobre a gestão dos resíduos de agroquímicos e os procedimentos feitos com as embalagens vazias.

Para analisar a gestão final das embalagens de agroquímicos no polo irrigado de Petrolina(PE) realizouse, ainda, uma entrevista com a ACAVASF. Cabe a ACAVASF cadastrar, autorizar, controlar, fiscalizar e inspecionar pessoas físicas e jurídicas que comercializem, pesquise, experimentem, usem, apliquem e distribuam agrotóxicos, seus componentes e afins, com finalidades fitossanitárias, a serem utilizados na produção, armazenamento e beneficiamento de material proveniente do setor agropecuário, destinados ao plantio, alimentação ou transformação. Além disso, fiscaliza o transporte interno e o destino final das embalagens e das sobras dos produtos. Esse trabalho é realizado por técnicos credenciados que fazem vistorias e emitem laudos, lavram autos de infração - que, a depender da gravidade, podem variar de multa até cancelamento de registro ou cadastro.

Os dados coletados foram tabulados e analisados.

\section{RESULTADOS E DISCUSSÃO}

Ao comprarem os agroquímicos, $80 \%$ dos pequenos produtores afirmaram que recebem orientações, tais como: tríplice lavagem mais furo na embalagem vazia, carência entre o momento de aplicação e a colheita, dosagem, devolução da embalagem à ACAVASF, classificação das embalagens, uso de EPI para aplicação dos agrotóxicos e guia de utilização e armazenamento de todos os agroquímicos. Entretanto, 20\% dos agricultores afirma que não recebe orientação na compra de agroquímicos, sendo esse fato uma infração à legislação brasileira. 
Quando os pequenos produtores foram questionados sobre o que fazem com a embalagem logo após o uso do agroquímico, $66,6 \%$ respondeu que realiza a tríplice lavagem, além de furar o recipiente, e 33,3\% faz apenas a tríplice lavagem, conforme Figura 1.

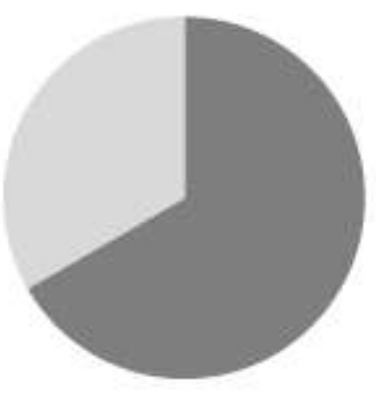

Faz a tríplice lavagem + furo

Faz a tríplice lavagem

Figura 1: Manejo da embalagem de agroquímico realizado pelos pequenos produtores no PISNC, em Petrolina-PE.

As embalagens vazias de agrotóxicos, quando abandonadas no ambiente ou descartadas em aterros e lixões, constituem potenciais fontes de contaminação. Se estiverem com resto de agrotóxicos, aumentam seu potencial de contaminação, uma vez que esses resíduos químicos tóxicos nelas contidos, sob ação da chuva, podem migrar para o solo e para as águas superficiais e subterrâneas (BARREIRA \& PHILIPPI, 2002; apud CANTOS, MIRANDA \& LICCO, 2008).

Segundo a Associação Nacional de Defesa Vegetal (ANDEF, 2007), 100 milhões de litros de agrotóxicos são vendidos no Brasil anualmente, sendo que 300 mil litros permanecem nas embalagens, oferecendo altos riscos aos que manipulam e ao meio ambiente. Com a prática da tríplice lavagem, os restos caem significativamente, reduzindo-se a contaminação que as embalagens vazias podem causar.

Assim, vê-se que o agricultor já age com cuidado com a embalagem vazia de agroquímico, realizando, pelo menos, a tríplice lavagem, ou esta seguida de furo no recipiente, o que é indício da eficácia dos programas de orientação e capacitação, corroborando com o dado já mencionado, em que $80 \%$ afirmam receber orientações no ato da compra do agroquímico. Dados semelhantes foram registrados por LEITE; COUTO; SÁ (2011) em estudo realizado no Rio Grande do Sul.

Para determinar a média de embalagens de agroquímicos geradas ao mês, adotou-se duas categorias: embalagens de agrotóxicos e embalagens de adubo e fez-se uma média de geração de resíduos por hectare de área cultivada, conforme Tabela 1. 
Tabela 1: Quantidade de embalagens de agroquímicos descartadas ao mês por pequenos produtores do PISNC, em Petrolina-PE

\begin{tabular}{|c|c|c|c|c|}
\hline Produtor & $\begin{array}{l}\text { Area } \\
\text { cultivada(ha) }\end{array}$ & Culturas & $\begin{array}{l}\text { Quantidade de embalagem } \\
\text { de agroquímico descartada } \\
\text { ao mês }\end{array}$ & $\begin{array}{l}\text { Quantidade de } \\
\text { embalagem de adubo } \\
\text { descartada ao mês }\end{array}$ \\
\hline 1 & 6,5 & Manga e Coco & Não Sabe & 16 sacos \\
\hline 2 & 3,5 & Manga e Uva & 12 & 40 sacos \\
\hline 3 & 2,5 & Banana e Coco & Não Usa & 10 sacos \\
\hline 4 & 4,0 & Acerola e Uva & Não sabe & Não sabe \\
\hline 5 & 2,0 & Banana & Não sabe & $6 \operatorname{sacos}$ \\
\hline 6 & 2,5 & Goiaba & 3 & 4 sacos \\
\hline 7 & 2,5 & Coco e Banana & 2 & 8 sacos \\
\hline 8 & 5,0 & Goiaba e Manga & 12 & 70 sacos \\
\hline 9 & 6,6 & Uva e Manga & 19 & 50 sacos \\
\hline 10 & 12 & Manga e Goiaba & Não sabe & Não sabe \\
\hline 11 & 4,5 & Goiaba e Acerola & Não sabe & Não sabe \\
\hline 12 & 12 & Uva & Não sabe & Não sabe \\
\hline 13 & 7 & Manga & Não sabe & Não sabe \\
\hline 14 & 4 & Uva & 25 & Não sabe \\
\hline 15 & 2,5 & Uva & 20 & 30 sacos \\
\hline 16 & 12 & Manga & 60 & 30 sacos \\
\hline 17 & 6 & Uva e Goiaba & 30 & 83 sacos \\
\hline 18 & 6 & Manga & 16 & 8 sacos \\
\hline 19 & 4 & Goiaba e Manga & 16 & 25 sacos \\
\hline 20 & 6 & Goiaba & 6 & Não sabe \\
\hline 21 & 4,5 & Goiaba e Manga & 11 & 23 sacos \\
\hline 22 & 4,8 & Goiaba e Manga & 9 & 14 sacos \\
\hline 23 & 4 & Uva e Acerola & 3 & 7 sacos \\
\hline 24 & 3 & Acerola e Coco & 20 & 15 sacos \\
\hline 25 & 6,8 & Manga e Goiaba & Não sabe & Não sabe \\
\hline 26 & 5,0 & Coco e Goiaba & Não sabe & Não sabe \\
\hline 27 & 12 & Uva & 30 & 10 sacos \\
\hline 28 & 8 & Goiaba e Banana & 4 & 51 sacos \\
\hline 29 & 7,5 & Manga e Acerola & 5 & 8 \\
\hline 30 & 6 & Goiaba e Banana & Não sabe & 12 sacos \\
\hline
\end{tabular}

Identificou-se na Tabela 1 que a média de hectares cultivados foi de 5,75ha, sendo que, 33,3\% dos pequenos produtores não sabe a quantidade de embalagem de agrotóxico descartada por mês e 30\% desses produtores não sabe a quantidade de embalagens vazias de adubo gerada mensalmente. Dos agricultores que informaram a quantidade de embalagens descartada, identificou-se uma média de 10,3 embalagens de agrotóxico e uma média de 17,5 embalagens de adubos vazias geradas por mês. Considerando-se a média de ha plantados, infere-se que, cada hectare gera, ao mês, 4,84 embalagens de agroquímicos (agrotóxico+adubo).

Esses resultados quantitativos refletem o uso de muito agroquímico, gerando resíduos em quantidade significativa. Segundo Bedor et al., (2007), na região do Vale do São Francisco a produção agrícola, principalmente, a destinada à exportação, tem os agroquímicos como essencial para o prolongamento 
no ciclo de vida de seus produtos. Observa-se cotidiana aplicação desses defensivos químicos em grandes quantidades, principalmente nas áreas irrigadas.

Em relação ao destino final das embalagens vazias de agroquímicos, $100 \%$ dos entrevistados informou que a ACAVASF recolhe essas embalagens. Segundo o INPEV (2007) os estabelecimentos comerciais de uma mesma região se organizam em associações e viabilizam a construção de uma única unidade de recebimento para uso e gerenciamento compartilhado.

A ACAVASF é uma central de recebimento. De acordo com a ABNT (2003), a central de recebimento é definida como um local de recebimento, registro, classificação quanto aos tipos de embalagens vazias de agrotóxicos e afins, que atende aos usuários e postos de recebimento e possui equipamento para a redução de volume para acondicionamento, até a retirada das embalagens para a destinação final adequada (Figuras 2 e 3 ).

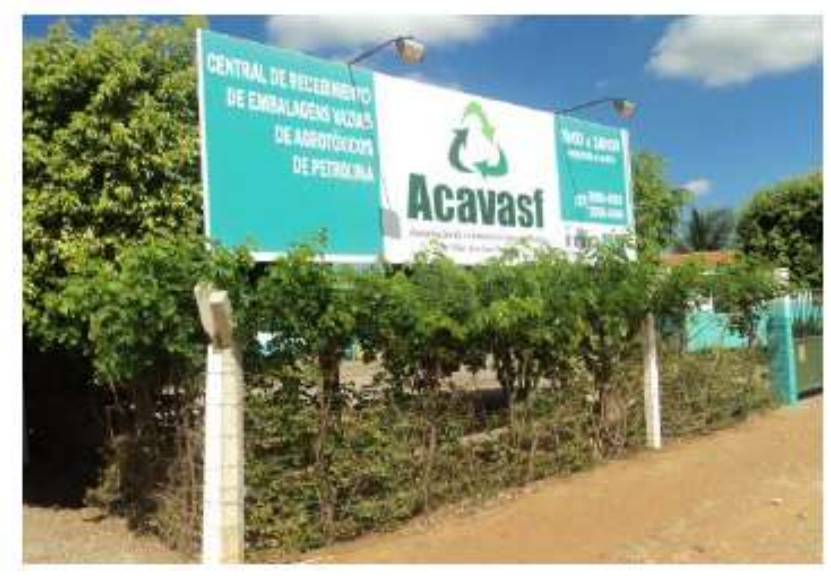

Figura 2: Vista Externa da ACAVASF, Petrolina(PE)

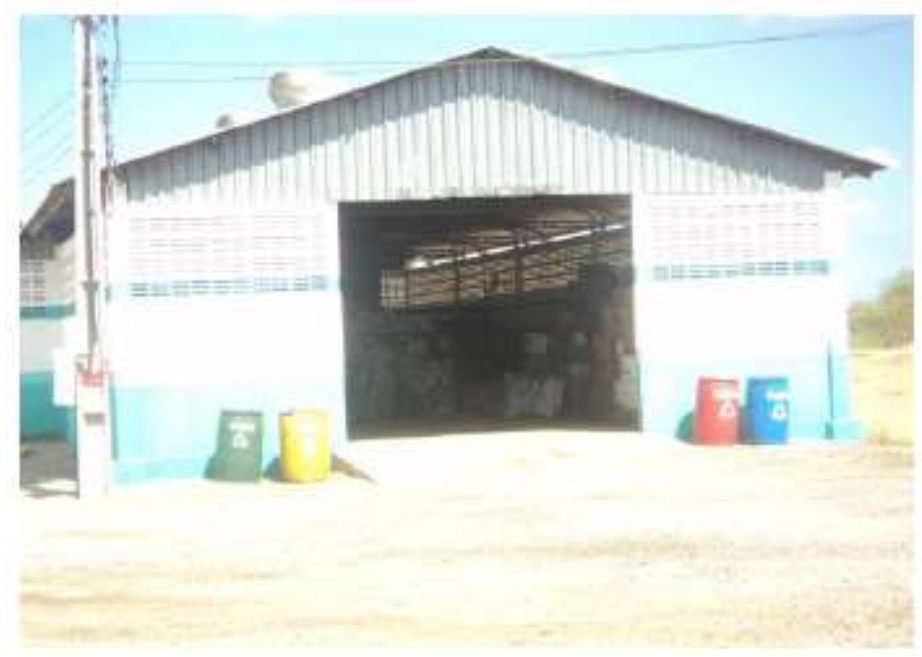

Figura 3: Vista Interna da ACAVASF, Petrolina(PE) 
A ACAVASF é filiada ao INPEV - Instituto Nacional de Processamento de Embalagem Vazia, entidade sem fins lucrativos, que operacionaliza a coleta no país, desde 2002. No Vale do São Francisco, a ACAVASF realiza a logística reversa das embalagens vazias de agroquímicos, recolhendo as embalagens nas áreas agrícolas periodicamente.

\section{CONCLUSÕES}

Os agricultores se manifestaram positivamente à obrigatoriedade de devolução das embalagens vazias de agrotóxicos, desde que não implique em custos de deslocamento, o que é realizado pela ACAVASF. Não há gestão completa dos resíduos, uma vez que cerca de $30 \%$ dos pequenos agricultores afirmou não saber a quantidade de resíduos gerados. Para os que quantificaram o total de resíduos de embalagens vazias, esse número indica o consumo em quantidade elevada de tais produtos nos perímetros irrigados de Petrolina(PE). Isso implica na redução de mercado para esses agricultores, uma vez que as frutas destinadas à exportação para EUA e Europa devem ter resíduo zero ou próximo a zero, conforme protocolos de certificação e a quantidade de agroquímicos usados, em um mês, num hectare de área cultivada se contrapõe a tais protocolos. 


\section{REFERÊNCIAS}

ASSOCIAÇÃO NACIONAL DE DEFESA VEGETAL. Institucional. Disponível

em:http://www.andef.com.br/2003/index.asp. Acesso em: 02 ago 2012.

ASSOCIAÇÃO BRASILEIRA DE NORMAS TÉCNICAS - ABNT. NBR 14029: agrotóxico e afins: validação de métodos analíticos. Rio de Janeiro, 2003.

BEDOR, C. N. G.; RAMOS, L. O., REGO, M. A. V., PAVÃO, A. C., AUGUSTO, L. G. S. 10.

Avaliação e reflexos da comercialização e utilização de agrotóxicos na região do submédio do Vale do São Francisco. Rev. Baiana Saúde Pública. 2007; 31(1):68-76.

BRASIL. Lei de № 12.305 de 02 de Agosto de 2010. Publicada no DOU 03 de Agosto de 2010.

Disponível em: http://www.planalto.gov.br/ccivil_03/_ato2007-2010/2010/lei/l12305.htm.

CANTOS, C.; MIRANDA, Z. A. I.; LICCO, E. A. Contribuições para a gestão das embalagens vazias de agrotóxicos. Interfacehs - Revista de Gestão Integrada em Saúde do Trabalho e Meio Ambiente -

v.3, n.2, Seção Interfacehs 1, abr./ agosto. 2008.

INPEV. Instituto Nacional de Processamento de Embalagens vazias. Tríplice Lavagem ou Lavagem sobre pressão. 2007. Disponível em: http://www.inpev.org.br/responsabilidades/ triplice_lavagem/responsabilidade_agricultor/responsabilidade_agricultor.asp. Acesso em: 20 jul. 2012.

LEITE, T. da S.; COUTO, R. S.; SÁ, J. S. de. Diagnóstico da disposição final de Resíduos Sólidos de

Propriedades Agrícolas na Localidade de Passo do Vieira, Cerrito, RS. XX Congresso de Iniciação Cientifica da Mostra Cientifica. UFPEL, 2011.

World Health Organization. Public health impact of pesticides used in agriculture. Geneva: World Health Organization;1995 


\section{Capitulo 7}

doi) $10.37423 / 210704543$

\section{CARACTERIZAÇÃO E AVALIAÇÃO DO POTENCIAL POLUIDOR DA ÁGUA RESIDUÁRIA PROVENIENTE DO PROCESSAMENTO DO FRUTO DO AÇAIZEIRO}

RENATO AUGUSTO PAMPLONA PEREIRA

FERNANDA LAMEDE FERREIRA DE JESUS

RAFAELA FERREIRA CARVALHO

\section{LUCIANA YUMIE SASAKI BORGES}

ADRIANO BICIONI PACHECO

JHENIFER COSTA DE OLIVEIRA

\section{ARTHUR CARNIATO SANCHES}

\section{CRISTIANE FERNANDES LISBOA}

JANNAYLTON EVERTOA OLIVEIRA SANFOS
Universidade Federal Rural da Amazônia UFRA campus Tomé-Açu

Universidade Federal Rural da Amazônia UFRA campus Tomé-Açu

Universidade Federal Rural da Amazônia UFRA campus Tomé-Açu

Universidade/Federal Rural da Amazônia UFRA campus Tomé-AçU

Universidade Federal Rural da Amazônia UFRA campus Tome-Açu

Universidade Federal Rural da Amazônia UFRA campus Tomé-Açu

Universidade Federal da Grande Dourados

Universidade Federal Rural da Amazônia UFRA campus Tomé-Açu

Universidade Federal Rural da Amazônia UFRA campus Tomé-AÇu 
Resumo: O município de Tomé-Açu possui diversos pontos de beneficiamento do açaí (Euterpe oleraceae) e o resíduo líquido desse processamento não recebe nenhum tratamento para sua reutilização. O objetivo da pesquisa foi caracterizar o potencial poluidor da água residuária proveniente do processamento do fruto do açaizeiro e sugerir alternativas para sua disposição final. Para determinar o potencial poluidor bem como caracterizar a água residuária proveniente do processamento do açaí foram coletadas amostras de vários pontos de beneficiamento do açaí. Os parâmetros de identificação estudados foram: Potencial Hidrogeniônico, Temperatura, Condutividade Elétrica, Fósforo, Ferro, total Potássio, Cálcio, Sódio, Nitrogênio total, Manganês, Magnésio, Enxofre, Cobre e Zinco. A temperatura e condutividade corroboraram os padrões de lançamento de efluentes de acordo com a norma $\mathrm{N}^{\circ} 430$ da CONAMA de 2011, enquanto o pH de algumas amostras não atenderam os requisitos. As análises das amostras constataram que em concentrações de Nitrogênio, Fósforo e Enxofre figuram a água residuária do processamento do açaí como poluente, e nesse sentido, precisam de tratamento, em contrapartida os outros elementos analisados estão dentro da norma $N^{\circ} 430$ da CONAMA de 2011 a qual dispõe sobre condições, parâmetros, padrões e diretrizes para gestão do lançamento de efluentes em corpos de água receptores.

Palavras-chave: Efluente, Poluição, Euterpe oleracea. 


\section{INTRODUÇÃO}

A fruticultura está presente em toda região amazônica, tanto nativas quanto exóticas, destacando-se por possuir uma grande importância econômica (SANTOS, 2016). Dentre as nativas é notório o açaizeiro (Euterpe oleraceae), cultura importante para o estado do Pará e seu uso pode ser feito de diversas formas, dentre os quais está o processamento da polpa do fruto que cujo fim é a alimentação, fator sociocultural importante para economia regional (SANTANA, 2014; FARIAS NETO, 2010).

A agroindústria é uma das principais fontes na geração de resíduos, como as águas residuárias (MORAIS et al., 2020). Nas pequenas agroindústrias de beneficiamento do açaí estão presentes sete etapas que compreendem todo processamento, são elas: descarregamento, lavagem, amolecimento, despolpamento, filtragem e embalagem e congelamento (FARIAS NETO, 2010). Além disso Feio et al. (2014) afirmam que a água residuária do processamento do açaí nos pontos comerciais está presente em duas etapas, sendo: a água de amolecimento do fruto e de lavagem da máquina despolpadeira. Durante a etapa do despolpamento o fruto é levado às máquinas de aço inoxidável circular juntamente com uma certa quantidade de água (COHEN et al., 2011).

A legislação ambiental brasileira a respeito do lançamento de efluentes líquidos provenientes da agroindústria é clara na estratégia de controlar o processo de poluição, em todos os níveis de grau poluidor. (FAGUNDES et al., 2016; VON SPERLING, 1998).

A água contaminada sem nenhum tipo de tratamento despejada na natureza pode ocasionar diversos fatores danosos ao meio ambiente à curto e a longo prazo (DERÍZIO, 2016; CARVALHO et al., 2015). Também a geração de efluentes tal como as águas residuárias tornam-se caracterizados como fator poluente não pontuado pois não podem ser observados em uma área limitada de concentração sendo muito difíceis de serem controladas e medidas (MATOS, 2020).

As características físico-químicas indicadas da água e de soluções permitem associar os elementos e componentes iônicos presentes com os efeitos no qual eles podem exercer sob a natureza (MATOS, 2020). Portanto, elementos como por exemplo Nitrogênio (N), Fosforo (P) seguem parâmetros classificatórios para determinação do grau poluidor de um corpo hídrico (SANTOS et al.,2018). Além disso, a demanda bioquímica de oxigênio (DBO) e a demanda química de oxigênio (DQO) são fatores indicadores acerca da qualidade da água para sua reutilização, pois indicam o teor de matéria orgânica e consequentemente o seu potencial poluidor no meio ambiente, visto que o aporte de matéria 
orgânica, em corpos hídricos, por exemplo, pode propiciar a eutrofização (BARBOSA; VARGAS, 2017; PEREIRA et al, 2015).

O município de Tomé-Açu localizado no estado do Pará possui diversos pontos de beneficiamento do açaí sem nenhum tratamento e reutilização para o resíduo líquido desse processamento. Sendo assim o objetivo da pesquisa foi caracterizar o potencial poluidor da água residuária proveniente do processamento do fruto do açaizeiro e sugerir alternativas para sua disposição final.

\section{MATERIAL E MÉTODOS}

A pesquisa foi realizada no município de Tomé-Açu outubro de 2020 e janeiro de 2021, localizado no nordeste do estado do Pará ( $22^{\circ} 5^{\prime} 09^{\prime \prime}$ S, $48^{\circ} 33^{\prime} 20^{\prime \prime}$ W) e a parte norte do município faz fronteiras com os municípios de Aurora do Pará e Concordia do Pará, a parte sul com Ipixuna e ao leste com Tailândia. Tomé-açu caracteriza-se por possuir relevo de platô aplainados, terraços e várzeas (BOLFE; BATISTELLA, 2011; PACHÊCO et al., 2011).

Em Tomé-açu, no período de janeiro à maio, durante cada mês o total de chuvas atinge valor acima $200 \mathrm{~mm}$, com excedente hídrico médio dos meses de 111,2 mm, onde verifica-se que o mês de maior precipitação é o mês de março chegando a 447,2. Já de junho a dezembro o valor total de cada mês ficou inferior à $200 \mathrm{~mm}$ gerando uma deficiência média de 265,5 mm. A região apresenta uma média anual de temperatura do ar de $32,8 C^{\circ}$. (PACHÊCO et al., 2011).

Para determinar o potencial poluidor bem como caracterizar a água residuária proveniente do processamento do açaí foram coletadas amostras de vários pontos de beneficiamento e processamento do açaí que estão distribuídos em toda a cidade. Os parâmetros de identificação estudados são: Potencial Hidrogeniônico, Temperatura, Condutividade Elétrica, Fósforo, Ferro, total Potássio, Cálcio, Sódio, Nitrogênio total, Manganês, Magnésio, Enxofre, Cobre e Zinco.

Foram coletadas 10 amostras de $300 \mathrm{ml}$, sendo observados apenas os critérios de potencial Hidrogeniônico $(\mathrm{pH})$, temperatura e condutividade elétrica, que foram realizados no laboratório de Química e Bioquímica da Universidade Federal Rural da Amazônia no campus de Tomé-Açu e 2 amostras de $500 \mathrm{ml}$ para análise de Fósforo (P), Potássio (Ka) ,Ferro (Fe), Cálcio (Ca), Sódio (Na), Manganês (Mn), Enxofre (S), Cobre (Cu), Nitrogênio total $(\mathrm{N})$ que foram analisadas no Laboratório Terra / Análises para agropecuária LTDA em Goiânia - Goiás.

As amostras foram analisadas com auxílio do pHmetro de bancada modelo mPA-210 da marca MS Tecnopon ${ }^{\oplus}$ e da sonda digital TDS ${ }^{\oplus}$. 
A água residuária foi coletada em estabelecimentos de venda de açaí localizados no município de Tomé-Açu, as características químicas da água natural (água de abastecimento urbano) e residuária estão apresentadas na Tabela 1.

O método estatístico descritivo foi usado nas amostras.

O método de análise usado para cada amostra foi em triplicata, posteriormente foram obtidos as médias aritméticas e o desvio padrão de cada parâmetro verificado, onde foi realizada a comparação dos resultados com a legislação e artigos relacionados. Os resultados foram tabulados através do software Excel 2019.

\section{RESULTADOS E DISCUSSÃO}

A partir dos resultados, verificou-se que há uma tendência de linearidade quanto aos valores de $\mathrm{pH}$ e temperatura, sendo o $\mathrm{pH}$ variando entre 4,4 e 5,6 e a temperatura entre 24,9 à $26,9^{\circ} \mathrm{C}$ (Tabela 1 ). $\mathrm{O}$ desvio padrão do $\mathrm{pH}$, temperatura $\left({ }^{\circ} \mathrm{C}\right)$ e condutividade elétrica $\left(\mu \mathrm{S} . \mathrm{cm}^{-1}\right)$ respectivamente foram de $0,40,1,06,475,16$ demonstrado na tabela 2 com as médias de cada parâmetro analisado com as 10 amostras.

Tabela 1. Valores de pH, Temperatura e Condutividade elétrica das amostras de água residuária do açaí, Tomé-Açu, 2021.

\begin{tabular}{cccc}
\hline & & & \\
& ${ }^{\circ} \mathrm{C}$ & - & $(\mu \mathrm{S} / \mathrm{cm})$ \\
\hline 1 & 27,2 & 5,2 & 342 \\
3 & 25,1 & 5,1 & 290,7 \\
4 & 24,9 & 4,6 & 1620 \\
5 & 25,7 & 4,7 & 1099,9 \\
6 & 25,1 & 5,1 & 337,3 \\
7 & 26 & 4,2 & 111,7 \\
8 & 28,1 & 5,6 & 627,3 \\
9 & 26,9 & 5,1 & 178,6 \\
10 & 26,8 & 4,4 & 807 \\
\hline Valor médio & 26,2 & 4,9 & 362,3 \\
\hline Desvio padrão & $\pm 1,06$ & $\pm 0,40$ & $\pm 474,16$ \\
\hline
\end{tabular}


A instrução normativa de № 31, de 7 de outubro de 2009 firmado pela secretária do estado do meio ambiente do estado do Pará (SEMA) afirma no artigo 4 na seção IV que a deve haver a caracterização do efluente por meio de análises físico-químicas; caracterizando a carga poluidora do efluente. (PARÁ, 2009; SIQUEIRA et al., 2019)

A resolução CONAMA N $N^{\circ} 430$, na sua seção II informa que os efluentes lançados a qualquer corpo receptor deve atender o padrão de pH entre 5 e 9 e afirma que a temperatura do resíduo deve ser inferior a $40^{\circ} \mathrm{C}$ (RESOLUÇÃO CONAMA, 2011). Neste caso, as amostras 3, 6 e 9 não atenderam a norma.

O valor de $\mathrm{pH}$ encontrado é considerado médio, fator ideal utilizado para o uso dessa água para a irrigação conforme Silva et al. 2020 e FEIGIN et al. 1991. A média de temperatura encontrada nas amostras pode ser classificada como ideal, pois demonstra ser inferior à de $40{ }^{\circ} \mathrm{C}$ de acordo com a resolução CONAMA $N^{\circ} 430$, porém deve ser verificado a temperatura do corpo receptor pois ele não deve variar à 3 ㅇ (CUNHA, 2013; FAUSTINO et al.,2020; NASCIMENTO, 1998). A condutividade elétrica encontrada nas amostras e demonstradas na tabela 1, mostram que há uma forte disparidade entre as amostras devido a concentração de sólidos de algumas amostras.

A resolução CONAMA N 430 não estabelece valores adequados de condutividade elétrica que um efluente de qualquer espécie possa conter, porém em determinadas concentrações, se os efluentes despejados no solo com o teor verificado for acima de $4 \mu \mathrm{S} . \mathrm{m}^{-1}$, o solo ficará considerado salino. Como o maior nível de condutividade elétrica detectado foi de $1,6 \mu \mathrm{S} \cdot \mathrm{m}^{-1}$ na amostra 3 , caso fosse lançado no meio ambiente, ainda considerado de sem efeito agravante ao meio ambiente (CUNHA, 2013; RESOLUÇÃO CONAMA, 2011).

A presença de nutrientes foi observada nas demais amostras que foram analisadas no laboratório Terra. Os valores médios dos nutrientes analisados bem como o desvio padrão de cada elemento estão descritos na tabela 2.

Tabela 2. Valores de pH, Temperatura e Condutividade elétrica das amostras de água residuária do açaí, Tomé-Açu, 2021.

\begin{tabular}{ccc} 
& $\left(\mathrm{mg} . \mathrm{L}^{-1}\right)$ & - \\
\hline $\mathrm{N}\left(\mathrm{NO}_{3}{ }^{+} \mathrm{NH}_{4}\right)$ & 66,81 & $\pm 27,9$ \\
$\mathrm{P}$ & 7,5 & $\pm 9,1$ \\
$\mathrm{~K}$ & 132 & $\pm 56,5$
\end{tabular}




\begin{tabular}{ccc}
$\mathrm{Ca}$ & 26,8 & \pm 27, \\
$\mathrm{Mg}$ & 5,1 & $\pm 4,5$ \\
$\mathrm{~S}$ & 38,5 & $\pm 43,4$ \\
$\mathrm{Cu}$ & 0,01 & 0 \\
$\mathrm{Fe}$ & 0,535 & $\pm 0,5$ \\
$\mathrm{Mn}$ & 0,4 & $\pm 0,28$ \\
$\mathrm{Zn}$ & 0,025 & $\pm 0,02$ \\
$\mathrm{Na}$ & 95 & $\pm 7,0$ \\
\hline
\end{tabular}

\subsection{FÓSFORO}

O Fósforo $(P)$ presente nas amostras demonstrou uma concentração média de $7,5 \mathrm{mg} \cdot \mathrm{L}^{-1}$. Segundo Parron et al. 2011, o fósforo encontrado nas amostras de águas residuárias pode ser oriundo de detergentes fosfatados, algo que pode ter sido empregado na utilização na etapa da lavagem maquinário do processamento do açaí, daí pode-se explicar a presença dessa concentração nas amostras. O despejo de água residual com substâncias fosfatadas pode ocasionar a aceleração do crescimento de microrganismos que favorecem o processo de eutrofização (MATOS,2020; DERíZIO, 2016).

\subsection{NITROGÊNIO}

A presença de nitrogênio nas amostras de água residuária está ligado diretamente principalmente com a presença de matéria orgânica decomposta do açaí sendo Nitrato $\left(\mathrm{NO}_{3}\right)$ e Amônia $\left(\mathrm{NH}_{4}\right)(\mathrm{CABRAL}$ ,2020).

A quantidade média encontrada de Nitrato presente nas amostras demonstra que há processos microbiológicos ativos na água, servindo como agente poluidor. (BALIEIRO; ALVES, 2017) A ocorrência de $\mathrm{NH}_{3}$ em corpos d'água, com concentrações superiores a $3 \mathrm{mg} \cdot \mathrm{L}^{-1}$, figura-se como água contaminada. (PARRON et. Al. 2011)

Sendo assim, Cabral, 2020 diz que outro fator que pode ocorrer com a presença de Nitratos em efluentes domésticos contaminados é que este resíduo pode entrar em contato direto com águas superficiais, pois esse composto possui alta capacidade de solubilidade e adsorção por isso o nitrato apresenta dificuldades na remoção do íon quando utilizado método artificiais por meio de tecnologias de tratamento convencional. (CABRAL, 2020; DERízIO, 2016). 
O amônio é recorrente em pequenos teores em águas naturais, porém ele pode estar presente em maiores concentrações em efluentes domésticos e industriais devido a presença da degradação matéria orgânica e inorgânica (CABRAL, 2020). Desta forma a concentração média de 66,81 mg.L-1 encontrada nas amostras são indicativas de poluição. A classificação de uma água contaminada por amônio se dá pela concentração de até 10 mg.L-1 , (FIA et al. 2017; PARRON et.al 2011).

Em fontes de águas naturais, normalmente é encontrado concentrações na faixa de 1 à $3 \mathrm{mg} . \mathrm{L}^{-1}$. Sendo que a resolução CONAMA determina que a concentração de nitrogênio amoniacal lançados por efluentes não deve ser superior a $20 \mathrm{mg} \cdot \mathrm{L}^{-1}$, sendo assim a alta concentração de amônio observados nas amostras revela o grau poluidor deste resíduo.

\subsection{POTÁSSIO.}

O nível médio de potássio encontrado nas amostras de $132 \mathrm{mg} \cdot \mathrm{L}^{-1}$ é considerado alto em comparação a outros elementos analisados.

O potássio encontrado nas amostras de água residuária não depende somente da mineralização de matéria orgânica para estar presente, as concentrações de potássio encontrados em águas subterrâneas variam entre $0,5 \mathrm{mg} \mathrm{L}^{-1}$ à $5 \mathrm{mg} \mathrm{L}^{-1}$ (PARRON et al. 2011; SILVA; VARGAS, 2017). O potássio dissolvido no solo possui alta solubilidade e é rapidamente absorvido pelas plantas (MATOS, 2020). Algo que pode explicar o fato do nível alto encontrado na água do resíduo líquido é que ela advém do sistema de abastecimento de água do município de Tomé Açu.

\subsection{CÁLCIO E MAGNÉSIO}

Cálcio e magnésio são considerados elementos responsáveis pelo atributo de dureza em corpos d'água, nesse caso, a concentração média de cálcio observado nas amostras foi de $26,8 \mathrm{mg} . \mathrm{L}^{-1} \mathrm{e}$ de magnésio foi 5,1 mg.t-1.

Sendo assim estudos comprovaram que o Cálcio pode auxiliar na diminuição do elemento fosforo (P) e alguns constituintes tóxicos de uma água residuária (MATOS, 2020). É possível encontrar concentrações de magnésio à $4 \mathrm{mg} \cdot \mathrm{L}^{-1}$ em águas naturais e em águas subterrâneas $5 \mathrm{mg} \cdot \mathrm{L}^{-1}$ (PARRON et al. 2011). A formação de dolomita e calcita acontece nos solos de forma onerosa, o despejo da água residuária com esses níveis encontrados de cálcio e de magnésio não determinaria um grau poluidor, visto que a CONAMA não discrimina concentrações ideais para esse efluente. 


\subsection{FERRO E ENXOFRE}

O enxofre pode-se apresentar em diversas formas em águas residuárias, dentre as formas está o sulfato e sulfeto de hidrogênio (MATOS,2020). A concentração de sulfato sugerida pela CONAMA na dispersão de efluentes é de $1 \mathrm{mg} \cdot \mathrm{L}^{-1}$. A quantidade média encontrada na amostra de $38,5 \mathrm{mg} \cdot \mathrm{L}^{-1}$ sugere que ao entrar em contato com o solo, o enxofre pode ocasionar ações oxidativas e redutivas, além disso o enxofre pode se estabelecer como sulfato e entrar em contato com gases atmosféricos formando o ácido sulfúrico, podendo ocorrer a chuva ácida. (PARRON et al. 2011).

Em contato com a presença de Ferro, em ambientes anaeróbicos, o enxofre pode assumir a forma de sulfeto férrico, fazendo que o Fósforo permute de insolúvel para solúvel. A média de ferro de 0,535 mg. $\mathrm{L}^{-1}$ é baixa em comparação com que a CONAMA informa, sendo a concentração ideal de $15 \mathrm{mg} \cdot \mathrm{L}^{-1}$ de água residuária. Nesse caso a água residual do açaí está muito abaixo do padrão.

\section{5 COBRE, MANGANÊS E ZINCO}

Neste caso, a quantidade média de cobre manganês e zinco foram de 0,4, 0,025 e 0,01 respectivamente, nesse caso, os elementos encontrados nas amostras estão muito abaixo do recomendado, pois a resolução do CONAMA afirma que a quantidade de Cobre e Manganês lançados por efluentes não devem ultrapassar $1 \mathrm{mg} \cdot \mathrm{L}^{-1}$ enquanto a de Zinco é de $5 \mathrm{mg} . \mathrm{L}^{-1}$.

\subsection{SÓDIO}

Parron et. al. 2011 afirmam que a quantidade de sódio encontradas em corpos hídricos depende de fatores geológicos e de descarga de efluentes, pois a quantidade elevada de sódio pode ocasionar a salinização do solo (REZENDE et al 2020). A média de sódio encontrado nas amostras foi de $95 \mathrm{mg} . \mathrm{L}^{-1}$ A tabela I de Padrões de lançamento de efluentes da resolução $N^{\circ} 430$ do CONAMA não demonstra a concentração ideal que um efluente pode ter.

\section{CONCLUSÃO}

Os parâmetros temperatura e condutividade elétrica encaixam-se no padrão da norma $\mathrm{N}^{\circ} 430$ da CONAMA de 2011, a qual dispõe sobre as condições e padrões de lançamento de efluentes. Entretanto, o pH de algumas amostras não atenderam os requisitos.

As análises das amostras constataram que em concentrações de Nitrogênio, Fósforo e Enxofre figuram a água residuária do processamento do açaí como poluente quando lançadas de forma inadequada 
sem o prévio tratamento, em contrapartida os outros elementos analisados estão em conformidade aos valores previstos na referida legislação brasileira. 


\section{REFERÊNCIAS}

BALIEIRO, F. de C.; ALVES, BJR. Nitrogênio total: Kjeldahl. Embrapa Solos-Capítulo em livro técnico (INFOTECA-E), 2017.

BARBOSA, D. N. R.; VARGAS, R.R. estudo comparativo da dbo e dqo em amostras de águas superficiais na microbacia cubas, guarulhos-sp. Revista Educação-UNG-Ser, v. 11, n. 3 ESP, p. 53, 2017.

CABRAL, G. A. J. Comportamento dos compostos nitrogenados, amônia, nitrito e nitratos, em águas subterrâneas. 2020. 45 f. Trabalho de Conclusão de Curso (Graduação em Química Bacharelado) Universidade Federal do Ceará, Fortaleza, 2020.

CARVALHO, B. G. P; MENDONÇA, N. M.; ANDRADE, F. S.; ISE, J. I. S.; BARBOSA, P. A. V.; DIAS, L. C. Avaliação do desempenho de uma estação de tratamento de esgoto durante o período de estiagem Estudo de caso na ETE Vila da Barca, Belém, Pará. Congresso Nacional de Meio Ambiente. Poços de Caldas. 2015.

COHEN, K. O.; MATTA, V. M.; FURTADO, A, A. L.; MEDEIROS, N. L.; CHISTÉ, R. S. Contaminantes microbiológicos em polpas de açaí comercializadas na cidade de Belém-PA. Revista Brasileira de Tecnologia, v. 5, n. 02, p. 524-530, 2011.

DEUS, D. G. F.; CALIJURI, M. C.; LAMPARELLI, M. C.; MENEGON JUNIOR, N. Resolução CONAMA 357/2005: análise espacial e temporal de não conformidades em rios e reservatórios do estado de São Paulo de acordo com seus enquadramentos (2005-2009). Engenharia Sanitária e Ambiental, v. 18, n. 2, p. 159-168, 2013.

SILVA, M. A; VARGAS, R.R. Análise de fósforo e DQO em amostras de águas naturais no município de Guarulhos. Revista Educação-UNG-Ser, v. 11, n. 3 ESP, p. 81, 2017.

DERÍSIO, J. C. Introdução ao controle de poluição ambiental. Oficina de Textos, 2016.

FARIAS NETO, J. T; VASCONCELOS, M. A. M.; SILVA, F. C. F. Cultivo, processamento, padronização e comercialização do açaí na Amazônia. Instituto de desenvolvimento da fruticultura e agroindústria Frutal - Fortaleza: Instituto Frutal, 2010.

FAUSTINO, A. M. C.; SILVA, R. F. impactos ambientais e eficiência do sistema de tratamento de efluentes líquidos do abatedouro regional de Paudalho-PE. Sustentare, v. 4, n. 1, p. 24-36, 2020.

FEIO, V. F.; GIRARD, L., MENDONÇA, N. Problemática da geração de efluentes oriundos do processamento de açaí na região metropolitana de Belém-PA. Revista Monografias Ambientais, v. 13, n. 3, p. 3335-3340, 2014.

MATOS, A.T. Poluição ambiental: impactos no meio físico. Editora UFV, 2020.

MORAIS, N. W. S.; COELHO, M. M. H.; SILVA, F. S. S.; PEREIRA, E. L.; SANTOS, A. B. Caracterização físicoquímica e determinação de coeficientes cinéticos aeróbios de remoção da matéria orgânica de águas residuárias agroindustriais. Engenharia Sanitária e Ambiental, v. 25, n. 3, p. 489-500, 2020.

NASCIMENTO, L. V. Análise dos padrões de efluentes das águas e de lançamento de efluentes líquidos estabelecidos pela resolução CONAMA № 020/1986: uma abordagem para águas doces. 1998 
Dissertação (Mestrado em Engenharia) - Escola de Engenharia. Universidade Federal de Minas Gerais, Belo Horizonte, 1998.

PARÁ - Governo do Estado. Normativa no 31, de 7 de outubro de 2009. Considerando a necessidade de normatização de procedimentos no âmbito da Secretaria de Estado de Meio Ambiente e, em especial, da Diretoria de Recursos Hídricos, para análise técnica e administrativa das solicitações de outorga de direito de uso de recursos hídricos em corpos d'água de domínio do Estado, tendo em vista a eficiência administrativa. Belém: Diário Oficial do estado do Pará. 2009.

PARRON, et al. Manual de procedimentos de amostragem e análise físico-química de água. Embrapa Florestas-Documentos (INFOTECA-E), 2011.

PEREIRA, B.; GANDRA, M. M. S.; FONSECA, A. L. D. Nutrientes e gases dissolvidos na coluna da água e teor da matéria orgânica no sedimento ao longo da Lagoa da Conceição e sua relação com o processo de eutrofização. Rev. Discente Express. Geografia, v. 1, p. 1-16, 2015.

RESOLUÇÃO CONAMA- Conselho Nacional do Meio Ambiente $n^{\circ}$ 430. Dispõe sobre classificação de corpos d'água e estabelece as condições e padrões para lançamento de efluentes, e dá outras providências. 2011.

SANTANA, A. C.; SANTANA, A. L.; SANTOS, M. A.; OLIVEIRA, C. M. Análise discriminante múltipla do mercado varejista de açaí em Belém do Pará. Revista Brasileira de Fruticultura, v. 36, n. 3, p. 532-541, 2014.

SANTOS, S. A.; GASTALDINI, M. C. C.; GHESTI PIVETTA, G.; SCHMIDT FILHO, O. Avaliação da qualidade da água na bacia hidrográfica urbana Cancela-Tamandaí, Santa Maria/RS. Revista Sociedade \& Natureza, v. 30, n. 2, p. 23-44, 7 set. 2018a.

VON SPERLING, M. Análise dos padrões brasileiros de qualidade de corpos d'água e de lançamento de efluentes líquidos. Revista Brasileira de Recursos Hídricos, v. 3, n. 1, p. 111-132, 1998. 


\section{Capítulo 8}

doi) $10.37423 / 210804555$

\section{PESCA, AQUICULTURA E QUALIDADE DE VIDA: UM ESTUDO DE CASO NAS ILHAS DE ANANINDEUA, PARÁ.}

PÂMELA MELO COSTA

FRANCISCA NARA CONCEIÇÃO MOREIRA

ANA RACHEL BRONI DE JESUS

EVERTON SILVA TEIXEIRA
INSTITUTO FEDERAL DE EDUCACÃO.

CIÊNCIA E TECNOLOGIA DO PRÁ

CAMPUS BELÉM

INSTITUTO FEDERAL DE EDUCACÃO, CIÊNCIA E TECNOLOGIA DO PRÁ

CAMPUS BELÉM

INSTITUTO FEDERAL DE EDUCAÇÃO, CIÊNCIAE TECNOLOGIA DOPRÁ . CAMPUS BELÉM

INSTITUTO FEDERAL DE EDUCACÃO, CIÊNCIA E TEENOLOGIA DO PRÁ. CAMPUS BELÉM 
Resumo: Este trabalho faz referência aos estudos e análises de campo, que vem sendo realizado no Projeto "Levantamento do Potencial Pesqueiro, Aquícola e de Qualidade de Vida nas Ilhas de Ananindeua, Pará". A região estudada localiza-se próxima à capital paraense. Contudo, mesmo com a proximidade dos centros urbanos, vem se apresentando com poucas informações a respeito das temáticas de Pesca, Aquicultura e de Indicadores de Qualidade de Vida, nos âmbitos técnicos, científico, informacionais ou mesmo de ações de desenvolvimento local. Os moradores locais desenvolvem atividades inerentes a captura e cultivo de pescado, extração de produtos florestais e trabalhos na agricultura e ocorre a inexistência de ações voltadas para desenvolvimento local.

Palavras-chave: aquicultura, desenvolvimento, Ihas de Ananindeua, pesca, qualidade de vida 


\section{INTRODUÇÃO}

Na Amazônia as atividades agroextrativistas ganham ampla expressividade pelos moradores dos locais que "detém" os recursos naturais, nela incluem-se as atividades de captura do pescado, extração florestal (açaí, coleta de sementes, frutos da mata, cipós e talas) e extração do pescado (peixes crustáceos, moluscos). Nesse contexto é que a atividade pesqueira vem aumentando seu espaço e ganhando maior importância seja como atividade econômica, social e/ou cultural para cada região, além de apresentar o pescado como a principal fonte de proteína local (PETRERE Jr, 1978 e ALMEIDA, 2006).

Segundo Ruffino (2000), em relação às demais regiões brasileiras, a pesca na região amazônica destaca-se tanto nas áreas costeiras quanto em áreas de águas interiores, pela diversidade de espécies exploradas, pela quantidade de pescado capturado e pela dependência das populações tradicionais à esta atividade.

No estado do Pará, $1 / 4$ da população apresenta dependência do setor pesqueiro para a sua sobrevivência, correspondendo a 1,2 milhões de pessoas, das quais 200 mil são pescadores ativos. Outra informação importante é expressa pelo fato de $60 \%$ da produção pesqueira da Amazônia ser oriundo da pesca de subsistência ou de mercados locais. (PETRERE Jr, 1978).

Nas últimas três décadas, houve uma reconhecida diminuição da abundância de alguns estoques de peixes na Amazônia (o que fomenta o desenvolvimento de atividades de aquicultura). Aliado a isto tem-se a falta de ação eficiente do poder público, responsável por gerenciar o recurso oriundos das atividades de pesca, em que as normas existentes para o ordenamento pesqueiro vigente, em muitos casos, são inadequadas às realidades locais, não sendo cumpridas e nem fiscalizadas.

Em detrimento às tais circunstâncias e somado ainda à exclusão da pesca e aquicultura (familiar) como prioridade nos programas governamentais de gerenciamento dos recursos naturais da região, permitindo um aumento descontrolado de exploração de alguns estoques de peixes, que por seu elevado valor econômico, a atividade pesqueira sofre com seu esforço (ISAAC et al. 1995; ISAAC \& CERDEIRA, 2004).

O estudo focou as Ilhas de Ananindeua, onde são aproximadamente 14 ilhas que possuem sua base econômica, social, ambiental e cultural atrelada as atividades extrativistas de pesca, de produtos florestais e cultivos de peixes e hortaliças de forma familiar, sem suporte técnico, financeiro e reconhecimento regional. 
Este cenário pouco é divulgado, sendo poucos os estudos científicos e/ou relatórios técnicos que informam sobre a realidade das Ilhas, motivo este que norteia a realização e consecução deste estudo. Aliado a isto possui como objetivo levar em consideração a participação de pescadores e pescadoras da região das Ilhas de Ananindeua em programas e projetos de pesquisa, de extensão e atuações de assistência técnica são escassos, observa-se, a ausência de uma política de fomento à manutenção e/ou conservação dos recursos pesqueiros, e mesmo política de Educação Ambiental atreladas às bases de desenvolvimento sustentável, fazendo-se necessário gerar um olhar à categoria, de pescadores e pescadoras, com vistas a tentar proporcionar a conservação dos recursos pesqueiros (McGRATH, 1993).

\section{MATERIAL E MÉTODOS}

A pesquisa equivaleu-se para sua realização de técnicas metodológicas para suas análises. Dentre estas técnicas pode-se ressaltar: o levantamento secundário, onde se tem a obtenção de materiais teóricos a cerca dos temas do projeto bem como da localidade de atuação. Para isso contando com pesquisas em acervos bibliográficos, trabalhos científicos (dissertações, artigos, dentre outros), pesquisa em secretarias do município e agências de turismo; observação de campo, momento para procurar recolher e registrar os fatos da realidade das Ilhas de Ananindeua, assim como suas respectivas comunidades pesqueiras; entrevistas semi-estruturadas: no intuito de obter respostas aos questionamentos norteadores do levantamento em questão (pesqueiro, aquícola e de qualidade de vida) nas comunidades das ilhas de Ananindeua; reuniões comunitárias: participação nas reuniões comunitárias, a fim de contracenar com a maioria dos representantes locais nos momentos de organização comunitária.

\section{RESULTADOS E DISCUSSÃO}

Ananindeua localiza-se dentro da região metropolitana de Belém. Os limites de Ananindeua se confundem com os limites da capital paraense, onde o acesso se dá pela rodovia BR-316. É um município brasileiro do estado do Pará localizado na Grande Belém (IBGE, 2010). O município possui 12 ilhas reconhecidas pelos moradores locais (legítimas), contudo legalmente fazendo parte de Belém, municípios de Benevides, e Santa Bárbara, muitos moradores locais confundem a distinção de comunidades e ilhas, sobretudo somente nove (09) destas são reconhecidas legalmente.

Dentre estas ilhas existe a presença de comunidades ribeirinhas, que dependem ou vivem usufruindo direta ou indiretamente dos recursos aquáticos. Faz confluência ao norte com as ilhas de Mosqueiro 
e São Pedro. Ao sul com as ilhas de Caratateua, Viçosa e a área continental de Ananindeua. Ao leste com as ilhas de Santa Rosa, Sororoca e Sassunema. Os rios que banham as ilhas são o Maguari e Baía do Guajará, além dos afluentes de descargas recebidos pelos aportes oceânicos (ALMEIDA, 2010).

A região é dotada de áreas de manguezais, ocorrendo a presença de vegetação de mangue, como mangue preto (Avicennia schaueriana), mangue vermelho (Rhizophora mangle) bem como fauna de manguezal à exemplo de crustáceos como caranguejos (Ucides cordatus), siris (Tyrannus melancholicus) e Uca ou chama maré (Uca pugnax). Ocorre ainda a presença da vegetação de várzea, nas áreas sujeitas às inundações, dentre algumas espécies florísticas encontram-se o açaí (Euterpe oleracea), miriti (Mauritia flexuosa), virola (Virola sp.), andiroba (Caraba guianensis).

Os moradores que na maioria dos casos nasceram ali naquela região, possuem pouco contato mesmo com as regiões mais próximas Curuçambá e Ananindeua (centro) que leva em torno de uma hora e meia do porto do surdo no Curuçambá. As únicas formas de acesso ocorrem por vias fluvias, que podem ser viagens de uma hora e meia até três horas de duração dependendo do porto. Estes foram identificados como Portos do Surdo no distrito do Curuçambá, Porto do Fidelis no distrito de Icoaraci, Porto do Fama em Icoaraci, Porto do Adonias no distrito de Murinim (Benevides), além de outros acessos pelo distrito de Mosqueiro, Santa Bárbara e Cotijuba.

Para o acesso às llha o barco pode ser fretado, e existem casos de barcos de linhas, com horas marcadas e determinadas pelas demandas das comunidades.

As Ilhas de Ananindeua receberam a categorização de Projetos de Assentamentos (PAE), onde a Ilha de João Pilatos faz parte desde o ano de 2007 e apresenta-se com os benefícios do INCRA (como residências de alvenaria) e cumprimentos no que diz respeito aos Projetos de Assentamentos. 
Tabela 1 - Entidades organizativas ligadas à atividade pesqueira e à aquicultura nas llhas de Ananindeua.

\begin{tabular}{|c|c|c|}
\hline Ilhas & Organizações ligadas a Pesca e Aquicultura & $\begin{array}{l}\text { Número de } \\
\text { Famílias } \\
\text { Envolvidas }\end{array}$ \\
\hline Sassunema & $\begin{array}{l}\text { Associação de Pescadores Artesanais, Aquicultores, Marisqueiros e } \\
\text { Pequenos Produtores Rurais da Ilhas de Sassunema - APAMPRISA }\end{array}$ & 30 \\
\hline Sororoca & $\begin{array}{l}\text { Associação de Pescadores Artesanais, Aquicultores, Marisqueiros e } \\
\text { Pequenos Produtores Rurais da Ilhas de Sororoca - APAMAPRIS }\end{array}$ & 25 \\
\hline Viçosa & $\begin{array}{l}\text { Associação de Pescadores Artesanais, Aquicultores, Marisqueiros e } \\
\text { Pequenos Produtores Rurais da Ilhas de Viçosa - AMPPRIV }\end{array}$ & 32 \\
\hline Santa Rosa & $\begin{array}{l}\text { Associação de Pescadores Artesanais, Aquicultores e Pequenos } \\
\text { Produtores Rurais das Ilhas de Ananindeua - APAAPRIAN }\end{array}$ & 48 \\
\hline Maritubinha & Colônia de Pescadores Z- 93 de Ananindeua -Maritubinha & $\begin{array}{l}\text { Não } \\
\text { informado }\end{array}$ \\
\hline Guajarina & $\begin{array}{l}\text { Associação de Pescadores Artesanais, Aquicultores, Marisqueiros e } \\
\text { Pequenos Produtores Rurais da Ilhas Guajarina - APAMPRIG }\end{array}$ & $\begin{array}{l}\text { Não } \\
\text { informado }\end{array}$ \\
\hline
\end{tabular}

A atividade de pesca é exercida de maneira artesanal, com utilização de tarrafas, espinhel, zagaia nos igarapés à dentro e nos rios praticada com malhadeiras. As principais espécies de pescado capturado são: pescada branca (Plagioscion squamosissimus), mandubé (Ageneiosus brevifilis), mandii (Pimelodus spp.), dourada (Brachyplatystoma rousseauxii), filhote (Brachyplatystoma filamentosum), piramutaba (Brachyplatystoma vaillantii), traíra (Hoplias malabaricus), matrinchã (Brycon spp), curimatã (Prochilodus spp.), camarão regional (Macrobrachium amazonicum), caranguejo (Ucides Cordatus).

A pesca é voltada para comercialização em pequena escala e consumo familiar. As mulheres praticam as atividades de pescarias de crustáceos com utilização do matapi (como apetrecho). A pesca é praticada tanto nos períodos de chuvas intensas quanto nos períodos menos chuvosos.

A atividade de aquicultura é realizada pelos moradores locais como atividade complementar às atividades extrativas, funcionando como uma poupança, onde as capturas provenientes dos cultivos são voltadas à alimentação familiar. As atividades de aquicultura são destinadas à piscicultura, sendo 
realizados cultivos de peixes tropicais de água doce, em viveiros escavados, estes feitos individualmente ou em mutirões comunitários. As espécies utilizadas são o Tambaqui (Colossoma macropomum), Curimatã (Prochilodus spp.), e alguns casos de Tilápias (Oreochromis niloticus), contudo sem observações quanto às normas ambientais vigentes.

Nestes cultivos a alimentação é feita de forma natural e artificial (rações peletizadas) adquiridas em Belém. A captação de água é feita por gravidade e ocorre a presença de perdas de água por infiltração. Os cultivos foram feitos sem apoio técnico, sem capacitação local, estando os moradores interessados nestas formas de assistência.

Os indicadores de qualidade de vida observados estão ligados aos aspectos educacionais, de saúde e ambientais. Quanto à educação, nas ilhas ocorre a presença de uma única escola de ensino médio e fundamental, possuindo um barco e uma lancha para atendimento dos alunos de moradias distantes, estando condicionada à continuidade dos estudos para as regiões de Ananindeua (Centro Urbano) e Belém. As Ilhas não possuem posto de saúde, agente comunitário de saúde, nem medicamentos para casos de urgência e emergência. Com relação aos indicadores ambientais, foi possível observar indícios de poluição, sendo observado despejo de plásticos, garrafas pet, papéis nas áreas de terra firme, em áreas de igarapés e em rios.

\section{CONCLUSÕES}

Com o estudo e execução do projeto foram observadas as necessidades de implementação de projetos de pesquisas, projetos de extensão, atuações por parte de órgãos governamentais e mesmo não governamentais, capacitação técnica e captação de recursos financeiros para execução de atividades de manejo dos recursos pesqueiros. Instrumentos como políticas públicas municipais voltadas à inserção de medidas regulatórias para práticas de aquicultura e preservação do meio ambiente são necessárias à conservação dos recursos naturais, aliadas a busca permanente de melhorias nos níveis educacionais com propostas de inserções dos pescadores, pescadoras, jovens e crianças em programas federais, estaduais e municipais a fim de que se possam aprimorar a formação de consciência ambiental e mesmo estimular nos mais novos.

\section{AGRADECIMENTOS}

O presente estudo não seria possível sem a participação dos comunitários das Ilhas de Ananindeua, sem o apoio financeiro na forma de bolsas de estudo pelo Programa Institucional de Bolsas de 
Extensão - PIBEX através do edital da Diretoria Geral 2012 do Instituto Federal de Educação, Ciência e Tecnologia do Pará e da Coordenação dos Recursos Pesqueiros e Agronegócios campus Belém.

\section{REFERÊNCIAS}

AIMEIDA, O.T. Manejo de pesca na Amazônia brasileira. São Paulo. 2006.

ALMEIDA, ADRIELSON FURTADO. Análise etnoecológica da floresta de Várzea na llha de Sororoca, Ananindeua, Pará, Brasil. Dissertação (Mestrado em Ciências Ambientais), Programa de PósGraduação em Ciências Ambientais, Instituto de Geociências. UFPA/MPEG/EMBRAPA. Belém, 2010.

ISAAC, V.J.; BARTHEM, R.B. Os recursos pesqueiros da Amazônia Brasileira. Bol. MPEG. Série Antropologia. 11(2). 1995

ISAAC, V.J. \& CERDEIRA, R.G.P. Avaliação e monitoramento de impactos dos acordos de pesca na região do Médio Amazonas / Victoria Judith Isaac - Manaus: IBAMA/Provárzea, 2004. 64p.

McGRATH, D.; CASTRO, F.; FUTEMA, C.; AMARAL, B. \& CALABRIA. J. Fisheires and the evolution of resource management on the lower Amazon floodplain. Human Ecology 21 (2) 1993. 167-95

PETRERE Jr. Pesca e esforço de pesca no estado do Amazonas. II. Locais e aparelhos de captura e estatística de desembarque. Acta Amazônica, Manaus, v.8, n.3, suplemento 2, p.1-54, 1978 b.

RUFFINO, M. L. Manejo dos recursos pesqueiros no médio Amazonas. Brasília: IBAMA, 2000. (Coleção Meio Ambiente. Série Estudos da Pesca, 22). 350p. 


\section{Capítulo 9}

doi) $10.37423 / 210804561$

\section{SUPERAÇÃO DA DORMÊNCIA DE SEMENTES DE QUALEA PARVIFLORA MART. (PAU-TERRA)}


Resumo: Qualea parviflora Mart. conhecida como pau-terra, pertencente à família Vochysiaceae, é uma espécie arbórea nativa do Cerrado brasileiro que apresenta interesse comercial, como ornamental e medicinal, podendo ainda ser empregada em reflorestamentos heterogêneos, destinados também à recomposição de áreas degradadas. Nesse contexto, objetivou-se avaliar a eficiência da escarificação química e mecânica na superação da dormência de sementes de Qualea parviflora Mart. (pau-terra). Os tratamentos foram: testemunha não possuiu nenhum tratamento (T1), imersão em ácido acético por 12 horas (T2), imersão em ácido acético por 24 horas (T3), escarificação mecânica com alicate (T4), Escarificação mecânica com alicate + adição de ácido giberélico (T5), imersão em solução de ácido giberélico (T6) e imersão em ácido sulfúrico (T7). A germinação foi máxima (100\%) em T4 e T5, no T5, a maioria sementes germinou na primeira contagem, com 89\% e 94\% de germinação. Nas sementes, o IVG (Índice de Velocidade de Germinação) de todos os tratamentos foi superior à testemunha. O TMG (Tempo Médio de Germinação) das sementes do foi reduzido para 2,11 dias com o T5. Portanto, os tratamentos mais eficientes para a superação da dormência das sementes de Qualea parviflora Mart. (pau-terra) foram escarificação mecânica com alicate e escarificação mecânica com alicate + adição de ácido giberélico.

Palavras-chave: Cerrado; dormência; germinação e sementes florestais. 


\section{INTRODUÇÃO}

Entre os biomas brasileiros, o Cerrado é o segundo maior em extensão territorial, superado apenas pelo Bioma Amazônico, possuindo uma área em torno de 205 milhões de hectares, o que corresponde a $25 \%$ do território nacional (Seno et al. 2008). Além disso, o Cerrado se destaca pela riqueza de sua biodiversidade, apresentando uma flora com várias espécies endêmicas, sendo uma das mais ricas formações savânicas do mundo (Palhares et al. 2010).

Assim como os outros biomas brasileiros, o Cerrado vem sofrendo com a expansão agropecuária, sendo hoje alvo de diversas empresas. Em contrapartida, nas últimas décadas o incentivo pela diminuição das taxas de desmatamento vem ganhando força (Sarmento \& Vilela, 2010). Apesar da redução do desmatamento, ainda não é possível prever quando as florestas permaneceram em níveis estáveis de conservação (Melo et al. 2011).

Para conservar as florestas, é importante restaurar, sendo assim, a atividade básica na restauração florestal é a produção de mudas nativas, que é uma atividade regulamentada pela legislação ambiental na promoção do aumento de demanda de sementes de espécies nativas (Sarmento \& Vilela, 2010).

Em contraste com os incentivos à produção de mudas nativas, Melo et al. (2011) ressalta que ainda é inexpressiva a quantidade de estudos voltados para a espécies nativas. Uma das barreiras encontradas ao se trabalhar com espécies nativas é a dificuldade na produção, causada pela dormência das sementes.

A Qualea parviflora Mart. pertencente à família Vochysiaceae é conhecida popularmente como pauterra, pau-terra-do-campo ou pau-terra-do-cerrado, sendo uma espécie heliófita, pioneira, decídua, que ocorre em formações primárias e secundárias. É uma espécie que apresenta alta densidade em formações vegetacionais do Cerrado além de ser acumuladora de alumínio, característica importante para o estabelecimento em solos como os do cerrado ricos neste elemento (Haridasan, 1982; Costa; Araujo, 2001; Barreira et al., 2002;).

A família Vochysiaceae compreende cerca de 240 espécies e oito gêneros. São lenhosas, geralmente arbóreas, de folhas opostas ou verticiladas, simples, estípulas às vezes glandulares (Qualea), com flores períginas ou epíginas, diclamídeas ou monoclamídeas, frequentemente zigomorfas, isoladas ou em inflorescência do tipo tirso, cálice geralmente calcarado, corola frequentemente com número reduzido de pétalas e um único estame fértil, com frutos capsulares ou samaróides e sementes geralmente aladas (Barbosa 1999, Shimizu 2009). Outro fator a destacar é o seu grande interesse 
comercial, devido a suas várias finalidades, sendo utilizado como planta ornamental ou como planta medicinal, bem como fonte de madeira e para fins ambientais.

A madeira das espécies da família Vochysiaceae pode ser usada em marcenaria, confecção de brinquedos, caixotaria, cabo de ferramentas, bem como lenha e carvão (combustível) e uso interno em construção civil, como vigas, ripas, caibros, tabuado etc. (Lorenzi, 2002).

É um xerófito heliofítico e seletivo, sendo espécies pioneiras adaptadas a terras pobres, o que lhe permite ser explorado em reflorestamento heterogêneo de áreas destinam-se a restauração de preservação permanente áreas degradadas (Lorenzi, 2000).

A dormência de sementes representa recurso eficaz para a perpetuação das espécies, conferindo à semente resistência às condições desfavoráveis do ambiente e distribuindo a germinação no tempo (Brancalion et al., 2011). Entretanto é, geralmente, uma característica indesejável para os viveiristas, gerando problemas como desuniformidade entre as mudas, além de maior tempo de exposição às condições adversas, como a ação de insetos e doenças, e maior risco de perda de sementes por deterioração (Azeredo et al., 2010).

A produção de mudas de Qualea parviflora pode ser prejudicada pela a dormência das sementes, que pode impedir a germinação homogênea da espécie. Entretanto, Nascimento et al. (2009), afirmam que para aumentar a germinação desta espécie, destacam-se as técnicas de escarificação mecânica, a escarificação química e a adição de hormônios vegetais que atuam na germinação para quebra da dormência tegumentar.

As sementes de muitas espécies florestais apresentam restrições à passagem de água e do oxigênio impostas pelo tegumento, neste caso, a semente apresenta dormência física porque os tecidos que a envolvem exercem um impedimento que precisa ser superado para que a germinação aconteça (Ramalho,I.C. et al. 2019).

Portanto, diante da necessidade na produção de mudas e da importância de se ampliar as informações sobre a superação da dormência de sementes de Qualea parviflora, objetivou-se avaliar a eficiência da escarificação e de tramentos químicos na superação da dormência de suas sementes

\section{MATERIAIS E MÉTODOS}

As sementes utilizadas no experimento foram coletadas em duas localidades do Parque Estadual do Lajeado, Palmas-TO, sendo elas pertencentes ao estado do Maranhão e Tocantins. A coleta das 
sementes foi realizada em fevereiro de 2019, em um número mínimo de 15 plantas-mãe (lote), logo após foram transportadas até a casa de sementes da unidade de conservação, onde foram beneficiadas e selecionadas manualmente, descartando-se as que apresentavam injurias ou estavam deformadas, sequencialmente após a secagem as mesmas foram armazenadas em temperatura ambiente por 6 meses, no laboratório de sementes da Universidade Federal do Tocantins, campus Gurupi-TO.

O delineamento estatístico utilizado foi o inteiramente casualizado em esquema fatorial 2 (procedências) X 7 (métodos para superação da dormência).

O experimento foi conduzido no Parque Estadual do Lajeado, Palmas - TO, em casa de vegetação e dispostas em canteiros separadamente, sendo irrigada diariamente. A separação das sementes aptas, foram em lotes de 100 sementes nos sete tratamentos aplicados, divididas em 4 repetições contendo 25 sementes, utilizando como substrato solo de barranco, colocando as sementes para germinar em saquinhos de 350 gramas.

A avaliação do peso de mil sementes (Brasil, 2009) foi realizada com a pesagem em balança de precisão de 8 amostras, retiradas do lote de sementes de cada procedência, contendo 100 sementes de Qualea parviflora Mart. em condições de armazenamento em cada amostra.

Antes da instalação do experimento, as sementes foram esterilizadas, com imersão em hipoclorito de sódio ( $\mathrm{NaClO}$ ) por 5 minutos, sendo esse procedimento importante para controlar a proliferação de fungos que poderiam interferir na confiabilidade dos dados do experimento. Após o tempo de imersão, as sementes foram retiradas do $\mathrm{NaClO}$ com o auxílio de uma peneira, e em seguida as sementes foram lavadas em água corrente por 5 minutos.

Após a desinfestação as sementes foram submetidas aos seguintes tratamentos para superação da dormência: Testemunha (T1) - sementes intactas e sem imersão em nenhum ácido. Imersão em ácido acético por 12 horas (T2) - Após o período determinado, a sementes foram lavadas em água corrente por 5 minutos. Imersão em ácido acético por 24 horas (T3) - Após o período determinado, a sementes foram lavadas em água corrente por 5 minutos. Escarificação mecânica com alicate (T4) - as sementes foram escarificadas manualmente com alicate. Escarificação mecânica com alicate + adição de ácido giberélico (T5) - após a escarificação, as sementes foram imersas em uma solução de 200 ppm de ácido giberélico por 3 horas. Imersão em solução de ácido giberélico com $100 \mathrm{ml}$ de água destilada (T6) - as sementes foram imersas em uma solução de 200 ppm de ácido giberélico por 3 horas. Imersão em ácido sulfúrico - (T7) - imersão em ácido sulfúrico (98\%) por um período de 15 minutos. 
Durante os 27 dias de semeadura, foram calculadas as variáveis: porcentagem de germinação, tempo médio de emergência (TME), índice de velocidade de emergência (IVE). Após os 27 dias de semeadura das sementes, foi realizado a classificação das plântulas em normais fortes, normais fracas e anormais, comprimento de plântulas, massa úmida e seca das plântulas, de acordo com as instruções para análise de sementes de espécies florestais (BRASIL, 2013).

Os dados em porcentagem foram transformados em $\operatorname{arcsen} \sqrt{x / 100}$. Estes foram submetidos ao teste de kolmogorov-Smirnov para verificação da normalidade e de Levene para verificação da homocedasticidade das variâncias. Nos casos em que a distribuição foi normal e as variâncias homogêneas foi realizada análise de variância, seguida do Teste de Tukey com probabilidade (p) de 0,05 . Nos casos em que a distribuição não foi normal, foi realizado o teste de Kruskal-Wallis, com probabilidade (p) de 0,05 e o software utilizado foi o ASSISTAT versão 7.7 (Silva \& Azevedo 2016).

\section{RESULTADOS E DISCUSSÃO}

Os dados de porcentagem de germinação e velocidade de germinação não apresentaram distribuição normal e foram submetidos ao teste de Kruskal-Wallis. Com relação a germinação das sementes, verificou-se que $100 \%$ germinaram nos tratamentos que correspondem à escarificação mecânica com alicate (T4), escarificação mecânica com alicate + adição de ácido giberélico (T5) e imersão em ácido sulfúrico por 15 minutos (T7). Entretanto, para as sementes dos tratamentos T1 (39\%), T2 (27\%) e T3 (24\%) (testemunha, imersão em ácido acético por 12 horas e imersão em ácido acético por 24 horas, respectivamente) não diferiram do tratamento T6 (41\%) imersão em solução de ácido giberélico, respectivamente. Notou-se que os tratamentos com ácido giberélico, combinado ou não com escarificação mecânica, bem como o tratamento com ácido sulfúrico proporcionaram a máxima germinação das espécies (T4, T5 e T7) (Gráfico 1).

Melo et al. (2011) verificaram que para Parkia panurensis Benth., e Parkia velutina Benoist., a escarificação com ácido sulfúrico foi o tratamento mais eficiente para a superação da dormência. Resultado semelhante foi observado em Piptadenia moniliformis Benth., onde a escarificação química com ácido sulfúrico concentrado por 20, 25 e 30 minutos foram mais eficientes na superação da dormência (Azeredo et al., 2010). A escarificação ácida foi também o método mais eficientes para a superação da dormência das sementes de Qualea parviflora Mart., proporcionando maior vigor na germinação e maiores médias de massa seca para as raízes primárias (Gráfico 1). 
Gráfico 1. Porcentagem de Germinação de sementes de Qualea parviflora Mart. coletadas no Parque Estadual do Lajeado, Palmas-TO de Qualea parviflora Mart. de diferentes procedências (Tocantins e Maranhão), submetidas a diferentes tratamentos visando a superação da dormência (Testemunha (T1), Imersão em ácido acético por 12 horas (T2), Imersão em ácido acético por 24 horas (T3), Escarificação mecânica com alicate (T4), Escarificação mecânica com alicate + adição de ácido giberélico (T5), Imersão em solução de ácido giberélico (T6) e Imersão em ácido sulfúrico (T7)). Foi aplicado o teste não paramétrico de Kruskal-Wallis ao nível de $5 \%$ de probabilidade.

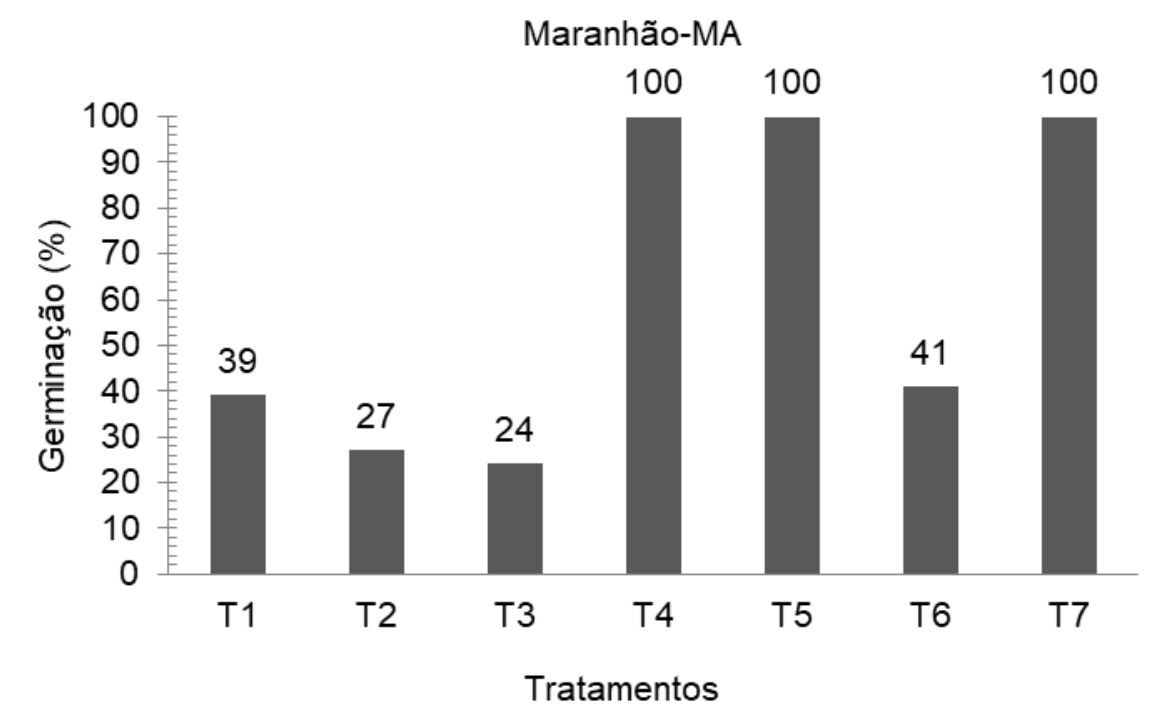

Os dados das primeiras contagens de germinação não apresentaram normalidade e, de acordo com o teste de Kruskal-Wallis, as duas progênies tiveram comportamento semelhante frente aos diferentes tratamentos (Gráfico 2). No tratamento que combinou escarificação mecânica e adição de ácido giberélico (T5), a maior parte das sementes já havia germinado na primeira contagem (segundo dia de teste), com 89\% de germinação das sementes. Nenhuma semente dos tratamentos Testemunha (T1), Imersão em ácido acético por 12 horas (T2), Imersão em ácido acético por 24 horas (T3) e Imersão em solução de ácido giberélico (T6) germinou na primeira contagem, Imersão em ácido acético por 12 horas (T2), Imersão em ácido acético por 24 horas (T3). Os resultados da primeira contagem de germinação evidenciaram a maior germinação com o uso de escarificação química com $\mathrm{H}_{2} \mathrm{SO}_{4}$ ou mecânica (T7, T4), na superação da dormência das sementes de Qualea parviflora. Como pode ser observado no gráfico 2, a imersão em ácido giberélico sem escarificação (T6) não foi suficiente para promover a uniformidade da germinação. A primeira contagem da germinação das sementes que foram submetidas a imersão em ácido acético, por 12 (T2) ou 24 horas (T3) não diferiu da testemunha, indicando que este ácido não foi capaz de causar rompimento no tegumento para permitir a entrada de água. 
Gráfico 2. Primeira contagem de germinação de sementes coletadas no Parque Estadual do Lajeado, Palmas-TO de Qualea parviflora submetidas a diferentes tratamentos visando a superação da dormência (Testemunha (T1), Imersão em ácido acético por 12 horas (T2), Imersão em ácido acético por 24 horas (T3), Escarificação mecânica com alicate (T4), Escarificação mecânica com alicate + adição de ácido giberélico (T5), Imersão em solução de ácido giberélico (T6) e Imersão em ácido sulfúrico (T7)). Foi aplicado o teste não paramétrico de Kruskal-Wallis ao nível de $5 \%$ de probabilidade.

\section{Tocantins-TO}

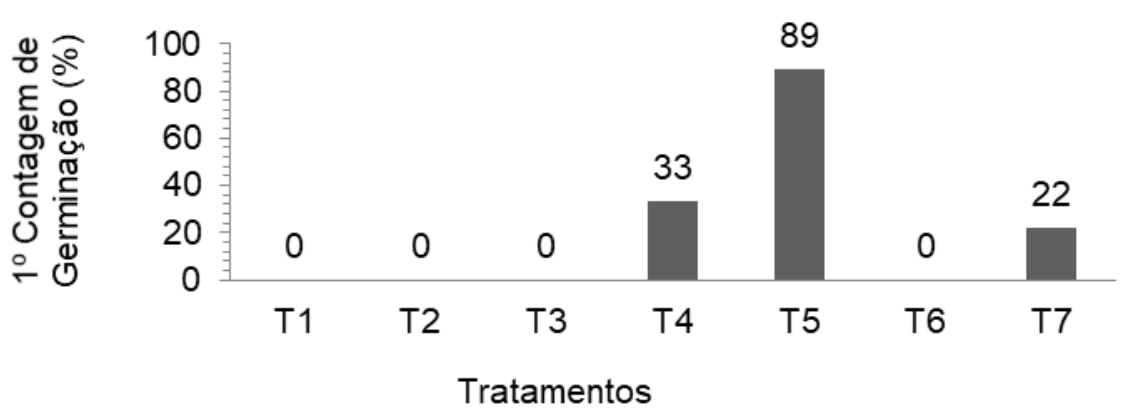

O maior IVE foi obtido quando as sementes foram submetidas ao tratamento que combinou escarificação mecânica com alicate e adição de ácido giberélico (T5). Para Campos et al. (2015) a interação entre a escarificação mecânica e diferentes doses de ácido giberélico (GA3) proporciona aumento na porcentagem de emergência de biribá Rollinia mucosa (Jacq.) Baill, em torno de 30\%.

Contudo, de acordo com os resultados da análise estatística, este tratamento (T5) diferiu apenas da testemunha $(1,545)$ e da imersão em ácido acético por 24 horas T3 (1,677), diferiu apenas dos tratamentos de imersão em ácido acético por 12 horas T2 e $(1,306)$ e imersão em ácido acético por 24 horas T3 $(1,143)$ (Gráfico 3). Este resultado indica que o uso do ácido acético não é apropriado para a superação da dormência das sementes de Qualea parviflora Mart., uma vez que os tratamentos com este ácido não aumentaram o IVG. 
Gráfico 3. Índice de velocidade de germinação de sementes de Qualea parviflora Mart. coletadas no Parque Estadual do Lajeado, Palmas-TO de diferentes procedências (Tocantins e Maranhão), submetidas a diferentes tratamentos visando a superação da dormência (Testemunha (T1) , Imersão em ácido acético por 12 horas (T2), Imersão em ácido acético por 24 horas (T3), Escarificação mecânica com alicate (T4), Escarificação mecânica com alicate + adição de ácido giberélico (T5), Imersão em solução de ácido giberélico (T6) e Imersão em ácido sulfúrico (T7)). Foi aplicado o teste não paramétrico de Kruskal-Wallis ao nível de $5 \%$ de probabilidade.

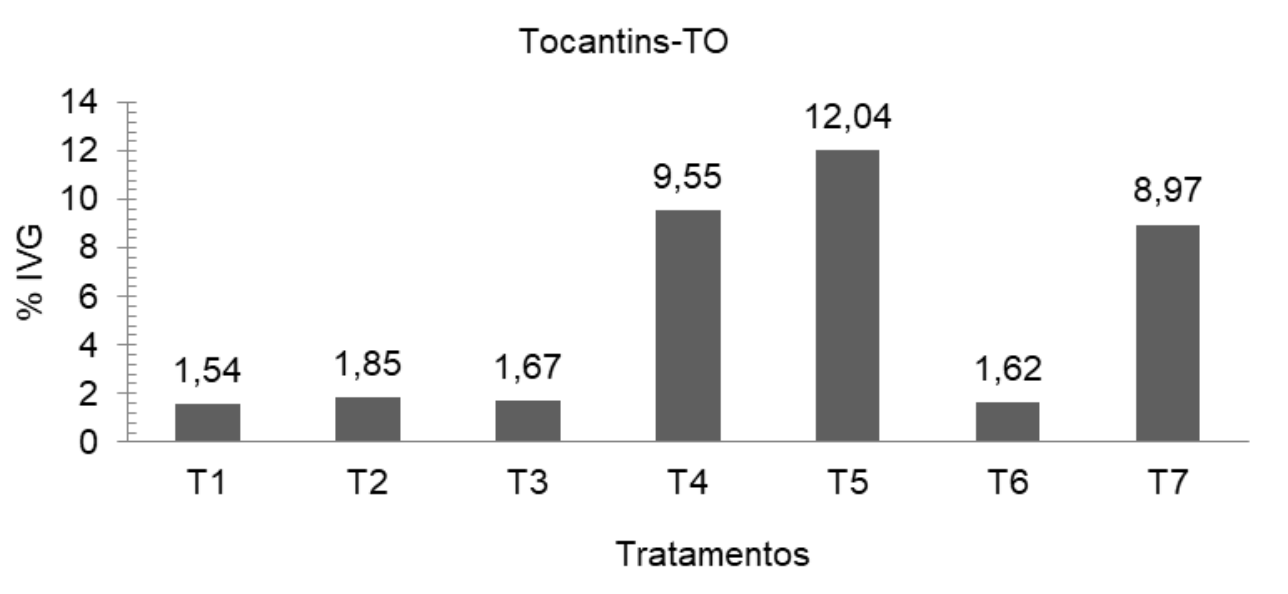

O Tempo Médio de Germinação (TMG) das sementes foi menor no tratamento (T5) escarificação mecânica com alicate + adição de ácido giberélico 2,11 dias, o qual diferiu significativamente da testemunha 10,86 dias e dos T2- tratamento imersão em ácido acético por 12 horas 9,54 dias e T3 tratamento imersão em ácido acético por 24 horas 12,60 dias (Gráfico 4). Estes que corroboram com o trabalho realizado com sementes de Parkia biglobosa Jacq., cujo o tempo médio de germinação foi reduzido com o uso da escarificação mecânica quando comparada à escarificação química (Okunlola et al., 2011). 
Gráfico 4. Sementes coletadas no Parque Estadual do Lajeado, Palmas-TO obtiveram tempo médio de germinação de Qualea parviflora Mart. de diferentes procedências (Tocantins e Maranhão) submetidas a diferentes tratamentos visando a superação da dormência (Testemunha (T1), Imersão em ácido acético por 12 horas (T2), Imersão em ácido acético por 24 horas (T3), Escarificação mecânica com alicate (T4), Escarificação mecânica com alicate + adição de ácido giberélico (T5), Imersão em solução de ácido giberélico (T6) e Imersão em ácido sulfúrico (T7)). Foi aplicado o teste não paramétrico de Kruskal-Wallis ao nível de $5 \%$ de probabilidade. As médias seguidas pela mesma letra, nas colunas de mesma cor, não diferem estatisticamente entre si.

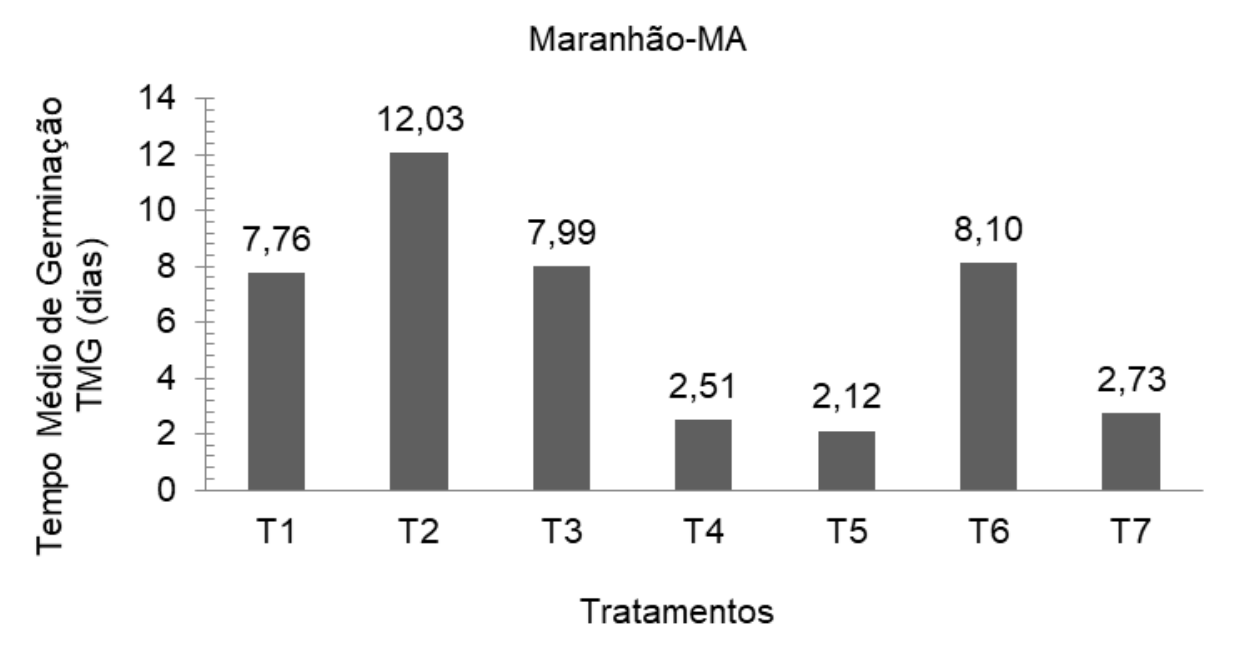

\section{CONCLUSÃO}

Conclui-se que a máxima germinação das sementes de Qualea parviflora Mart. (pau-terra) foi nos tratamentos correspondentes à escarificação mecânica com alicate (T4) e escarificação mecânica com alicate + adição de ácido giberélico (T5), além de concluir-se que o tempo médio de germinação das sementes foram reduzidos para 2,11 dias com a escarificação mecânica com alicate + adição de ácido giberélico.

Portanto, os tratamentos mais eficientes para a superação da dormência das sementes de Qualea parviflora Mart. (pau-terra) foram escarificação mecânica com alicate e escarificação mecânica com alicate + adição de ácido giberélico. 


\section{REFERÊNCIAS}

ALVES, E.U, BRUNO, R. D. L. A., OLIVEIRA, A. D., ALVES, A. U., ALVES, A. U., PAULA, R. D. Influência do tamanho e da procedência de sementes de Mimosa caesalpiniifolia Benth. sobre a germinação e vigor. Revista Árvore; 29 (6): 877-885; 2005.

Alves, A. A., SAles, R. O., Neiva, J. N., Medeiros, A. N., BRAGA, A. P., \& AZEVedo, A. R. Degradabilidade ruminal in situ de vagens de faveira (Parkia platycephala Benth.) em diferentes tamanhos de partículas. Arquivo Brasileiro de Medicina Veterinária e Zootecnia; 59 (4): 1045-1051; 2007.

AZEREDO, G.A., DE PAULA, R.C., VELERI, S.V., MORO, F.V. Superação de dormência de sementes de Piptadenia moniliformis Benth. Revista Brasileira de Sementes, 32(2): 49-5, 2010.

BRANCALION P.H.S, MONDO V.H.V \& NOVEMBRE A.D.LC (2011) Escarificação química para a superação da dormência de sementes de saguaraji-vermelho (Colubrina glandulosa Perk. Rhamnaceae). Revista Árvore, 35:119-124.

BRASIL. Ministério da Agricultura, Pecuária e Abastecimento. Instruções para Análise de Sementes de Espécies Florestais. Ministério da Agricultura, Pecuária e Abastecimento. Secretaria de Defesa Agropecuária. Brasília, DF: Mapa/ACS, 2013; 97p.

BRASIL. Ministério da Agricultura, Pecuária e Abastecimento. Regras para Análise de Sementes. Ministério da Agricultura, Pecuária e Abastecimento. Secretaria de Defesa Agropecuária. Brasília, DF: Mapa/ACS, 2009;

CAMPOS, L.F.C.; ABREU, C.M.A.; GUIMARÃES, R.N. SELEGUINI, A. Escarificação e ácido giberélico na emergência e crescimento de plântulas de biribá. Ciência Rural, Santa Maria, v.45, n.10, p.1748-1754, out, 2015. 395p.

JAYASURIYA, K. G.; WIJETUNGA, A. S.; BASKIN, J. M.; BASKIN, C. C. Gehan et al. Seed dormancy and storage behaviour in tropical Fabaceae: a study of 100 species from Sri Lanka. Seed Science Research, 23(4): 257-269, 2013.

LORENZI, H. Árvores brasileiras: manual de identificação e cultivo de plantas arbóreas do Brasil, v. 2. (2. ed.). Nova Odessa, SP: Instituto Plantarum, 2002.

LORENZI, H. Árvores brasileiras: manual de identificação de cultivo de plantas arbóreas nativas do Brasil. Vol. 2, ed. 4, Nova Odessa, SP: Instituto Plantarum, 2013.

MELO, M. G. G., DE MENDONÇA, M. S., NAZÁRIO, P., MENDES, A.S. Superação de dormência em sementes de três espécies de Parkia sp. Revista Brasileira de Sementes, 2011; 33(3) 533-542.

NASCIMENTO, I. L., ALVES, E. U., BRUNO, R. D. L. A., GONÇALVES, E. P., COLARES, P. N. Q., \& Medeiros, M.S. Superação de dormência em sementes de faveira (Parkia platycephala Benth). Revista Árvore, 2009; 33(1): 35-45.

OKUNLOLA, A. I.; ADEBAYO, R. A.; ORIMOGUNJE, A. D. Methods of braking seed dormancy on germination and early seedling growth of African locust bean (Parkia biglobosa) (JACQ.) Benth. Journal of Horticulture and Forestry, 2011; 3(1): 1-6. 
OliVEIRA, A. K. M.; RIBEIRO, J. W. F.; PEREIRA, K.; RONDON, E. V.; BECKER, T. J. A.; BARBOSA, L. A. Superação de dormência em sementes de Parkia gigantocarpa (Fabaceae-Mimosoidae). Ciência Florestal, Santa Maria, 2012; 22(3): 533-540.

PALHARES, D.; FRANCO, A. C.; ZAIDAN, PENTEADO L.B. Respostas Fotossintéticas de Plantas de Cerrado nas Estações Seca e Chuvosa. Revista Brasileira de Biociência, 2010; 8 (2): 213-220.

PELISSARI, F.; VIEIRA, C. V.; SILVA, CÉLIO JACINTO DA. Germinação de sementes de três espécies do gênero parkia submetidas a diferentes métodos de superação de dormência e temperatura. Revista de Biologia Neotropical, 2013; 10 (1): 28-35.

PEREIRA, S. A.; FERREIRA, SA.N. Superação da dormência em sementes de visgueiro-do-igapó. Revista Acta Amazonica, 2010; 40(1): 151-156.

RAMALHO, C. I.; DE LIMA, F. C., F; PARANAGUÁ, L. A.M.N.; GOMES, G. L. da S. Avaliação de diferentes tratamentos pré-germinativos para sementes de Jatobá do Cerrado (Hymenaea stigonocarpa L.). Revista Brasileira de Meio Ambiente, ano 2019, v. 7, n. 2, p. 2-9

SANO, E. E.; ROSA, R.; BRITO, J. L. S.; FERREIRA, L. G. Mapeamento de Cobertura Florestal do Bioma Cerrado. Boletim de Pesquisa e Desenvolvimento: Embrapa Cerrados, 2008; 205: 60p.

SARMENTO, M.B.; VILLELA, F.A. Sementes de espécies florestais nativas do Sul do Brasil. Informativo ABRATES, 2010; 20(1,2): 39-44.

SILVA, F. A. S.; AZEVEDO, C. A. V. The Assistat software version 7.7 and its use in the analysis of experimental data. African Journal of Agricultural Research, v. 11, n. 39, p. 3733-3740, 2016. 


\section{Capítulo 10}

doi $10.37423 / 210804562$

ANÁLISE DAS CONCENTRAÇÕES DE BIOGÁS EM LIXÃO DESATIVADO NO MUNICÍPIO DE JUAZEIRO DO NORTE-CE

\section{Érika Romana Gomes}

\section{Perboyre Barbosa Alcântara}

Francisco Gleson dos Santos Moreira

\section{Jéssica Bezerra de Sousa}

Instituto Federal de Educacão, Ciência e Tecnologia do Ceará

Instituto Federal de Educação, Ciência e Tecnologia do Ceará

Instituto Federal de Educação, Ciência e Tecnologia do Ceará

Instituto Federal de Educação, Ciência e Techologia do Ceará 
Resumo: Nos lixões o manejo dos resíduos sólidos é feito de forma diferenciada do observado em aterros sanitários e, portanto, a evolução do processo de biodegradação, bem como a composição do biogás pode ser alterada em relação aos aterros sanitários. O estudo da geração e da composição do biogás tem sido feito principalmente em aterros sanitários ou em aterros controlados, entretanto são poucas as informações sobre as suas concentrações em lixões, especialmente, em áreas do semiárido brasileiro. Sendo assim, este trabalho tem como objetivo determinar as concentrações dos principais componentes do biogás $\left(\mathrm{CH}_{4}\right.$ e $\left.\mathrm{CO}_{2}\right)$ no lixão desativado do municipal de Juazeiro do Norte-CE. A investigação de campo, realizada em março de 2011, consistiu da instalação de dispositivos para o monitoramento das concentrações do biogás por meio de um detector de gases (Eagle Series Portable Multi-Gas Detector). Os resultados obtidos indicaram que nos pontos analisados as contrações de metano e de dióxido de carbono são típicas da fase de maturação de aterros sanitários.

Palavras-chave: geração de biogás, lixão, resíduos sólidos urbanos 


\section{INTRODUÇÃO}

A Pesquisa Nacional de Saneamento Básico (PNSB) de 2008 (IBGE, 2010) revelou que de 1989 a 2008 houve um crescimento considerável do percentual de municípios que destinavam seus resíduos aos aterros sanitários e aterros controlados. Entretanto, apesar dos avanços no Brasil, na Região Nordeste a situação da destinação final dos resíduos sólidos urbanos (RSU) ainda é muito crítica. Em 89,3 \% dos municípios nordestinos os lixões são utilizados para o destino final dos resíduos sólidos, a exemplo do que ocorre no município de Juazeiro do Norte e na imensa maioria dos municípios do estado do Ceará.

Nos aterros sanitários a fase gasosa é constituída inicialmente, em grande parte, pelo ar atmosférico incorporado aos vazios dos resíduos durante os procedimentos operacionais de aterramento. Com a evolução do processo de biodegradação há uma alteração na composição da fase gasosa, devido à atuação dos diversos grupos microbianos que promovem a transformação de compostos orgânicos complexos em substâncias gasosas mais simples (ALCÂNTARA, 2007). Como bem afirma El-fadel et al. (1997), o aterro é um meio de interações multifase no qual cada uma das fases apresenta significativa variação no tempo e no espaço. Na fase aeróbia inicial, o $\mathrm{CO}_{2}$ é produzido numa taxa proporcional ao consumo de oxigênio $\left(\mathrm{O}_{2}\right)$, enquanto a redução do nitrogênio é relativamente pequena. Após o consumo de $\mathrm{O}_{2}$ e o estabelecimento inicial de condições anaeróbias, verifica-se uma redução brusca das concentrações de $\mathrm{N}_{2}$ e já são produzidas quantidades relativamente altas de $\mathrm{CO}_{2}$. Apesar da redução de $\mathrm{N}_{2}$ e da produção de hidrogênio $\left(\mathrm{H}_{2}\right)$, o metano ainda não é produzido na fase de transição. $\mathrm{Na}$ fase ácida, intensifica-se a atividade microbiana, e o $\mathrm{CO}_{2}$ é o principal gás gerado. Também são produzidas pequenas quantidades de $\mathrm{H}_{2}$ e em alguns casos, já se verifica o início da produção de metano. Com a evolução do processo de degradação, se intensifica, na fase seguinte, a atividade dos microrganismos metanogênicos que convertem ácido acético, $\mathrm{CO}_{2}$ e $\mathrm{H}_{2}$ em $\mathrm{CH}_{4}$ e $\mathrm{CO}_{2}$. Após a conversão em $\mathrm{CH}_{4}$ e $\mathrm{CO}_{2}$ de praticamente todo o material biodegradável, segue a fase de maturação final caracterizada pela redução considerável da taxa de geração de gás e pelo ressurgimento de $\mathrm{N}_{2} \mathrm{e}$ $\mathrm{O}_{2}$ (FARQUHAR \& ROVERS, 1973; REES, 1980; POHALAND e HARPER, 1985; TCHOBANOGLOUS, et al., 1993).

A geração e a composição do biogás nos aterros dependem, fundamentalmente, da composição dos resíduos, mas a taxa de bioconversão do material orgânico em biogás pode ser influenciada por diversos outros fatores que incluem aspectos ambientais, o manejo do aterro e os parâmetros físicoquímicos, que estão na maioria das vezes, relacionados entre si (ALCÂNTARA e JUCÁ, 2011). Nos lixões, como o manejo dos resíduos é feito de forma diferenciada do observado em aterros sanitários, 
a evolução do processo de biodegradação, bem como a composição do biogás pode ser alterada em relação aos aterros sanitários. O estudo da geração e da composição do biogás tem sido feito principalmente em aterros sanitários ou em aterros controlados, entretanto são poucas as informações sobre as suas concentrações em lixões especialmente, em áreas do semiárido brasileiro. Sendo assim, o presente trabalho tem como objetivo determinar as concentrações dos principais componentes do biogás (metano e dióxido de carbono) em um lixão desativado no municio de Juazeiro do Norte-CE, contribuindo assim para uma melhor compreensão do processo de biodegradação do lixo urbano depositado nos vazadouros a céu aberto e para uma melhor avaliação do potencial de emissão de gases de efeito estufa nessas áreas.

\section{MATERIAL E MÉTODOS}

\section{CARACTERÍSTICAS GERAIS E LOCALIZAÇÃO DA ÁREA DE ESTUDO}

O município de Juazeiro do Norte - CE com uma população de 249.936 habitantes (IBGE, 2010), situase na Região Metropolitana do Cariri e fica na porção sul do estado do Ceará, limitando-se com os municípios de Caririaçu, Missão Velha, Barbalha e Crato (Figura 1). Compreende uma área de 219 km², localizada na carta topográfica Crato (SB.24-Y-D-I) (CEARÁ, 2003; BRASIL, 1998), com uma área urbanizada de aproximadamente $12,7 \mathrm{~km}^{2}$ (MIRANDA, et al. 2005). Do ponto de vista políticoadministrativo o município, está incluído na Macrorregião de Planejamento Cariri Centro-Sul, Mesorregião Sul Cearense e na Microrregião do Cariri (CEARÁ, 2010).

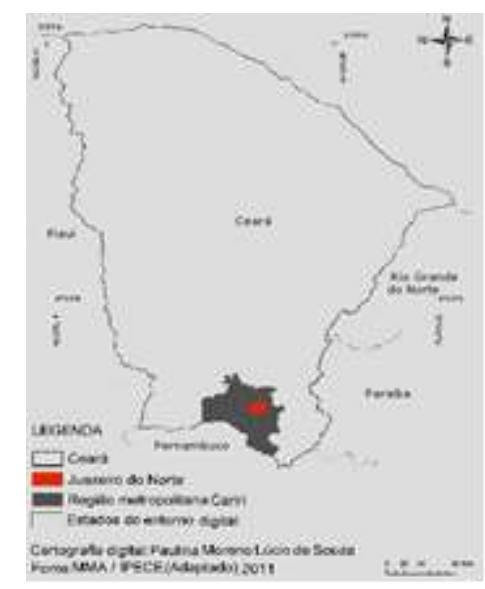

Figura 1: Localização do município de Juazeiro do Norte-CE.

O município de Juazeiro do Norte - CE está assente sobre coberturas sedimentares mesozóicas e sobre o embasamento cristalino. O substrato do território é formado por xistos, quartzitos e granitos do PréCambriano indiviso, conglomerados e arenitos do Paleozóico e arenitos e calcários do Mesozóico. Dois 
compartimentos morfológicos são observados no município: as formas aplainadas, pouco dissecadas da Depressão Sertaneja e a sul, mais destacado na topografia, o relevo de planalto da chapada do Araripe. Solos aluviais e podzólicos são registrados na área, e a vegetação que sobre eles encontra-se desenvolvida é a de caatinga arbórea (floresta caducifólia espinhosa) e de cerrado (BRASIL, 1998; CEARÁ, 2010). O clima do município é caracterizado como Tropical Quente Semi-árido e Tropical Quente Semi-árido Brando com precipitação média anual de 925,1 mm, distribuída, principalmente, nos meses de janeiro a maio, e temperatura média de 24 C a 26 C (CEARÁ, 2010). Cálculos de balanço hídrico mostram um excesso da precipitação sobre a evapotranspiração nos meses de janeiro a abril, e déficit no restante do ano.(BRASIL, 1998).

\section{ÁREA DE ESTUDO}

A área de estudo, antigo lixão, se localiza a cerca de $250 \mathrm{~m}$ da rodovia CE 060 à, aproximadamente, 4,5 km do centro da cidade. A área situa-se mais ao norte do município em uma região de domínio cristalino. A morfogênese do local é comandada pelas condições de semiaridez, verificam-se processos intensos de intemperismo físico e remoção de detritos pelo escoamento difuso e concentrado, um pequena espessura do manto de alteração das rochas com afloramentos em alguns pontos e predomínio de neossolos litolíticos. A cobertura vegetal predominante é caracterizada por caatinga com mudanças localizadas em função de alterações e de variações pedológicas. As operações de disposição final de resíduos sólidos no antigo vazadouro, foram encerradas a aproximadamente oito anos, mas não foi implementado um plano de recuperação da área ou de contenção para evitar a contaminação das áreas do entorno. Os resíduos foram cobertos com uma fina camada de solo que com a erosão superficial, deixa a vista parte dos resíduos aterrados. A área, visivelmente contaminada, tem sido utilizada para a agricultura como mostra a Figura 2, na qual é possível observar as culturas de milho e feijão, colhidas na safra de 2011.

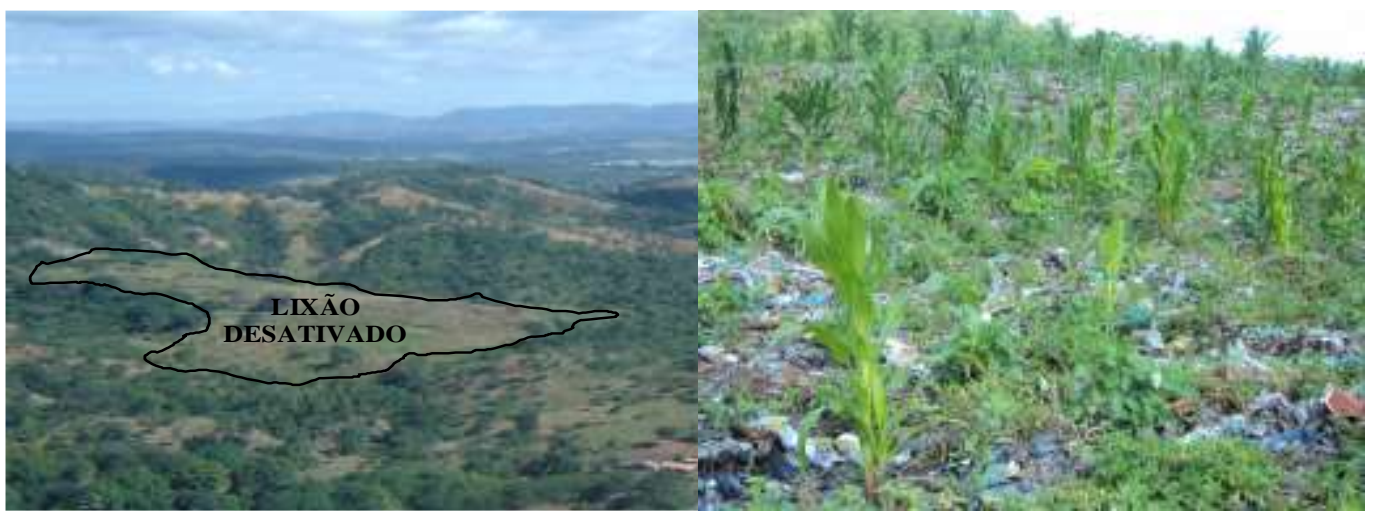

Figura 2: Vista aérea do antigo lixão de Juazeiro do Norte-CE e detalhe de plantações de grãos. 


\section{PROCEDIMENTOS DE INVESTIGAÇÃO DE CAMPO}

A investigação de campo, realizada em março de 2011, teve como principal objetivo a determinação das concentrações de gases provenientes do processo de biodegradação dos resíduos sólidos depositados no antigo vazadouro a céu aberto. Para isso, inicialmente, foi feito um levantamento na área de estudo visando à identificação dos pontos para a medição das concentrações de gases, que foram designados por P1, P2 e P3. Posteriormente, em cada ponto, foi instalado um dispositivo de medição conforme ilustrado na Figura 3.

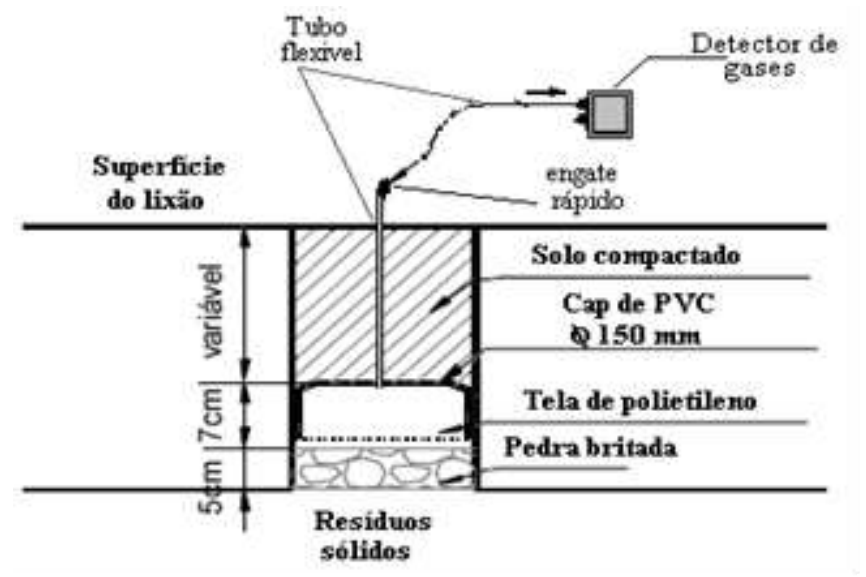

Figura 3: Esquema ilustrativo da instalação de aparato para leitura do biogás.

(modificado de MACIEL, 2003).

Para a instalação de cada dispositivo foi feito um furo superficial na camada de cobertura de solo até atingir a massa de lixo sobre a qual se colocou uma camada de brita com espessura de, aproximadamente, $5 \mathrm{~cm}$. Em seguida foi inserido um CAP de PVC (diâmetro de $150 \mathrm{~mm}$ e altura de 70 $\mathrm{mm}$ ) com uma tela na parte inferior para evitar obstrução do mesmo. Na parte superior do CAP instalou-se um tubo flexível para a conexão do equipamento de leitura do biogás, como ilustrado na Figura 4. A Figura 5 apresenta a localização aproximada dos dispositivos para leitura do biogás. 


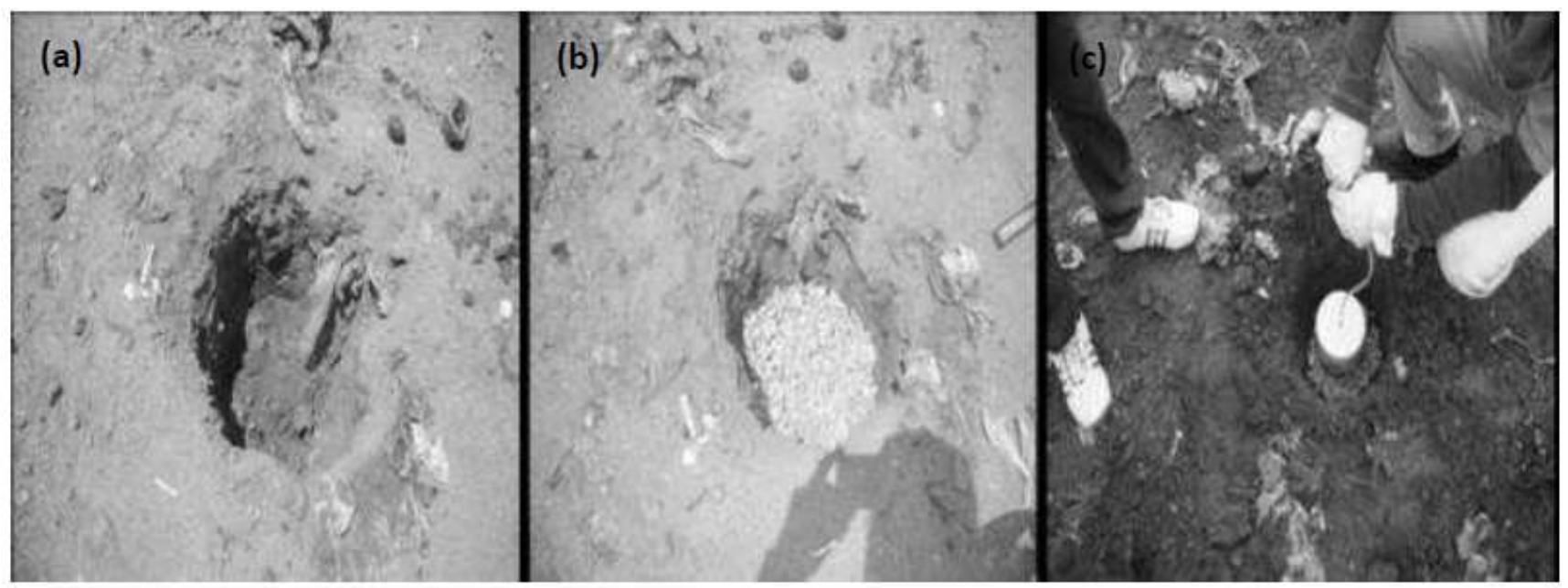

Figura 4: Instalação do aparato para leitura do biogás: a) Furo na camada de cobertura de solo; b) Adição de camada de brita; c) Inserção do CAP de PVC.

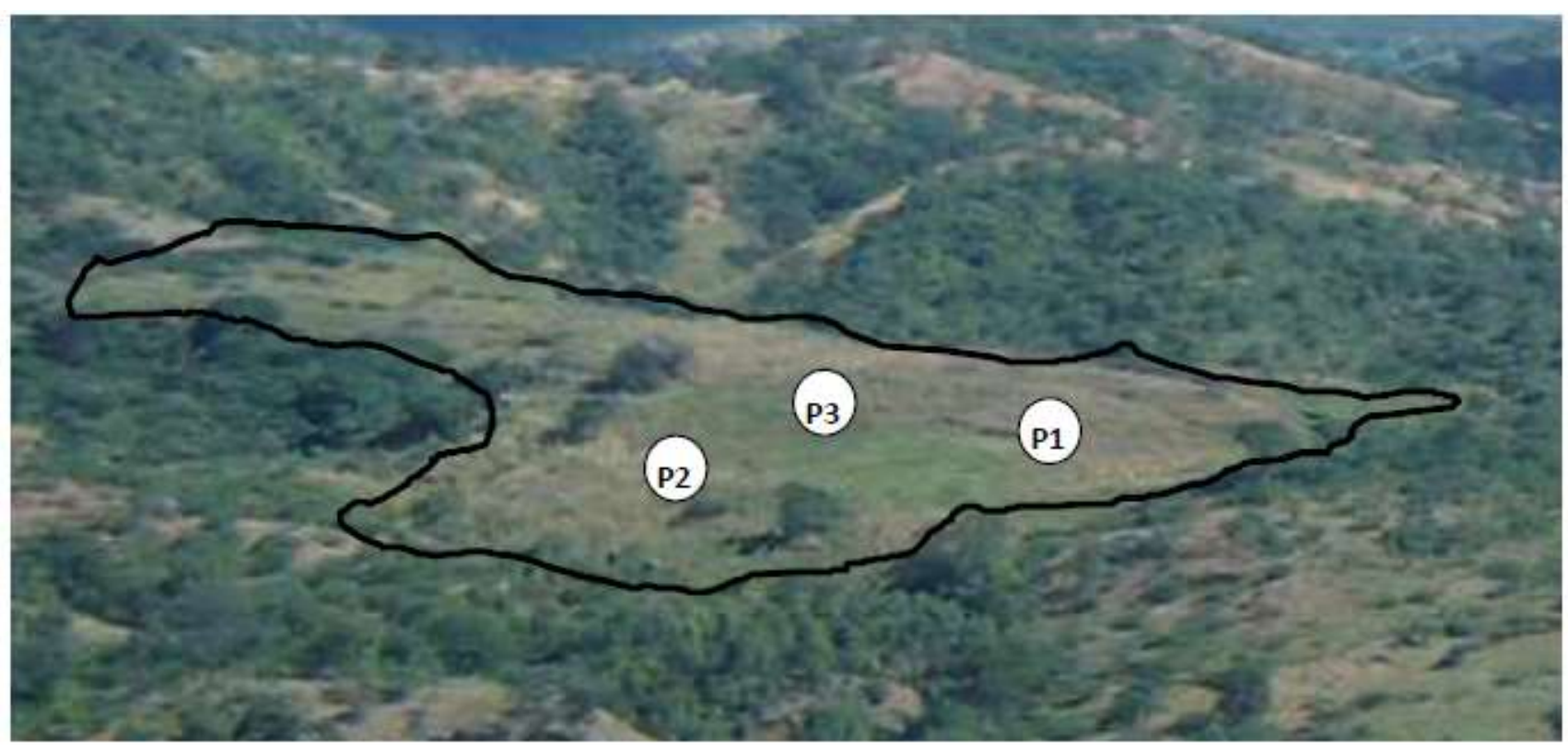

Figura 5: Localização dos dispositivos de leitura de gases na área do lixão desativado.

A estimativa das concentrações de metano $\left(\mathrm{CH}_{4}\right)$ e dióxido de carbono $\left(\mathrm{CO}_{2}\right)$, fez-se por meio de um detector de gases (Eagle Series Portable Multi-Gas Detector) dotado de um sistema de sucção acionado automaticamente, conforme ilustrado na Figura 6. As leituras foram realizadas em todos os pontos, sendo os valores expressos em porcentagem de volume (\% VOL.) e, para baixas concentrações, em partes por milhão (ppm). A detecção de metano e de dióxido de carbono é feita através de um sensor IR com faixa máxima de leitura de $0 \%-100 \%$ e $0 \%-50 \%$ (Tabela 1 ) respectivamente. A Figura 6 ilustra a medição das concentrações de $\mathrm{CH}_{4}$ e $\mathrm{CO}_{2}$ no ponto P3. 


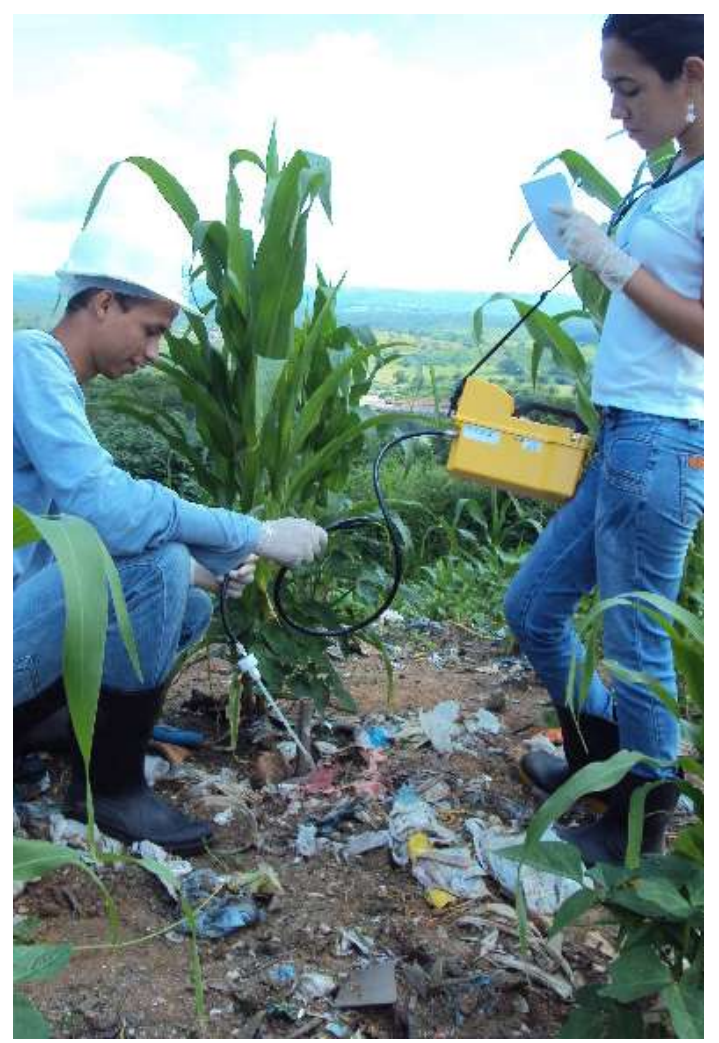

Figura 6: Leitura das concentrações do biogás no antigo lixão de Juazeiro do Norte-CE.

Tabela 1: Indicação da faixa de leitura dos sensores de gás.

\begin{tabular}{r|c}
\hline Sensor de gás & Faixa de mediç \\
\hline & $0-5000 \mathrm{ppm}$ \\
& $0-10000 \mathrm{ppm}$ \\
Dióxido de carbono- C & $0-5 \%$ Vol. \\
(IR Sensor) & $0-20 \%$ Vol. \\
& $0-50 \%$ Vol. \\
\hline Metano- $\mathrm{CH}_{4}$ (IR Sens & $0-100 \% \mathrm{LEL}$ \\
& $0-100 \%$ Vol. \\
\hline
\end{tabular}

\section{RESULTADOS E DISCUSSÃO.}

As análises realizadas indicaram que o biogás nos pontos P1e P2 (Figura 7) não apresentou concentrações de metano e apresentou concentrações de $\mathrm{CO}_{2}$ no ponto $\mathrm{P} 1$ de $0,4 \%$ e $6,8 \%$ em apenas duas leituras e no ponto P2 de 2,8 \%, 2,4 \% e 2,7 \% em três leituras (Figura 7). Em condições anaeróbias, a biodegradação da fração orgânica dos resíduos produz o biogás que é composto, principalmente, por $\mathrm{CH}_{4}$ e $\mathrm{CO}_{2}$, além de traços de outros gases. $\mathrm{O}$ monitoramento dos gases gerados em aterros sanitários serve para analisar a evolução do processo de decomposição da matéria orgânica. Vários autores admitem, de forma conceitual, que a biodegradação de RSU em aterros ocorre em, até, cinco etapas seqüenciais: i) fase aeróbia inicial; ii) fase de transição; iii) fase ácida 
anaeróbia; iv) fermentação metânica e v) fase de maturação. As leituras nos pontos P1 e P2 são típicas do final da fase de maturação. Nessa fase, considerada a última do processo de degradação em aterros, ocorre a redução da atividade biológica em virtude da escassez de nutrientes, uma vez que a maioria dos compostos orgânicos de rápida e média degradação sob condições anaeróbias já foi convertida em biogás ou retirados do meio juntamente com o lixiviado, restando, apenas, matérias de degradação lenta e inertes. A fase de maturação é caracterizada pela redução na produção de $\mathrm{CH}_{4}$, $\mathrm{CO}_{2}$ e pelo aumento nas concentrações de $\mathrm{O}_{2}$ e $\mathrm{N}_{2}$ (ALCÂNTARA, 2007). Em aterros sanitários a evolução das concentrações desses gases pode durar décadas até atingir a fase de maturação. Entretanto, no lixão em estudo, a exemplo de outros vazadouros a céu aberto, não é era feita a cobertura diária do lixo com solo o que contribuiria para a infiltração de grande quantidade de água de chuvas e lixiviação da matéria orgânica. A falta de cobertura diária e a compactação inadequada do lixo também possibilitam que as transformações biológicas da matéria orgânica complexa em produtos mais simples ocorram, nos lixões, em condição semi-aeróbia alterando assim a evolução do processo de biodegradação da matéria orgânica, em relação ao observado nos aterros sanitários. Por outro lado, em lixões, frequentemente, ocorre a queima dos resíduos com conseqüente redução dos materiais biodegradáveis em algumas áreas o que também contribuiria para a redução das concentrações do biogás em um tempo bem inferior ao observado nos aterros sanitários. Finalmente, vale ressaltar que os valores nulos de $\mathrm{CH}_{4}$ e muito baixos de $\mathrm{CO}_{2}$ nos pontos $\mathrm{P} 1$ e $\mathrm{P} 2$, também podem ser decorrentes da presença de uma elevada concentração de resíduos industriais que eram dispostos no lixão, especialmente resíduos da indústria de calçados que são de difícil biodegradação. 


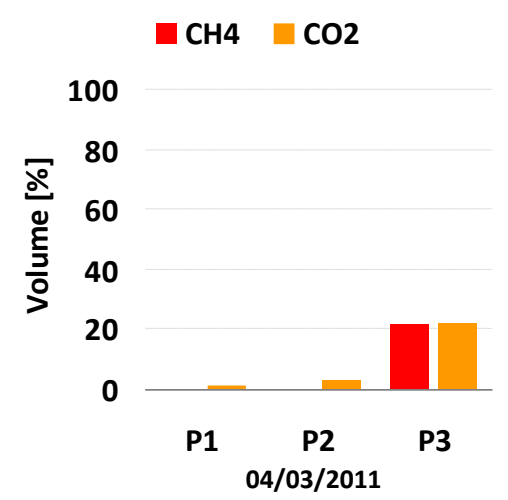

(a)

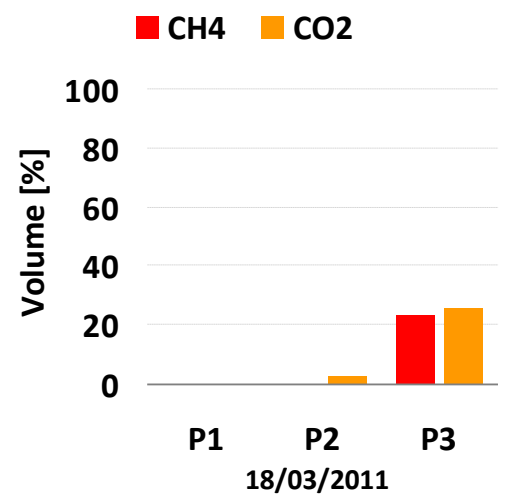

(c)

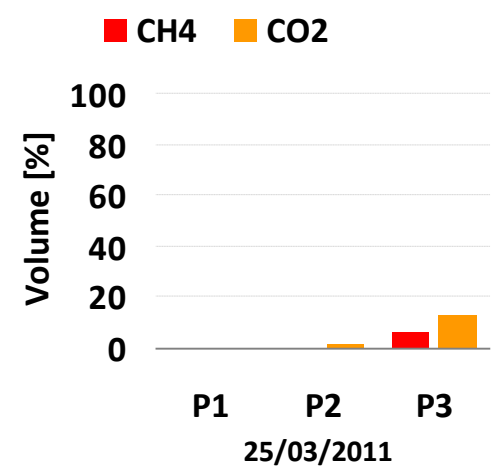

(e)

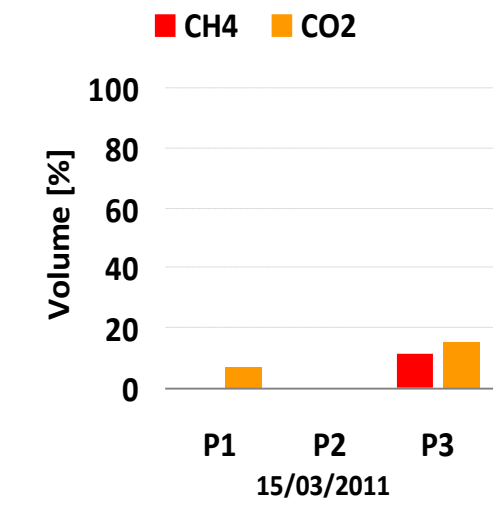

(b)

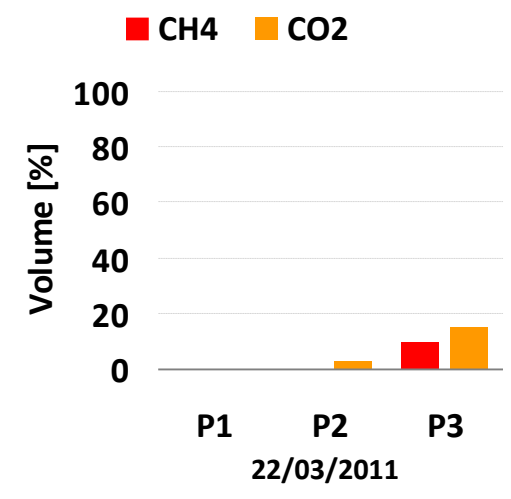

(d)

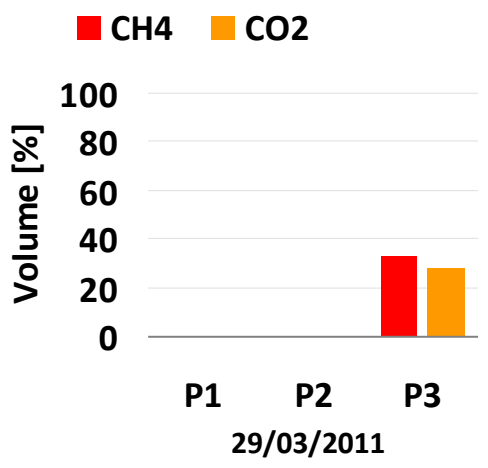

(f)

Figura 7: Leitura das concentrações de gases nos pontos P1, P2 e P3.

No ponto P3 foram observadas concentrações de metano e de dióxido de carbono em todas as leituras. Os valores de $\mathrm{CO}_{2}$ variaram de $13 \%$ a $28 \%$ e os de $\mathrm{CH}_{4}$ ficaram na faixa de $6 \%$ a $33 \%$ (Figura 7). Esses valores, mais elevados, ainda seriam típicos do trecho médio da fase de maturação. Na fase de fermentação metânica que antecede a fase de maturação acentua-se a atividade dos microrganismos acetotróficos e hidrogenotróficos produtores de metano e as concentrações de metano e $\mathrm{CO}_{2}$ atingem, respectivamente, valores numa faixa de $50 \%-70 \%$ e $30 \%-50 \%$ do volume do biogás produzido. Valores estes que começam a cair no início da fase de maturação. Nota-se ainda na Figura 7, uma variação considerável nas concentrações medidas que pode estar associado, entre outros fatores, às condições de umidade do solo de cobertura. As maiores leituras, especialmente, de 
metano foram verificadas quando o solo apresentava um teor de umidade mais elevado. Nessa condição se reduz consideravelmente a permeabilidade do solo ao gás o que justificaria uma maior retenção de gás na massa de lixo com a redução das emissões através da camada de cobertura.

\section{CONCLUSÃO}

Considerando os pontos analisados e as concentrações de metano e de dióxido de carbono medidas, pode-se concluir que o processo de biodegradação da matéria orgânica no antigo lixão encontra-se na fase (intermediária e final) de maturação que é caracterizada pela redução considerável da taxa de geração de biogás.

\section{AGRADECIMENTOS}

Os autores agradecem à Fundação Cearense de Apoio ao Desenvolvimento Científico e Tecnológico (FUNCAP), pelo apoio financeiro que possibilitou o desenvolvimento deste trabalho de pesquisa. 


\section{REFERÊNCIAS}

ALCÂNTARA, P.B. Avaliação da influência da composição de resíduos sólidos urbanos no comportamento de aterros simulados. Tese (doutorado) Departamento de Engenharia Civil, Universidade Federal de Pernambuco. Recife, 2007.

ALCÂNTARA, P. B, JUCÁ, J. F. T. Recalque em aterros: influência da composição dos resíduos sólidos urbanos, do clima e da biodegradação. Geotecnia (Lisboa), 2010.

BRASIL, MINISTÉRIO DE MINAS E ENERGIA, CPRM - Serviço Geológico do Brasil. Programa de Recenseamento de Fontes de Abastecimento por Água Subterrânea no Estado do Ceará. Diagnóstico do Município de Juazeiro Do Norte, 1998.

CEARÁ, Secretaria do Planejamento e Gestão (SEPLAG), Instituto de Pesquisa e Estratégia Econômica do Ceará ( IPECE) Perfil Básico Municipal - Juazeiro do Norte, Fortaleza-CE, 2010.

EL-FADEL, M.; FINDIKAKIS, A. N.; LECKIE, J. O. Gas simulation models for Solid Waste Landfills". Crit. Rev.Environ. Sci. Technol. v. 27, n.3, p. 237-283, 1997.

FARQUHAR, G. H.; ROVERS, F. A. Gás production during refuse decomposition. Water Air Soil Pollut. v.2, p.483-495, 1973.

INSTITUTO BRASILEIRO DE GEOGRAFIA E ESTATístICA - IBGE, Pesquisa Nacional de Saneamento Básico 2008 - PNSB. Rio de Janeiro 2010.

MIRANDA, E. E. de; GOMES, E. G. GUIMARÃES, M. Mapeamento e estimativa da área urbanizada do Brasil com base em imagens orbitais e modelos estatísticos. Campinas: Embrapa Monitoramento por Satélite, 2005.

MACIEL, F. J. Estudo da geração, percolação e emissão de gases no aterro de resíduos sólidos da Muribeca/PE. 158 p. Dissertação (mestrado) - Universidade Federal de Pernambuco. Recife, 2003.

MACIEL, F. J., \& , JUCÁ, J. F. T. (2011). Evaluation of landfill gas production and emissions in a MSW large-scale Experimental Cell in Brazil . Waste Management, 31 966-977

POHLAND, F.G.; HARPER, S.R. Critical review and summary of leachate and gas production from landfills. Cincinnati: US Environmental Protection Agency, 1985. EPA/600/2-86/07.

TCHOBANOGLOUS, G.; THEISEN, H.; VINIL S. Integrated solid waste management : engineering principles and management issues. New York : Irwin MacGraw-Hill, 1993. 978 p.

REES, J.F. The fate of carbon compounds in the landfill disposal of organic matter. J. Chem. Technol. Biotech. v. 30, p. 161-175, 1980. 


\section{Capítulo 11}

doi) $10.37423 / 210804566$

\section{A REFLECTÂNCIA DO MATERIAL PLÁSTICO EM PROL DA GERAÇÃO DE TECNOLOGIAS LIMPAS}

Sebastião Leandro de Souza

Juliana Verçosa Batinga

Vicente Rodolfo Santos Gezar

Renato de Mei Romero

José Aparecido da Silva Gama

Adelmo Lima Bastos
Instituto Federal de Alagoas, Campus

Marechal Deodoro.

Instituto Federal de Alagoas, Campus Marechal Deodoro

Instituto Federal de Alagoas, Campus Marechal Deodoro

Instituto Federal de Alagoas, IFAL, Campus Marechal Deodoro

Instituto Federal de Alagoas - Campus Marechal Deodoro

Instituto Federal de Alagoas- Campus Marechal Deodoro 
Resumo: O Litro Luz é um processo artesanal de captação de energia solar, feito com materiais que seriam descartados; gera vantagens ao ser utilizado, já que preserva o meio ambiente, evitando o descarte desse material em áreas, muitas vezes, impróprias. Este trabalho teve como objetivo a implantação da tecnologia do Litro Luz que visa estabelecer a diminuição no consumo de energia em comunidade de baixa renda. O experimento foi conduzido no Povoado Massagueira de Baixo, localizado no município de Marechal Deodoro, onde colheu se dados durante dois meses (janeiro e fevereirode2012). Para a montagem do Litro Luz, foram utilizados os seguintes materiais: garrafa pet; telha de argila ou de amianto; adesivo para vedação(cola); água potável; cloro; invólucro de filmes. A montagem do experimento teve a seguinte metodologia: primeiro projetou-se na telha de amianto, uma circunferência no mesmo diâmetro da garrafa Pet; recortou-se a telha com a makita seguindo a circunferência; a garrafa foi introduzida na telha e fixada com cola para vedação; posteriormente colocou-se água potável e $10 \mathrm{ml}$ de cloro; foi vedado com a caixinha escura de embalagem de filmes; esperou-se a secagem por doze horas e logo após prendeu-se ao telhado, deixando exposta ao sol, apenas $1 / 4$ da garrafa. Na telha de amianto, o processo é bem mais simples para fazer o corte. O que mudou foi à ferramenta de corte, tipo furadeira tico-tico. Outra consideração a ser feita é que foi realizado na parte do desenho mais alto da telha, para que a água da chuva não ficasse represada na telha. Foi elaborado um questionário sócio econômico de 10 casas da localidade. Observou-se que a casa que teve o menor índice de redução foi de 03 kwh e o maior de 41 kwh. A média de redução da energia nas residências foi de 13,1 KWH. A maior redução ocorreu com o valor de $\mathrm{R} \$ 17,51$ (casa 02 ) e o menor valor de $\mathrm{R} \$ 1,28$ (casa 4). A média das 10 residências ficou no valor de $\mathrm{R} \$$ 5,60. Observouse que a grande maioria da população local é do sexo feminino (64\%), enquanto que os homens representam apenas 36\%. Observou-se que a grande maioria da população local não estuda 43,63\%; uma outra classe considerável, é a que possui educação fundamental, onde a média foi de $27,27 \%$. Conclui-se que houve eficiência do uso do Litro Luz com a redução dos kwh e dos respectivos valores em reais. Os dados de que a diminuição do consumo de energia, comparado ao mês anterior à implantação demonstram que Litro Luz nas residências, foi favorável.

Palavras-chave: diagnóstico sócio econômico, energia alternativa, litro luz. 


\section{INTRODUÇÃO}

Sabe-se que o planeta está passando por um momento crítico em relação ao meio ambiente, sofrendo crises que causam desproporcionalidade e que a humanidade ainda não tinha presenciado. As alterações climáticas tornam-se foco de discussões em que a intervenção do homem na natureza é palco principal. Algumas dessas ações podem ser vistas como consequência do desenvolvimento e do progresso. Tecnologias surgem todos os dias seja em prol do homem quanto a favor da ciência, tampouco se observa as leis que venham punir àqueles que infringem as regras tidas como leis, causando queimadas, pesca predatória, assoreamento de rios, emissão de gases maléficos na atmosfera e outros meios de impactos ambientais.

Sabe-se que esse processo não se dá de forma correta e justa, onde a distribuição é parcial e quem paga por isso é uma sociedade leiga, que não sabe dos seus direitos e deveres. Florestas são transformadas em condomínios fechados, praias são transformadas em áreas privada, manguezais são transformados em loteamentos e, assim, vai se acabando o pouco que resta de um ecossistema,que pede socorro. O trabalho em destaque é a implantação do projeto Litro Luz, que vem com o propósito de reduzir energia representando um valor significativo ao término do trimestre e traz uma grande vantagem de manutenção.

O Litro Luz é um processo artesanal de captação de energia solar. Feito com materiais que seriam descartados, gera vantagens ao ser utilizado, já que preserva o meio ambiente, evitando o descarte desse material em áreas, muitas vezes, impróprias. Ao implantar o Litro Luz, obtêm-se vantagens, pois além da conta de energia ficar mais acessível, as lâmpadas alocadas nas residências tem vida útil aumentada para aproximadamente 12 meses.

O processo atual de desenvolvimento do país e do mundo, de uma maneira geral, ainda é baseado em um modelo socioeconômico onde concentra a riqueza na mão de alguns poucos e deixa a grande maioria em condições desiguais, além de ser um sistema que utiliza dos recursos naturais para manter a geração de economia atual (BASTOS et al., 2021).

Além de diversos aspectos relacionados aos padrões de consumo e outros bens e serviços, acontece que as cidades crescem e expandem as áreas urbanas, trazendo consigo alterações e degradações no meio ambiente, e isso é ainda mais grave no litoral, onde tais procedimentos vinculados à vulnerabilidade dos ambientes naturais compõem um cenário de grandes impactos socioambientais negativos (SILVA, GAMA \& BASTOS, 2021). 
Este trabalho teve como objetivo a implantação da tecnologia do Litro Luz que visa estabelecer a diminuição no consumo de energia em comunidade de baixa renda.

\section{MATERIAL E MÉTODOS}

O experimento foi conduzido no Povoado Massagueira de Baixo, localizado no município de Marechal Deodoro, com área de 363,3 km2, localização - Litoral Sul, com população de 28.215 habitantes, clima tropical quente e úmido, temperatura média $26^{\circ} \mathrm{g}$, dista da capital Maceió - 28,2 km e acesso pela AL 101 Norte e AL 215.

O povoado possui 71 residências e em 10 casas foi implantado o Projeto Litro Luz, perfazendo um total de $14,08 \%$. Este povoado foi selecionado em virtude de se ser ter uma idéia abstrata que seria uma comunidade de baixa renda. O projeto foi implantado no mês de dezembro de 2011, onde se colheu dados durante dois meses (janeiro e fevereiro de 2012).

\subsection{IMPLANTAÇÃO}

A confecção do Litro Luz tem por finalidade tornar compensador o processo de energia alternativa, tendo em vista que é feito com materiais que iriam para descarte, tais como: garrafa pet, pote de filme, água potável e um tipo de adesivo para vedação; foi utilizados objetos perfuro/cortante, tipo furadeira, tico-tico e makita com lâmina para azulejo, além de material de segurança como óculos, luvas e máscaras.

Para a montagem do Litro Luz, foram utilizados os seguintes materiais:

- Garrafa Pet;

- Telha convencional ou de amianto;

- Adesivo para vedação (cola);

- Água potável;

- Cloro;

- Invólucro de filmes.

\subsection{TELHA CONVENCIONAL (ARGILA)}

A montagem do experimento teve a seguinte metodologia: primeiro projetou-se na telha, uma circunferência no mesmo diâmetro da garrafa Pet; recortou-se a telha colonial com a makita seguindo a circunferência; a garrafa foi introduzida na telha e fixada com cola para vedação; posteriormente colocou-se água potável e $10 \mathrm{ml}$ de cloro; foi vedado com a caixinha escura de embalagem de filmes; 
esperou-se a secagem por doze horas e logo após prendeu-se ao telhado, deixando exposta ao sol, apenas $1 / 4$ da garrafa.

Com essa tecnologia ocorreu o processo da refração da luz, com um gasto mínimo e, consequentemente, aprimorando o conhecimento e aproveitando materiais que seriam descartados, prejudicando o meio ambiente.

\subsection{TELHA DE AMIANTO}

Na telha de amianto, o processo é bem mais simples para fazer o corte. O que mudou foi à ferramenta de corte, tipo furadeira tico-tico. Outra consideração a ser feita é que foi realizado na parte do desenho mais alto da telha, para que a água da chuva não ficasse represada na telha. Foi elaborado um questionário com a comunidade para obter-se informações de cunho sócio-ambiental enfatizando que não houve gastos com o projeto.

\subsection{AVALIAÇÃO DO SISTEMA}

Fez-se uma comparação com os dois mesmos meses do ano anterior (janeiro e fevereiro de 2011), através dos recibos de energia das casas para analisar a vantagem real do projeto na comunidade. 0 valor adotado do KWH foi de 0,427101 (valor identificado na conta de energia).

\section{RESULTADOS E DISCUSSÃO}

Observa-se na Tabela 1 os dados colhidos previamente e que foram usados no comparativo com os meses idênticos do ano seguinte.

Tabela 1 - Dados colhidos antes da implantação (5 a 10 de dezembro 2011).

\begin{tabular}{|l|l|}
\hline Casas & DEZEMBRO 2011 \\
\hline 1 & $96 \mathrm{KWH}$ \\
\hline 2 & $181 \mathrm{KWH}$ \\
\hline 3 & $96 \mathrm{KWH}$ \\
\hline 4 & $33 \mathrm{KWH}$ \\
\hline 5 & $104 \mathrm{KWH}$ \\
\hline 6 & $139 \mathrm{KWH}$ \\
\hline 7 & $85 \mathrm{KWH}$ \\
\hline 8 & $145 \mathrm{KWH}$ \\
\hline 9 & $186 \mathrm{KWH}$ \\
\hline
\end{tabular}


Os dados foram colhidos em dez residências no bairro de Massagueira de Baixo a fim de subsidiar as informações para exploração dos objetivos do projeto.

Na Tabela 2 observa-se o comparativo de consumo de energia entre dezembro de 2011 e janeiro de 2012.

Tabela 2 - Comparativo da medição de consumo de energia (dezembro/2011 e janeiro 2012).

\begin{tabular}{|c|c|c|c|}
\hline Casas & DEZEMBRO 2011 & JANEIRO 2012 & APÓS IMPLANTAÇÃO \\
\hline 1 & $96 \mathrm{KWH}$ & $90 \mathrm{KWH}$ & $06 \mathrm{KWH}$ \\
\hline 2 & $181 \mathrm{KWH}$ & $140 \mathrm{KWH}$ & $41 \mathrm{KWH}$ \\
\hline 3 & $96 \mathrm{KWH}$ & $83 \mathrm{KWH}$ & $13 \mathrm{KWH}$ \\
\hline 4 & $33 \mathrm{KWH}$ & $30 \mathrm{KWH}$ & $03 \mathrm{KWH}$ \\
\hline 5 & $104 \mathrm{KWH}$ & $100 \mathrm{KWH}$ & $04 \mathrm{KWH}$ \\
\hline 6 & $139 \mathrm{KWH}$ & $128 \mathrm{KWH}$ & $11 \mathrm{KWH}$ \\
\hline 7 & $85 \mathrm{KWH}$ & $73 \mathrm{KWH}$ & $12 \mathrm{KWH}$ \\
\hline 8 & $145 \mathrm{KWH}$ & $125 \mathrm{KWH}$ & $20 \mathrm{KWH}$ \\
\hline 9 & $186 \mathrm{KWH}$ & $175 \mathrm{KWH}$ & $11 \mathrm{KWH}$ \\
\hline 10 & $179 \mathrm{KWH}$ & $169 \mathrm{KWH}$ & $10 \mathrm{KWH}$ \\
\hline
\end{tabular}

De acordo com a tabela pode-se observar que a casa que teve o menor índice de redução foi de 03 kwh e o maior de 41 kwh. A média de redução da energia nas residências foi de $13,1 \mathrm{KWH}$. Esse fato vem provar a eficiência do uso da tecnologia do litro luz, pois, em todas as residências ocorreu a redução do consumo da energia.

No gráfico 1, observa-se o comparativo do valor de consumo de energia em reais (dezembro/2011 e janeiro/2012). 
Gráfico 1 - Comparativo do valor de consumo de energia em reais (dezembro/2011 e janeiro 2012).

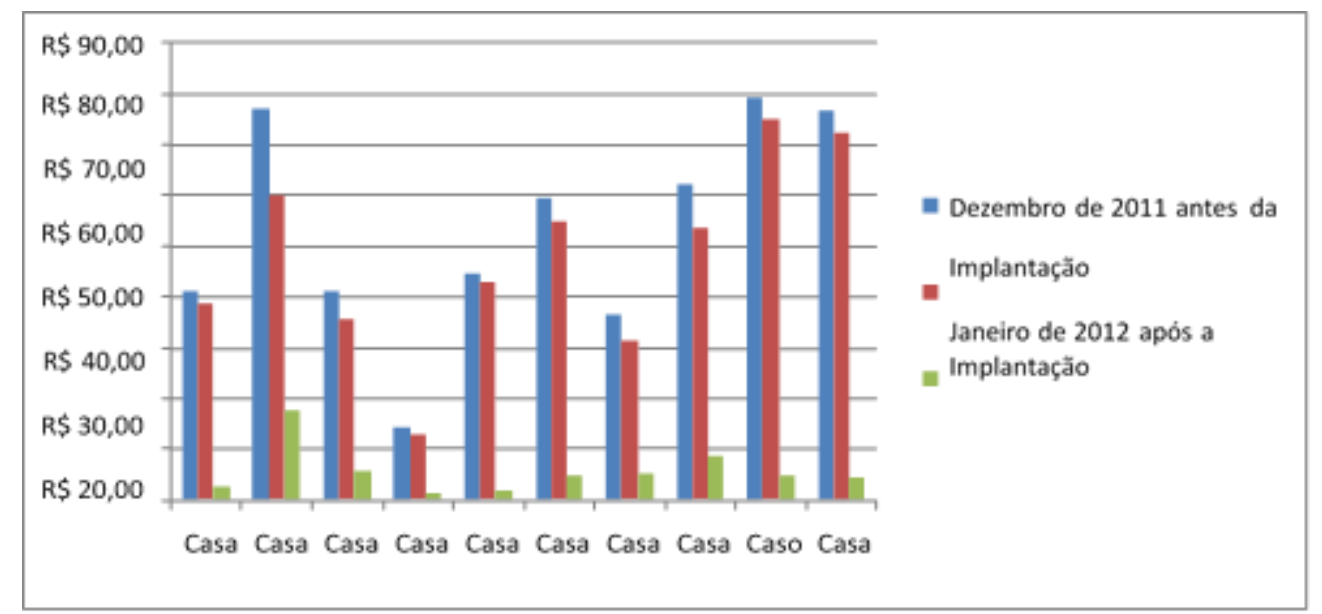

Observa-se no gráfico que a maior redução ocorreu com o valor de $\mathrm{R} \$ 17,51$ (casa 02 ) e o menor valor de $R \$ 1,28$ (casa 4). Portanto, estes foram os intervalos de maior e menor consumo. A média das 10 residências ficou no valor de $\mathrm{R} \$ 5,60$.

Foi constatado que houve uma redução no consumo de energia após um mês de implantação do projeto conforme demonstrativo abaixo (tabela 3).

De acordo com a tabela 3 pode-se observar que a casa que teve o menor índice de redução foi de 07 kwh (casa 4) e o maior de 84 kwh (casa 10). A média de redução da energia nas residências foi de R\$ 13,154 KWH. Também esses dados provam a eficiência da tecnologia do Litro Luz.

Tabela 3 - Comparativo da medição de consumo de energia (dezembro/2011 e fevereiro 2012).

\begin{tabular}{|c|c|c|c|}
\hline Casas & DEZEMBRO 2011 & FEVEREIRO 2012 & REDUÇÃO \\
\hline 1 & $96 \mathrm{KWH}$ & $79 \mathrm{KWH}$ & $17 \mathrm{KWH}$ \\
\hline 2 & $181 \mathrm{KWH}$ & $129 \mathrm{KWH}$ & $52 \mathrm{KWH}$ \\
\hline 3 & $96 \mathrm{KWH}$ & $79 \mathrm{KWH}$ & $17 \mathrm{KWM}$ \\
\hline 4 & $33 \mathrm{KWH}$ & $26 \mathrm{KWH}$ & $07 \mathrm{KWH}$ \\
\hline 5 & $104 \mathrm{KWH}$ & $86 \mathrm{KWH}$ & $18 \mathrm{KWH}$ \\
\hline 6 & $139 \mathrm{KWH}$ & $120 \mathrm{KWH}$ & $19 \mathrm{KWH}$ \\
\hline 7 & $85 \mathrm{KWH}$ & $69 \mathrm{KWH}$ & $16 \mathrm{KWH}$ \\
\hline 8 & $145 \mathrm{KWH}$ & $93 \mathrm{KWH}$ & $52 \mathrm{KWH}$ \\
\hline 9 & $186 \mathrm{KWH}$ & $160 \mathrm{KWH}$ & $26 \mathrm{KWH}$ \\
\hline 10 & $179 \mathrm{KWH}$ & $95 \mathrm{KWH}$ & $84 \mathrm{KWH}$ \\
\hline
\end{tabular}


No gráfico 2, observa-se o Comparativo do valor de consumo de energia em reais (Dezembro / 2011 e Fevereiro 2012).

Gráfico 2 - Comparativo do valor de consumo de energia em reais (Dezembro / 2011 e Fevereiro 2012).

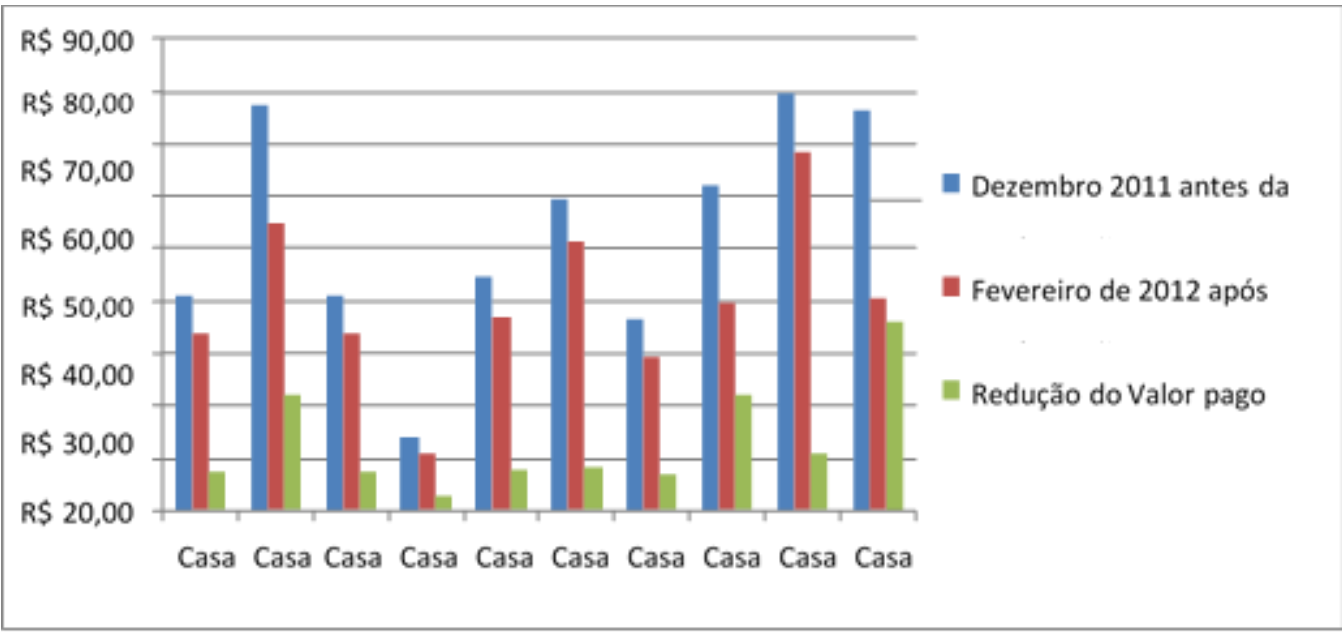

De acordo com o observado no gráfico 2, pode-se inferir que o menor valor foi $R \$ 2,99$ (casa 4) e o maior valor de $\mathrm{R} \$ 35,88$ (Casa 10 ). A média observada de redução foi de $\mathrm{R} \$ 13,154$.

Após os dados apresentados foi possível apresentar um diagnóstico comparativo entre os meses de janeiro 2011/2012, nos seguintes moldes:

Total de 2011: $\mathrm{R} \$ 619,24$

Total da redução: 155,64;

Média: 15,564

Total das residências (71) :1105,044

Total dos meses (12):186,768

Valor em $\mathrm{R} \$ \mathbf{1 3 . 2 2 5 , 7 0}$

Estima-se que o valor de redução que foi obtido com a implantação do Litro Luz no Povoado Massagueira de Baixo, possui uma grande possibilidade de se tornar um referencial no que diz respeito a energias alternativas, propondo assim, que este meio sirva de modelo para a sociedade alagoana.

Seja ela de classe baixa, média ou alta, uma vez que o valor que se obteve com a implantação dessa energia alternativa, poderia ser revertido para a utilização em outros investimentos na comunidade em questão. 


\section{CONCLUSÕES}

Os resultados desta pesquisa podem ser considerados positivos, tendo em vista que o seu objetivo foi plenamente alcançado, quando se provou a eficiência do uso do Litro Luz com a redução dos kWh e dos respectivos valores em reais. Os dados de que a diminuição do consumo de energia, comparado ao mês anterior à implantação demonstram que Litro Luz nas residências, foi favorável.

Após dois meses da sua implantação foi constatado realmente essa diminuição, estes resultados indicam um benefício na economia da conta mensal do usuário do Litro Luz, sendo verificado na conta mensal.

A pesquisa pode constatar que a economia da população em estudo basea-se em salário mínimo e auxílio do Programa Bolsa Família, o que leva racionalizar o consumo de energia, porém com a implantação do projeto houve mudanças, assim tanto na diminuição de consumo de energia e na renda familiar, porque houve um investimento na compra de cesta básica ou nos medicamentos ao mês.

A população do povoado caracterizada em pescadores, aposentados e tiradores de coco, onde se verificou que houve interesse na implantação do projeto que teve como resposta vários benefícios e principalmente a aplicação de uma tecnologia limpa. 


\section{REFERÊNCIAS}

ALBUQUERQUE, José de Lima;OlIVEIRA,Célia Vicente.economia e Meio Ambiente.In . Gestão Ambiental e Responsabilidade Social :conceitos,ferramentas e aplicações.São Paulo:Atlas,2009.

BASTOS, L.B., GAMA, J.A.S., SILVA, J.H.S. Análise da Zona Costeira de Marechal Deodoro-AL: Desenvolvimento Turístico, Populacional e Sustentável. In: ENGENHARIA AGRíCOLA: Princípios fundamentais. Ed. Conhecimento Livre, Piracanjuba, Goiás, 2021, p 23 a 33.

BASTOS, A.L.,GAMA, J.A.S, CARDOSO, L.M.B., BARROS, T.V. Políticas Públicas e o Modelo Econômico Sustentável. In: CIÊNCIAS AGRÁRIAS: A multidiciplinaridade dos recursos naturais. Ed. Conhecimento Livre, Piracanjuba, Goiás, 2021, p 58 a 68.

BEZERRA, Maria do Carmo de Lima; BURSZTYN, Marcel (orgs.). Ciência e Tecnologia para o desenvolvimento sustentável. Brasília: Ministério do meio Ambiente, 2000.

BIASI, Renato de. A energia nuclear no Brasil. Rio de Janeiro: Biblioteca do Exército, 1979. (Coleção General Benício, 169) 


\section{Capítulo 12}

doi $10.37423 / 210804567$

\section{AVALIAÇÃO DO CURSO TÉCNICO EM COOPERATIVISMO: LIMITES E PERSPECTIVAS A PARTIR DOS OLHARES DOS DISCENTES.}

DENISE CÁSSIA DA SILVA

\section{Lúcia de Fátima Lúcio da Costa}


Resumo: O presente artigo pretende discutir os resultados da pesquisa "Avaliação do Curso Técnico em Cooperativismo: Limites e Perspectivas a partir dos olhares dos discentes". Nesta, avaliou-se e analisou-se, por meio de questionários e entrevistas realizadas com alunos, professores, psicóloga, pedagoga e assistente social do Instituto Federal de Educação, Ciência e Tecnologia do Rio Grande do Norte, Campus João Câmara, a trajetória acadêmica do curso Técnico em Cooperativismo nos dois primeiros anos letivos de sua existência, no que se refere ao desempenho curricular, motivação e perspectivas de imersão no mercado de trabalho e prática profissional. Entretanto o foco deste artigo é apresentar a avaliação do curso de cooperativismo a partir da análise dos discentes. Assim, de modo geral, cruzando o perfil do curso com o perfil dos alunos, apresenta-se um questionamento a ser reavaliado, levando em consideração que o curso tem um foco eminentemente agrícola, que o Território do Mato Grande está em potencial desenvolvimento e que o curso abrange uma maioria de alunos da zona urbana, os quais não se identificam com o foco rural dado ao curso em questão, fato que pode vir a comprometer a sua sustentabilidade. Sinalizamos, assim, a necessidade de estudos mais aprofundados, como, por exemplo, uma pesquisa de marketing, para a determinação do perfil do profissional Técnico em Cooperativismo. Desde já, atestamos a existência de um novo plano de curso realizado em 2011, que apresenta um foco maior na gestão e no setor de serviços, o que possibilitará estudos comparativos.

Palavras-chave: Avaliação, Cooperativismo, Prática profissional. 


\section{INTRODUÇÃO}

No Brasil, a cultura da cooperação é observada desde a época da colonização portuguesa. Esse processo emergiu no Movimento Cooperativista Brasileiro surgido no final do século XIX, estimulado por funcionários públicos, militares, profissionais liberais e operários, para atender às suas necessidades (OCB). O cooperativismo é uma aposta para o desenvolvimento da região do Mato Grande, com potencial eminentemente agrícola.

Diante disso, o Instituto Federal de Educação, Ciência e Tecnologia do Rio Grande do Norte - IFRN, instalado há dois anos no município de João Câmara, onde se encontra, em suas redondezas, um número significativo de associações com um potencial para torna-se cooperativas e onde já há o registro de algumas poucas cooperativas, atualmente necessita profissionalizar a sua gestão. Após a realização de uma audiência pública, o referido instituto criou o curso Técnico em Cooperativismo, na perspectiva de contribuir para o desenvolvimento social e econômico do Território do Mato Grande por meio do associativismo e do cooperativismo. O presente trabalho, especificamente um projeto de Apoio Técnico à coordenação do Curso Técnico em Cooperativismo, apresenta como conteúdo a avaliação deste curso, um estudo de como ele vem sendo desenvolvido, das opiniões essenciais de alunos que vivenciaram, durante dois anos, as dificuldades de pioneiros em uma instituição nova, com toda uma equipe de servidores e professores novos. Em síntese, o objetivo maior é entender o perfil do Técnico em Cooperativismo. Muitas questões serão analisadas, como a identidade profissional plena do curso Técnico em Cooperativismo, levando em consideração o grande potencial da Região do Mato Grande para a agricultura. É importante analisar a identidade dos discentes em relação ao curso escolhido, pensando desde onde vem este discente, as suas experiências e vivências, quais suas expectativas diante de seu futuro profissional e quais as escolhas que devem ser tomadas. É preciso, ainda, identificar como foram ou poderão ser resolvidas as questões relativas a possíveis dificuldades enfrentadas no decorrer do curso, dificuldades estas que fazem com que o discente, muitas vezes, acabe desistindo de prosseguir no curso, às vezes por causa do trabalho, por não ter com quem deixar seu filho e devido ao acesso à instituição, que fica um pouco distante da cidade no perímetro urbano.

A pesquisa se ateve em coletar informações que possam subsidiar a construção de indicadores de monitoramento e avaliação que verifiquem, de forma clara, os objetivos propostos neste trabalho:

- Analisar o perfil socioeconômico e cultural dos matriculados do curso técnico Subsequente de Cooperativismo, turmas 2009.2 e 2010.1, em relação à idade, gênero, renda familiar, empregabilidade, local onde concluiu o ensino médio básico, entre vários outros fatores importantes; 
- Examinar as perspectivas profissionais dos estudantes em relação ao aproveitamento em sua trajetória profissional da formação técnica recebida no IFRN/João Câmara;

- Analisar os motivos e a taxa de evasão do curso;

- Identificar as dificuldades apresentadas pelos alunos no que se refere à trajetória e permanência no curso;

- Analisar a grade curricular ofertada pelo curso, através das opiniões dos alunos;

- Identificar as dificuldades encontradas pelos alunos em relação aos métodos de ensino e ao material didático utilizado pelos professores;

- Analisar o processo de construção de identidade com o curso de Cooperativismo a partir dos relatos dos discentes no setor pedagógico e no setor de psicologia;

- Analisar a identidade dos discentes com o cooperativismo e como eles avaliam o curso e o desempenho dos alunos.

Assim, a avaliação do curso trará novos limites e perspectivas para o cooperativismo na Região do Mato Grande. Conhecer um pouco mais sobre as necessidades dos alunos torna possível oferecer programas mais direcionados, atraindo-os mais para o curso, e atender a uma das tendências atuais do cooperativismo, que é a profissionalização da gestão. É preciso compreender o curso através da avaliação dos docentes, que acompanham os alunos diariamente, e analisar como eles percebem o perfil do profissional Técnico em Cooperativismo desenvolvido pelo IFRN e o que é feito para atender às tendências e expectativas do mercado de trabalho. É importante ressaltar, ainda, que achamos pertinente e necessário incluir a visão da pedagogia para analisar o processo de ensino-aprendizagem dos alunos e também a visão da psicologia, buscando dados para compreender os motivos de evasão do curso e os relatos de como os alunos vêem o curso e como se sentem nele.

\section{MATERIAL E MÉTODOS.}

Nesta pesquisa a metodologia utilizada baseia-se na utilização de uma pesquisa quantitativa e qualitativa. Realizou-se, primeiramente, um espaço de formação com o tema da pesquisa por meio de leituras de artigos sobre avaliação e indicadores de desempenho, assessorando a construção do referencial teórico. Para a coleta de dados, optamos pela aplicação de questionários semiestruturados, por meio de um formulário eletrônico, que alterna perguntas com opções já pré- 
definidas para a resposta, com questões abertas, onde o entrevistado pode falar livremente sobre 0 que lhe é perguntado, com a segurança de não ser identificado.

O seguinte questionário elaborado no projeto consta de cinco tópicos importantes para avaliar o curso através dos alunos concluintes do Subsequente, turmas 2009.2, uma no período vespertino e outra no período noturno, e turma 2010.1 período noturno. São eles: Motivação para escolha do curso; Perfil do aluno; Perfil do curso; Perfil do professor e Atuação profissional.

Outro instrumento utilizado para traçar o perfil sócioeconômico dos participantes da pesquisa foram os dados fornecidos pela Assistência Social, possibilitando levantar dados como a idade, sexo, estado civil, endereço, situação de moradia, renda familiar, estado civil dos pais, escolaridade, instrução escolar dos pais, motivo da escolha pelo IFRN e pelo curso de Cooperativismo e meio de transporte utilizados para se locomover.

Utilizamos, nesta pesquisa, como fonte de dados, o Q-Acadêmico, que é um portal eletrônico utilizado pelo IFRN permitindo aos pais, alunos e docentes acompanhar o percurso acadêmico do aluno, com relação ao seu desempenho e rendimento. É uma ferramenta que pode ser utilizada para estudo, em que podem ser postados os materiais didáticos utilizados nas disciplinas. Além dos dados analisados através do Q-Acadêmico, também foi disponibilizada, pelo Setor da Secretária Acadêmica, uma lista com informações referentes às turmas do curso de cooperativismo 2009.2 e 2010.1. Através desde documento, tornou-se possível levantar o número de alunos reprovados e os motivos da reprovação, se por falta ou por nota, e ainda por abandono, bem como o número de trancamentos de matrículas, número de alunos evadidos e, por fim, os alunos que estão com a matrícula em aberto, mas que não têm turma para eles no semestre em que se encontravam.

Em resumo a pesquisa utilizou-se de um estudo de caso, que consiste em um processo específico para o desenvolvimento de uma investigação qualitativa, onde se apresentam coletas e análises de dados, que se baseiam fortemente no trabalho de campo. Em geral, os estudos de caso representam a estratégia preferida quando se colocam questões do tipo "como" e "porque", quando o pesquisador apresenta pouco conhecimento sobre a pesquisa e quando o foco se encontra em acontecimentos da vida real. (YIN, 2005).

Através do questionário desenvolvido nessa pesquisa para os alunos concluintes do curso, registrouse as opiniões de 44 alunos da turma de Cooperativismo 2009.2, sendo que 21 do turno Vespertino e 23 do turno noturno e 14 alunos da turma de Cooperativismo 2010.1, todos do turno noturno, 
totalizando, assim, 58 discentes de um universo de 84 alunos das turmas de Cooperativismo 2009.2 e 2010.1.

\section{RESULTADOS E DISCUSSÃO}

Avaliação é o melhor instrumento para favorecer a aprendizagem e se faz presente em todos os domínios da atividade humana. A avaliação de desempenho é um processo institucional sistemático e tem como objetivos básicos o autoconhecimento, a tomada de decisão e o aperfeiçoamento ou reconstrução, que corresponde a uma análise sistemática do desempenho da instituição em função das atividades que realiza, das metas estabelecidas, dos resultados alcançados e do seu potencial de desempenho.

O processo de avaliação nos ajuda a definir "a análise crítica do programa (política) com o objetivo de mostrar, principalmente, em que medidas as metas estão sendo alcançadas, a que custo, quais os processos ou efeitos colaterais que estão sendo ativados (previstos ou não previstos, desejáveis ou não desejáveis) indicando novos cursos de ação mais eficazes" (Lima Júnior, 1978). O objetivo final da avaliação de desempenho é contribuir para o autoconhecimento e desenvolvimento, onde quer que ela seja aplicada. O acompanhamento de sua implantação, suas reformulações e ajustes são um importante instrumento para a melhoria da eficiência, da qualidade e da divulgação do curso de Cooperativismo na região do Mato Grande. Como lembra Barry, avaliar é atribuir valor: é determinar se as coisas são boas ou más

(Barry, 1975, p. 340). Para tanto, é necessário estabelecer critérios da avaliação que nos permitem dizer se e porque uma política é preferencial à outra.

Portanto, é avaliando que você saberá onde seu aluno "se encontra". A avaliação também é importante em todo processo de ensino-aprendizagem, ajuda a você "perceber" se os seus objetivos foram alcançados. E é importante saber avaliar qualitativamente, pois o processo de avaliação não precisa ser demorado ou custoso, mas é preciso que sejam estabelecidos objetivos claros durante a fase de planejamento. Tipicamente, as avaliações incluem pesquisas de opinião, estudos de caso e análise de dados; no caso do nosso relatório de Apoio Técnico, o estudo de caso auxilia-nos na avaliação do curso Técnico em Cooperativismo.

Analisar a identidade dos discentes com o cooperativismo e como eles avaliam o curso, as motivações e o desempenho dos alunos tornou-se relevante para fundamentar a pesquisa. Podemos encontrar várias definições para o termo identidade, mas sempre com o mesmo significado do conceito. De 
modo geral, a identidade refere-se a um indivíduo de características próprias e exclusivas em um conjunto de elementos que permitem saber quem uma pessoa é na sociedade.

O processo de construção da identidade profissional está relacionada a valores, conceitos e informações, além de mudanças ocorridas cada vez com mais frequência no mercado de trabalho, no momento de escolha da profissão, o indivíduo passa por muitos processos dos quais identifica a formação de sua identidade, assim, se identifica como profissional.

O curso Técnico em Cooperativismo abrange um número total de 84 alunos, entre os da Turma Subsequente 2009.2 e 2010.1, estes oriundos de 10 cidades da Região do Mato grande, em que a grande maioria, ou seja, 71\% dos estudantes, moram na localidade do Instituto, em João Câmara.

É interessante ressaltar que todos os alunos entrevistados concluíram o ensino médio em escolas públicas, 96\% na zona Urbana, entre os anos de 1984 a 1991, a maior parte dos alunos são solteiros, sem filhos e ainda moram na casa de seus pais, conforme dados adquiridos no Questionário disponibilizado pela Assistência Social.

De acordo com o questionário, $62 \%$ dos alunos concluintes, ou seja, 36 alunos entrevistados que escolheram o curso de cooperativismo, não sabiam do que se tratava, mas, por não ter afinidade com nenhum outro curso ofertado pela instituição, optaram por Cooperativismo, já outros $17 \%$ dos alunos, que representam 10 alunos dos entrevistados, disseram que a escolha pautou-se pela menor concorrência, e, por fim, 7\% ouviram falar em rádio, internet ou programa de TV.

Ao analisar as experiências e vivências coletivas anteriores ao ingresso no curso de cooperativismo, verificamos que apenas $22 \%$ dos participantes da pesquisa, ou seja, 13 alunos, já haviam participado de algum movimento social, estudantil ou político em seu município ou região.

Ao serem perguntados sobre a atuação profissional, pretendeu-se analisar se eles já realizaram ou estão realizando alguma atuação profissional, é importante sabermos quantos alunos já havia tido contato com o mercado de trabalho e em qual setor/área. Observamos que apenas um dos entrevistados tem atuação direta com o Cooperativismo, 59\% não estavam realizando nenhuma atuação profissional e $41 \%$ já realizou alguma atuação profissional nos seguintes setores/área: Educação como professor infantil ou de EJA; Saúde como agente de endemias, PSF e em consultório ondotológico; dentre outros como operador de caixa.

Uma questão relevante adotada no questionário para a avaliação do curso é a avaliação das disciplinas feitas pelos alunos, revelando que 18 dos entrevistados, totalizando 31\%, acham que há alguma 
disciplina para ser excluída da grade curricular do curso, e 69\%, um total de 40, acredita que não há nenhuma disciplina a ser excluída do curso. Dentre as disciplinas que deveriam sair da grade curricular do curso, as mais citadas para serem retiradas foram as disciplinas das Agroindústrias (Mandiocultura e Laticínios, 40\%, Cajucultura e Apícola, 35\%) e Inglês Instrumental, com 35\%, 15\% Filosofia do Cooperativismo, Matemática e Leitura e

Produção de Textos com 10\%, e com 5\% Língua Portuguesa, Administração de Empresas Cooperativas e Segurança do Trabalho.

Duas das falas citadas no questionário da pesquisa no item avaliação das disciplinas, mostra que é preciso repensar sobre o foco de atuação do curso de Cooperativismo, pois, embora a região do Mato Grande seja riquíssima em recursos naturais e, em especial, em recursos minerais, a maior parte dos alunos reside em área urbana, isso fica claro nas resposta do questionário, como as seguintes: "pois acredito que a visão que tiveram daqui foi que nós da região vivia da agricultura por isto colocaram este curso" e "Mandiocultura, Cajucultura, Laticínio, Apícola quem mora na zona rural muito bem conhece o assunto, mais os alunos que nasceram na cidade faltou aula de campo e aulas práticas."

No momento de criação do curso realmente levou-se em consideração as muitas das potencialidades da região, com maior nível na agricultura diversificada, sendo que alguns produtos, como o abacaxi, cana de açúcar, mandioca, castanha de caju e o coco se destacam dos demais, pois a região tem condições naturais excelentes para a sua produção e caprino- ovinocultura. Existem grandes áreas de caatinga que, com o uso de tecnologias adaptadas, como o rebaixamento, raleamento e enriquecimento do extrato herbáceo com leguminosas nativas associadas a um manejo adequado dos animais, poderiam ser uma alternativa econômica viável à agricultura familiar da região. Mas a comercialização da produção é um grave problema enfrentado pela maioria dos agricultores e agricultoras familiares do território, são poucas as alternativas que se tem, praticamente toda a produção são escoadas pelos atravessadores, que normalmente ficam com a maior parte do lucro.

Diante de tais constatações sobre o potencial da Região do Mato Grande e verificando que as disciplinas da agroindústria foram as mais indicadas a serem retiradas do curso, parece haver uma incoerência, que pode ser entendida a partir da origem dos alunos, que são, em sua grande parte, da zona urbana e não da rural; ao mesmo tempo, é preciso fazer perceber que temos um mercado de trabalho em expansão e com carência de profissionais técnicos capacitados para viabilizar, por exemplo, a comercialização da produção e a organização das cadeias produtivas, sejam do Laticínio, Mandiocultura, Apicultura ou Cajucultura. E, ainda, cabe um questionamento acerca da necessidade 
de repensar o próprio curso, bem como a maneira como vem sendo divulgado e para quem, pois, pela avaliação apresentada, não parece ser eficiente, não há uma coesão entre a grade curricular e os perfis dos alunos.

Assim, se a grade permanecer com as agroindústrias, o foco de divulgação precisaria ser concentrado em associações, sindicatos, cooperativas e nos espaços rurais. Na visão dos alunos, há falta de disciplinas ligadas à administração orientadas para a gestão, carecendo de aspectos como Marketing, Estratégia e Finanças. Uma pesquisa de Marketing para a divulgação do curso se faz pertinente para atrair o público certo de acordo com o perfil do profissional a ser formado. Essa percepção dos alunos de que o curso carece de disciplinas mais ligadas ao eixo temático gestão e negócios já podem ser percebidas na reestruturação do curso de cooperativismo com a aprovação do novo plano de curso pelo CONSUP em 2011.

Nestes dois anos de curso, $86 \%$ dos alunos conseguiram participar de um ou mais eventos envolvendo Cooperativismo e Associativismo na instituição de ensino IFRN, que organizou vários eventos, como o Ciclo de Palestras sobre cooperativismo, o Encontro Regional de Cooperativas, apoiada pela SESCOOP e OCB, e a I EXPOTEC do Campus João Câmara, com palestras e minicursos sobre a área em questão.

Como o curso é novo na região, parece não ter sido fácil essa iniciativa de convênios com as associações e cooperativas da região, para que aceitassem esses jovens como estagiários, conforme relatos da Coordenação de Extensão do instituto em reunião sobre pratica pedagógica com os alunos. Embora ainda observássemos que a relação entre projeto e estágio não é muito distante, ou seja, 29\% dos alunos, mesmo com todas as dificuldades de parcerias, realizavam estágio e $32 \%$ realizavam projetos no momento da pesquisa.

Durante o questionário, os alunos puderam se expressar também e falar um pouco sobre suas maiores dificuldades durante o percurso do curso. Segundo a afirmativa de um dos alunos

entrevistados, podemos perceber a real dificuldade da maioria dos entrevistados: Inserção no mercado/Estágio, Transporte, Vida pessoal/Estudantil, Identidade com o curso, Poucos acessos aos laboratórios de informática, Ritmo de ensino mais avançado comparado ao ensino médio precário, muitas dificuldades em relação a recursos para realizar as visitas de campo, falta de livros didáticos ligados ao cooperativismo e ao associativismo, entender melhor o objetivo do curso na região e Divulgação e orientação da população externa. 
Ao verificar as expectativas dos discentes em relação às possibilidades de atuação profissional, 36\%, total de 21, gostariam de atuar na área, mas não tinham conhecimento sobre onde poderiam atuar profissionalmente, $24 \%$, total de 14 , gostariam de atuar na área, no entanto, segundo eles, a Região não oferece as condições, já 21\%, total de 12, disseram que querem atuar na área e que a Região oferece sim as condições, $12 \%$ não querem atuar na área e 7\% desejam atuar na área, mas em outra região.

\section{CONCLUSÕES}

O desenvolvimento da pesquisa mostrou-se bastante interessante, pois todos os pontos de foco do projeto se desenvolveram paralelamente. Ao seu término, ficou evidente o quanto o curso de cooperativismo serviu de preparação para o futuro profissional destes alunos, contribuindo para a visão de futuro deles, ampliando a capacidade de desenvolvimento pessoal, cultural e intelectual, independente de qual profissão irão seguir, atuando como técnico em Cooperativismo ou não. Todavia, o conhecimento adquirido durante o curso se estende a diversos setores de trabalho e os alunos saem preparados com conhecimento pra qualquer setor no qual venham a querer atuar, uma vez que o curso foca também gestão e empreendedorismo.

Na pesquisa realizada, identificamos que o curso estava em conflito com o seu real perfil, pois em sua grade curricular, apesar de ter as disciplinas focadas na agricultura, os alunos registraram seu interesse por aquelas direcionadas à gestão, pelo simples fato do perfil dos alunos ser urbano e não rural. Assim, sentiram a necessidade de terem aulas práticas e de disciplinas que foquem mais a realidade onde eles vivem.

Entretanto, no que tange ao perfil do curso, o IFRN entende que o técnico em Cooperativismo encontra espaço no mercado de trabalho local, principalmente na indústria agropecuária e em empresas de prestação de serviços, no ramo do cooperativismo, por se tratar de um profissional em condições de criar e viabilizar atividades de cooperativismo, tendo em vista a potencialidade da Região. Seu objetivo geral é formar o profissional para atuar na formação, desenvolvimento e gestão de cooperativas da Agroindústria, planejando e executando os processos cooperativos nas diversas áreas de atuação (IFRN).

Esse é um pensamento de muitos dos alunos que cursam Cooperativismo no Campus João Câmara e vivem na cidade, uma questão delicada pede o repensar do plano de curso, já que, ao observar a criação deste, levou-se em consideração as muitas potencialidades da região, com maior foco na 
agricultura diversificada; mas, infelizmente, ainda não é assim que o curso é visto por aqueles que são concluintes. Realmente, há muito trabalho para ser feito e a divulgação do curso é uma das formas de apresentar à região os profissionais capacitados que estão sendo formados para o seu desenvolvimento e regar mais produtividade e crescimento dos pequenos produtores e empreendedores.

As mudanças sugeridas para o curso com relação às disciplinas parece já estar sendo percebida pelos docentes ao propor mudanças na perspectiva de um foco maior em gestão e no setor de serviços com a aprovação do novo Plano de Curso de Cooperativismo (PPC), que começa a ser implantado nas novas turmas do primeiro semestre letivo de 2012, nos Integrados matutino, em que aparecem disciplinas já sugeridas nessa pesquisa, como Administração Financeira, Qualidade nos serviços cooperativistas e Marketing.

Outra forma de associarmos as respostas dadas pelos alunos entrevistados foi através de uma análise de itens comparativos a uma resposta padrão. Em todas as questões as respostas quase sempre se interligavam através de palavras que demonstravam seus sentimentos e conclusões a respeito do curso. Havia explicito, nessas palavras, um choque de identidade, estabelecido por aqueles que moram na cidade e aqueles que moram na zona rural, pois os mesmos já vivenciavam o curso em suas vidas diárias, através de seus pais ou parente próximo. É interessante destacar que o cooperativismo já não era uma novidade para quem morava na zona rural, mas quem morava na cidade afirmara que pouco conhecia sobre o curso e só o escolheram por não ter afinidade com os outros cursos ofertados. É aí que destacamos um grande choque de identidade, pois os que haviam afirmado são maioria, residem na cidade e julgam que o perfil profissional é outro.

Ao buscar compreender o processo de evasão escolar e identificar os possíveis motivos para tais acontecimentos, percebeu-se que, na maioria das vezes, o aluno se evade da instituição por falta de identificação com o curso e incompatibilidade de horário com o trabalho, mais um fato que nos mostra o quanto o perfil do curso não está associado ao seu verdadeiro público de alunos.

Concepções à parte, o presente estudo constatou que os alunos tiveram dificuldades em relação à prática profissional, com o pioneirismo do curso na região; começar do zero nas parcerias de convênios foi e ainda está sendo uma realização lenta, mas eficaz. A elaboração da prática profissional foi umas das dificuldades mais comentadas pelos discentes. Como havia muitos alunos para poucos estágios, também foi adotada como pratica profissional a elaboração de projetos, uma opção que, no início, não foi bem aceita pelos alunos, que alegavam que o estagio seria mais oportuno para mostrarem 
seus conhecimentos e ter uma oportunidade de vivenciar a prática do cooperativismo. No entanto, a elaboração de projetos está sendo a prática mais adotada pelos alunos, que, no final, puderam concluir que elaborar projetos também é um excelente meio de se trabalhar com cooperativas e também aplicar seus conhecimentos, sem falar a região do Mato Grande é muito propícia a esse tipo de prática. 


\section{REFERÊNCIAS}

BARRY, Brian \& RAE, Douglas W. Political evaluation. In: GREENSTEIN, F. \& POLSBY, N., ed. Handbook of politicai science. Reading, Addison- Wesley, 1975. v.1: Politicai scíence: scope and theory, p.340.

LIMA Junior., Olavo B.; SILVA, Ari de Abreu; LEITE, Maria Claudia. Intervenção planejada na realidade social: escopo e limites da pesquisa de avaliação. Rio de Janeiro, IUPERJ, 1978.

YIN, Robert K. Estudo de Caso: Planejamento e Métodos. 3. ed. Porto Alegre: Bookman, 2005. Trad. Daniel Grassi. 


\section{Capítulo 13}

doi) $10.37423 / 210804569$

\section{FITOSSOCIOLOGIA E USO MÚLTIPLO DE ESPÉCIES ARBUSTIVAS-ARBÓREAS DE UM FRAGMENTO DE CERRADO, REGIÃO NORTE DA AMAZONIA LEGAL}


Resumo: Objetivou-se caracterizar a composição florística e fitossociológica, potencial madeireiro e não madeireiro das espécies vegetais, além de relacionar síndromes de dispersão e distribuição diamétrica de um fragmento de Cerrado em Cariri do Tocantins. Foi realizado um inventario florestal em uma área cerrado sensu stricto, com área equivalente a 3,60 ha, onde foram instaladas cinco parcelas permanentes com dimensões de $20 \times 50 \mathrm{~m}\left(1000 \mathrm{~m}^{2}\right)$ cada, totalizando 0,5 ha, sendo distanciadas dez metros da borda entre elas, as parcelas foram inventariadas pelo método de amostragem de área fixa. Foram amostradas todas as espécies arbustivas-arbóreas com diâmetro $\geq$ $10 \mathrm{~cm}$, medidos a 1,30 m, sendo mensurados todos os indivíduos vivos e mortos em pé. Foram amostrados em uma área de 0,5 ha, um total de 1020 indivíduos, sendo 963 vivos e 57 mortos em pé, distribuídos em 34 famílias botânicas e 80 espécies. O índice de árvores mortas em pé foi de 5,58 \%, a espécie Callisthene major, pertencente à família Vochysiaceae compõe um total de 19,41\% das espécies. A distribuição diamétrica indicou o estabelecimento de novos indivíduos em duas classes diamétrica de 1 a 8,1 cm e 8,2 a 16,3 cm, onde apresentaram elevado número de indivíduos presentes nas primeiras classes de indivíduos pode representar uma comunidade estoque, sendo normal em áreas com idade e espécies variadas, pois os mesmos fazem parte de grupos ecológicos das espécies secundarias iniciais e tardias, indicando assim um alto valor de regeneração em virtude da elevada entrada de indivíduos, possibilitando uma favorável ascensão para estágios sucessionais maduros.

Palavras-chave: Estrutura Florística, Síndrome de dispersão, Distribuição Diamétrica, Potencial madereiro e não madereiro. 


\section{INTRODUÇÃO}

O domínio Cerrado é visto como a savana mais rica biologicamente do mundo, com um terço da biodiversidade brasileira e apresenta em média 5\% da fauna e flora do planeta (MIRANDA et al., 2013). As espécies de plantas vasculares nesse bioma são de aproximadamente 12.456 espécies, dessa maneira a alta distribuição de habitats e um grande grau de endemismo, põem o Cerrado na lista de hotspots mundiais, considerado como uma das 34 áreas preferencial para a conservação da diversidade no mundo (SANO et al., 2010).

O Cerrado abrange uma área total de $2.036 .448 \mathrm{~km}^{2}$, o que corresponde a mais ou menos $22 \%$ do território nacional (BRASIL, 2014). São incluídos no bioma alguns estados, Goiás, Tocantins, Distrito Federal, parte dos Estados da Bahia, Ceará, Maranhão, Mato Grosso, Mato Grosso do Sul, Minas Gerais, Piauí, Rondônia e São Paulo. No entanto tem se fragmentos do domínio Cerrado ao norte do País nos Estados do Amapá, Amazonas, Pará e Roraima e ao sul as ilhas no Paraná (SANTOS, 2015; BRASIL, 2016). A área do Cerrado é também apontada como um grande e importante local agrícola mundial, tornando-se um dos biomas mais afetados do planeta (SANO et al., 2010). Devido essa exploração em excesso para aumento das áreas rurais as quantidades de territórios nativos têm abaixado de forma muito drástica (GANEM et al., 2013; MMA, 2015).

Devido aos estudos florísticos e fitossociológicos tem se em mente a alta biodiversidade do domínio Cerrado e sabendo que o estudo sobre o mesmo tem sido uma das grandes influencias na mudança da estrutura e dinâmica, faz com que percebamos a importância da síndrome das dispersões quanto a forma de distribuição e ocorrência das espécies no procedimento de sucessão ecológica (MENDONÇA et al., 2008).

Uma das maneiras de preservar a vegetação nativa do cerrado é conservando as áreas de preservação permanente e reservas legais nas propriedades rurais, que tem como objetivo reabilitar e conservar os recursos ecológicos, manter a biodiversidade e proteger a fauna e flora de origem, segundo a Lei $\mathrm{n}^{\circ}$ 12.727 de 17 de outubro de 2012 que define o novo Código Florestal Brasileiro (BRASIL, 2015). Ainda conforme o Código Florestal Brasileiro, são estabelecidas taxas de 20\% e 35\% de área de imóvel rural que, coberta por vegetação natural, pode ser explorada com o manejo florestal de modo sustentável em propriedades rurais situadas no bioma Cerrado e áreas introduzidas na Amazônia Legal, respectivamente (BRASIL, 2015). 
As síndromes de dispersão também são importantes método de regeneração natural, fundamentais nos processos de regeneração natural das comunidades vegetais, depois da dispersão de um diásporo sua implantação ocorre naturalmente, tornando-se um dos grandes elementos de propágulos para a regeneração de locais danificados (MARTINEZ-RAMOS; SOTO-CASTRO, 1993). Após a dispersão das sementes, ocorre a deposição das mesmas no solo e o aglomerado de sementes vigorosas presentes na superfície é aterrada formando o chamado banco de sementes (GARWOOD, 1989; ALMEIDACORTEZ, 2004). Essas são possíveis plantas adultas, mantendo o equilíbrio entre as espécies (BAKER, 1989).

A flora natural do Bioma Cerrado pode ser amplamente utilizada visto o potencial alimentício, medicinal, oleaginoso, artesanal, madereiro, ornamental e energético dentre outros (FELFILI et al., 2004). No entanto observam-se poucos estudos retratando os potenciais usos das espécies de maneira ampla. Tais estudos podem auxiliar na utilização e manejo ideal, valorizando esses recursos e eliminando o uso inadequado. Com base nessas informações, percebe-se que o fator limitante para um bom uso e aproveitamento das espécies com potencial econômico do Cerrado está na falta de conhecimento sobre sua biologia e utilização. O reconhecimento da importância dessas espécies colaborou para melhor manejo e aproveitamento dos produtos nas áreas de reserva em sua propriedade (ALMEIDA et al., 1998).

Florestas inequiâneas, são aquelas que não foram muito alteradas e possui dispersão de diâmetro das espécies em forma semelhante de um "J" inverso, e as categorias diamétrica inferiores de indivíduos são as que apresentam maiores frequências (ALVES JÚNIOR et al., 2007).

Por tanto, a distribuição diamétrica é um atributo muito importante para averiguação do aumento ou expansão do estoque (FERREIRA et al., 1998). A distribuição de diâmetro é um dos objetos de estudo adotado para o entendimento do segmento e dinâmica de uma vegetação lenhosa, ou seja, explica o arranjo de uma determinada área florestal, permite uma predição futura quanto ao crescimento da floresta (PAULA et al., 2004; SIMINSKI et al., 2004; MACHADO et al., 2010).

No território tocantinense, onde a cobertura vegetal apresenta ambientes das regiões fitoecológicas do Cerrado, Floresta Estacional e Floresta Ombrófila, essas áreas de ecótono são compostas por florestas ainda pouco estudadas em termos florísticos e estruturais. Visando ampliar o conhecimento sobre a vegetação do Tocantins, o presente estudo tem por objetivo caracterizar a composição florística e fitossociológica, potencial madeireiro e não madeireiro das espécies vegetais, além de 
relacionar síndromes de dispersão e distribuição diamétrica de um fragmento de Cerrado em Cariri do Tocantins.

\section{MATERIAL E MÉTODOS}

Caracterização da área de estudo

O estudo foi desenvolvido numa área de cerrado sensu stricto, inserido na região da Amazônia Legal, sul do estado do Tocantins, município de Cariri do Tocantins, em uma propriedade particular com 23,2 hectares.

O clima da região de acordo com Köppen é do tipo Aw, definido como tropical úmido com estação chuvosa no verão e seca no inverno, sua precipitação varia entre $1.400 \mathrm{~mm}$ a $1.500 \mathrm{~mm}$, a altitude média de 295 m e predominância de solos do tipo argissolo, latossolos e plintosolos (SEPLAN, 2012) (Figura 1).

Figura 1 - Localização da área de estudo e do município de Cariri do Tocantins.

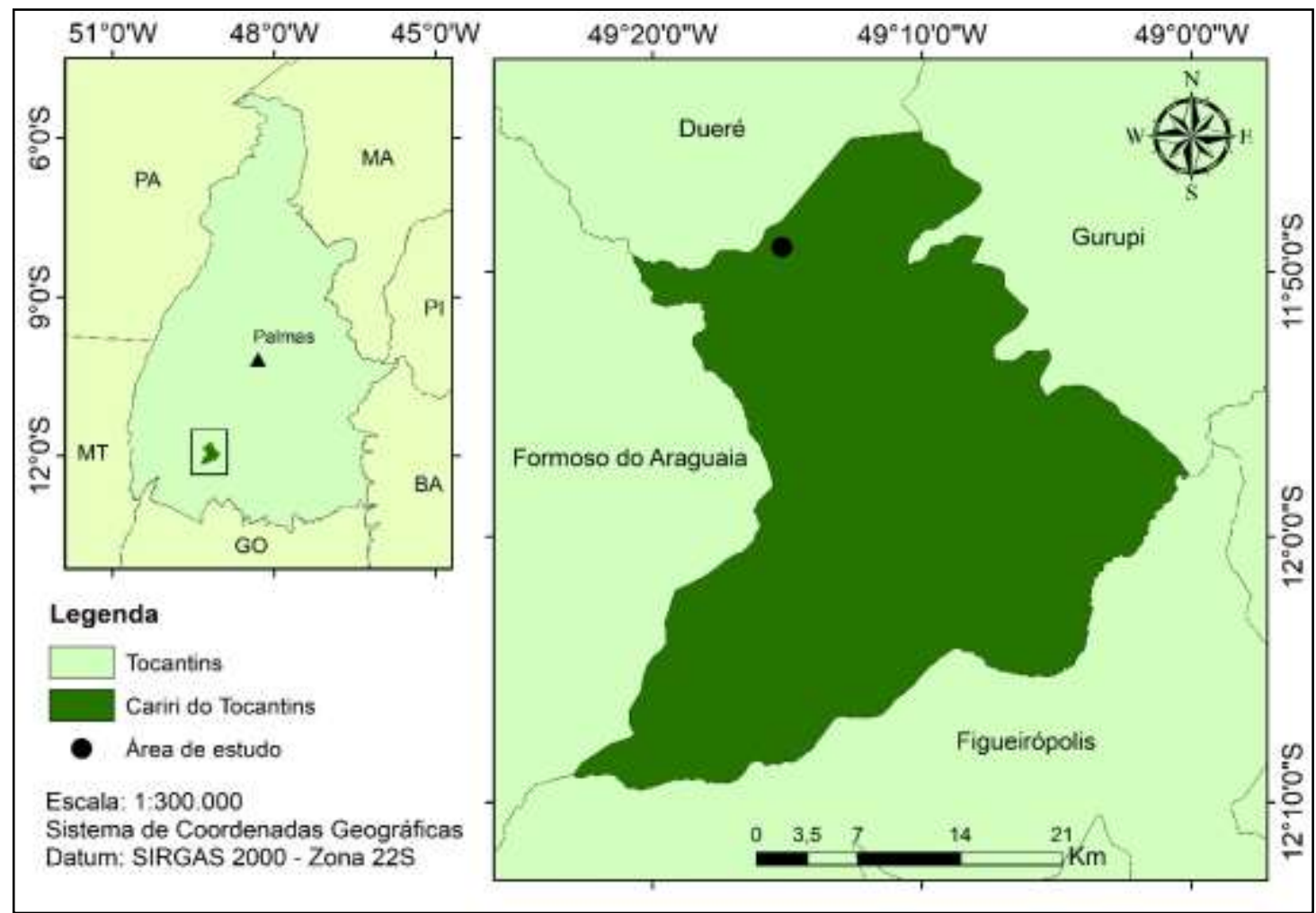

Fonte: Elaborado pelo autor. 


\section{COETA E ANÁLISE DOS DADOS}

Foi realizado um inventario florestal em uma área cerrado sensu stricto, com área equivalente a 3,60 ha, onde foram instaladas cinco parcelas permanentes com dimensões de $20 \times 50 \mathrm{~m}\left(1000 \mathrm{~m}^{2}\right)$ cada, totalizando 0,5 ha, sendo distanciadas dez metros da borda e entre elas, as parcelas foram inventariadas pelo método de amostragem de área fixa (MUELLER - DOMBOIS \& ELLENBERG, 1974).

A distribuição das parcelas foi realizada sistematicamente e padronizada de acordo com o projeto Biogeografia do Bioma Cerrado (FELFILI; SILVA JUNIOR, 1992; FELFILI et al., 1997; FERREIRA, 2015). Foram amostradas todas as espécies arbustivas-arbóreas com diâmetro $\geq 10 \mathrm{~cm}$, medidos a 1,30 m do solo com auxílio de uma fita métrica, sendo mensurados todos os indivíduos vivos e mortos em pé.

As espécies arbustivas-arbóreas coletadas no local foram identificadas taxonômicamente e em seguida herborizadas e conferidas em literatura especializada, com especialistas e, quando necessário, foi comparado com o material de Porto Nacional, da Universidade Federal do Tocantins. O sistema Angiosperm Phylogeny Group IV foi utilizado para classificação das famílias botânicas (ANGIOSPERM PHYLOGENY GROUP, 2016). Todos os nomes das espécies e seus respectivos autores e sinonímias foram confirmados e atualizados pelo site da Lista de Espécies da Flora do Brasil (REFLORA, 2019).síndrome de dispersão e usos pontenciais

As síndromes de dispersão das espécies foram classificadas segundo os fundamentos apresentados por Van Der Pijl (1982), adotando os critérios morfológicos dos frutos, de acordo com as características que definem seu modo de dispersão, e por meio de consulta a Lorenzi (2002); Lorenzi (2002); Vieira et al. (2002); Silva Júnior (2009); Rubim et al., (2010); Lopes (2011) e Silva Júnior (2012). Dessa maneira, foram classificados em três grupos: zoocóricas (frutos que apresentam características que facilitam a dispersão por animais) anemocórica (frutos apresentam mecanismos que facilitam a dispersão pela ação do vento), autocóricas (frutos que apresentam auto dispersão, como a deiscência explosiva ou dispersam os diásporos por gravidade). Para a realização do agrupamento, observou -se morfologicamente os caracteres que indicam seu modo de dispersão, e por meio de bancos de dados literários disponíveis (PINHEIRO; RIBEIRO; 2001; KUHLMANN; 2016).

Para a classificação quanto aos usos potencias das espécies amostradas, foram realizadas classificações em sete categorias diferentes sendo elas: espécies para interesse alimentício e medicinal, oleaginoso, artesanal, madereiro, ornamental e energético, sendo estas classificações, 
baseadas nos trabalhos de (ALMEIDA et al., 1998; LORENZI, 2002; SILVA JÚNIOR, 2009; SILVA JÚNIOR, 2012; SILVA et al., 2012; (KUHLMANN, 2012).

Os valores para análise fitossociológica como densidade relativa (DR), densidade absoluta (DA), dominância relativa (DOR), dominância absoluta (DoA), frequência relativa (FR), frequência absoluta (FA), índice de valor de importância (IVI), índices de diversidade de Shannon ( $\mathrm{H}^{\prime}$ ) e equabilidade de Pielou (J'), foram obtidos a partir do programa Fitopac versão 2.1.2 (SHEPPERD, 2010).

A distribuição diamétrica ocorreu de acordo com o cômputo dos indivíduos amostrados de cada espécie dentro da classe diamétrica a que pertencessem, ou seja, os indivíduos amostrados foram agrupados por classes de diâmetros estabelecidas previamente para distribuição com base neste critério. As classes de diâmetro foram estabelecidas com amplitude de $5 \mathrm{~cm}$, a partir do diâmetro mínimo de inclusão dos indivíduos (HARPER, 1977).

\section{RESULTADOS E DISCUSSÃO}

\section{ANÁLISE FITOSSOCIOLÓGICA}

Foram amostrados em uma área de 0,5 ha, um total de 1020 indivíduos, sendo 963 vivos e 57 mortos em pé, distribuídos em 34 famílias botânicas e 80 espécies, dados este que corrobora com a riqueza amostrada por (FERREIRA, et al., 2015).

O índice de árvores mortas em pé foi de 5,58 \%, valor parecido ao encontrado por Cavassan (1982), no qual se encontrou 5,80\% de indivíduos mortos, assim como Silva e Souza (2016), com valor de 3,1\%, algo natural em florestas nativas brasileiras. As arvores mortas em pé possui $100 \%$ de presença em todas as parcelas amostradas, significando assim que não há mortes localizadas, deste modo essas perdas podem ser ocasionadas de acidentes como, ventos, doenças, parasitas ou morte naturais.

A alta concentração de espécies sucessionais, aponta o elevado poder e domínio das espécies secundárias iniciais, tardia e regenerantes no local, apresentando uma alta diversidade e riqueza de indivíduos. Das 80 espécies amostradas cinco espécies e um gênero foram predominantes em número de indivíduos e outros índices na área de estudo, sendo elas, Callisthene major (191), Byrsonima pachyphylla (78), Alibertia sp. (52), Copaifera langsdorffii (45), Protium Heptaphayllum (41) e Qualea multiflora (35) espécies estas, habitualmente encontradas neste tipo de fisionomia de cerrado sensu stricto (Tabela 1). 
Tabela 1 - Análise dos parâmetros fitossociológicos das espécies arbustivas-arbóreas amostradas na área de estudo, Cariri do Tocantins. Onde: Onde: $\mathrm{NI}=$ número de indivíduos; $\mathrm{DA}=$ densidade absoluta (número de indivíduos/ha); DR = densidade relativa; FrA = frequência absoluta (unidade de amostra/total de amostra); FR = frequência relativa; DoA = dominância absoluta; DoR = dominância relativa e IVI = índice de valor de importância.

\begin{tabular}{|c|c|c|c|c|c|c|c|c|}
\hline Espécies & N.I & DA & $\begin{array}{l}\text { DR } \\
(\%)\end{array}$ & FrA & $\begin{array}{l}\text { FR } \\
(\%)\end{array}$ & $\begin{array}{c}\text { DoA } \\
\left(\mathbf{m}^{2} / \mathbf{h a}\right)\end{array}$ & $\begin{array}{c}\text { DoR } \\
(\%)\end{array}$ & $\begin{array}{l}\text { IVI } \\
(\%)\end{array}$ \\
\hline Callisthene major & 198 & 396 & 19,41 & 100 & 2,31 & 75,6 & 36,31 & 19,34 \\
\hline $\begin{array}{l}\text { Byrsonima } \\
\text { pachyphylla }\end{array}$ & 78 & 156 & 7,65 & 100 & 2,31 & 7,78 & 3,75 & 4,57 \\
\hline Alibertia sp. & 52 & 104 & 5,10 & 100 & 2,31 & 6,95 & 3,36 & 3,59 \\
\hline $\begin{array}{l}\text { Copaifera } \\
\text { langsdorffii }\end{array}$ & 45 & 90 & 4,41 & 100 & 2,31 & 13,51 & 6,52 & 4,42 \\
\hline $\begin{array}{l}\text { Protium } \\
\text { heptaphayllum }\end{array}$ & 41 & 82 & 4,02 & 80 & 1,85 & 4,87 & 2,35 & 2,74 \\
\hline Qualea multiflora & 35 & 70 & 3,43 & 60 & 1,39 & 3,95 & 1,91 & 2,24 \\
\hline Roupala montana & 32 & 64 & 3,14 & 100 & 2,31 & 6,37 & 3,07 & 2,84 \\
\hline Magonia pubescens & 26 & 52 & 2,55 & 100 & 2,31 & 6,49 & 3,13 & 2,67 \\
\hline Curatela americana & 24 & 48 & 2,35 & 100 & 2,31 & 4,48 & 2,16 & 2,28 \\
\hline Luehea grandeflora & 21 & 42 & 2,06 & 100 & 2,31 & 4,45 & 2,15 & 2,17 \\
\hline Outras espécies & 468 & 936 & 45,88 & 3,38 & 78,28 & 72,84 & 35,29 & 53,14 \\
\hline TOTAL & 1020 & 2040 & 100 & 4,32 & 100 & 207,29 & 100 & 100 \\
\hline
\end{tabular}

Fonte: Elaborado pelo autor.

Cabe ressaltar que as espécies Callisthene major e Byrsonima pachyphylla pertencente à família Vochysiaceae e Rubiaceae são as espécies com maior valor de importância, segundo Haridasan (1982), estas famílias são típicas acumuladoras de alumínio capacidade que possibilita benefício em crescimento para competir com as demais espécies em solos distróficos.

As espécies Callisthene major, Byrsonima pachyphylla e Copaifera langsdorffii, obtiveram 100\% de frequência absoluta, já as espécies Protium heptaphayllum e Qualea multiflora obtiveram 80\% e 60\% respectivamente, demonstrando que não foram distribuídas de forma continua na área estudada (Tabela 1).

Dentre as 80 espécies amostradas 44 apareceram com cinco ou menos indivíduos, apresentando um índice de $55 \%$ do total das espécies presentes na área estudada. Ao analisar o elevado número de espécies com poucos indivíduos, nota - se um fator preocupante visto que, caso ocorra a morte natural ou uma catástrofe ambiental as espécies locais podem se extinguir naturalmente. (AGUIAR et al; 2018). 
Tabela 2 - Análise dos parâmetros fitossociológicos das Famílias arbustiva-arbórea amostrada na área de estudo, Cariri do Tocantins. Onde: Onde: $\mathrm{NI}=$ número de indivíduos; $\mathrm{DA}=$ densidade absoluta (número de indivíduos/ha); DR = densidade relativa; FrA = frequência absoluta (unidade de amostra/total de amostra); FR = frequência relativa; DoA = dominância absoluta; DoR = dominância relativa e IVI = índice de valor de importância.

\begin{tabular}{|c|c|c|c|c|c|c|c|c|}
\hline Famílias & N.I & DA & $\begin{array}{l}\text { DR } \\
(\%)\end{array}$ & FrA & $\begin{array}{l}\text { FR } \\
(\%)\end{array}$ & $\begin{array}{l}\text { DoA } \\
\left(\mathrm{m}^{2} / \mathbf{h a}\right)\end{array}$ & $\begin{array}{l}\text { DoR } \\
(\%)\end{array}$ & $\begin{array}{l}\text { IVI } \\
(\%) \\
\end{array}$ \\
\hline Vochysiaceae & 267 & 534 & 26,18 & 100 & 4,35 & 86,82 & 41,89 & 24,14 \\
\hline Fabaceae & 115 & 230 & 11,27 & 100 & 4,35 & 23,71 & 11,44 & 9,02 \\
\hline Malvaceae & 51 & 102 & 5 & 100 & 4,35 & 14,05 & 6,78 & 5,38 \\
\hline Rubiaceae & 78 & 156 & 7,65 & 100 & 4,35 & 8,54 & 4,12 & 5,37 \\
\hline Malpighiaceae & 78 & 156 & 7,65 & 100 & 4,35 & 7,78 & 3,75 & 5,25 \\
\hline Morta & 57 & 114 & 5,59 & 100 & 4,35 & 8,2 & 3,96 & 4,63 \\
\hline Sapindaceae & 35 & 70 & 3,43 & 100 & 4,35 & 7,41 & 3,57 & 3,78 \\
\hline Proteaceae & 35 & 70 & 3,43 & 100 & 4,35 & 6,88 & 3,32 & 3,70 \\
\hline Myrtaceae & 50 & 100 & 4,9 & 100 & 4,35 & 2,68 & 1,29 & 3,51 \\
\hline Burseraceae & 41 & 82 & 4,02 & 80 & 3,48 & 4,87 & 2,35 & 3,28 \\
\hline Anacardiaceae & 25 & 50 & 2,45 & 100 & 4,35 & 5,86 & 2,83 & 3,21 \\
\hline Dilleniaceae & 24 & 48 & 2,35 & 100 & 4,35 & 4,48 & 2,16 & 2,95 \\
\hline Bignoniaceae & 25 & 50 & 2,45 & 80 & 3,48 & 4,54 & 2,19 & 2,71 \\
\hline Rhamnaceae & 23 & 46 & 2,25 & 100 & 4,35 & 2,69 & 1,3 & 2,63 \\
\hline Loganiaceae & 22 & 44 & 2,16 & 80 & 3,48 & 2,19 & 1,06 & 2,23 \\
\hline Combretaceae & 10 & 20 & 0,98 & 80 & 3,48 & 3,81 & 1,84 & 2,10 \\
\hline Annonaceae & 13 & 26 & 1,27 & 80 & 3,48 & 1,51 & 0,73 & 1,83 \\
\hline Polygonaceae & 16 & 32 & 1,57 & 60 & 2,61 & 2,54 & 1,22 & 1,80 \\
\hline Lythraceae & 13 & 26 & 1,27 & 80 & 3,48 & 1,04 & 0,5 & 1,75 \\
\hline Apocynaceae & 8 & 16 & 0,78 & 60 & 2,61 & 2,28 & 1,1 & 1,50 \\
\hline Metteniusaceae & 4 & 8 & 0,39 & 60 & 2,61 & 1,87 & 0,9 & 1,30 \\
\hline Boraginaceae & 4 & 8 & 0,39 & 60 & 2,61 & 1,2 & 0,58 & 1,19 \\
\hline Caryocaraceae & 5 & 10 & 0,49 & 60 & 2,61 & 0,77 & 0,37 & 1,16 \\
\hline Chrysobalanaceae & 3 & 6 & 0,29 & 60 & 2,61 & 0,35 & 0,17 & 1,02 \\
\hline Nyctaginaceae & 3 & 6 & 0,29 & 40 & 1,74 & 0,18 & 0,08 & 0,71 \\
\hline Dichapetalaceae & 2 & 4 & 0,2 & 40 & 1,74 & 0,18 & 0,09 & 0,67 \\
\hline Erythroxylaceae & 2 & 4 & 0,2 & 20 & 0,87 & 0,18 & 0,09 & 0,38 \\
\hline Salicaceae & 2 & 4 & 0,2 & 20 & 0,87 & 0,1 & 0,05 & 0,37 \\
\hline Sapotaceae & 2 & 4 & 0,2 & 20 & 0,87 & 0,09 & 0,04 & 0,37 \\
\hline Ebenaceae & 1 & 2 & 0,1 & 20 & 0,87 & 0,11 & 0,05 & 0,34 \\
\hline Melastomataceae & 1 & 2 & 0,1 & 20 & 0,87 & 0,03 & 0,01 & 0,33 \\
\hline Outras famílias & 5 & 10 & 0,5 & 80 & 3,43 & 0,35 & 0,17 & 1,38 \\
\hline TOTAL & 1020 & 2040 & 100 & 2300 & 100 & 207,29 & 100 & 100 \\
\hline
\end{tabular}

Fonte: Elaborado pelo autor. 
Das 34 famílias apresentadas na área de estudo, destacou se sete com maior número de especeis, entre as quais Fabaceae, Rubiaceae, Myrtaceae, Vochysiaceae, Malvaceae, Bignoniaceae, Apocynaceae; totalizando $56,25 \%$ de espécies representadas na área estudada, essas famílias são facilmente encontradas em locais com vegetação predominante de cerrado senso stricto e contém um elevado número de riqueza florística (NETTESHEIM et al., 2010; FINA; MONTEIRO, 2013; ROCHA et al., 2014; SILVA NETO et al., 2016).

Das famílias apresentadas em relação ao número e indivíduos destaca se Vochysiaceae (267), Fabaceae (115), Rubiaceae (78), Malpighiaceae (78), Malvaceae (51) e Myrtaceae (50).

As famílias Vochysiaceae e Fabaceae foram as que mais se destacaram em toda área de estudo, totalizando $37,45 \%$ dos indivíduos e 33,16\% do IVI total (Tabela 2). A família Fabaceae não se destaca apenas em áreas de Cerrado, destaca-se também em outras fisionomias, tanto em valores de importância como em riqueza. Segundo Saporetti, et al., 2003 e Pereira, et al., 2013, a família Vochysiaceae ocorre com frequência no bioma de Cerrado, é fácil de ser encontrada em levantamentos florísticos e fitossociológicos. Essa vantagem competitiva e boa adaptação das espécies da família Fabaceae se dá possivelmente pelas reações simbióticas com microrganismos, que permite o aumento da absorção de elementos de baixa concentração no solo como nitrogênio e fosforo e que são de extrema importância para o desenvolvimento das espécies. A família Fabaceae possui maior adaptação em regiões de Cerrado, devido a sua capacidade de nodulação, sendo esta uma das suas maiores vantagens em relação as outras espécies (CAMPELLO, 1998).

A maioria das espécies da família Vochysiaceae são típicas acumuladoras de alumínio capacidade que possibilita vantagem em crescimento para competir com as demais espécies em solos ácidos, portanto as espécies da família Vochysiaceae da fisionomia cerrado sensu stricto possuem elevados valores de riqueza florística (FELFILI; SILVA JÚNIOR, 1993).

O diâmetro médio encontrado nos indivíduos presentes na área de estudo foi de $29,93 \mathrm{~cm}$, com uma área basal de $103,64 \mathrm{~m}^{2} /$ ha e altura média dos indivíduos de 5,4m, característica de uma fisionomia de cerrado sensu stricto. Corroborando assim com os resultados obtidos por (NETO et al., 2016).

O índice de diversidade de Shannon $\left(\mathrm{H}^{\prime}\right)$ encontrado foi de 3,49, índice este usado para medir a diversidade em dados categóricos, analisando assim o número das espécies e as espécies dominantes, o valor de $\mathrm{H}^{\prime}$ encontrado foi semelhante aos encontrados em áreas de cerrado sensu stricto da Amazônia legal, e semelhantes ao encontrado por (FERREIRA et al., 2015; BRITO et al., 2006; SILVA e SOUZA, 2017). O índice de equabilidade de Pielou ( $\left.J^{\prime}\right)$ foi de 0,79 valor este que corrobora com o 
encontrado por Silva e Souza (2017) que foi de 0,77, este índice representa a regularidade da distribuição dos indivíduos entres as espécies da área.

Portanto das 80 espécies amostradas na área estudada, apenas 12 espécies foram as mais representativas em número de indivíduos e com alto potencial de exploração econômica. Dessa forma destaca-se Callisthene major (Pau de rato) com 198 indivíduos, utilizado para mourões, construções de pequenas casas, currais entre outros. Magonia pubescens, popularmente conhecida como tingui, com cinco principais utilizações sendo elas medicinal, artesanal, madeireiro, ornamental e energético, sendo bastante utilizada também na pesca pelos nativos, Copaifera langsdorffii, conhecida como Copaíba ou Pau de óleo, se destaca por ser uma planta oleaginosa e medicinal, o seu óleo é um antibiótico natural, utilizado para alivio e relaxamento de dores musculares, ativação da circulação sanguínea, anti-inflamatório entre outros, além de apresentar potencial madeireiro e ornamental (Tabela 3). (AQUINO et al., 2007).

Tabela 3 - Formas de utilização das espécies nativas do cerrado sensu stricto, em Cariri do Tocantins. Onde: N.I: Numero de indivíduos; Al: Alimentícia; Ml: Medicinal; Ol: Oleaginoso; At: Artesanal; M: Madeireiro; Or: Ornamental; En: Energético.

\begin{tabular}{|c|c|c|c|c|c|c|c|c|}
\hline Espécies & N.I & Al & Ml & Ol & At & $\mathbf{M}$ & Or & En \\
\hline Callisthene major & 198 & $\mathrm{X}$ & & & & $\mathrm{X}$ & & \\
\hline Byrsonima pachyphylla & 78 & $X$ & & & & & & $\mathrm{X}$ \\
\hline Alibertia sp. & 52 & $\mathrm{X}$ & & & & & & \\
\hline Copaifera langsdorffii & 45 & & $\mathrm{X}$ & $\mathrm{X}$ & & $\mathrm{X}$ & $\mathrm{X}$ & \\
\hline Protium heptaphayllum & 41 & $X$ & & & & $\mathrm{X}$ & & \\
\hline Qualea multiflora & 35 & $\mathrm{X}$ & $\mathrm{X}$ & & & & & $X$ \\
\hline Roupala montana & 32 & & & & & $\mathrm{X}$ & & \\
\hline Magonia pubescens & 26 & & $\mathrm{X}$ & & $X$ & $\mathrm{X}$ & $X$ & $X$ \\
\hline Curatella americana & 24 & $X$ & $X$ & & & $\mathrm{X}$ & & \\
\hline Rhaminidium elaeocarpus & 23 & & & & & $\mathrm{X}$ & & $X$ \\
\hline Antonia ovata & 22 & $X$ & & & & & & \\
\hline Luehea grandiflora & 21 & & & & & $\mathrm{X}$ & & $\mathrm{X}$ \\
\hline TOTAL & 597 & 7 & 4 & 1 & 1 & 8 & 2 & 5 \\
\hline
\end{tabular}

Fonte: Elaborado pelo autor.

Dentre os usos múltiplos citados, destacam-se a alimentícia e madeireira, seguido pelo potencial medicinal e energético, apresentando um número elevado de indivíduos, sendo os principais recursos 
naturais na área em Cariri do Tocantins. O destaque do cerrado no setor alimentício se dá principalmente pelos inúmeros animais que atuam como agentes de polinização e dispersores de sementes. Dessa forma observa se que, estas áreas são uteis na preservação da diversidade vegetal, portanto, podem sustentar uma boa variedade faunística. Cabe ressaltar que variados tipos de espécies com baixo número de indivíduos no cerrado em estudo, apresentam uso medicinal popular, assim como a Anacardiun humile (cajuzinho do cerrado), utilizado para combater a diarreia, expectorante, contra inflamação na garganta, tratamento de diabetes e reumatismos, Qualea grandiflora (Pau terra da folha larga) é utilizada no tratamento de inflamações, diarreias, cólicas e amebas, a Bowdichia virgilioides (Sucupira preta), utiliza-se no tratamento de diabetes, sífilis, gota, reumatismo, febre, dermatoses e artrite, Hancornia speciosa (Mangaba), utilizada para cólica menstrual e luxações (Tabela 3) (AQUINO et al., 2007).

\section{SINDROME DE DISPERSÃO}

Na área estudada foram amostradas 80 espécies, distribuídas em 34 famílias entre as quais 43 são zoocóricas (dispersão por ação de animais), correspondente a (53,75\%), 31 anemocóoricas (dispersas pela ação do vento), (38,75\%) e 2 autocóoricas (dispersas por ação autônoma da planta) (2,5\%).

A família Fabaceae, foi a que apresentou maior variedade distribuição de espécies, tendo a dispersão (anemocórica) como destaque, e foi a única família com ocorrência das três dispersões, zoocóricas, anemocóricas, autocóricas. Seguido pela Família Rubiaceae e Myrtaceae, ambas dispersas pela ação de animais (zoocóricas), com número de espécies respectivamente (8 e 6) (Tabela 4).

Tabela 4 - Parâmetro fitossociológico da síndrome de dispersão nas famílias arbustivas-arbóreas amostradas na área de estudo em Cariri do Tocantins.

\begin{tabular}{cccc}
\hline Famílias & Anemocórica & Zoocórica & Autocórica \\
\hline Vochysiaceae & 5 & & \\
Fabaceae & 9 & 4 & \\
Malvaceae & 3 & 8 & \\
Rubiaceae & & 1 & \\
Malpighiaceae & & 1 & \\
Sapindaceae & 1 & 6 & \\
Proteaceae & 1 & 1 & \\
Myrtaceae & & 1 & \\
Burseraceae & 2 & 1 & \\
Anacardiaceae & 3 & & \\
Dilleniaceae & & & \\
Bignoniaceae & & & \\
Rhamnaceae & & &
\end{tabular}


Loganiaceae

Combretaceae

Annonaceae

Polygonaceae

Lythraceae

Apocynaceae

Caesalpiniaceae

Boraginaceae

Caryocaraceae

Chrysobalanaceae

Nyctaginaceae

Dichapetalaceae

Erythroxylaceae

Metteniusaceae

Sapotaceae

Ebenaceae

Melastomataceae

Outras famílias
1

1

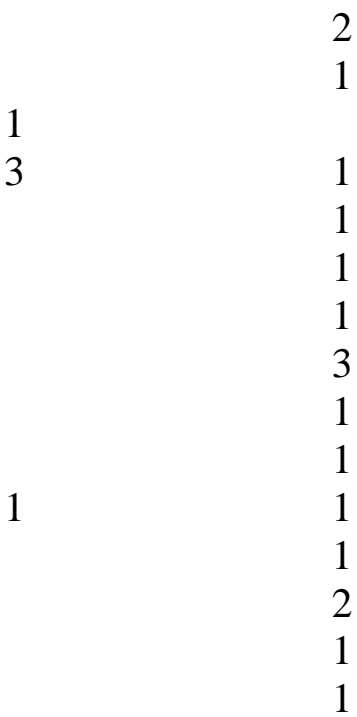

2 indet.

indet.

Fonte: Elaborado pelo autor.

A dispersão zoocória foi a síndrome que apresentou maior frequência (> 50\%) na área estudada, já a dispersão autocórica foi menor com (2,5\%). Observou-se que a dispersão zoocórica foi a síndrome que apresentou maior número de indivíduos (43) na área de estudo em Cariri do Tocantins, com a anemocórica vindo em segundo lugar com (31) e a dispersão autocórica (2), sendo inferior aos demais (Figura 2).

Figura 2 - Parâmetro fitossociológico da síndrome de dispersão das espécies, na área de estudo em Cariri do Tocantins.

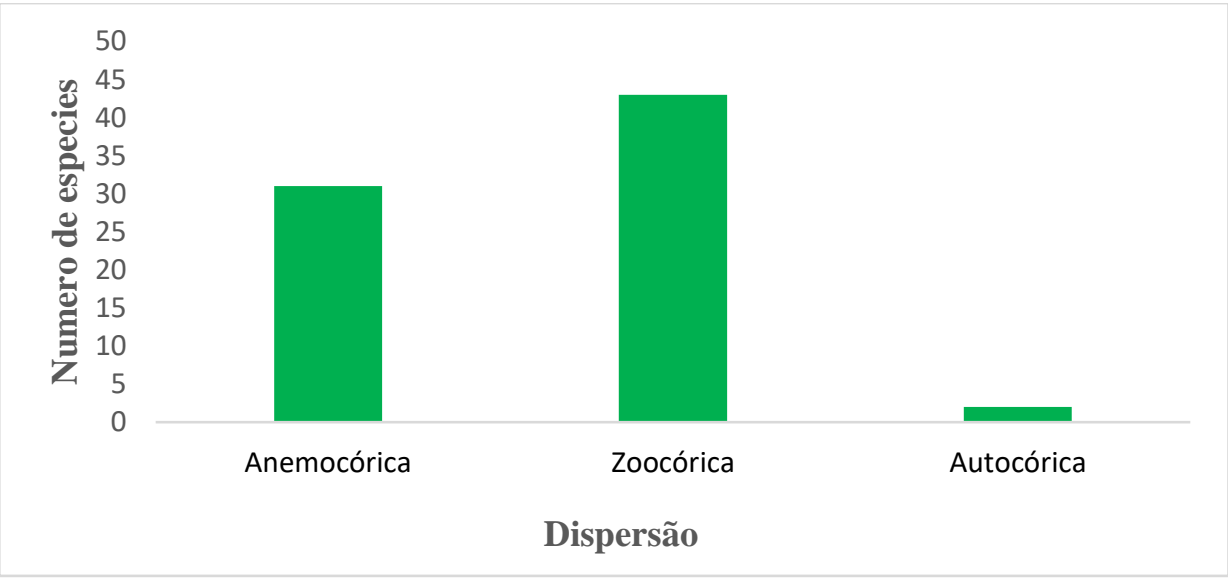

Fonte: Elaborado pelo autor.

Os resultados obtidos a partir da presente análise, apontam a uma variação significativa de dispersão, com a síndrome zoocória predominante em locais mais úmidos, e as anemocóricas presentes em áreas 
mais secas. Outros estudos apontam para variados tipos de síndromes de dispersão no Brasil. (TAKAHASHI e FINA 2004), constataram que a dispersão zoocórica e predominante no cerrado, enquanto (MACHADO et al., 1997), constataram que a dispersão autocórica e anemocórica é predominante na caatinga.

\section{Distribuição diamétrica}

Para a análise da distribuição diamétrica da área estudada foi relacionado o número de indivíduos ao seu diâmetro. Dessa forma, foram amostrados 1020 indivíduos representados em 80 espécies e 34 famílias, onde foram distribuídas em 9 classes de diâmetros, no qual apresenta amplitude de $8,1 \mathrm{~cm}$, que vai de $1 \mathrm{~cm}$ até a classe de $>64,9 \mathrm{~cm}$, visto que a classe de 56,8 a $64,9 \mathrm{~cm}$ não foi representada por nenhum indivíduo.

A disposição dos indivíduos nas classes diamétrica presentes na área de estudo apresentou formato Jinvertido, ou seja, exponencial negativa, assumindo assim, padrão típico das florestas naturais, no qual apresentam um alto número de arvores nas primeiras classes diamétricas com diâmetros baixos, e menores números de arvores nas classes que apresentam diâmetros maiores, valor este, que corrobora com (SILVA e SOUZA, 2017; REGO et al., 2015) (Figura 3).

Figura 3 - Distribuição diamétrica dos indivíduos de uma área de cerrado sensu stricto Cariri do Tocantins - TO.

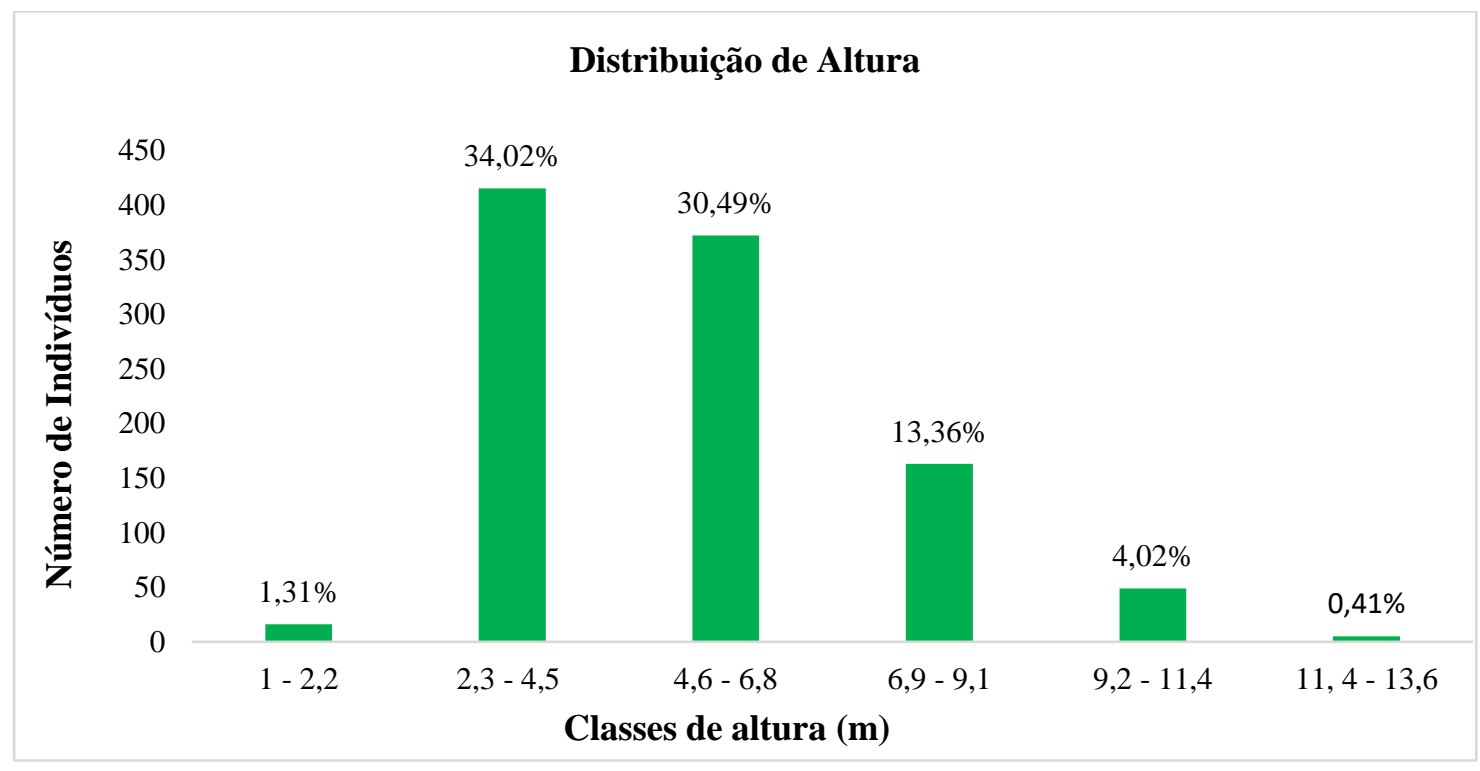

Fonte: Elaborado pelo autor.

Pode-se observar que a distribuição diamétrica indicou o estabelecimento de novos indivíduos em duas classes diamétrica de 1 a $8,1 \mathrm{~cm}$ e 8,2 a $16,3 \mathrm{~cm}$, onde apresentaram elevado número de 
indivíduos, totalizando 899 indivíduos, ou seja, 88,14\%. A grande quantidade de indivíduos presente nas primeiras classes de indivíduos pode representar uma comunidade estoque, sendo normal em áreas com idade e espécies variadas, pois os mesmos fazem parte de grupos ecológicos das espécies secundarias iniciais e tardias, indicando assim um alto valor de regeneração em virtude da elevada entrada de indivíduos, possibilitando uma favorável ascensão para estágios sucessionais maduros. (SILVA e SOUZA, 2017).

As espécies amostradas com maiores indivíduos foram Callisthene major e Byrsonima pachyphylla com diâmetro médio de 12,1cm e 7,7cm respectivamente. A espécie Callisthene major esteve presente em todas as classes diamétrica, seguido de Byrsonima pachyphylla na qual obteve-se maior número de árvores na segunda classe diamétrica, demostrando uma distribuição errática, visto que espécies com distribuição diamétrica errática, abrangem todo o gradiente ecofisiológico (SOUZA et al., 2012).

A distribuição de altura dos indivíduos, estão dispostas em 6 classes que vão de $1 \mathrm{~m}$ a 13,6m, com amplitude de 2,2m. Verificou - se que as classes de altura entre $(2,3$ a 4,5m) $(4,6$ a 6,8m) e $(6,9$ a 9,1m) somaram $77,87 \%$ do total dos indivíduos, no qual a classe 2 entre $(2,3$ a 4,5m) obtiveram o maior número de indivíduos, representando $34,02 \%$ do total, demonstrando assim que 415 indivíduos da área de estudo estão entre a altura de 2,3 e 4,5m e altura média do fragmento estudado é de 5,44m constatando que esta área apresenta uma excepcional autorregeneração dos indivíduos jovens (Figura 4).

Figura 4 - Distribuição diamétrica das classes de altura dos indivíduos de uma área de Cerrado em Cariri do Tocantins-TO.

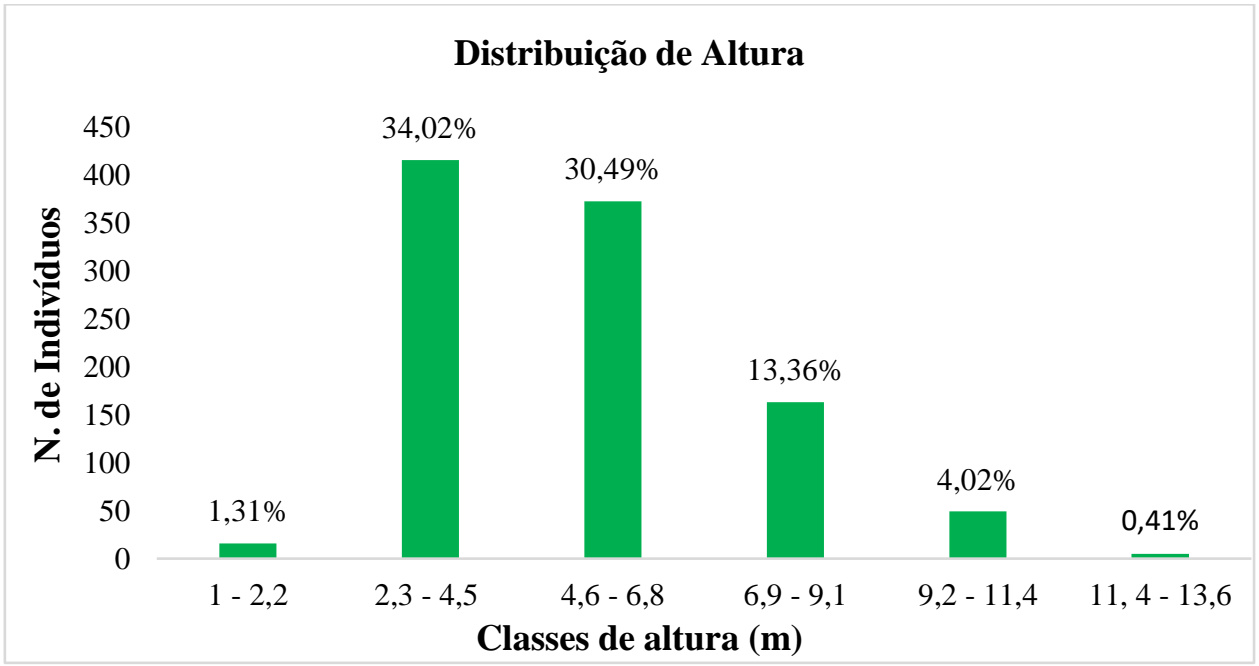

Fonte: Elaborado pelo autor. 


\section{CONCLUSÃO}

Conclui-se com cada vez mais a importância das pesquisas referente ao domínio Cerrado, possibilitando compor um banco de dados essencial para conservação da diversidade florística.

O potencial madereiro foi o que mais se destacou entre os analisados, é um recurso abundante e muito utilizado pelos seres humanos, mas deve ser conservado e manejado de forma adequada para garantir a existência deste recurso.

A maior frequência da síndrome de dispersão foi a zoocórica, isso significa que a população de fauna ao entorno da área estudada é rica e elevada.

A distribuição dos indivíduos arbóreos do cerrado sensu stricto, na área de estudo no município Cariri do Tocantins, demostrou um padrão característico de J-invertido. 


\section{REFERÊNCIAS}

AGUIAR, B. A. C.; CAMARGO, M. O.; FERREIRA, R. Q. S., TEIXEIRRA, P. R.; SILVA, R. S.; SOUZA, P. B. Florística e estrutura do componente arbustivo-arbóreo de um remanescente de cerrado sensu stricto, Gurupi, Tocantins. Revista Verde, v.13, n.1, p.45-51, 2018.

ALMEIDA-CORTEZ, J. S. Dispersão e banco de sementes. In: FERREIRA, A. G; BORGHETTI, (Eds.). Germinação: do básico ao aplicado. Porto Alegre: Artmed, cap. 14, p. 225-235, 2004.

ALVES JÚNIOR, F. T.; LINS C. F.; BRANDÃO, S.; ROCHA, K. D.; SILVA, J. T; MARAGON, L. C. Estrutura diamétrica e hipsométrica do componente arbóreo de um fragmento de mata atlântica, Recife-PE. Revista Cerne, Lavras, v.13, n.1, p.83-95, 2007.

ANGIOSPERM PHYLOGENY GROUP. An update of the Angiosperm Phylogeny Group classification for the orders and families of flowering plants: APG IV. Botanical Journal of the Linnean Society, London, v. 181, p. 1-20, jan. 2016.

AQUINO, F.G.; WALTER, B.M. T.; RIBEIRO, J. F. Espécies vegetais de Uso Múltiplo em Reservas Legais de Cerrado - Balsas, MA. Revista Brasileira de Biociências, v.45, p.147149, 2007.

BAKER, H. G. Some aspects of the natural history of seed banks. In: LECK, M. A.; ARKER, V. T.; SIMPSON, R. L. (Eds) Ecology of soil seed banks. San Diego: Academic Press, p.9-21, 1989.

BRASIL. Ministério do Meio Ambiente (MMA). Bioma Cerrado - 2016. Disponível em: Acesso em: 31 ago. 2016.

BRASIL. Ministério do Meio Ambiente. PPCerrado: Plano de Ação para prevenção e controle do desmatamento e das queimadas no Cerrado: 2a fase (2014-2015). Brasília: MMA, 2014. 132 p.

BRASIL. Novo código florestal. Brasília - DF: Palácio do Planalto, 2015. Disponível em: <http://www.planalto.gov.br/ccivil_03/_ato20112014/2012/lei/L12727.htm.>. Acesso em: 05 jun. 2015.

BRITO, E. R.; MARTINS, S. V.; OLIVEIRA FILHO, A. T.; SILVA. E.; SILVA, A. F. Estrutura fitossociológica de um fragmento natural de floresta inundável em área de orizicultura irrigada no município de Lagoa da Confusão. Revista Árvore, v.30, n.5, p.829-836, 2006.

CAMPELLO, E. F. C. Sucessão vegetal na recuperação de áreas degradadas. In: DIAS, L. E; MELLO, L. W. V. Recuperação de áreas degradadas. Viçosa: SOBRADE, 1998. p. 183-196.

CAVASSAN, O. Levantamento fitossociológico da vegetação arbórea da mata da Reserva Estadual de Bauru utilizando o método de quadrantes. 1982. 102p. Dissertação (Mestrado em Ciências Biológicas) -Instituto de Biociências de Rio Claro, Universidade. Estadual Paulista Julio de Mesquita Filho, Rio Claro.

FELFILI, J. M.; SILVA JÚNIOR, M. C. A comparative study of cerrado (sensu stricto) vegetation in Central Brazil. Journal of Tropical Ecology, n.9, p.277-289, 1993. 
FELFILI, J. M.; SILVA JÚNIOR, M. C.; REZENDE, A. V.; MACHADO, J. W. B.; WALTER, B.M.T.; SILVA, P.E.N.; HAY, J. D. Análise comparativa da florística e fitossociologia da vegetação arbórea do cerrado sensu stricto na Chapada Pratinha, DF - Brasil. Revista Acta Botanica Brasilica v.6, p.27-46. 1993.

FELFILI, J. M.; SILVA JÚNIOR, M. C.; REZENDE, A. V.; NOGUEIRA, P. E.; WALTER, B. M. T.; SILVA, M.; ENCINAS, J. I. Comparação florística e fitossociológica do Cerrado nas Chapadas Pratinha e dos Veadeiros. Brasília: Ed. UNB, 1997.

FELFILI, J. M.; SILVA JÚNIOR, M. C.; SEVILHA, A. C.; FAGG, C. W.; WALTER, B. M. T.; NOGUEIRA, P. E.; REZENDE, A. V. Diversity, floristic and structural patterns of Cerrado vegetation in Central Brazil. Plant Ecology, v.175, p.37-46, 2004.

FERREIRA, Q. S. F.; OLIVEIRA, C. M.; SOUZA, P. B.; ANDRADE, V. C. L. Fitossociologia e estrutura diamétrica de um cerrado sensu stricto, Gurupi - TO. Revista Verde de Agroecologia e Desenvolvimento sustentável, v. 10, n. 1, p. 229-235, 2015.

FERREIRA, R. L. C.; SOUZA, A. L.; JESUS, R. M. Dinâmica da estrutura de uma floresta secundária de transição. II - Distribuição diamétrica. Revista Árvore, Viçosa-MG, v. 22, n. 3, p. 331-344, 1998.

FINA, G. B.; MONTEIRO, R. Análise da estrutura arbustivo-arbórea de uma área de cerrado sensu stricto, município de Aquidauana - Mato Grosso do Sul. Revista Árvore. v.37, n.4, p.577-585, 2013.

FINGER, Z.; FINGER, F. A. Fitossociologia em comunidades arbóreas remanescentes de cerrado sensu stricto no brasil central. Floresta, v. 45, n. 4, p. 769-780, 2015.

GANEM R. S.; DRUMMOND J. A.; FRANCO J. L. A. Conservation polices and control of habitat fragmentation in the brazilian cerrado biome. Ambiente \& Sociedade, v. 16, n. 3, p. 99-118, 2013.http://dx.doi.org/10.1590/S1414- 753X2013000300007.F

GARWOOD, N. C. Tropical soil seed banks: a review. In: LECK M. A.; PARKER, V. T.; SIMPSON, R. L. (Eds.) Ecology of soil seed banks. San Diego: Academic Press, p.149-209, 1989.

HARIDASAN, M. Aluminium accumulation by some cerrado native species of central Brazil. Plant and Soil, 65:265-273, 1982.

HARPER, J.L 1977. Population biology of plants. Academic Press, New York.

KUHLMANN JR. M.; FERNANDES, F. S. Periódicos e história da educação: bases de dados como recurso metodológico. Textos FCC, n. 40, 2014. Disponível em . Acesso em 14 de novembro de 2019.

MACHAdO, E. L. M.; GONZAGA, A. P. D.; CARVALHO, W. A. C.; SOUZA, J. S.; HIGUCHI, P.; SANTOS, R. M.; SILVA, A. C.; OLIVEIRA-FILHO, A. T. Flutuações temporais nos padrões de distribuição diamétrica da comunidade arbóreo-arbustivo e de 15 populações em um fragmento florestal. Revista Árvore, Viçosa, v. 34, n. 4, p. 723-732, 2010.

MACHADO, I. C. S.; BARROS, L. M.; SAMPAIO, E. V. S. B. Phenology of Caatinga species at Serra talhada, PE, Northeastern Brazil. Biotropica, v.29, p. 57-68, 1997. 
MARTINEZ-RAMOS, M.; SOTO-CASTRO, A. Seed rain and advanced regeneration in a tropical rain forest. In: FLEMING; ESTRADA, A. (Eds). Frugivory and seed dispersal: Ecological and evolutionary Aspects. Dordrecht: Kluwer Academic Publishers, p.299-318, 1993.

MENDONÇA, R. et al. Flora vascular do bioma Cerrado: checklist com 12.356 espécies. In: SANO, S. M.; ALMEIDA, S. P.; RIBEIRO, J. F. Cerrado: ecologia e flora. [S.I.]: EMBRAPA Informações Tecnológicas, 2008. v. 2. p. 287-556.

MORI, S. A. et al. Manual de manejo de Herbário fanerogâmico. Ilhéus: CEPLAC, 1985. 97 p.

MIRANDA, S.D.C., DA SILVA JÚNIOR, M.C., DE CARVALHO, P.S. O efeito da proteção do fogo na estrutura da vegetação lenhosa de uma área de cerrado sentido restrito no Brasil Central. Heringeriana, v. 7, n. 1, p. 61-72, 2013. Disponível em: Acesso em: 16 ago. 2016.

MUELLER-DOMBOIS, D.; ELLENBERG, H. Aims and methods of vegetation ecology. New York: J. Wiley, $547 p, 1974$.

NETO, V. L. S.; OLIVERIA, A. L.; FERREIRA, R. Q. S.; SOUZA, P. B.; VIOLA, M. R. Fitossociologia e distribuição diamétrica de uma área de cerrado sensu stricto, Dueré -TO. Revista de Ciências Ambientais, Canoas, v. 10, n. 1, p. 91-2016, 2016.

NETTESHEIM, F. C. Estrutura e florística do estrato arbóreo no cerrado sensu stricto de Buritis, Minas Gerais, Brasil. Rodriguésia-Instituto de Pesquisas Jardim Botânico do Rio de Janeiro, v. 61, n. 4, 2010.

OLIVEIRA, P. E. A. M. Fenologia e Biologia Reprodutiva das Espécies de Cerrado. In: SANO, S.M.; ALMEIDA S.P.; RIBEIRO J.F. Cerrado: ecologia e flora. Planaltina: EMBRAPA-CPAC, p.273-290, 2008.

PAULA, A. D. et al. 2004. Sucessão ecológica da vegetação arbórea em uma floresta estacional semidecidual, Viçosa, MG, Brasil. Acta Botanica Brasilica; v.18 (3):407-423.

PEREIRA, I. M.; OLIVEIRA, N. F.; GONZAGA, A. P. D.; OLIVEIRA, M. L. R.;MACHADO, E. L. M.; KARAM, D. Estrutura fitossociológica de uma área de cerrado sensu stricto em Sete Lagoas, MG. Revista Enciclopédia Biosfera, v.9, n.17, p.2013-3433, 2013.

REFLORA - HERBÁRIO VIRTUAL. Jardim Botânico do Rio de Janeiro. Disponível em: http://reflora.jbrj.gov.br/reflora/herbarioVirtual/ Acesso em: 18 de out de 2019.

REGO, A. B. M. L.; SOUZA, P. B.; SILVA, R. R.; REGO, P. L.REFLORA- Flora do Brasil 2020 em construção. Jardim Botânico do Rio de Janeiro. Disponível em: < http://floradobrasil.jbrj.gov.br/ >. Acesso em: 01 junho. 2019

RIBEIRO, V.M.M. (Org.) Educação para Jovens e Adultos: ensino fundamental: proposta curricular - 1으 segmento - São Paulo: Ação Educativa: Brasília: MEC, 2001.

ROCHA, E.; REYS, P.; SILVA, P. O.; SOARES, M. P. Florística e fitossociologia de um remanescente de cerrado no sudoeste de Goiás. Revista Global Science Technology. v. 7, n. 3, p.110-118, 2014.

SANO, E. E.; ROSA, R.; BRITO, J. L. S.; FERREIRA, L. G. Land cover mapping of the tropical savanna region in Brazil. Environmental Monitoring and Assessment, v. 166, p.113-114, 2010. 
SANTOS, C. O espírito do capitalismo na ocupação dos cerrados brasileiros nos estados da Bahia e do Piauí. GOT, Revista de Geografia e Ordenamento do Território, n. 8, p. 229-253, 2015. Disponível em: Acesso em: 20 set. 2016. DOI: http://dx.doi.org/10.17127/got/2015.8.012

SAPORETTI JR. A, W.; MEIRA NETO, A. A. J.; ALMADO, R. et al. Fitossociologia de um sub-bosque de cerrado em talhão de Eucalyptus grandis W. Hill ex Maiden no município de Bom Despacho - MG. Revista Árvore, v.27, n.6, p.905-910, 2003.

SEPLAN - SECRETÁRIA DE PLANEJAMENTO DO TOCANTINS. Atlas do Tocantins: subsídios ao planejamento da gestão territorial, Palmas. Atual, v. 6, 2012.

SHEPERD, G. J. FITOPAC 2: manual do usuário. Campinas: Unicamp, 2010. 91p.

SILVA, G. O.; SOUZA, P. B. FITOSSOCIOLOGIA E ESTRUTURA DIAMÉTRICA DE UM REMANESCENTE DE CERRADO SENSU STRICTO, GURUPI - TO. Revista Desafios, v. 3 Especial, 2016 (Suplemento).

SILVA, G. O.; SOUZA, P. B. Fitossociologia e estrutura diamétrica de um fragmento de cerrado sensu stricto, Gurupi - To. Revista Desafios, ano 2016, v. 03, p. 22-29, 24 fev. 2017.

SILVA, N. V. L.; OLIVEIRA, A. L.; FERREIRA, R. Q. S.; SOUZA, P. B.; VIOLA, M. R. Fitossociologia e distribuição diamétrica de uma área de cerrado sensu stricto, Dueré - TO. Revista de Ciências Ambientais, v. 10, n. 1, p. p. 91-106, 2016.

SILVA, S. M.; SOUZA, A. C.; SILVA, L. F.;PADOVAN, M. P. Sistemas agroflorestais diversificados no Cerrado: alternativa para usos múltiplos. Anais $4^{\circ}$ Seminário de Agroecologia do Mato Grosso do Sul, v.7, n 2, 2012.

SIMINSKI, A.; MANTOVANI, M.; REIS, M. S.; FANTINI, A. C. Sucessão florestal secundária no município de São Pedro de Alcântara, litoral de Santa Catarina: Estrutura e diversidade. Ciência Florestal, Santa Maria, v.14, n.1, p.2133, 2004.

SOUZA, P. B.; MEIRA NETO, J. A. A; SOUZA, A. L. Diversidade florística e estrutura fitossociológica de um gradiente topográfico em Floresta Estacional Semidecidual Submontana, MG. Cerne, v. 19, p.4 89499, 2012.

TAKAHASI, A.; FINA, B.G. Síndromes de dispersão de sementes de uma área de Morro do Paxixi, Aquidauana. MS, Brasil. In: SIMPÓSIO SOBRE RECURSOS NATURAIS E SÓCIO-ECÔNOMICOS DO PANTANAL, 4, 2004. Corumbá. Anais. Corumbá: UFMS, 2004. P. 1-7.

VAN DER PIJL, L. 1982. Principles of dispersal in higher plants. 3rd ed. Springer-Verlag, Berlin. 


\section{Capítulo 14}

doi) $10.37423 / 210804570$

\section{DIAGNÓSTICO DO DESTINO FINAL DAS LÂMPADAS FLUORESCENTESPÓS- CONSUMO UTILIZADAS NA ILUMINAÇÃO PÚBLICA DOMUNICÍPIO DE BOA VISTA-RR}

\section{Daniela Cristina da Silva Melo}

Antonia Raniely Vieira da Silva

\section{Leovergildo Rodrigues Farias}

Instituto Federal de Educação, Ciência e Tecnologia de Roraima

Instituto Federal de Educação, Ciência e Tecnologia de Roraima

Instituto Federal de Educação, Ciência e Tecnologia de Roraima

Instituto Federal do Rio Grande do Norte 
Resumo: A intensificação das atividades urbanísticas tem ocasionado o aumento na geração dos resíduos sólidos, que atualmente vem se tornado um preocupante problema ambiental. Dentre esses resíduos, merece destaque as lâmpadas fluorescentes, que apesar de serem mais baratas e duráveis, oferecem riscos de contaminação do meio ambiente e à saúde humana. Sendo assim, este estudo tem por objetivo fazer o diagnóstico da situação das lâmpadas fluorescentes utilizadas na iluminação pública do município de Boa Vista-RR e, principalmente, do seu destino final. Desse modo, visando alcançar o objetivo proposto, aplicou-se a pesquisa de caráter exploratório com enfoque qualitativo e quantitativo, tendo sido necessário o emprego do referencial teórico, bem como a coleta de dadosnas instituições e empresas responsáveis pela iluminação pública, além do registro fotográfico de lugares, objetos e situações inseridos no contexto da pesquisa. Constatou-se que o setor de iluminação pública de Boa Vista faz uso das lâmpadas fluorescentes, sendo responsável pelo serviço a Superintendência de Iluminação Pública da Prefeitura, por meio da empresa terceirizada Urbeluz Energética S/A. Igualmente, constatou-se que a empresa em questão também é responsável pela manutenção do serviço, além de participar do processo de destinação final das lâmpadas. Verificou-se,ainda, que o Aterro Sanitário do município, possivelmente receptor de lâmpadas fluorescentes, encontra-se em estado crítico, oferecendo riscos ao meio ambiente e às pessoas. Por fim, constatou-se a relevância da pesquisa, não só por fazer o diagnóstico sobre o destino final das lâmpadas, mas também pelo fato de não constarem registros bibliográficos locais sobre o assunto. Permite também, a percepção da real situação da problemática abordada, além de apontar o grau de conhecimento e a preocupação por parte dos gestores com a questão do destino final das lâmpadas e comoa necessidade da implementação de soluções mais eficazes.

Palavras-chave: crescimento urbano, iluminação pública, lâmpadas fluorescentes, destino final. 


\section{INTRODUÇÃO}

Como consequência da aglomeração urbanística, que se deu a partir do século XX e continua presente no momento atual, houve o aumento da quantidade e da diversidade dos resíduos produzidos nas atividades antrópicas, incluindo as industriais, comerciais, profissionais e públicas.

Dentre os resíduos sólidos urbanos, é importante ressaltar as lâmpadas fluorescentes, que apesar de apresentarem em sua composição o mercúrio -substância classificada pelaNBR 10004 como perigosa à salubridade do meio ambiente e à saúde humana (ABNT, 2004) -surgiram no Brasil como medida paliativa na problemática do racionamento de energia e, que por razões econômicas e práticas, vêm sendo utilizadas em grande escala. Não foram encontrados registros na literatura sobre a quantificação nem sobre o destino final das lâmpadas fluorescentes impróprias para utilização no município de Boa Vista.

Sendo assim, considerando que essas lâmpadas contêm vapor de mercúrio, bem como,a suacrescente utilização e o risco potencial de intoxicação durante a manipulação, além do fato de que, sistematicamente, alguns manipuladores não demonstram preocupação com o manuseio e destino final dessas lâmpadas, que geralmente depois de quebradas são descartadas no lixo comum, este trabalho torna-se importante por avaliar o destino final das lâmpadas fluorescentes pós-consumo utilizadas na iluminação pública do município de Boa Vista-RR.

\section{MATERIAL E MÉTODOS}

\section{MATERIAIS}

Para coleta, armazenamento e tratamento dos dados foram utilizados os materiais descritos na Tabela 1. 
Tabela 1 -Material utilizado.

\begin{tabular}{|c|}
\hline MATERIAIS \\
\hline Bloco de anotação \\
\hline Caneta esferográfia \\
\hline Câmera fotográfica \\
\hline Aparelho celular \\
\hline Pen Drive \\
\hline Computador \\
\hline
\end{tabular}

\section{METODOLOGIA}

Trata-se de pesquisa científica desenvolvida no município de Boa Vista-RR, capital do estado de Roraima, abordando a problemática do destino final das lâmpadas fluorescentes, fazendo-se necessário, primeiramente, direcionar o foco do estudo para o setor de iluminação pública e, a partir disso, aplicar a pesquisa de campo de caráter exploratório com enfoque quantitativo e qualitativo.

O empregado do enfoque qualitativo ocorreu por meio da avaliação da qualidade do destino final dado às lâmpadas fluorescentes pós-consumo, com base na correlação feita entre o referencial teórico, a observação e os dados coletados no decorrer da pesquisa.

No que se refere à quantificação, foiefetivada por meio da coleta de dados junto a gestores e instituição/empresa responsáveis pela iluminação pública no município e pelo tratamento final dos resíduos gerados nesse processo.

Além da fundamentação teórica, serviram também como fonte de coleta de dados e informações, alguns órgãos e empresas públicas, a saber: Eletrobrás, Prefeitura Municipal de Boa Vista, por meio da Superintendência de Iluminação Pública, Urbeluz Energética S/A e Superintendência de Coleta de Lixo. 
Fizeram-se necessárias,ainda, visitas de campo a fim de verificar e registrar a presença de lâmpadas fluorescentes pós-uso, as condições em que se encontravam, bem como,o tipo de tratamento que recebem. Entretanto, essa fase da pesquisa apresentou certo grau de dificuldade,visto que se fez necessário contar com a colaboração das instituições envolvidas, além de esbarrar nos trâmites burocráticos.

É importante ressaltar, ainda, que na realização deste trabalho foram utilizados materiais representados na Tabela 1 , além da utilização do sistema de informação que éessencial para a efetivação de uma pesquisa.

\section{RESULTADOSE DISCUSSÃO}

O município de Boa Vista, capital do estado de Roraima (Figura 1), que segundo Freitas (2000, p. 11) é a única capital brasileira totalmente inserida no hemisfério norte do planeta, possui 284.313 habitantes, ocupando uma área de 5.687,022 km² e uma densidade demográfica igual a 49,99 hab./ $\mathrm{km}^{2}$ (IBGE, 2010).

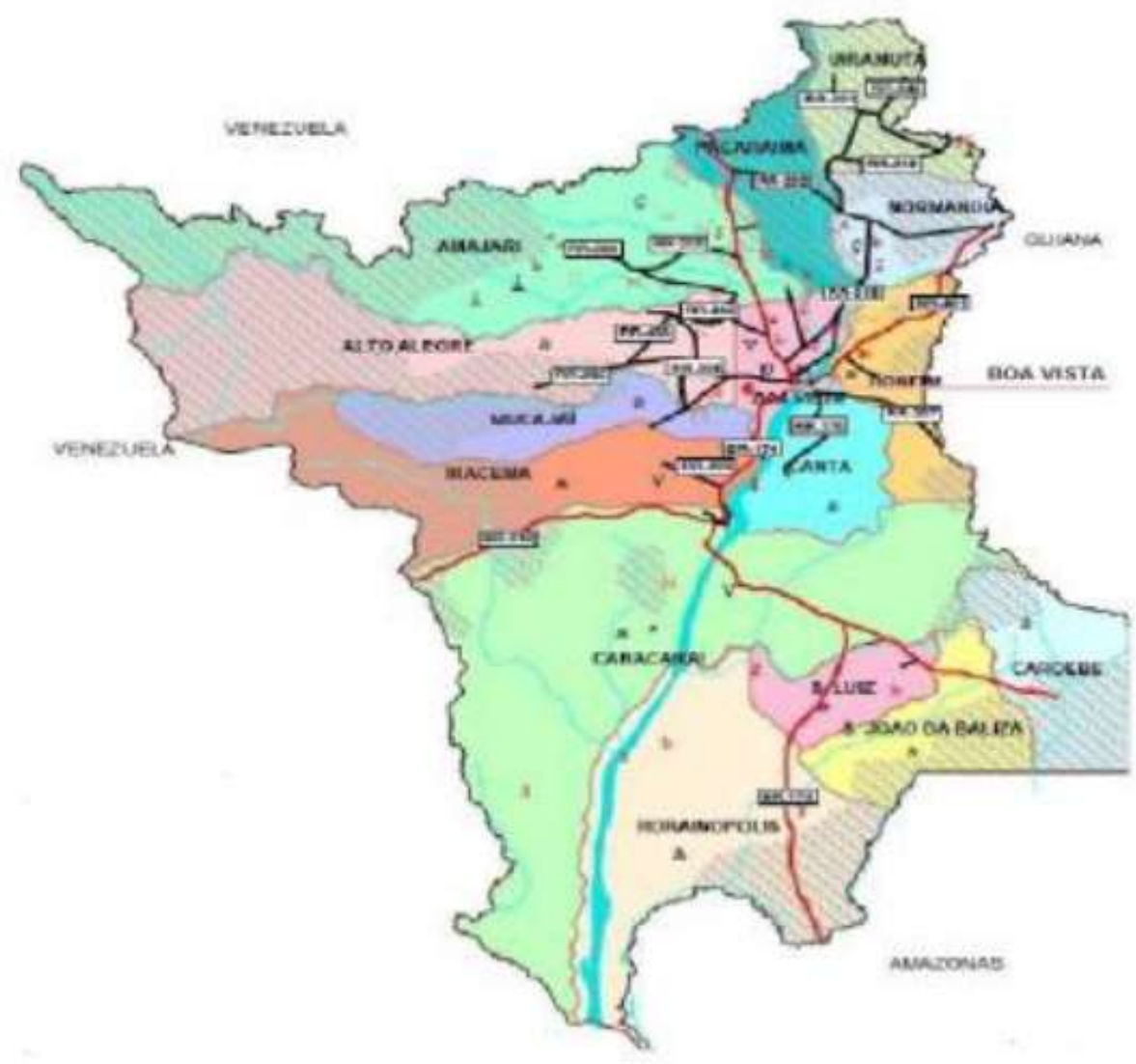

Figura 1 Mapa de Roraima. Fonte: SEPLAN/RR,2010 
Em Boa Vista, como em qualquer centro urbano, existe o serviço de iluminação pública, fundamental parar o desenvolvimento social e econômico de uma comunidade e para a qualidade de vida de seus cidadãos, no qual as lâmpadas fluorescentes são largamente utilizadas, não só por serem mais econômicas e duráveis, mas também por cumprirem sua finalidade com mais eficiência. Apesar disso, as lâmpadas fluorescentes, por sua periculosidade e nocividade, necessitam ser dispostas de maneiraambientalmente correta, bem como,receber destinação final adequada para que haja uma redução nos impactos ambientais e para que as relações entre o homem e o meio sejam viáveis.

Os resíduos sólidos são definidos de diversas maneiras e segundo Lima (2004, p. 11-12) são muitos os fatores que influenciam na formação do lixo no meio urbano. Desse modo, é importante ressaltar que eles são classificados de acordo com a atividade ou processo que lhes deu origem e, ainda, segundo a periculosidade que oferecem pelacapacidade de causar impactos ao meio ambiente e danos à saúde humana.

Sendo assim, se considerarmos a sua origem, as lâmpadas fluorescentes estão inseridas no grupo dos resíduos sólidos domiciliares ou comerciais, porém, se for levado em consideração a sua composição química e nocividade, elas são consideradas resíduos perigosos.

As lâmpadas fluorescentes são consideradas resíduos urbanos, pois,como o próprio termo pressupõe, esses resíduos são aqueles gerados nas atividades desenvolvidas no meio urbano e, segundo Philippi (2005, p. 276) incluem-se neles os resíduos produzidos nas instituições e serviços públicos, tais como, obras e iluminação pública.

Já a coleta, o transporte e a disposição final dos resíduos urbanos são de responsabilidade das prefeituras e, de acordo com Philippi (2005, p.278) "A coleta, o transporte, o tratamento, e a destinação desses resíduos constituem, portanto, serviço público de saneamento básico de alto interesse para a saúde pública".

Na capital do Estado de Roraima, a iluminação pública está sob a responsabilidade da Superintendência de Iluminação Pública da Prefeitura, que funciona no prédio da Secretaria Municipal de Obras e Urbanismo -SMOU (Figuras 2 e 3), por meio da empresa terceirizadaUrbeluz Energética S/A, proveniente do estado de São Paulo e que atua legalmente no município desde agosto de 2010. 


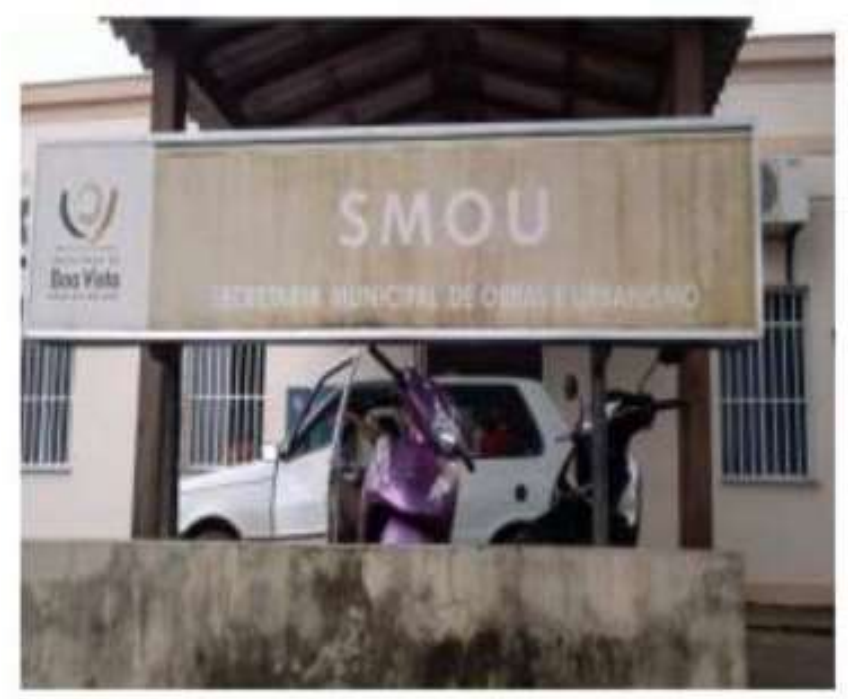

Figura 2 Prédio da SMOU de Boa Vista, 2012.

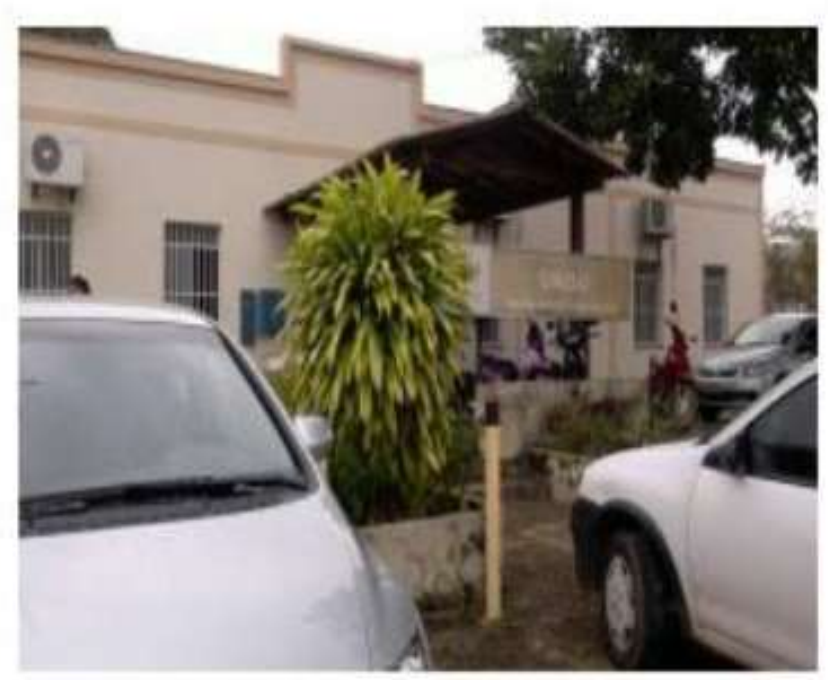

Figura 3 Sup. de lluminação Pública, 2012.

De acordo com dados fornecidos pela Superintendência de lluminação Pública, atualmente,o total de lâmpadas sendo utilizadas no parque de iluminação do município é de 43.480 mil, sendo que desse total 3.509 mil possuem vapor de mercúrio em sua composição (Figura 4) e as demais, apresentam o vapor desódio (Figura 5).

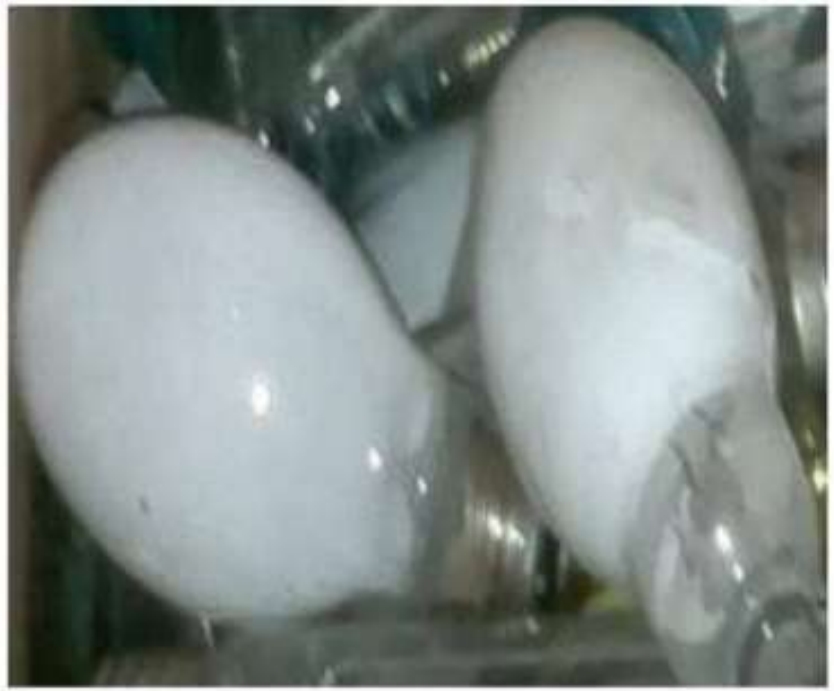

Figura 4 Lâmpadas contendo mercúrio, 2012 figura 5 Lâmpadas àvapor de sódio, 2012

É importante ressaltar que, realizaram-se três visitas à Superintendência de lluminação Pública com a finalidade de obter mediação junto à Urbeluz, já que grande parte das informações e dados necessários para a continuidade da pesquisa e fechamento deste relatório foi coletada na referida empresa, que é responsável pela manutenção do serviço de iluminação pública no município como, 
por exemplo, reposição de fios danificados ou daqueles que são furtados e troca das lâmpadas queimadas ou danificadas por ações de vandalismo, conforme demonstra a Figura 6.

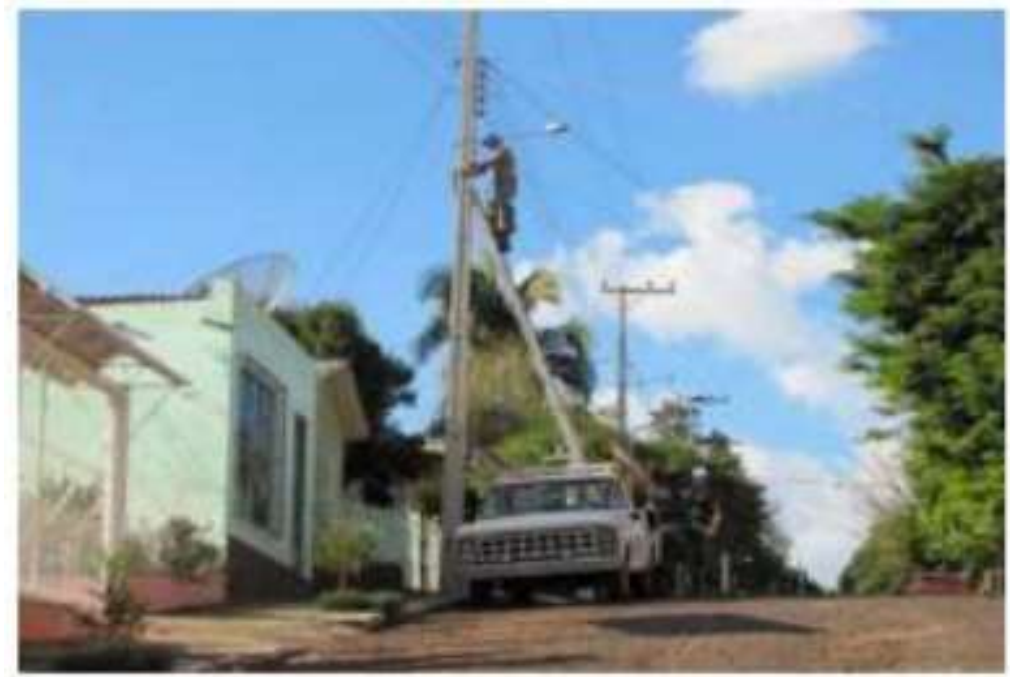

Figura 6 Urbeluz faz reparos na iluminação pública.

Fonte: Diário do Congresso, 2011.

Além de fazer a manutenção do serviço de iluminação pública no município, a Urbeluz também é responsável pelo controle da quantidade de lâmpadas pós-consumo geradas em determinado período de tempo, além de participar da fase inicial do processo de destinação final das lâmpadas, já que tem por incumbência recolher do parque de iluminação pública as lâmpadas inutilizadas, para, tecnicamente, realizar a triagem do material, conforme demonstra a Figura 7.

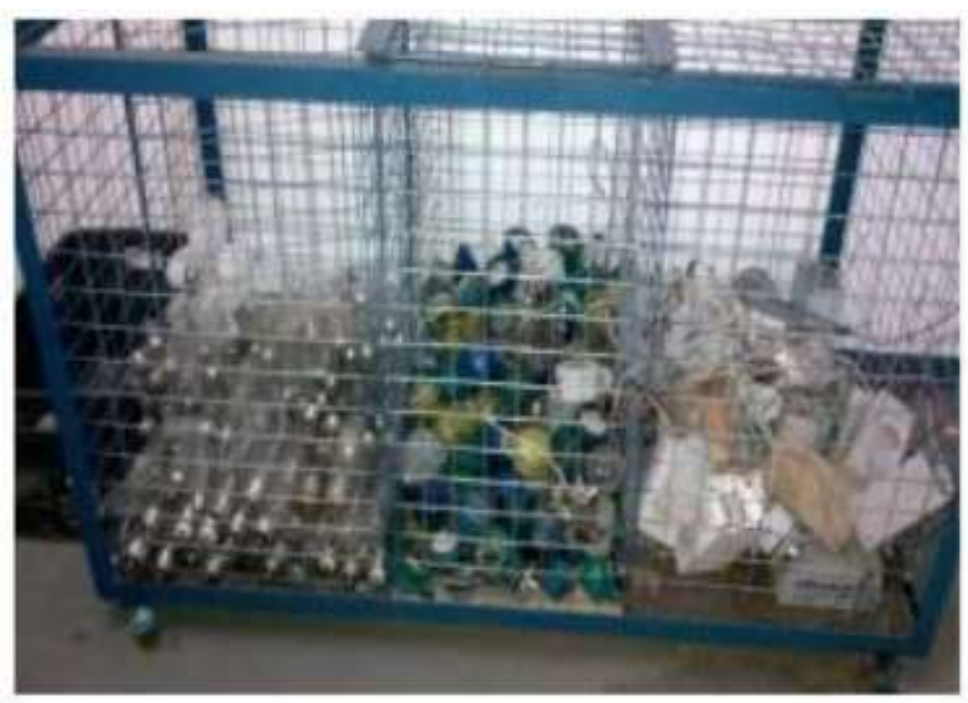

Figura 7 Contêiner utilizado na separação das lâmpadas, 2012. 
Em seguida, as lâmpadas são acondicionadas em embalagens plásticas resistentes e, por fim, estocadas na área de descarte (Figuras 8 e 9), até que sejam removidas para o depósito da Prefeitura.

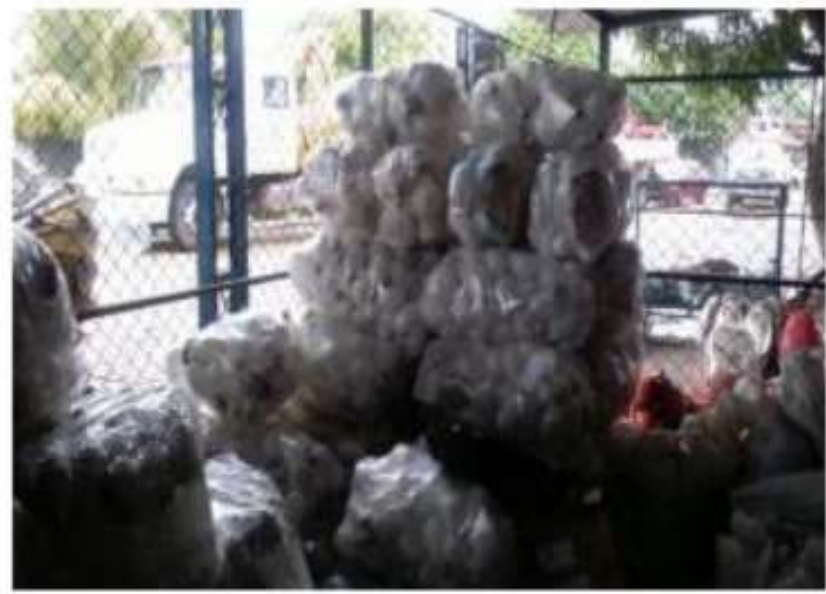

Figura 8 Lâmpadas embaladas, 2012.

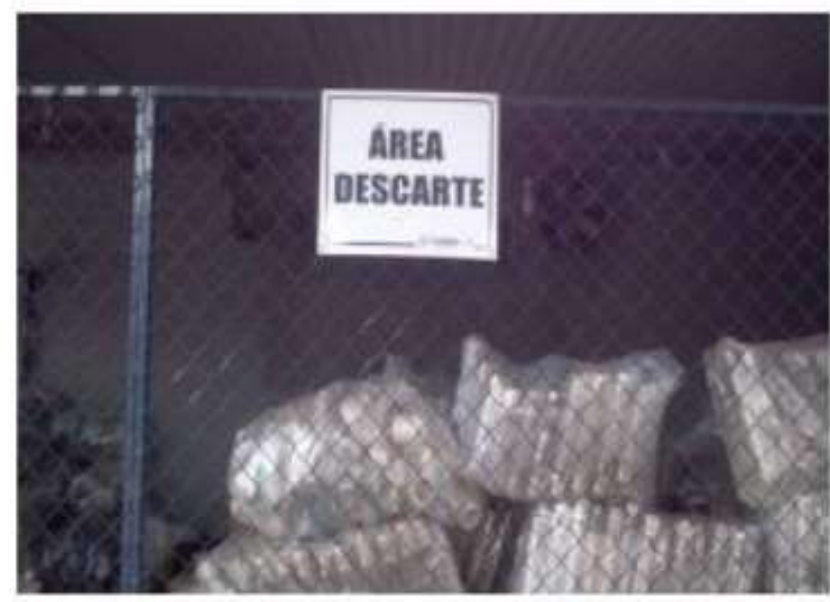

Figura 9 Área de descarte da Urbeluz, 2012.

Segundo informações coletadas "in loco", após serem encaminhadas ao depósito da Prefeitura, as lâmpadas são quebradas e/ou trituradas para logo em seguida serem acondicionadas em tambores que estão dispostos dentro do depósito reservado para esse fim. Constatou-se, no entanto, que o destino final dado às lâmpadas fluorescentes pós-consumo, além de provisório é inadequado, pois,a quebra desses resíduos é imprópria já que a partir do rompimento das lâmpadas ocorre a liberação do vapor de mercúrio e, consequentemente, a poluição do ar atmosférico, bem como,a contaminação dos manipuladores e seres vivos em geral.

Apesar da Lei n. 12.305/2010, que trata da política nacional dos resíduos sólidos, estabelecer a política reversa, isso não se aplica na realidade do município de Boa Vista, já que ele não dispõe de uma legislação regulamentadora específica. Diante dos fatos e de acordo com os relatos do superintendente de iluminação pública, apesar da destinação final mais acertada, do ponto de vista ambiental e econômico, ser a reciclagem, as lâmpadas pós-consumo permanecem estocadas, conforme demonstra a Figura 10, até que uma solução mais adequada seja definida, tendo em vista que Boa Vista e o estado de Roraima, não dispõem de um sistema de reciclagem ou de uma empresa recicladora desse tipo de resíduo. 


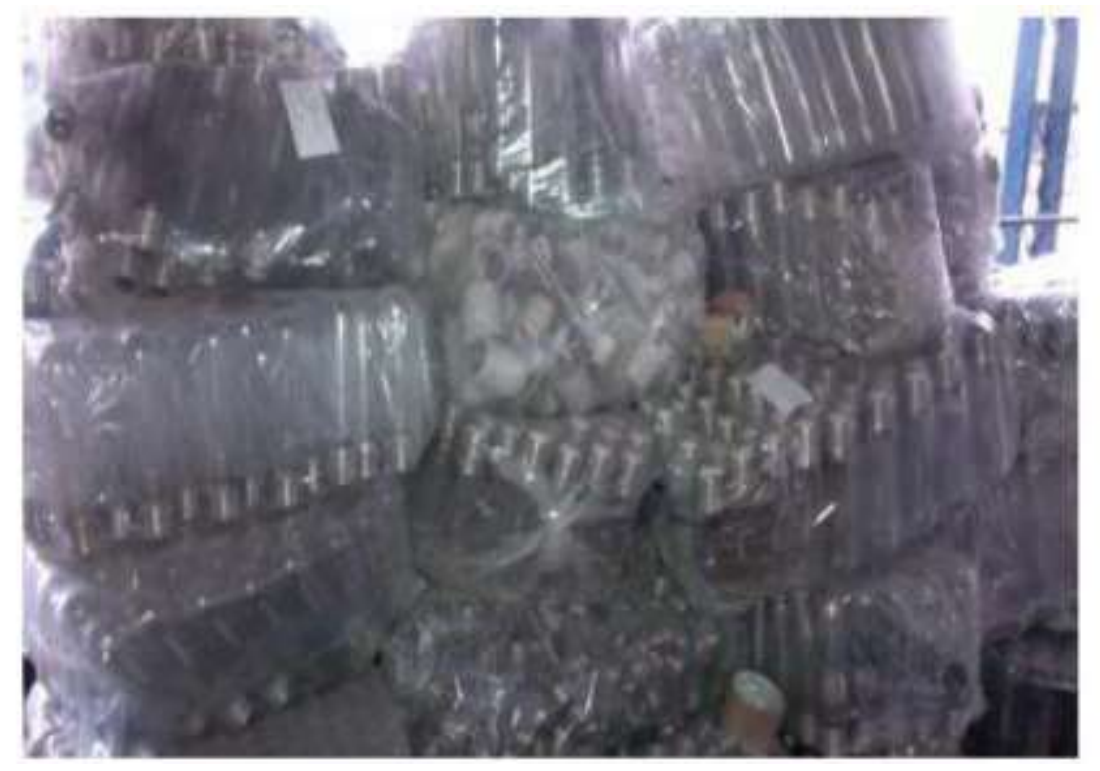

Figura 10 Lâmpadas fluorescentes embaladas e estocadas, 2012.

Infelizmente, a visita ao Aterro Sanitário de Boa Vista, de extrema contribuição para a pesquisa, ainda não foi autorizada pelo órgão responsável, Superintendência de Serviço Ambiental da Prefeitura, apesar de ter sido encaminhado, no dia 25.06.2012, um documento solicitando autorização da coleta de dados no local. Segundo o superintendente de serviço ambiental, as visitas somente serão liberadas após o término do período chuvoso.

Apesar de ainda não ter sido possível o acesso ao interior do aterro, efetuou-se visita "in loco" a sua área externa, onde se observou uma verdadeira montanha de lixo contendo os mais variados tipos de resíduos sólidos, conforme ilustrado na Figura 11, dentre os quais,possivelmente,estão inseridas as lâmpadas fluorescentes.

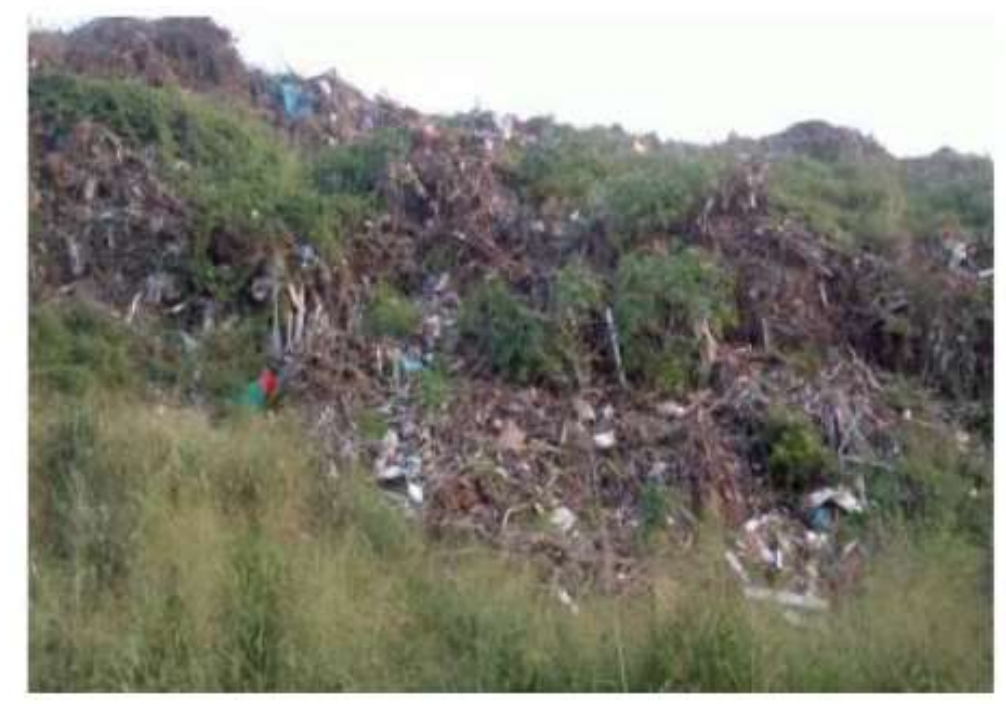

Figura 11 Montanha de lixo no Aterro Sanitário, 2012. 
Observou-se ainda a presença de focos de fogo e grande quantidade de fumaça ao longo da montanha de lixo, conforme representa a Figura 12. Esse fato comprova a cultura inadequada de atear fogo no lixo na tentativa de amenizar a problemática em relação à demanda de resíduos que não está mais sendo atendida pela estrutura do aterro. No entanto, essa tentativa de mitigar o problema acaba, na verdade, trazendo problemas ambientais maiores ainda, já que a combustão acaba liberando na atmosfera gases poluidores do ar e destruidores da camada de ozônio, trazendo riscos de explosões, além de possibilitar o rompimento de materiais de vidro, como as lâmpadas fluorescentes, o que viabiliza a poluição do solo, dos lençóis freáticos e da biota pelo mercúrio inerente a esse tipo de lâmpada.

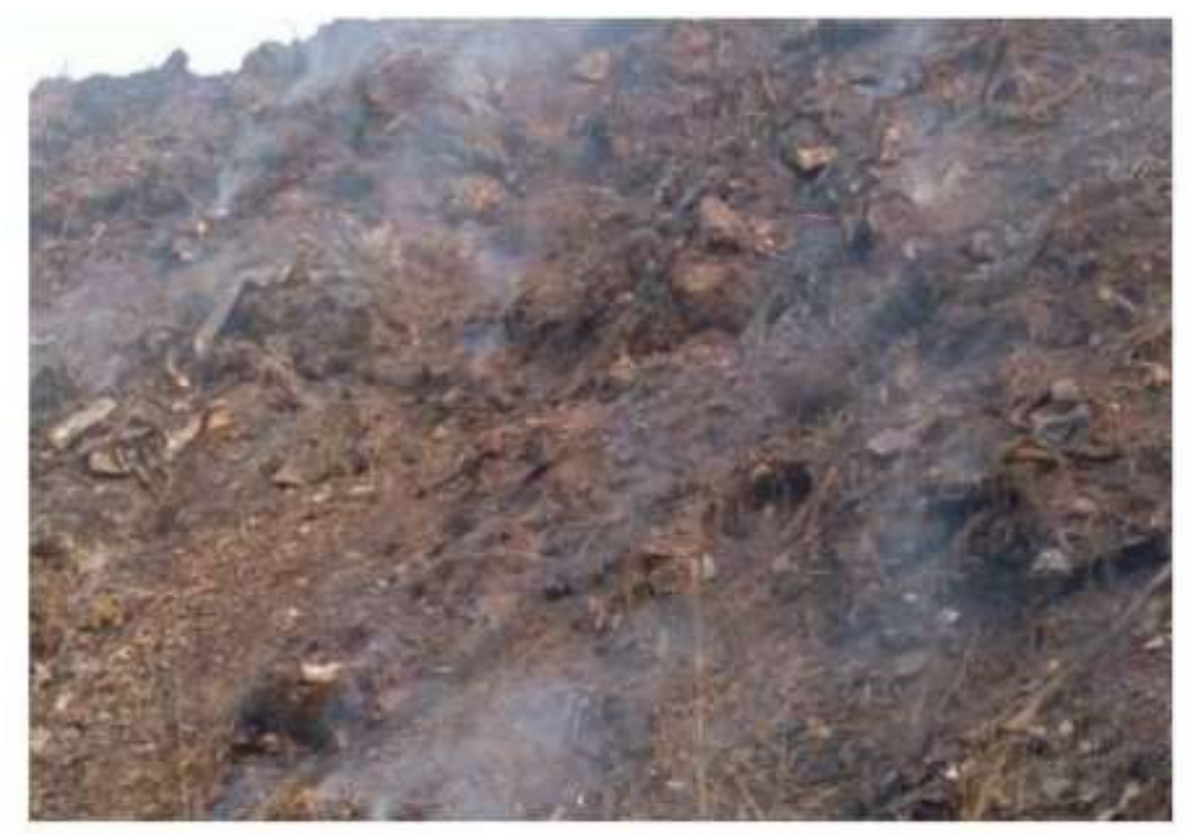

Figura 12 Montanha de lixo no aterro sanitário com presença de fogo e fumaça, 2012.

\section{CONSIDERAÇÕES FINAIS}

Considerando que o município de Boa Vista faz uso de lâmpadas fluorescentes no processo de iluminação pública e que esse tipo de lâmpada é classificada como resíduo perigoso pela nocividade que oferece ao meio ambiente e à saúde humana, esta pesquisa se torna de grande relevância, não só por fazer o diagnóstico sobre o destino final dado às lâmpadas, mas também pelo fato de não constarem registros bibliográficos locais sobre o assunto.

A pesquisa em tela também possibilita a percepção da real situação da problemática abordada e por mais que exista a boa intenção e o esforço por parte dos gestores que estão diretamente ligados ao processo de destinação final das lâmpadas, falta conhecimento mais aprofundado sobre o assunto e 
soluções mais eficazes para a problemática, como por exemplo, a implantação de uma empresa recicladora ou a exportação das lâmpadas para recicladoras de outros estados brasileirosou mesmooutros países (realizando a logística reversa). Entretanto, para que isso se torne possível, fazse necessário um maior empenho do poder público local no sentido de criar políticas públicas voltadas para essaquestão, como o incentivo à implantação de empresas de reciclagem e criação de convênios com outros municípios, além da devida regulamentação e fiscalização.

É importante ressaltar,também, que por meio deste trabalho, tornou-se possível avaliar o grau de conhecimento e a preocupação dos gestores com a questão do destino adequado das lâmpadas fluorescentes, além de permitir a identificação das pessoas mais vulneráveis de modo que, no futuro, se possa empreender ações de monitoramento mais sistematizadas, por meio da educação ambiental. Igualmente, deve-se ratificar que os resultados ora disponibilizados servem como referência para estudos posteriores, bem como, para motivar e auxiliar o desenvolvimento de trabalhos de conclusão de cursos. 


\section{REFERÊNCIAS}

ASSOCIAÇÃO BRASILE IRA DE NORMAS TÉCNICAS. NBR 10004: Resíduos Sólidos classificação . Rio de Janeiro: 2004. Disponível em: < http://www.aslaa.com.br>. Acesso em 28.03.2012. BRASIL.

Lei da Presidência da República n. 12.305 de 02 de agosto de 2010. Disponível em: <http:// www.planalto.gov.br>. Acessado em: 04.08.2012.

FREITAS, Aimberê. Geografia e História de Roraima . Ed. rev. e ampl. Boa Vista: DML, 2000, p.11.

INSTITUTO BRASILEIRO DE GEOGRAFIA E ESTATÍSTICA IBGE. Censo 2010 . Disponível em: http://www.ibge.gov.br>. Aces sado em 28.03.2012.

LIMA, Andrielly. Avenidas e ruas de Boa Vista recebem reparos de iluminação pública. Diário do Congresso . Boa Vista, nov., 2011. Disponível em: < http://diariodocongresso.com.br>. Acessado em: 02.08.2012.

LIMA, Luiz Mário Queiroz. Lixo Tratamento e Biorremediação . 3a ed. rev. e ampl. São Paulo: Hemus, 2004, p. 1112.

PHILIPPI, Arlindo Junior. Saneamento, Saúde e Ambiente. São Paulo: Manole, 2005, p. 276278 e 305.

SECRETARIA DE ESTADO DO PLANEJAMENTO E DESENVOLVIMENTO DE RORAIMA SEPL AN. Informações Socioeconômicas do Município de Boa Vista RR . Boa Vista: CGEES/SEPLAN RR, 2010, p. 56. 


\section{Capítulo 15}

doi $10.37423 / 210804573$

\section{AVALIAÇÃO DAS CARACTERÍSTICAS FÍSICO- QUÍMICAS DE FRUTOS DO NONI (MORINDA CITRIFOLIA LINN.)}

Wellkens David da Silva Praxedes

Lucas Figueira da Silva

Mateus Madruga da Silva

José Carlos da Silva

José Marcílio da Silva

Amanda Reges de Sena
Instituto Federal de Educação, Ciência e

Tecnologia de Pernambuco

Instituto Federal de Educação, Ciência e Tecnologia de Pernambuco

Instituto Federal de Educação, Ciência e Tecnologia de Pernambuco

Instituto Federal de Educação, Ciência e Techologia de Pernambuco

Instituto Federal de Educação, Ciência e Tecnologia de Pernambuco

Instituto Federal de Educação, Ciência e Tecnología de Pernambuco 
Resumo: O noni (Morinda citrifolia Linn.) é uma árvore tropical amplamente distribuída, crescendo nas ilhas do Pacífico Sul, sudeste Asiático, América Central, subcontinente Indiano e Caribe. Seus frutos e folhas têm um histórico de uso tanto na alimentação humana como para promoção da saúde. No entanto, sua comercialização ainda é vedada no país por não existir comprovação científica de que o fruto não seja nocivo à saúde humana. O presente trabalho teve por objetivo avaliar as características físico-químicas da polpa do noni cultivado no Instituto Federal de Educação, Ciência e Tecnologia de Pernambuco (Campus Barreiros). Foram realizadas as análises de $\mathrm{pH}$, umidade, acidez total titulável (ATT), sólidos solúveis totais (SST) e Vitamina C. Todas as análises foram realizadas em triplicata e conforme as Normas Analíticas do Instituto Adolf Lutz. A polpa apresentou valor médio de SST igual a 7,0 Brix, pH igual a 4,04, 0,29 g/100 g em ácido cítrico, 162,00 mg ácido ascórbico/100 g e 91,07 \% de umidade. Todos os dados obtidos estão em acordo com a literatura citada. Os resultados demonstraram que a polpa do noni apresenta uma significativa quantidade de vitamina $\mathrm{C}$ e alta relação sólidos solúveis/acidez titulável.

Palavras-chave: ácido ascórbico, Morinda citrifolia L., parâmetros físico-químicos, Rubiaceae 


\section{INTRODUÇÃO}

Morinda citrifolia Linn. (Rubiaceae), comumente conhecido como noni, é uma planta tropical e subtropical tipicamente encontrados no Havaí e ilhas do Taití. A espécie é uma pequena árvore perene encontrada crescendo em regiões costeiras e em áreas de floresta. É identificável pelo seu tronco reto, grandes folhas verdes brilhantes e elíptica, além de brancas flores tubulares. A fruta pode crescer até $12 \mathrm{~cm}$ ou mais, e tem uma superfície irregular coberta por poligonal em forma de secções. As sementes são de forma triangular e castanho avermelhado (Swanholm et al., 1959).

Recentemente seus extratos têm sido comercialmente processados e distribuídos internacionalmente como um suplemento dietético, tendo gerado em 15 anos alguns bilhões de dólares (Nandhasri et al., 2005). Diferentes partes da planta (casca, caule, raiz, folha e frutas) têm sido utilizadas tradicionalmente também na Polinésia, Sul Asiático e Austrália. Estudos demostram seus efeitos contra doenças relacionadas ao estilo de vida, tais como, aterosclerose, hipertensão, desordens vasculares, acidente vascular cerebral, diabetes e câncer. Além disso, seu suco é conhecido por conter substâncias com propriedades anti-inflamatórias, antioxidantes e contra a leishmaniose (Harada et al., 2009; Nayak et al., 2009; Takashima et al., 2007; Wang et al., 2002; Almeida-Souza et al., 2016; Gimenes et al., 2018). No entanto, estudos demostraram efeitos hepatotóxicos devido a presença de antraquinonas (Stadlbauer et al., 2005). Outra pesquisa, demonstrou que a presença de sequestradores de radicais livres são perdidos durante o processamento e estocagem de frutos e sucos de noni (Yang et al., 2007). O aumento dos produtos derivados como suplemento dietéticos sugere investigações urgentes com relação aos propósitos de controle de qualidade (Ikeda et al., 2009).

As características químicas relacionadas ao sabor, odor, textura e valor nutritivo, constituem atributos de qualidade à comercialização e utilização da polpa na elaboração de produtos industrializados (Oliveira et al., 1999). Há um grande marketing do suco de noni no Brasil e o seu cultivo é relatado nos Estados do Acre, São Paulo, Pará, Sergipe e Ceará, mas ainda são poucos os trabalhos de pesquisa desenvolvidos no Brasil com essa espécie (Correia et al., 2011). No entanto, vale ressaltar que é vedada a comercialização dos produtos oriundos dessa fruta, pois para a ANVISA (Agência Nacional de Vigilância Sanitária) não há comprovação científica de que o fruto não seja nocivo à saúde humana (Brasil, 2007).

A partir do exposto, o objetivo do trabalho foi avaliar alguns parâmetros físico-químicos dos frutos de noni introduzidos na área experimental do Institito Federal de Educação, Ciência e Tecnologia (IFPE), Campus Barreiros. 


\section{MATERIAL E MÉTODOS}

O presente experimento foi conduzido no Laboratório de Bromatologia do IFPE/Barreiros, localizado no município de Barreiros, $\mathrm{PE}$, às coordenadas geográficas de $08^{\circ} 49^{\prime}$ (S) e $35^{\circ} 11^{\prime}$ (W), a uma altitude média de $22 \mathrm{~m}$ e relevo ondulado a fortemente ondulado. O clima é do tipo AS' (quente e úmido) com chuvas de outono-inverno (Köppen, 1936), com temperatura e precipitação média anuais de $25^{\circ} \mathrm{C} \mathrm{e}$ $1.500 \mathrm{~mm}$, respectivamente.

Os frutos foram colhidos diretamente na copa da planta em fase de maturação fisiológica. Foram coletados como matéria-prima 50 frutos colhidos em doze (12) plantas com boas características externas de qualidade (Figura 1), localizadas no IFPE/Barreiros. Do lote foram retirados, aleatoriamente, dez frutos para a avaliação das características físico-químicas, sendo a polpa do fruto mantida congelada até o momento das análises.

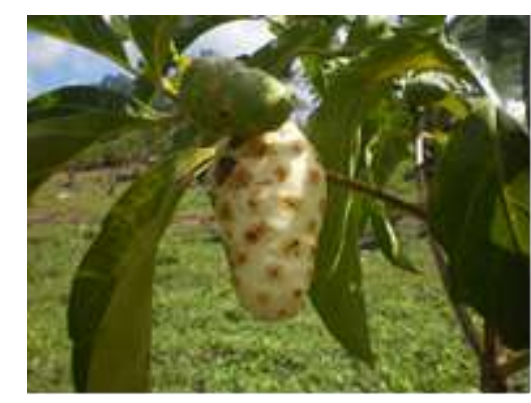

Figura 1 - Morinda citrifolia L. em fase de maturação fisiológica plantada na área experimental do Campus Barreiros

As características físico-químicas avaliadas na polpa foram: o pH através do método potenciométrico, umidade por secagem em estufa a $105^{\circ} \mathrm{C}$, acidez total titulável (ATT) expressa em gramas de ácido cítrico/100 g de polpa, sólidos solúveis totais (SST) determinados por refratometria, com os resultados expressos em ${ }^{\circ}$ Brix. A Vitamina $C$ (ácido ascórbico) foi determinada por titulação com iodato de potássio. Todas as análises foram determinadas segundo as normas analíticas do Instituto Adolf Lutz (2008). O delineamento experimental usado foi o inteiramente casualizado, com as análises realizadas em triplicata e os dados submetidos à análise estatística descritiva onde foram calculados a média aritmética e o desvio padrão.

\section{RESULTADOS E DISCUSSÃO}

A tabela 1 abaixo apresenta os resultados obtidos com a análise físico-química de frutos noni. A porcentagem de sólidos solúveis totais está relacionada principalmente com o sabor do fruto que 
inclui os açúcares e ácidos. Com o avanço da maturação o teor de sólidos solúveis aumenta devido à hidrólise do amido ocasionando assim, a síntese de açúcares menores. Este parâmetro também influencia o rendimento industrial, especialmente o peso final do produto processado. O valor médio encontrado para este parâmetro foi de 7,0 @Brix, bem inferior a outros frutos comercializados, como a uva, abacaxi, caju, mamão e manga. Este valor encontra-se próximo ao encontrado por Chan-Blanco et al. (2007), onde foi 7,3 oBrix. Sátiro et al. (2016) após avaliar frutos verdes e maduros do noni encontraram valores de 6,2 e 7,6 @Brix, respectivamente. Vale ressaltar que de acordo com a região esses valores podem ser diferentes.

A acidez titulável, representada pelo teor de ácido cítrico, também influencia o sabor do fruto, onde o valor foi de 0,3 g/100 g de polpa. Valores maiores $(3,2 \pm 0,0$ e 0,7 $\pm 0,1 \mathrm{~g} / 100 \mathrm{~g})$ foram obtidos por Canuto et al. (2010) e Gimenes (2018), respectivamente.

Tabela 1. Médias das características químicas do fruto noni in natura

\begin{tabular}{c|c}
\hline Características & Valores $^{\mathbf{1}}$ \\
\hline Sólidos Solúveis Totais $\left({ }^{\circ} \mathrm{Brix}\right)$ & $7,0 \pm 0,9$ \\
Acidez Total Titulável ATT $(\mathrm{g} / 100 \mathrm{~g})$ & $0,3 \pm 0,03$ \\
Ratio $^{2}$ & $23,3 \pm 4,04$ \\
$\mathrm{pH}$ & $4,04 \pm 0,1$ \\
Vitamina C (mg de ácido ascórbico/100 g de polpa) & $162,0 \pm 36,6$ \\
Umidade $(\%)$ & $91,07 \pm 0,01$ \\
\hline
\end{tabular}

${ }^{1}$ Valores médios obtidos a partir da análise das amostras \pm desvio padrão. ${ }^{2}$ Ratio é a relação entre sólidos solúveis totais e acidez total titulável.

Para o mercado de frutas frescas ou processadas a relação SST/ATT elevada é desejável (Aguiar et al., 2008; Sousa et al., 2011). Ela propicia uma boa avaliação do sabor dos frutos, sendo mais representativa do que a medição isolada de açúcares e de acidez (Correia et al., 2011). Os resultados obtidos neste trabalho encontram-se em acordo a pesquisa desenvolvida por Silva et al. (2009), com média de 25,8. Ao contrário dos resultados obtidos por Barros et al. (2008), os quais encontraram valor igual a 10,24. Já Silva et al. (2013) após avaliar 5 plamtas encontraram valores de ratio entre 23,3 e 62,7. O pH encontrado também está em acordo com o trabalho de Canuto et al. (2010) e Nunes et al. (2020), os quais verificaram valores de 4,1 e 4,2, respectivamente.

Em relação ao teor de vitamina $C$, pode-se verificar que o fruto é rico nesse constituinte quando comparado aos resultados obtidos por Correia et al. (2011), Nandhasri et al. (2005) e Shovic e Whistler (2001), os quais encontraram teores de $122,54 \mathrm{mg} / 100 \mathrm{~g} \pm 1,35$ e 64,45 mg/100 g e $155 \mathrm{mg} / 100 \mathrm{~g}$, respectivamente. Por outro lado, Sátiro et al. (2016) encontraram teor de 216,8 mg/100 g nos frutos de noni maduros. A disponibilidade de frutos ricos em vitamina C é importante no tocante à prevenção 
e manifestação de doenças, tornando o mesmo como um dos componentes nutricionais de maior importância, sendo utilizado como índice de qualidade dos alimentos (Chitarra; Chitarra, 2005). No entanto, vale destacar que essa vitamina é volátil, podendo ocorrer perdas no momento da coleta, no despolpamento, na trituração das amostras, além de outros fatores que podem interferir, como o tempo de estocagem, luminosidade, entre outros.

Quanto à umidade, pode-se notar com os dados que o noni é um fruto com índices elevados de água (91,07 \%). Esses resultados estão de acordo com aqueles divulgados na literatura, como os obtidos por Canuto et al. (2010), Chan-Blanco et al. (2006), West et al. (2011) e Gimenes et al. (2018), onde encontraram valores variando entre 90 a 91,91 \%. O valor obtido para este parâmetro o caracteriza como alimento de alta umidade favorecendo a deterioração por micro-organismos e afetando assim, a estabilidade, a qualidade e a composição do produto (Correia et al., 2011).

\section{CONCLUSÕES}

A avaliação dos parâmetros físico-químicos permite concluir que os frutos de noni plantados na área experimental do Campus Barreiros apresentam um grande potencial para seu aproveitamento comercial, como no beneficiamento de sucos, por apresentar significativa quantidade de vitamina Ce alta relação sólidos solúveis/acidez titulável.

\section{AGRADECIMENTOS}

Ao Instituto Federal de Educação, Ciência e Tecnologia de Pernambuco (IFPE), Campus Barreiros. 


\section{REFERÊNCIAS}

AGUIAR, L. P.; FIGUEIREDO, R. W.; ALVES, R. E.; MAIA, G. A.; SOUZA, V. A. B. Caracterização física e físico-química de frutos de diferentes genótipos de bacurizeiro (Platonia insignis Mart.). Ciência e Tecnologia de Alimentos, Campinas, v. 28, p. 423-428, 2008.

ALMEIDA-SOUZA, F.; CARDOSO, F. O.; SOUZA, B. V. C.; VALLE, T. Z.; SÁ, J. C.; OLIVEIRA, I. S. S.; SOUZA, C. S. F.; TELLIS, C. J.; CHAGAS, M. S. S.; BEHRENS, M. D.; ABREU-SILVA, A. L.; CALABRESE, K. S. Morinda citrifolia Linn. Reduces Parasite Load and Modulates Cytokines and Extracellular Matrix Proteins in C57BL/6 Mice Infected with Leishmania (Leishmania) amazonensis. Plos Neglected Tropical Diseases, p. 1-17, 2016.

BARROS, S. P. N.; MAIA, G. A.; BRITO, E. S.; NETO, M. A. S.; SOUSA, J. A. Caracterização físico-química da polpa de noni (Morinda citrifolia L.). Anais... XX Congresso Brasileiro de Fruticultura. 54th Annual Meeting of the Interamerican Society for Tropical Hoticulture. Vitória/ES, 2008.

BRASIL. Agência Nacional de Vigilância Sanitária. Informe Técnico n. 25, de maio de 2007. Esclarecimentos sobre as avaliações de segurança realizadas de produtos contendo Morinda citrifolia, também conhecida como noni. Disponível em:<http://antigo.anvisa.gov.br/documents/33916/388729/Informe+T\%C3\%A9cnico+n.+25\%2C+de +maio+de+2007/f1652e84-4529-4844-9c82-9d0f889e1fd0>. Acesso em: 03 ago. 2021.

CANUTO, G. A. B.; XAVIER, A. A. O.; NEVES, L. C.; BENASSI, M. T. Caracterização físico-química de polpas de frutos da Amazônia e sua correlação com a atividade anti-radical livre. Revista Brasileira Fruticultura, v. 32, p. 1196-1205, 2010.

CECCHI, H. M. Fundamentos teóricos e práticos em análise de alimentos. Campinas-SP: Unicamp, 2003. $207 p$.

CHAN-BLANCO, Y.; VAILLANT, F.; PEREZ, A. M.; REYNES, M.; BRILLOUET, JEAN-MARC.; BRAT, P. The noni fruit (Morinda citrifolia L.): a review of agricultural research, nutritional and therapeutic properties. Journal Food Composition and Analysis, v. 19, p. 645-654, 2006.

CHAN-BLANCO, Y.; VAILLANT, F.; PEREZ, A. M.; BELLEVILLE, MARIE-PIERRE.; ZÚÑIGA, C.; BRAT, P. The ripening and aging of noni fruits (Morinda citrifolia L.): microbiological flora and antioxidant compounds. Journal of the Science of Food and Agriculture, v. 87, p. 1710-1716, 2007.

CHITARRA, A. B.; CHITARRA, M. I. F. Pós-colheita de frutos e hortaliças: fisiologia e manuseio. 2.ed. Lavras: UFLA, 2005. 783p.

CORREIA, A. A. S.; GONZAGA, M. L. C.; AQUINO, A. C.; SOUZA, P. H. M.; FIGUEIREDO, R. W.; MAIA, G. A. Caracterização química e físico-química da polpa do noni (Morinda citrifolia) cultivado no estado do ceará. Alimentos e Nutrição, v. 22, p. 609-615, 2011.

GIMENES, L. A. C.; FERRERIA, L. P.; MORAES, F. T.; NUNES, C. R. Análise dos parametros fisico-quimicos e da ação antioxidante de Morinda citrifolia L. Interdisciplinary Scientific Journal, v. 5, p. 106-124, 2018. 
HARADA, S.; HAMABE, W.; KAMIAYA, K.; SATAKE, T.; YAMAMOTO, J.; TOKUYAMA, S. Preventive Effect of Morinda citrifolia Fruit Juice on Neuronal Damage Induced by Focal Ischemia. Biological and Pharmaceutical Bulletin, v. 32, p. 405-409, 2009.

IKEDA, R.; WADA, M.; NISHIGAKI, T.; NAKASHIMA, K. Quantification of coumarin derivatives in nomi (Morinda citrifolia) and their contribution of quenching effect on reactive oxygen species. Food Chemistry, v. 113, p. 1169-1172, 2009.

INSTITUTO ADOLFO LUTZ. Normas analíticas do IAL: métodos químicos e físicos para análise de alimentos. 5.ed. São Paulo, 2008. 1020 p.

KÖPPEN, W. Der geographische system der klimate. In: KOPPES, W.; GEIGER, R. (Ed.). Handbuch der klimatologie. Berlim: Borntrager, 1936. v. 1 part c.

NANDHASRI, P.; PAWA, K. K.; KAEWTUBTIM, J.; JEAMCHANYA, C.; JANSOM, C.; SATTAPONPUN, C. Nutraceutical properties of Thai "Yor", Morinda citrifolia and "Noni" juice extract. Songklanakarin Journal of Science Technology, v. 27, p. 579-586, 2005.

NAYAK, B. S.; SANDIFORD, S.; MAXWELL, A. Evaluation of the Wound-healing Activity of Ethanolic Extract of Morinda citrifolia L. Leaf. Evidence-Based Complementary and Alternative Medicine, v. 6, p. 351-356, 2009.

NUNES, R. C. S.; DUTRA, F. V.; RAMPAZOO, M. C.; SILVA, G. L.; CARDOSO, A. D.; JOSÉ, A. R. S. Características físico-químicas de frutos de Noni. In: Redin, E (Org.). Tópicos em Ciências Agrárias. Vol. 7. Belo Horizonte: Poisson, 2020. p. 46-50.

OLIVEIRA, M. E. B.; BASTOS, M. S. R.; FEITOSA, T.; BRANCO, M. A. A. C.; SILVA, M. G. G. Avaliação de parâmetros de qualidade físico-químicos de polpas congeladas de acerola, cajá e caju. Ciência e Tecnologia de Alimentos, v. 19, p. 326-332, 1999.

SÁTIRO, L. S.; COSTA, F. B.; LIMA, E. Q.; NASCIMENTO, A. M.; SANTIAGO, M. M.; SANTOS, K. P. Características físicas e químicas de frutos de noni colhidos em dois estádios de maturação. In: Dantas, C. O.; Filho, C. R. M. S.; Neto, J. F. S.; Medeiros, J. A (Eds.). Desafios da agroindústria no Brasil. 2 ed. Bananeiras: Instituto Bioeducação, 2016. p. 1412-1415.

SHOVIC, A. C., WHISTLER, W. A., 2001. Food sources of provitamin A and vitamin C in the American Pacific. Tropical Science, v. 41, 199-202.

SILVA, L. R. D.; MEDEIROS, P. V. Q. D.; ,EITE, G. A.; SILVA, K. J. P.; MENDONÇA, V.; SOUSA, J. A. D.; SILVA, M. S. Caracterização físico-química do fruto de noni (Morinda citrifolia L.). Disponível em: <http:sengepb.com.brsitewp-contentuploads200912t024.pdf>. Acesso em: 01 jul. 2012.

SILVA, L. R.; PONTES, C. A.; SOUSA, J. A.; SILVA, E. O. Qualidade de frutos de noni (Morinda citrifolia L.) cultivados em Trairi-CE. Revista Cubana de Plantas Medicinales, v. 18, p. 100-108, 2013.

SOUSA, P. B.; SILVA, E. F.; MONÇÃO, E. C.; SILVA, M. J. M.; TEIXEIRA, P. R. S. Caracterização físicoquímica do puçá-preto (Mouriri pusa) oriundo do cerrado piauiense. XVII Encontro Nacional e III Congresso Latino americano de Analistas de Alimentos. 03 a 07 de julho, 2011- Centro de Eventos do Pantanal. Cuiabá - MT, 2011. 
STADLBAUER, V.; FICKERT, P.; LACKNER, C.; SCHMERLAIB, J.; KRISPER, P.; TRAUNER, M.; STAUBER, R. E. Hepatotoxicity of NONI juice: Report of two cases. World Journal of Gastroenterology, v. 30, p. 47584760, 2005.

SWANHOLM, C. E.; ST JOHN, H.; SCHEUER, P. J. A survey of alkaloids in Hawaiian plants. Pacific Science, v. 13, p. 295-305, 1959.

TAKASHIMA, J.; IKEDA, Y.; KOMIYAMA, K.; HAYASHI, M.; KISHIDA, A.; OHSAKI, A. New constituents from the leaves of Morinda citrifolia. Chemical \& Pharmaceutical Bulletin, v. 55, p. 343-345, 2007.

WANG, M. Y.; WEST, B. J.; JENSEN, C. J.; NOWICKI, D.; SU, C.; PALU, A. K.; ANDERSON, G. Morinda citrifolia (Noni): A literature review and recent advances in Noni research. Acta Pharmacologica Sinica, v. 12, p. $1127-1141,2002$.

WEST, B. J.; DENG, S.; JENSEN, C. J. Nutrient and phytochemical analyses of processed noni puree. Food Research International, v. 44, p. 2295-2301, 2011.

YANG, J.; PAULINO, R.; JANKE-STEDRONSKY, S.; ABAWI, F. Free-radical-scavenging activity and total phenols of noni (Morinda citrifolia L.) juice and powder in processing and storage. Food Chemistry, $v$. 102, p. 302-308, 2007. 


\section{Capítulo 16}

doi) 103742821000454

ESTRATÉGIAS PARA O DESENVOLVIMENTO DE UMA COMUNIDADE MARGEADA PELO RIO IPANEMA E O CANAL DO SERTÃO EM SANTANA DO IPANEMA/AL 
Resumo: O presente trabalho visa contribuir para o entendimento das causas e do conceito de desertificação adotado pelas Nações Unidas trazendo também o desenvolvimento de uma área localizada na Microrregião de Santana do Ipanema/AL. Essa localidade está recebendo experimentos científicos para a produção da região e desenvolvimento socioeconômico das pessoas.

Palavras-chave: canal do sertão, desenvolvimento, Santana do Ipanema 


\section{INTRODUÇÃO}

A pesquisa faz parte da proposta de desenvolvimento de uma região localizada no sertão alagoano agregando: coordenação, planejamento e controle das pessoas que vivem em regiões do território alagoano da Mesorregião do Sertão e Microrregião de Santana do Ipanema afetada pela falta periódica de chuvas e pela degradação do sertanejo ao manejo errado da terra. Essa trabalho consiste no plantio de sementes de girassol que podem vir a se base da economia local e remanejamento, estruturação, forma de minimização da área afetada pela reorganização do pessoal e atuação de medidas de subsistência na terra, promoção estratégias eficazes fundamentalmente na expansão econômica da região. Outro desafio é a diminuição de desgaste do solo que pode ocasionar a desertificação da região. O referente estudo está sendo desenvolvido no Sítio Sementeira localizado no município Santana do Ipanema $220 \mathrm{~km}$ de Maceió pela AL-220 e visa potencializar indivíduos para produção de outras culturas ampliando o desenvolvimento da localidade e a pluralidade do homem do campo minimizando o processo de desertificação através de atividade rentável, para tal estratégia analisaremos como se dá a desertificação e como ela pode ser atenuada.

A degradação da Terra representa a degradação dos solos e dos recursos hídricos; a "degradação da vegetação e da biodiversidade, e a redução da qualidade de vida da população afetada".

Por desertificação entende-se a degradação da terra, principalmente nas zonas áridas, semi-áridas e sub-úmidas secas, resultante de vários fatores incluindo as variações climáticas e as ações humanas (por degradação da terra compreende-se a deterioração dos solos, dos recursos hídricos, da vegetação, além da redução acentuada da qualidade de vida das populações afetadas), pondo em risco a biodiversidade e a sobrevivência das comunidades humanas. A falta periódica de chuva é o processo natural que mais contribui para a desertificação do solo, devido à alta latitude da região, por outro lado, a ação humana pode induzir esse processo através do mau uso das terras agrícolas e da alta densidade demográfica em regiões propensas a isso.

A desertificação é resultante da irregularidade de chuvas aliadas ao processo de lixiviação do solo paralelamente ao intemperismo físico identificado nas regiões do nordeste. É produto da "degradação da terra nas zonas áridas, semiáridas e subsumidas secas resultantes de fatores diversos", tais como as variações climáticas, (longos períodos de seca) as atividades humanas e culturais como (plantio, manejo da terra de modo incorreto), desmatamento da vegetação (para carvoarias). 
A administração é uma alternativa de atividade como suporte de comando, de apoio às produções humanas como: a motivação, relocamento, estimulação, planejamento de metas para o desenvolvimento de empresas de micro e pequenas (MPEs) e em direção de organizações do terceiro setor podendo transformar e direcionar metas, programas a serem seguindo para a autoafirmação da empresa e sobrevivência desta em um mundo de multinacionais em uma região de baixa produção cientifica para as bases da mesma.

A importância do empreendedor para as pessoas que são capacitadas para o cultivo na terra nessa região é de suma importância de crescimento, aperfeiçoamento do local e de criação de sua própria subsistência, assim como o termo empreender já diz. Ele possui um conjunto de atribuições e tarefas, e é o conjunto de qualificações que uma pessoa deve possuir adquirir ou desenvolver para ocupar o cargo. Estes são os chamados de atributos ou capacidade técnica. Um profissional da área vai desenvolver estas competências empreendedoras à seguir: cultivar na terra; Aumentar sua produção; Como investir; Como utilizar a água, plantar conforme demanda, manejo do acesso à água. A região em estudo (Sítio Sementeira) é abastecida por um poço artesiano e detém também a poucos km a passagem do rio intermitente Santana do Ipanema.

\section{EMBASAMENTO TEÓRICO}

Segundo SAMPAIO (2002), o Brasil ratificou a definição oficial de desertificação estabelecida pela Convenção das Nações Unidas de Combate à Desertificação, adotando que: “A desertificação deve ser entendida como a degradação da terra nas zonas áridas, semiáridas e sub-úmidas, resultante de vários fatores, incluindo as variações climáticas e as atividades humanas". O texto da Convenção também define que a desertificação pode ocorrer em função da degradação da terra, das zonas climáticas específicas e dos fatores resultantes de processos antrópicos, podendo se manifestar em qualquer parte do planeta, com exceção das zonas polares e subpolares, sendo tecnicamente estabelecida uma razão entre a precipitação anual e a evapotranspiração potencial compreendido entre 0,05 e 0,65 (SAMPAIO, 2002).

ANDRADE (1999) diz que o grau de aridez de uma área para outra é muito variável, "havendo aquelas classificadas como hiper-áridas, onde a umidade é muito baixa durante todo ano" e outras consideradas apenas áridas com chuvas esporádicas e, ainda, outras áreas semiáridas, "quando a estação úmida é curta, de três a quatro meses por ano, permitindo o desenvolvimento de culturas de ciclo vegetativo curto", sendo esta a característica primordial da Região de Xingó, como se verifica nos 
índices pluviométricos registrados ao longo dos últimos 20 anos (CPTEC/INPE, 2002). Assim, o período cronológico objeto desta pesquisa, face à disponibilidade de imagens satelitais para estudos ambientais, está restrito ao período compreendido entre o final da década de 1980 até 2001. Entretanto, convém observar que "a aridez ou a semi-aridez, não tornam estas terras improdutivas, apesar da pobreza dos solos em matéria orgânica, uma vez que os mesmos podem ser enriquecidos com adubos orgânicos ou podem ser irrigados" (ANDRADE, 1999), como ocorre em diversos países do mundo.

O Nordeste brasileiro tem $80 \%$ de sua extensão classificada como semiárida, possuindo cerca de 34 milhões de hectares com Caatinga e expandindo-se pelos nove estados que compõem a região (REIS, 1984). Os restantes $20 \%$ são formados, basicamente, pela mata Atlântica, cerrados e zonas de coqueirais. "A Caatinga, seu principal componente, além de rigorosamente atingida pela seca, sofre um processo de devastação provocado pelo próprio homem". Portanto, as tecnologias que permitam mapear os processos desertificatórios revestem-se de fundamental importância para a proteção das áreas naturais ainda existentes e, também, para a recuperação de áreas degradadas do meio ambiente.

\section{DISCRISSÃO DA FORMAÇÃO CAUDAL DO IPANEMA}

\section{BACIA DO RIO IPANEMA}

Segundo o relatório final do Governo do Estado de Alagoas (Secretária do Planejamento e Desenvolvimento). In: ESTUDOS ECONOMICOS DAS BACIAS HIDROGRÁFICAS DO ESTADO DE ALAGOAS. 1998, diz o seguinte: “O Rio Ipanema é uma sub-bacia do São Francisco, destacando-se como uma das principais do sertão alagoano, estimando-se que nesta bacia exista uma população rural de 52.103 habitantes e que suas cidades abriguem em torno de 32218 habitantes. As cidades localizadas às margens do Ipanema e de seus tributantes são diversas, entre as quais ganham importância Santana do Ipanema, Batalha, Dois Riachos, Olivença, Maravilha, Ouro Branco e Poço das trincheiras.

A bacia do Ipanema em Alagoas atinge $1.617 \mathrm{KM}^{2}$, mas sua maior parte se situa no vizinho estado de Pernambuco, onde nasce. O Rio Ipanema entra em Alagoas no município de Poço das Trncheiras, na altura do povoado de Guandu, para atravessas o restado e finalmente encontrar o Rio São Francisco em Barra do Ipanema, no município de Belo Monte, dois Riachos, Jaramataia, Major Izidoro, Maravilha, Olivença, Olho d'Água das Flores, Ouro branco, Poço das trincheiras e Santana do Ipanema. 
Um pouco a jusante de Guandu, Ipanema recebe o Riacho Pedra da Bota. Mas a jusante ele encontra o riacho Tenente e perto de Patos o riacho Lages. Na altura de Canivete (Poço das Trincheiras) o Ipanema recebe as aguas do riacho Sítio e dentro do município de Santana do Ipanema, contribuem para este Rio os riachos: Camuxinga, Gravatá e João Gomes. O principal tributário do Ipanema é o Dois Riachos, que se origina em Pernambuco e em alagoas recebe a contribuição do riacho Mar Ferreira. 0 riacho Dois riacho se junta ao Ipanema em Barra Nova (Major Izidoro). Um pouco a jusante, o rio Ipanema recebe o escoamento proveniente da bacia do rio Cachoeira. Dentro do município de Batalha, desemboca também o riacho Desumano. Existem ainda vários riachos de menor importância que durante a época chuvosa aumentam o caudal do Ipanema.

\section{POSIÇÕES GEOGRÁFICAS DA BACIA}

Ocupa a parte Centro-Meio-Sul-Ocidental de norte a sul da Microrregião homogênea da Batalha, e faz parte da zona fisiográfica do sertão, com a bacia leiteira alagoana".

Municípios que drena:

\begin{tabular}{|l|l|}
\hline Batalha & $205 \mathrm{~km}$ \\
\hline Belo monte & $160 \mathrm{~km}$ \\
\hline Dois riacho & $212 \mathrm{~km}$ \\
\hline Jaramataia & $10 \mathrm{~km}$ \\
\hline Major izidoro & $265 \mathrm{~km}$ \\
\hline Maravilha & $105 \mathrm{~km}$ \\
\hline Olivença & $150 \mathrm{~km}$ \\
\hline Olho d' Água das Flores & $30 \mathrm{~km}$ \\
\hline Ouro Branco & $60 \mathrm{~km}$ \\
\hline Poço das trincheiras & $180 \mathrm{~km}$ \\
\hline Santana do Ipanema & $240 \mathrm{~km}$ \\
\hline Totais- 11 & $1.617 \mathrm{~km}$ \\
\hline
\end{tabular}

1.3 Regime dos rios: Torrenciais com violentas enxurradas no períodos de mais chuvas.

\section{MATERIAL E MÉTODOS}

A preparação da área para plantio é fundamental para desenvolvimento da agricultura, vários processos de preparação do solo foram realizados além de matérias adquiridos para fins de cultivo, manejo da terra e fertilização do solo. Foram utilizadas enxadas, regadores, baldes, mangueiras d' água, corda de nalho, corda, tubos de PVC $\mathrm{n}^{\circ}$ 100, facão, caneta esferográfica, ciscadores de grama, adubos orgânicos (bovino e caprino), capinagem para a limpeza da área, fósforo para moldar o cano de PVC, ripas para planificação da área não deixando irregularidades ou desníveis no plantio, adubação 
e irrigação, separação por lotes para a diversidade plantada e a abertura de covas para o plantio das sementes.

O solo da região trabalhada tem sua formação no latossolo significando potencialidades para produzir, mas tem que trabalhá-lo no que se refere a irrigação e ter cuidado com salinização do solo. O solo tem em sua composição areia fina como componente principal do latossolo amarelo realçado pela presença de silte drenagem imperfeita (irregularidade de chuva) impede que haja uma natural boa produtividade.

\section{RESULTADOS E DISCUSSÃO}

O desenvolvimento que irá trazer o canal do sertão vai trazer também necessidade da valorização dos projetos que irão ser implantados na localidade mediante a construção do canal do sertão em Alagoas, irá necessitar de pessoal com disposição e espírito proativo para uma boa instalação de um negócio financeiramente rentável que irá empregar aperfeiçoar e fazer do sertão uma empresa, e como e de conhecimento do administrador, dessa empresa expandir, atualizar e retirar lucros.

Com a conscientização de todos nas regiões beneficiadas e algumas campanhas por parte de órgãos públicos, e privados, e ONGs que atuam na Bacia Leiteira, há algumas fábricas de pequeno e médio porte, hotéis, pousadas e restaurantes fazer com que essa microrregião se desenvolva economicamente.

\section{CONCLUSÕES}

Causa presente no desenvolvimento de empreendimento MPEs:

- Pesquisar sobre o assunto entre a comunidade científica, apesar de muitas produções serem para empresas de grande porte, transcrever as informações obtidas para a realidade regional, local e de micro e pequenas empresas.

- Conscientizar os produtores sobre uma boa coordenação, planejamento, organização e a eficiência de especialistas desde técnicos agrícolas a gestores:

- Fazendo e desenvolvendo projetos de ampliação, mostrando-lhes que a competência técnica pode ser muito útil para a venda e o aumento da produção.

- Propor uma melhor qualidade de vida à população evitando-se o êxodo rural

- Consumo planejado dos recursos vegetais, naturais e líquido principalmente sendo implementada para a permanência do desenvolvimento alongando seu tempo de vida. 


\section{REFERÊNCIAS}

ANDRADE, Manuel Correia. A Problemática da Seca. Recife: Líber Gráfica e Editora, 1999. 97 p.

CAMPOS, Hernani Loebler. O Processo de Desertificação: Vulnerabilidade Aos Fenômenos Climáticos. Disponível em: < http://www.ufpe.br/revistageografia/index.php/revista/ article/viewFile/206/167>. Acesso em: 05 mai. 2012.

CAMP, Robert. Benchmarking: identificando, analisando e adaptando as melhores práticas da administração que levam à maximização da performance empresarial: o caminho da qualidade total. São Paulo: Pioneira, 3 ed, 1998;

Convênio Sema/ SUDENE/ Governo de Alagoas, Secretaria de planejamento Coordenação do Meio Ambiente: "Estudo enquadramento e classificação de Bacias hidrográficas do Estado de Alagoas", de 1979

DRUCKER, Peter Ferdinand. Administrando em tempos de grandes mudanças. São Paulo: Pioneira; São Paulo: Publifolha, 1999;

MATALLO JÚNIOR, Heitor. Indicadores de Desertificação: histórico e perspectivas. Brasília: UNESCO, 2001.

SAMPAIO, Everaldo, et alli. Impactos ambientais da agricultura no processo de desertificação no nordeste do Brasil. Disponível em: <http://www.ufpe.br/revistageografia/ index.php/revista/article/viewFile/38/8>. Acesso em: 02 mai. 2012.

Governo de Alagoas, Secretaria de planejamento e desenvolvimento, Coordenação de Desenvolvimento Científico e Tecnológico. "Estudo Econômico das Bacias Hidrográficas do Estado de Alagoas."

Governo do Estado de Alagoas, Secretária do Planejamento e Desenvolvimento. In: ESTUDOS ECONOMICOS DAS BACIAS HIDROGRÁFICAS DO ESTADO DE ALAGOAS. 1998 


\title{
Capítulo 17
}

doi) $10.37423 / 210804579$

\begin{abstract}
AVALIAÇÃO DA POTENCIALIDADE DE TRÊS CULTIVARES DE MANDIOCA PARA A PRODUÇÃO DE ETANOL NA REGIÃO CENTRAL DO ESTADO DO TOCANTINS
\end{abstract}

Kallyana Moraes Carvalho Dominices

Valdira Dias Pereira de Carvalho

Tarso da Costa Alvim
Instituto Federal de Educação, Ciência e Tecnologia do Tocantins

Universidade Federal do Tocantins

Universidade Federal do Tocantins 
Resumo: Os biocombustíveis têm demonstrado um grande potencial para a substituição em escala maior dos derivados de petróleo. Existem diversas fontes disponíveis para a produção destes novos tipos de combustíveis e, como em sua grande maioria se tratam de fontes vegetais, pode-se garantir a continuidade da produção e com isto evitar uma eventual crise de abastecimento energético. Com isso, o objetivo deste foi avaliar os teores de amido e matéria seca de três cultivares ('Amarelinha', 'Cacau Roxa' e 'Tapioqueira') avaliadas a fim de se verificar como potencialidade, para a produção de etanol na Região Central do Tocantins. O delineamento experimental utilizado foi o DIC (Delineamento Inteiramente Casualizado) com sete repetições. Os teores de amido e matéria seca apresentados tiveram médias de $46,08 \%$ e $41,55 \%$, respectivamente. A cultivar que apresentou maior índice de amido foi a 'Cacau Roxa', com 49,00\%, ou seja, com potencial para a produção de etanol. Já os valores de matéria seca das cultivares estudadas, variaram de 38,95\% a 42,87\%, sendo que a cultivar 'Cacau Roxa' obteve maiores índices não diferindo estatisticamente da cultivar 'Amarelinha'.

Palavras-chave: amido, matéria seca, rendimento 


\section{INTRODUÇÃO}

A busca por fontes limpas e renováveis de energia tem levado ao desenvolvimento de novas tecnologias alternativas aos processos convencionais. Os biocombustíveis têm demonstrado um grande potencial para a substituição em escala maior dos derivados de petróleo. Existem diversas fontes disponíveis para a produção destes novos tipos de combustíveis e, como em sua grande maioria se tratam de fontes vegetais, pode-se garantir a continuidade da produção e com isto evitar uma eventual crise de abastecimento energético. Cana-de-açúcar, beterraba, milho, oleaginosas como a soja, mamona, dendê, pinhão-manso (Jatropha curcas), além da biomassa vegetal da celulose, hemicelulose, lignina se apresentam como fontes interessantes para a geração desse tipo de combustível (SANTANA, 2007; SILVA, 2010).

Com as fortes evidências das mudanças climáticas e associadas à perspectiva do fim do petróleo em 2050, a busca por novas fontes de matéria-prima para produção de etanol passou a ser uma prioridade internacional, que certamente irá redefinir um novo posicionamento geopolítico, em função da entrada dos países na rota de produção dos biocombustíveis (SILVEIRA, 2008).

Nesse cenário a mandioca (Manihot esculenta) destaca-se como alternativa potencial para a produção de etanol, visto que Cardoso (2003) afirmam que o cultivo da mandioca está associado ao Brasil desde o seu descobrimento e tem destacada importância na alimentação humana e animal, além de ser utilizado como matéria-prima em inúmeros produtos industriais. Pode ser cultivada entre $30^{\circ} \mathrm{N}$ e 30 'S de latitude, desde o nível do mar até 2.300 m de altitude (ALVES, 2006). Seu crescimento, conforme Conceição (1983) é favorecido quando a temperatura média anual varia de $25^{\circ} \mathrm{C}$ a $29{ }^{\circ} \mathrm{C}$, porém de acordo com estudos realizados por Alves (2006) pode tolerar temperaturas de $16^{\circ} \mathrm{C}$ a $38^{\circ} \mathrm{C}$.

Bringhenti et al., (2007) afirmaram que a mandioca se destacara como excelente opção para a fermentação alcoólica por apresentar alto teor de amido, tradição de cultivo em considerável área do Brasil, com capacidade de expansão em solos menos férteis e grande importância à agricultura familiar.

Outro motivo que faz com que a mandioca tenha destaque nesse cenário é o fato das agroindústrias produtoras de farinha gerarem um resíduo, conhecido como manipueira, que se apresenta como substrato potencial para processos fermentativos (CEREDA, 1996; LEONEL et al., 1999; LEONEL, 2003; CAMILI et al., 2004; NEVES, 2004; BRINGHENTI et al., 2007). 
A mandioca possui uma série de vantagens em relação a outros cultivos, tais como a fácil propagação, elevada tolerância a estiagens, rendimentos satisfatórios mesmo em solos de baixa fertilidade, pouco exigente em insumos modernos, potencial resistência ou tolerância a pragas, elevado teor de amido nas raízes, boas perspectivas de mecanização do plantio a colheita, possibilidade de consórcio com inúmeras plantas alimentícias e industriais (VENTURINI FILHO e MENDES, 2003).

Diante disso, um dos caminhos alternativos é o incentivo à inserção de tecnologias que visem o fortalecimento da agricultura familiar, o desenvolvimento de novos setores produtivos, das potencialidades regionais, capacitação técnica, geração de renda e inclusão social, como as voltadas para o manejo de biomassas regionais e cultiváveis, de baixo impacto ambiental e direcionadas à produção de bioenergia. Com isso, objetivou-se com este estudo avaliar os teores de amido e matéria seca de três cultivares ('Amarelinha', 'Cacau Roxa' e 'Tapioqueira') avaliadas a fim de se verificar como potencialidade para a produção de etanol na Região Central do Tocantins.

\section{MATERIAL E MÉTODOS}

\subsection{MATÉRIA-PRIMA - MANDIOCA}

As raízes de mandioca avaliadas neste experimento foram provenientes de três cultivares: 'Amarelinha', 'Cacau Roxa' e 'Tapioqueira', cultivadas em sistema sequeiro e obtidas na Chácara Santa Fé, localizada no município de Palmas, TO. A colheita foi realizada no dia vinte e três de fevereiro de dois mil e dez no período da manhã. Após a colheita $50 \mathrm{~kg}$ de raízes de cada uma das variedades foram acondicionadas em sacos limpos de polietileno.

As raízes foram levadas para o Laboratório de Sistemas de Produção de Energia a partir de Fontes Renováveis (LASPER) no Centro Tecnológico Agroindustrial e Ambiental da Universidade Federal do Tocantins - Campus Palmas. As raízes foram lavadas em água corrente para retirada das sujidades e da película amarronzada que recobre a raiz, desprezando-a. Em seguida, as mesmas foram raladas e foi realizado o procedimento para a quantificação dos teores de amido e matéria seca descritos a seguir.

\subsection{DELINEAMENTO EXPERIMENTAL}

O delineamento experimental utilizado foi o DIC (Delineamento Inteiramente Casualizado) composto por três cultivares de mandioca ('Amarelinha', 'Cacau Roxa' e 'Tapioqueira') em sete repetições. 
Os dados foram submetidos a testes de homogeneidade da variância dos erros. Atendidas as pressuposições, realizou-se análise de variância, adotando-se o teste $F$. As variáveis cujo teste $F$ foi significativa $(p \leq 0,05)$ foram submetidas à análise de comparação múltipla, adotando-se o teste Tukey ao nível de 5\% de probabilidade, com auxílio do programa estatístico SISVAR.

\subsection{METODOLOGIAS}

\subsubsection{DETERMINAÇÃO DO TEOR DE AMIDO NA FARINHA DE MANDIOCA}

O método utilizado foi o descrito pelo Instituto Adolfo Lutz (BRASIL, 2005), que tem como base a hidrólise do amido presente na amostra, pela ação de base e ácido, para formação de açúcares redutores. Posteriormente à hidrólise, os açúcares formados foram determinados pelo método de Lane-Eynon. O teor de amido foi calculado pela equação abaixo:

$$
\% \text { Amido }=\frac{100 \times \text { Vf }}{\operatorname{mv}} \times 0,9
$$

[Equação 1]

Onde: V - volume da solução da amostra;

$f$ - fator das soluções de Fehling;

m - massa da amostra;

v - volume da solução da amostra gasto na titulação;

0,9 - fator de transformação de açúcares redutores em amido.

\subsubsection{DETERMINAÇÃO DA UMIDADE E MATÉRIA SECA DA MANDIOCA}

Pesou-se, acuradamente, os cadinhos feitos de papel alumínio, devidamente limpos e secos. Em seguida adicionou-se aproximadamente $5 \mathrm{~g}$ da amostra, que foi levada à estufa a $105^{\circ} \mathrm{C}$, por $24 \mathrm{~h}$.

Após este período, as amostras foram retiradas e colocadas em dessecador e pesadas até peso constante (AOAC, 1994). A determinação da umidade foi feita pela diferença de peso entre a amostra úmida e seca.

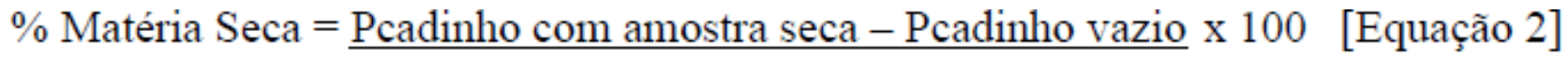 (EST) Pamostra}


Onde: Pcadinho com amostra seca - Peso do cadinho com a amostra seca;

Pcadinho vazio - Peso do cadinho vazio;

Pamostra - Peso da amostra.

$$
\% \text { Umidade }=100-\text { EST }
$$

[Equação 3]

Onde: EST - Extrato Seco Total, ou seja, Matéria Seca

\section{RESULTADOS E DISCUSSÃO}

\subsection{AMIDO E MATÉRIA SECA}

Para essas análises, pode-se observar na Tabela 1 que houve diferença estatística significativa $(p \geq 0,05)$. O Quadro 1 apresenta as médias dos teores de amido encontradas para as cultivares estudadas, podendo-se observar que as percentagens variaram de $42,78 \%$ a $49,00 \%$. Esses valores foram superiores aos encontrados por Fialho et al. (2002), onde a maioria das variedades enquadravase no intervalo de 24,4 a $33,0 \%$, enquanto Borges et al. (2002) obtiveram teores de $30,86 \%$ a $33,55 \%$ para variedades de mesa.

A cultivar que apresentou maior índice de amido foi a 'Cacau Roxa', com 49,00\%. O teor médio de amido geral foi de $46,08 \%$, que consiste num bom teor de amido para os presentes materiais e para a finalidade do experimento.

Conforme Cereda e Vilpoux (2003), a raiz de mandioca acumula amido como principal componente de massa seca, correspondendo a aproximadamente $80 \%$, podendo-se imaginar uma correlação positiva entre massa seca e amido.

Tabela 1. Resumo do quadro das análises de variância para amido e matéria seca.

\begin{tabular}{cccc}
\hline \multirow{2}{*}{ F.V. } & \multirow{2}{*}{ G.L. } & \multicolumn{2}{c}{ Quadrado Médio } \\
\cline { 3 - 4 } & & AMIDO & MATÉRIA SECA \\
\hline Cultivares & 2 & $68,575900^{*}$ & $35,557633^{*}$ \\
Erro & 18 & 10,824033 & 0,443246 \\
\hline TOTAL & 20 & & 41,5538095 \\
\hline Média Geral & & 46,0800000 & 1,60 \\
\hline C.V. $(\%)$ & & 7,14 &
\end{tabular}

\footnotetext{
* significativo ao nível de $5 \%$ de probabilidade pelo Teste $\mathrm{F}$

${ }^{\text {ns }}$ não significativo
} 
No Quadro 1 é apresentado os valores de matéria seca das cultivares estudadas, que variaram de 38,95\% a 42,87\%, sendo que a cultivar 'Cacau Roxa' obteve maiores índices não diferindo estatisticamente da cultivar 'Amarelinha'. Estes resultados encontrados são semelhantes aos encontrados por Cereda et al. (1982), Leonel et al. (1998), Ribeiro et al. (2007) e Sacchi et al. (2006), em outras cultivares, onde as raízes apresentaram médias de $37,14 \%$ de matéria seca, portanto os valores encontrados neste estudo apresentam melhores índices, com média de 41,55\%. Do ponto de vista industrial, os resultados encontrados nesta pesquisa são muito interessantes, pois cultivares que apresentam maiores teores de matéria seca resultam em maior rendimento de etanol no processo, portanto, menos quantidade de água residual. É importante ressaltar que, de acordo com estudos realizados por Cereda e Vilpoux (2003), a medida da massa seca pode servir como referência para avaliar as melhores raízes, com indicação sobre o teor de amido. Carvalho (2007) ressalta que o teor de matéria seca é normalmente o caráter que determina o maior ou menor valor pago pelas empresas aos produtores, no momento da comercialização, uma vez que está diretamente relacionado ao rendimento industrial dos diversos produtos derivados da mandioca.

Quadro 1. Médias dos teores de amido (\%) e matéria seca (\%).

\begin{tabular}{|l|c|c|}
\hline CULTIVARES & AMIDO (\%) & MATÉRIA SECA (\%) \\
\hline 'Amarelinha' & $46,457143 \mathrm{AB}$ & $42,835714 \mathrm{~A}$ \\
\hline 'Cacau Roxa' & $49,004286 \mathrm{~A}$ & $42,874286 \mathrm{~A}$ \\
\hline 'Tapioqueira' & $42,778571 \quad \mathrm{~B}$ & $38,951429 \mathrm{~B}$ \\
\hline Média & 46,0800000 & 41,5538095 \\
\hline C.V. (\%) & 7,14 & 1,60 \\
\hline
\end{tabular}

Na coluna as médias seguidas pela mesma letra maiúscula, não diferem entre si, pelo teste de Tukey, a $5 \%$ de probabilidade.

Os teores de matéria seca nas raízes podem ser correlacionados com os teores de amido; e dependem da variedade, do local onde se cultiva, da idade e época de colheita. Vários estudos sobre o potencial de produção de amido foram desenvolvidos com a cultura da mandioca no Brasil, observando-se uma ampla diversidade genética da espécie para este fator, variando de 5\% a 43\% (FUKUDA et al., 2006).

\section{CONCLUSÕES}

Através do trabalho realizado conclui-se que há uma relação entre os teores de matéria seca e os teores de amido, sendo que estes dependem da variedade, do local onde se cultiva, da idade e época 
de colheita. A cultivar 'Cacau Roxa' apresentou maiores valores de amido e matéria seca, portanto, pode-se afirmar que as demais cultivares avaliadas neste estudo também apresentaram índices satisfatórios quando comparadas com outras cultivares, além de que estas tem grande potencial para a obtenção de etanol, e podem ser exploradas em outros estudos e na região Central do Estado do Tocantins. Enfim, o amido tem papel preponderante em relação à produção de etanol, sendo característica indicada para qualquer programa de melhoramento genético que vise obter culturas com essa finalidade, entendendo que a indústria efetuara o pagamento não pela tonelada de raiz, mas pelo os teores de amido, que estão diretamente correlacionados com a matéria seca. 


\section{REFERÊNCIAS}

ALVES, A.A.C. Fisiologia da mandioca. In: Aspectos sócio-econômicos e agronômicos da mandioca. Editor: Luciano da Silva Souza... [et al.]. Cruz das Almas: Embrapa Mandioca e Fruticultura Tropical, 2006. p.138-169.

ASSOCIATION OF OFFICIAL ANALYTICAL CHEMISTS. Official methods of analytical chemists. Washington, 1994.

BORGES M. de F.; ROSSETTI, A.G.; FUKUDA, W.M.G. Avaliação de variedades de mandioca para consumo humano. Pesquisa agropecuária brasileira, v. 37 n. 11, Brasília, 2002.

BRASIL. Ministério da Saúde. Agência Nacional de Vigilância Sanitária. Métodos Físico-Químicos para Análise de Alimentos. 4a Edição. 2005.

BRINGHENTI, L. Fermentação alcoólica de substrato amiláceo hidrolisado enriquecido com melaço de cana. Revista Ciência e Agrotecnologia. Lavras, v. 31, n. 2, p. 429-432, mar/abr, 2007.

CAMILI, E. A.; CABELLO, C. Produção de etanol de manipueira tratada com processo de flotação. Cerat/Unesp. Botucatu, 2004.

CARDOSO, C. E. L. Competitividade e Inovação Tecnológica na Cadeia Agroindustrial de Fécula de Mandioca no Brasil. 2003. 207p. Tese (Doutorado em Economia Aplicada) - Escola Superior de Agricultura "Luiz de Queiroz", Universidade de São Paulo, Piracicaba, 2001.

CARVALHO, P. R. N. Avaliação da exatidão, precisão e robustez do método de análise do teor de matéria seca de mandioca (Manihot esculenta Crantz) por meio da determinação do peso específico (balança hidrostática). 2007.

CEREDA, M.; VILPOUX, O. F. Tecnologia, usos e potencialidades de tuberosas amiláceas Latino Americanas. Série Culturas de tuberosas amiláceas latino americanas - vol. 3. São Paulo. Fundação Cargill, 2003.

CEREDA, M. P. Caracterização, usos e tratamentos de resíduos da industrialização da mandioca. Botucatu: Centro de Raízes Tropicais, 1996. 56p.

CEREDA, M.P., CONCEIÇÃO, F.D.A ., CAGLIARI, A . M., HEEZEN, A . M., FIORETTO, R. A . Estudo comparativo de variedades de batata doce (Ipomoea batatas), visando aproveitamento em indústrias de alimentos. Turrialba, San Jose, v.32, p.365-370, 1982.

CONCEIÇÃO, A.J. A Mandioca. São Paulo: Ed. Nobel, 1983.

FIALHO, J. de F. et al.; Avaliação de variedades de mandioca de mesa nas condições de Cerrado do Distrito Federal. Boletim de Pesquisa e Desenvolvimento 73, Planaltina, DF, 2002.

FUKUDA, W. M. G.; FUKUDA, C.; DIAS, M. C.; XAVIER, J. J. B. N.; FIALHO, J. F. Variedades. In: Aspectos Socioeconômicos e Agronômicos da Mandioca. Editor: Luciano da Silva Souza ... [et al.]. - Cruz das Almas: Embrapa Mandioca e Fruticultura Tropical, 2006. p.433-454. 
LEONEL, M. Caracterização da fibra e uso do farelo de mandioca com base para produtos dietéticos. Série Culturas de tuberosas amiláceas latino americanas - vol. 3. São Paulo. Fundação Cargill, 2003.

LEONEL, M.; CEREDA, M.P.; ROAU, X. Aproveitamento do resíduo da produção de etanol a partir de farelo de mandioca, como fonte de fibras dietéticas. Revista Ciência e Tecnologia de Alimentos. Campinas, v. 19, n. 2, maio/agosto, 1999.

LEONEL, M.; JACKEY, S.; CEREDA, M.P. Pocessamento industrial de fécula de mandioca e batata doce - Um estudo de caso. Botucatu: Centro de Raízes Tropicais, UNESP, 1998.

NEVES, V. J. M. Uso do resíduo da produção de farinha de mandioca (crueira) na produção de álcool fino. 2004. 64p. Dissertação (Mestrado em Ciências Agronômicas) - Faculdade de Ciências Agronômicas, Universidade Estadual Paulista "Júlio Mesquita Filho", Botucatu, 2004.

RIBEIRO, S.S.; CARVALHO, H. W. L.; FUKUDA, W. M. G.; OLIVEIRA, I. R.; OLIVEIRA, V. D.. Avaliação de cultivares de mandioca para consumo humano na Zona centro-sul do estado de Sergipe. CERAT. UNESP. 2007.

SACCHI, R. T.; PADOVAN, M. P.; OTSUBO, A. A.; ALVES, L. O.; MORAES, R. M.; OLIVEIRA, A. Desempenho de variedades de mandioca para fins industriais cultivadas sob manejo orgânico no Mato Grosso do Sul. CERAT. UNESP. 2006.

SANTANA, N. B. Eficiência da hidrólise de amido de mandioca por diferentes fontes de enzimas e rendimento da fermentação alcoólica para produção de etanol. 2007. 115p. Dissertação (Mestrado em Ciência e Tecnologia de Alimentos) - Universidade Federal de Viçosa, Viçosa, 2007.

SILVA, F.M. Avaliação e seleção de clones de batata-doce quanto à produtividade e capacidade de bioconversão em etanol. 2010. 60p. Dissertação (Mestrado em Agroenergia) - Universidade Federal do Tocantins, Palmas, 2010.

SILVEIRA, M. A. A Cultura da batata-doce como fonte de matéria prima para produção de etanol. BOLETIM TÉCNICO-UFT, 38p, 2008.

VENTURINI FILHO, W.G.; MENDES, B.P. Fermentação alcoólica de raízes tropicais. In: Cereda, M.P. et al. (Coord). Tecnologias, Usos e Potencialidades de Tuberosas Amiláceas Latino Americanas. Série Tuberosas Amiláceas Latino Americanas, Volume 3. Cap. 19; Fundação CARGILL. p. 530 - 575, 2003. 


\section{Capítulo 18}

doi $10.37423 / 210804586$

\section{A REGIÃO MERCOESTE E O FUTURO DA PRODUÇÃO DE BIODIESEL NO BRASIL}

Vinícius Souza Ribeiro

José Eustáquio Canguçú Leal
Instituto Federal de Educação, Ciência e

Tecnologia do Tocantins - IFTO

Instituto Federal de Educação, Ciência e Tecnologia do Tocantins - IFTO 
Resumo: No contexto da preocupação mundial com a geração de novas fontes de energia limpas surge a alternativa do biodiesel. Nessa perspectiva o Mercoeste brasileiro, surge como região de potencial crescimento para a produção do biodiesel, uma vez que $80 \%$ do biodiesel nacional é produzido através da soja e essa região tem taxas de produtividade do grão acima da média nacional. Através do levantamento de dados secundários vinculados à produção e produtividade de soja, assim como da produção de biodiesel nos estados do Mercoeste e Brasil, o artigo tem como finalidade demonstrar o potencial da região para a produção de biodiesel, através da soja, e os benefícios possíveis da exploração desse potencial. O estudo aponta um grande potencial dessa região para a produção de biodiesel, principalmente tendo como matéria prima a soja, que aliada à crescente demanda mundial pelo combustível leva a uma grande oportunidade de reversão da matriz exportadora da soja do Brasil, passando do grão em natura, de baixo valor agregado, para o biodiesel, de alto valor agregado. O que contribuirá para uma maior diversificação da matriz energética mundial, geração de divisas para o país e redução dos impactos ambientais na produção de combustíveis.

Palavras-chave: agroenergia, biocombustível, cadeia produtiva, regionalismo, soja 


\section{INTRODUÇÃO}

Sob a perspectiva do consumo de energia, o Mundo aponta para o contínuo aumento da demanda a partir de diversas fontes disponíveis, essa tendência nos leva a necessidade de se realizar esforços mundiais que propiciem o aumento da oferta e diversificação da matriz energética. Concomitantemente, realizar esforços no sentido de reduzir os impactos ambientais para mitigação dos problemas causados com o aquecimento global. O Brasil é reconhecidamente como um dos países que detém condições de absorver boa parte da demanda global por energia limpa (Ribeiro, 2012).

Nesse contexto surge o biodiesel, também conhecido como diesel vegetal é um combustível obtido de fontes renováveis, tais como óleos vegetais e gorduras animais, por intermédio de processos químicos como o da transesterificação ou do craqueamento térmico. Quimicamente é definido como um éster monoalquílico de ácidos graxos de cadeia longa com características físico-químicas semelhantes ao diesel mineral. Por ser perfeitamente miscível e físico quimicamente semelhante ao óleo diesel mineral, o Biodiesel pode ser utilizado puro ou misturado em quaisquer proporções, em motores do ciclo diesel sem a necessidade de significantes ou onerosas adaptações (Brasil, 2003).

Mundialmente passou-se a adotar uma nomenclatura bastante apropriada para identificar a concentração do Biodiesel na mistura. É o Biodiesel BXX, onde XX é a percentagem em volume do Biodiesel à mistura. Por exemplo, o B2, B5, B20 e B100 são combustíveis com uma concentração de 2\%, 5\%, 20\% e 100\% de Biodiesel, respectivamente. Por ser biodegradável, não-tóxico e praticamente livre de enxofre e aromáticos, é considerado um combustível ecológico. Como se trata de uma energia limpa, não poluente, que pode ser usada pura ou misturada com o diesel mineral em qualquer proporção, o seu uso num motor diesel convencional resulta, quando comparado com a queima do diesel mineral, numa redução substancial de monóxido de carbono e de hidrocarbonetos não queimados (Brasil, 2003).

O Mercoeste é um projeto estratégico regional alavancado pelo SENAI e concebido em 1997, pelos presidentes das federações das indústrias dos estados de GO, MT, MS, TO, RO, AC e DF (Grupo dos Sete), O Mercoeste é, basicamente, o esforço de articulação planejada que visa a aglutinar as forças das lideranças empresariais, políticas e comunitárias do Oeste brasileiro, que compreende os Estados do Centro-Oeste, acrescidos dos Estados do Acre, Rondônia e Tocantins, com vistas à viabilização do seu desenvolvimento auto-sustentado (FIETO, 2012). Este trabalho irá se restringir a esta região e a produtividade de grãos que possam servir de matéria-prima para produção de biodiesel, focando na produção da soja. 
A escolha da soja se dá, pois, essa é uma cultura onde todas as suas etapas de produção já estão consolidadas pela cadeia produtiva, e com sua produção adaptada a uma vasta extensão do território nacional. A escolha da soja também se dá pelo fato de que a oleaginosa demonstra ser a matéria prima para produção de biodiesel mais competitiva do mercado, em 2012 , $80 \%$ do biodiesel do país derivou desse grão (ANP, 2012).

O presente estudo nasce da necessidade de diversificação da matriz energética mundial, através de uma produção maior de biodiesel, assim como da carência de diversificar a pauta de exportações de soja do Brasil. Sendo que, com a participação cada vez maior do biodiesel na matriz energética mundial serão reduzidos cada vez mais os impactos ambientais na produção de combustíveis, além de ampliar a segurança energética, na medida em que o globo não ficará tão dependente como é hoje dos combustíveis fósseis. Além disso, ao diversificar a matriz pauta exportadora, vendendo mais biodiesel, produto com valor agregado, o país será capaz de gerar mais divisas e também de não depender da exportação concentrada de um único produto.

Esse artigo tem como objetivos, conceituar a região Mercoeste e o biodiesel, além de apresentar os dados relativos à produção de soja e biodiesel no Brasil e na região de estudo. Adicionalmente, demonstrar o potencial do Mercoeste para a produção de biodiesel, através da soja, e os benefícios possíveis da exploração desse potencial.

\section{MATERIAL E MÉTODOS}

O estudo baseou-se em levantamento bibliográfico realizado entre o período de agosto de 2011 e abril de 2014. Foram consultadas publicações relacionadas ao tema da pesquisa, sendo possível também coletar dados secundários relativos à produção de soja e biodiesel nos estados que compõem o Mercoeste. De acordo com Vergara (2003, p.50) a pesquisa está caracterizada quantos aos meios, como pesquisa bibliográfica e quanto aos fins como do tipo descritiva.

As informações acerca da produção de soja foram obtidas a partir de dados da CONAB (Companhia Nacional de Abastecimento) e da Produção Agrícola Municipal - PAM de 2009, já os dados relativos as produções e empresas produtoras de biodiesel no Brasil, em 2010/2011, foram coletados junto à ANP (Agência Nacional de Petróleo e Gás). 


\section{RESULTADOS E DISCUSSÃO}

As safras de oleaginosas a serem utilizadas para produção de biodiesel somente são viáveis quando existe demanda de mercado para todos os subprodutos obtidos na cadeia de produção. Neste caso, merece atenção especial o plantio de grãos para a produção de proteínas para uso em larga escala na alimentação humana e sob a forma de ração animal, como é o caso da soja. Na figura 1, podemos observar o relevante crescimento histórico do Mercoeste no mapa do cultivo da soja brasileira, entre 1970 e 2003.

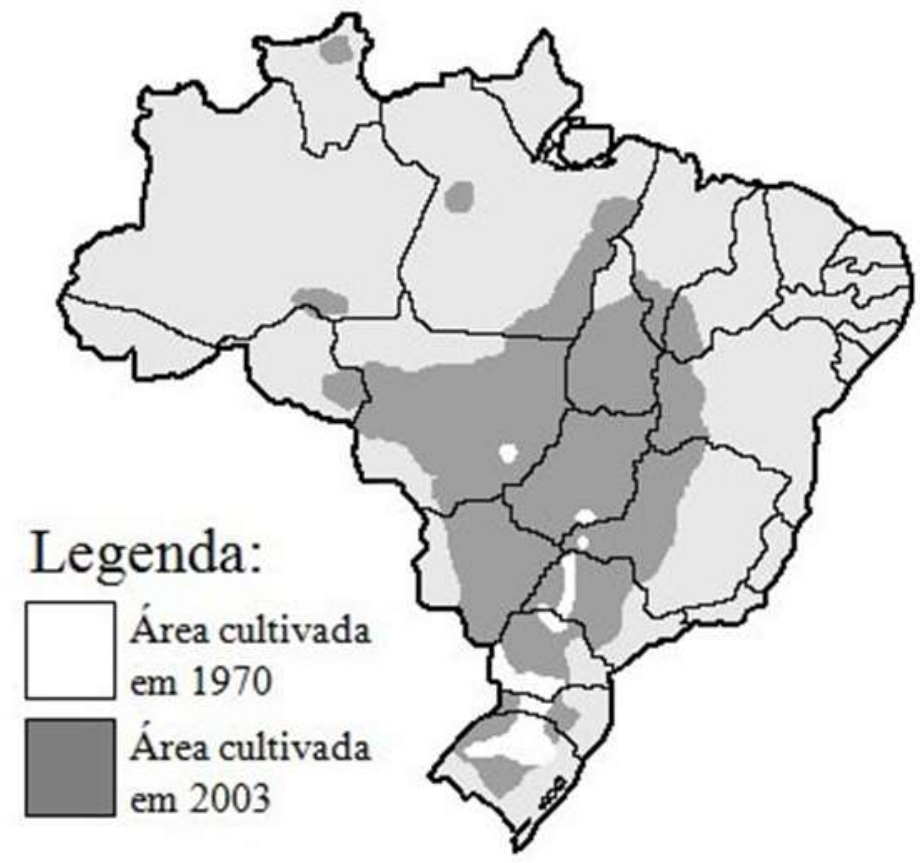

Figura1. Mapa do cultivo da soja no Brasil

Fonte: Amaral (2003).

De acordo com a figura 2, a maior produtividade ficou por conta do Estado do Acre com 3.300 $\mathrm{kg} /$ hectare, porém, essa produtividade advém de uma pequena área com o intuito de inserir a oleaginosa no Estado. Os índices de produtividade para safra 2008/2009 de todos os estados são altos, principalmente se levarmos em conta que a média de produtividade do Brasil que é de $2.629 \mathrm{~kg} / \mathrm{ha}$, superando inclusive a produtividade nos EUA estimada em $2.666 \mathrm{~kg} /$ hectare (CONAB, 2012). 


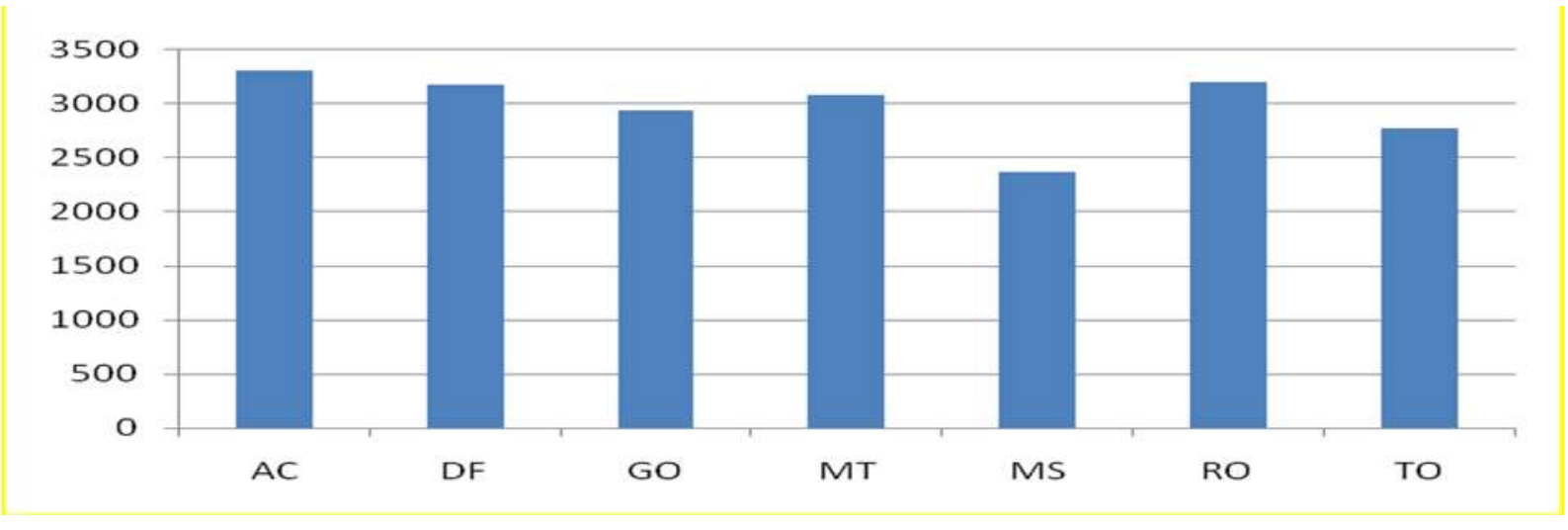

Figura 2. Produtividade da soja no Mercoeste por estado

Fonte: IBGE, 2010.

Quanto à quantidade produzida de grãos de soja em toneladas para o mesmo período, a região Mercoeste é responsável por 52,67\% da produção nacional (IBGE, 2010).

A Agroenergia oferece a oportunidade de fomentar o crescimento em muitos dos países mais pobres do mundo, ao suscitar um renascimento agrícola e fornecer energia moderna á população mundial. Neste cenário, a busca por fontes energéticas renováveis se fortalece como uma solução lucrativa para os produtores de oleaginosas, matérias-primas dos biocombustíveis derivados de óleo vegetal (Biodiesel). De acordo com APROBIO (2012) a soja responde historicamente por $80 \%$ da produção de óleo vegetal no Brasil, isso significa que a indústria processadora brasileira é fortemente amparada pela cultura da soja tornando-a uma cultura promissora para contribuir na produção de biodiesel. Todas as etapas da produção de soja são mecanizadas - o preparo do solo, o plantio, toda a adubação, prevenção de pragas, colheita, transporte e armazenamento. A restrição da soja na sua utilização na produção de biodiesel é em relação ao baixo conteúdo de óleos em seus grãos.

A maior parte da exportação de soja feita pelo Brasil é na forma de grãos devido, basicamente, os menores custos da sua logística. E nesse contexto, insere-se o Mercoeste, com sua enorme produção de grãos e capacidade suficiente de atender a essa demanda emergente. O Mercoeste dispõe de potencial energético hídrico, gasodutos interligando o Brasil à Bolívia, a malha rodoviária da região é extensa com suas principais estradas pavimentadas, rede de transporte hidroviário com potencial de expansão por meio da ampliação do calado e da implantação de terminais de transbordo em localidades estratégicas, ferrovias como a Ferronorte ligando São Paulo, Mato Grosso, Mato Grosso do Sul, Rondônia, Amazônia e Pará, e a Norte-Sul, ligando Goiás, Tocantins e Pará, trazendo a essa região um grande fator competitivo, reduzindo os custos de transportes para os produtos. 
O potencial complexo soja da região Mercoeste poderia impulsionar a indústria de biodiesel redirecionando parte dos grãos exportados para a indústria esmagadora, agregando desta forma valor ao produto, seja este exportado na forma de biodiesel ou do farelo resultante do processamento dos grãos.

\subsection{PRODUÇÃO DE BIODIESEL NO MERCOESTE}

\subsubsection{REGIÃO MERCOESTE (ESTADOS DO CENTRO-OESTE)}

Tabela 1 Usinas de Biodiesel / Região Centro-Oeste

(continua)

\begin{tabular}{|c|c|c|}
\hline \multirow[t]{2}{*}{ Empresa - UF } & \multicolumn{2}{|c|}{$\mathrm{m}^{3} /$ ano -2010} \\
\hline & Capacidade estimada & $\begin{array}{r}\text { Produção } \\
\text { efetiva }\end{array}$ \\
\hline ADM do Brasil Ltda. MT & 343.800 & 237.535 \\
\hline Granol Indústria, Comércio e Exportação S/A. GO & 220.680 & 176.402 \\
\hline Caramuru Alimentos S /A. São Simão/ GO & 225.000 & 153.860 \\
\hline Fiagril Ltda. MT & 202.680 & 109.430 \\
\hline Cooperbio - Cooperativa de Biocombustíveis. MT & 122.400 & 82.349 \\
\hline Binatural Ind. e Comércio de Óleos Vegetais Ltda. - GO & 162.000 & 67.098 \\
\hline Biocamp Ind. e Com. Imp. e Exp. de Biodiesel Ltda. MT & 108.000 & 47.698 \\
\hline Caramuru Alimentos S /A. Ipameri/GO & 225.000 & 44.933 \\
\hline Barralcool - Usina Barrálcool S/A. MT & 58.823 & 24.191 \\
\hline CLV Indústria e Comércio de Biodiesel ltda.MT & 36.000 & 14.399 \\
\hline Agrosoja - Comércio e Exportação de Cereais Ltda. MT & 28.800 & 13.600 \\
\hline Biopar Produção de Biodiesel Parecis Ltda. MT & 36.000 & 12.353 \\
\hline Biocar Ind. e Com. de Óleos Vegetais e Biodiesel Ltda. & 10.800 & 7.179 \\
\hline Grupal Agroindustrial S/A - MT & 43.200 & 6.848 \\
\hline Araguassú Óleos Vegetais Indústria e Comércio Ltda. MT & 36.000 & 6.296 \\
\hline \multirow[t]{2}{*}{ Bionorte Indústria e Comércio de Biodiesel Ltda. GO } & 3.600 & 1.567 \\
\hline & & (Conclusão) \\
\hline Beira Rio Biodiesel Ltda. MT & 4.320 & 846 \\
\hline SSIL - Sociedade Sales Industrial Ltda. MT & 1.800 & 796 \\
\hline Delta Biocombustíveis Indústria e Comércio Ltda. & 108.000 & 620 \\
\hline Agrenco Ind. e Com. de Óleos e Biodiesel Ltda. MT & 235.294 & 521 \\
\hline Cooperfeliz Coop. Agroindustrial dos Prod. Rurais. MT & 2.400 & 236 \\
\hline Coomisa - Cooperativa mista Sapezalense & 4.320 & 189 \\
\hline Cooperbio Coop. Mercantil e Ind. dos Produtores. MT & 1.440 & 153 \\
\hline
\end{tabular}




\begin{tabular}{l|r|r}
\hline Tecnodiesel Biodiesel e Derivados Ltda. MS & 3.960 & 29 \\
\hline Bio Vida Produção e Comércio de Biodiesel Ltda. MT & 6.480 & 26 \\
\hline Bionasa Combustível Natural S /A. GO & 235.080 & $\mathrm{~N} / \mathrm{d}$ \\
\hline Bionorte Indústria e Comércio de Biodiesel Ltda. GO & 29.411 & $\mathrm{~N} / \mathrm{d}$ \\
\hline Minerva S /A. GO & 16.200 & 00 \\
\hline Rondobio Biocombustível Ltda. MT & 3.600 & $\mathrm{~N} / \mathrm{d}$ \\
\hline Tauá Biodiesel Ltda. MT & 36.000 & $\mathrm{~N} / \mathrm{d}$ \\
\hline Transportadora Caibiense Ltda. MT & 36.000 & $\mathrm{~N} / \mathrm{d}$ \\
\hline Usibio Ind. e Com. de Biocomb. do Centro-Oeste ltda. MT & 7.200 & 00 \\
\hline Total = 32 & 2.594 .288 & 870.680 \\
\hline
\end{tabular}

Fonte: ANP, 2011.

De acordo com a tabela 1 a região Centro-Oeste detém a maior quantidade de empresas produtoras por região e a maior produção de biodiesel do país, $870.680 \mathrm{~m}^{3}$, correspondendo por $36,32 \%$, do total produzido de $2.396 .955 \mathrm{~m}^{3}$ de biodiesel no país, no ano de 2010 . Grandes conglomerados do agronegócio brasileiro como a ADM, Granol e Caramuru estão instalados na região, os complexos industriais escolheram a região devido à disponibilidade de terra para produção e a capacidade produtiva dos agricultores. A cadeia produtiva do biodiesel necessita de matéria-prima próxima aos centros de industrialização, garantia de entrega de quantidades razoáveis para garantir a produção e qualidade também, devido a problemas de logística; como transporte e armazenagem, nesse caso o biodiesel têm na soja da região, sua principal fonte de óleo vegetal para produção, devido a sua disponibilidade e o domínio da cadeia produtiva dos seus co-produtos. Na figura 3 se percebe como está a divisão do mercado.

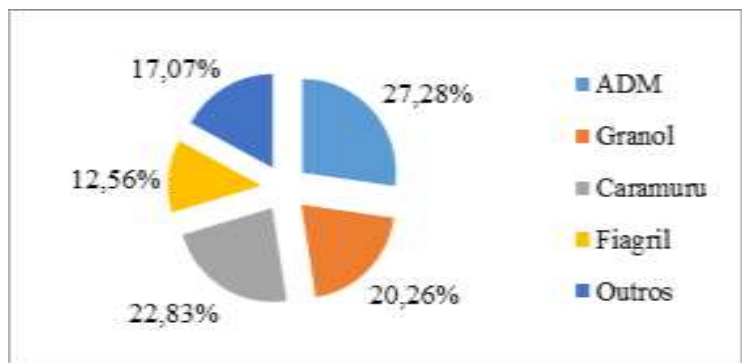

Figura 3. Participação de mercado região Centro-Oeste.

Fonte: ANP, 2011.

A região conta com quatro empresas que estão entre as dez maiores produtoras de biodiesel do país; a ADM com $237.535 \mathrm{~m}^{3}$ que corresponde a $27,28 \%$ do que foi produzido na região, a Granol com $176.402 \mathrm{~m}^{3}$ e $20,26 \%$ do mercado, a Caramuru com suas duas unidades alcançaram $198.793 \mathrm{~m}^{3}$ com 
$22,83 \%$ de participação e a Fiagril com $109.430 \mathrm{~m}^{3}$ produzidos e $12,56 \%$ de participação do mercado da região Centro-Oeste.

\subsubsection{REGIÃO MERCOESTE (ESTADOS DO NORTE)}

Tabela 2 - Usinas de Biodiesel / Região Norte

\begin{tabular}{l|r|r}
\hline \multirow{2}{*}{ Empresa - UF } & \multicolumn{2}{|c}{$\mathrm{m}^{3 / a n o}-2010$} \\
\cline { 2 - 3 } & Capacidade estimada & $\begin{array}{c}\text { Produção } \\
\text { efetiva }\end{array}$ \\
\hline Brasilecodiesel Ind.e Com. de Biocomb. S.A. TO & 129.600 & 74.577 \\
\hline Biotins Companhia Prod. de Biocomb. S.A. TO & 29.160 & 10.769 \\
\hline Amazonbio Ind. e Com. de Biodiesel Ltda. RO & 7.200 & 6.186 \\
\hline Ouro Verde Indústria e Comércio de Biodiesel Ltda. RO & 3.240 & 04 \\
\hline Total =4 & 169.200 & 91.536 \\
\hline
\end{tabular}

Fonte: ANP, 2011.

Observa- se na tabela 2, das indústrias produtoras de biodiesel da região Norte, a unidade da Brasilecodiesel foi a que mais produziu. Somando as produções de suas outras unidades pelo país, faz com que ela fique entre as dez maiores produtoras do biodiesel do Brasil, esta unidade está situada no município de Porto Nacional-TO, com produção efetiva de $74.557 \mathrm{~m}^{3}$ e participação de mercado de $79,43 \%$ da produção da região norte no ano de 2010 , que usa a soja como componente principal na industrialização. A 2a colocada, a Biotins de Paraíso do Tocantins-TO, com $10.769 \mathrm{~m}^{3}$ e participação de mercado de $11,47 \%$, que tem como um dos componentes principais o sebo bovino, por estar estrategicamente próxima de grandes frigoríficos da região.

As outras empresas produtoras da região norte que compõe o Mercoeste são Rondônia: A Amazonbio com $6.186 \mathrm{~m}^{3}$ e participação de mercado $6,76 \%$ e a Ouro verde com $4 \mathrm{~m}^{3}$ e com menos de $0,01 \%$ de participação.

A figura 4 demonstra a divisão da produção de biodiesel da região Norte e destaca a importância da produção da empresa Brasilecodiesel para a região, pois representou mais de $80 \%$ da produção total. 


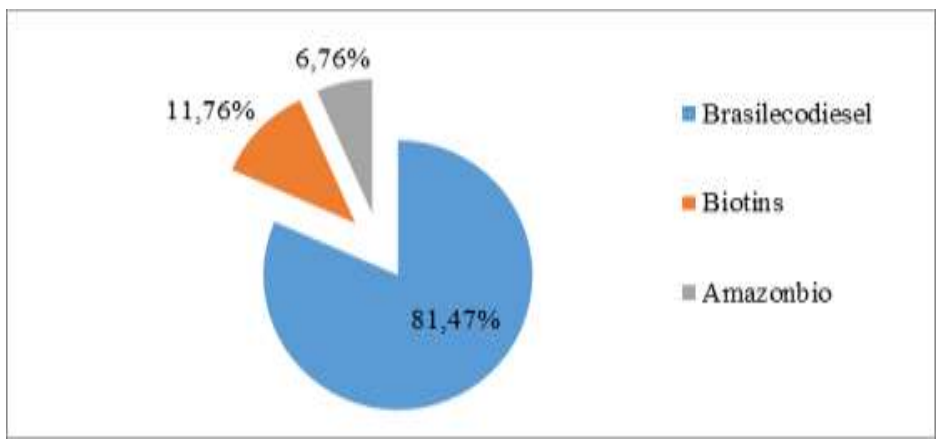

Figura 4. Participação de mercado dos estados da Região Norte pertencentes ao Mercoeste Fonte: ANP, 2011.

Em relação à produção efetiva nacional de biodiesel para o ano de 2010, na ordem de $2.249 .650 \mathrm{~m}^{3}$, a região Mercoeste responde por aproximadamente 43\% desse total (Leal, 2012).

\section{CONCLUSÕES}

O Mercoeste coloca-se de uma forma protagonista para acelerar o desenvolvimento e produção tanto de óleo vegetal como de biodiesel para os próximos anos, devido às vantagens em relação aos fatores de produção que dispõe como logística favorável, disponibilidade hídrica, terras férteis e vocação agropecuária da região.

Além dessas vantagens, somam-se a grande produtividade dos estados da região Mercoeste no cultivo da soja, acima da média nacional, e a participação na produção nacional da oleaginosa acima de $50 \%$. Não obstante a participação das usinas da região na produção de biodiesel é também significativa, acima de $40 \%$ da produção nacional.

Sendo, assim de acordo discussões e os dados, conclui-se que há um grande potencial dessa região para a produção de biodiesel, principalmente tendo como matéria prima a soja, que aliada à crescente demanda mundial pelo combustível leva a uma grande oportunidade de reversão da matriz exportadora da soja do Brasil, passando do grão em natura, de baixo valor agregado, para o biodiesel, de alto valor agregado. O que contribuirá para uma maior diversificação da matriz energética mundial, geração de divisas para o país e redução dos impactos ambientais na produção de combustíveis. 


\section{REFERÊNCIAS}

AMARAL, D. A construção do Brasil novo. Brasília: Senado Federal. 2003.

ANP. Lista de empresas produtoras 2010.Disponível em:

http://www.anp.gov.br/?pg=57522\&m=\&t1=\&t2=\&t3=\&t4=\&ar=\&ps=\&cachebu=1315321053232.

Acesso em 06/09/2011.

. Boletim mensal do biodiesel de junho de 2012. Disponível em: https://www.gov.br/anp/pt$\mathrm{br} /$ assuntos/producao-e-fornecimento-de-biocombustiveis/biodiesel/if/bmb/2012/boletimbiodiesel-06.pdf. Acesso em 07/07/2012.

APROBIO. Biodiesel e a soja no Brasil. Disponível em: http://www.aprobio.com.br. Acesso em 07/07/2012.

BRASIL. O Biodiesel e a inclusão social. Brasília: Câmara dos Deputados, Coordenação de Publicações. 2003.

CONAB. Séries históricas relativas às safras 1976/77 a 2009/2010 de área plantada, produtividade e produção. Brasília, DF, 2012. Disponível em:

https://www.conab.gov.br/conteudos.php?\%20a=1252\&t=. Acesso em: 11/12/2011.

FIETO. Mercoeste. Disponível em: http://www.fieto.com.br/Mercoeste.aspx?Cat=1. Acesso em 03/04/2012.

IBGE. Pesquisa Agrícola Municipal (PAM - 2009). Disponível em http://www.sidra.ibge.gov.br/. Acesso em 02/03/2012.

LEAL, J.E.C. Análise das estratégias competitivas das dez maiores empresas produtoras de biodiesel no Brasil. 2012. 121f. Dissertação (Mestrado em Agroenergia) - Universidade Federal do Tocantins, Programa de Pós-Graduação em Agroenergia, Palmas, 2012.

RIBEIRO, V. S. Política Pública do Biodiesel e o Desenvolvimento Local Sustentável para a Agricultura Familiar. In: XII Colóquio Internacional sobre o Poder Local. Salvador-BA, 2012. https://www.researchgate.net/publication/340788445_Politica_Publica_do_Biodiesel_e_o_Desenvo Ivimento_Local_Sustentavel_para_a_Agricultura_Familiar

RIBEIRO, V. S. Biodiesel e agricultura familiar no Tocantins: uma análise a partir da teoria dos conjuntos Fuzzy. 2014. 115f. Dissertação (Mestrado em Desenvolvimento Regional) - Universidade Federal do Tocantins, Programa de Pós-Graduação em Desenvolvimento Regional, Palmas, 2014. http://dx.doi.org/10.13140/RG.2.2.12588.26248

RIBEIRO, V. S.; LEAL, J.E.C. A produção de biodiesel e o cultivo da soja na região Mercoeste. In: VII CONNEPI- Congresso Norte Nordeste de Pesquisa e Inovação. Palmas-TO, 2012. https://www.researchgate.net/publication/353741485_A_PRODUCAO_DE_BIODIESEL_E_O_CULTIV O_DE_SOJA_NA_REGIAO_MERCOESTE?_sg=K9uoriEXjApd1osg5j6VWYc8D-CXJ6gFCobvpPynk_dyYUZjAKjqgsKyc8MaBHFiNjJDLcfqMnSB_zCCfyGpy- 
DIFqdoXxmx38B_zFP.wW5QSxMwjLjes_x5e-

alMxsqwRERdRDMzC8fS9cNiUReekVdyLDFt2G1IYoFIFipLdrAZ2BhGhYyekK2IEb1pA 


\section{Capítulo 19}

doi) $10.37423 / 210804587$

PROGRAMA NACIONAL DE PRODUÇÃO E USO DE BIODIESEL (PNPB): REFLEXÕES ACERCA DA AGRICULTURA FAMILIAR, DESENVOLVIMENTO SUSTENTÁVEL E GESTÃO SOCIAL

\section{Vinícius Souza Ribeiro}

José Eustáquio Canguçú Leal
Instituto Federal de Educação, Ciência e Tecnologia do Tocantins - IFTO

Instituto Federal de Educação, Ciência e Tecnologia do Tocantins - IFTO 
Resumo: O objetivo deste artigo é analisar se o Programa Nacional de Produção e Uso de Biodiesel (PNPB) é capaz de contribuir para a promoção do desenvolvimento local sustentável da agricultura familiar no Brasil, sob a égide da gestão social. Entendendo que essa se coloca como um promissor modelo de gestão para a formulação e implementação de políticas públicas que busquem a melhoria das condições de vida dos produtores familiares. $O$ artigo também aborda a importância da agricultura familiar para a economia nacional e as diferentes perspectivas do conceito de agricultura familiar e desenvolvimento. Dentro do objetivo proposto, o estudo sinaliza que o PNPB não apresenta características que possam classificá-lo como uma política pública pautada na gestão social e que dessa forma possa contribuir para o desenvolvimento local sustentável. Sendo necessário para tanto, que o Estado seja capaz de formular políticas públicas inclusivas e que através da decisão participativa e descentralizada seja capaz de administrar os conflitos sociais de forma neutra e eficiente. 


\section{INTRODUÇÃO}

Ao contrário do que muitos imaginam a maior parte da geração de empregos no campo e produção de alimentos no país são provenientes da agricultura familiar, sendo esse tipo de propriedade a grande maioria do total dos estabelecimentos rurais do Brasil. As discussões que envolvem o conceito da agricultura familiar e sua dimensão econômica nacional serão realizadas na seção a seguir.

Na seção três será discutida a produção de biodiesel a partir do cultivo de oleaginosas e a sua inclusão na matriz energética brasileira a partir de 2004 quando o Estado formulou o PNPB que visava de forma sustentável implantar a produção e uso de biodiesel, com enfoque na inclusão social do agricultor familiar e desenvolvimento regional. A seção quatro é dedicada à questão do desenvolvimento e suas diferentes abordagens, fazendo uma discussão que chega ao desenvolvimento pensado no âmbito local e de forma sustentável ligado ao modelo de gestão social. A partir da seção anterior, na seguinte é realizada uma análise da capacidade de contribuição da política pública do biodiesel para promoção do desenvolvimento local sustentável no âmbito da agricultura familiar no Brasil, que é o objetivo desse texto. As considerações finais e sugestões para trabalhos futuros são propostos na sexta e última seção do artigo.

Com relação aos métodos, esse estudo foi baseado em um levantamento bibliográfico realizado em sítios, artigos e revistas, dissertações e teses, entre janeiro e dezembro de 2012, sendo dessa forma possível coletar dados secundários relativos à agricultura familiar no Brasil. Assim como, levantar legislações, conceitos e formulações teóricas que fundamentaram a construção desse artigo que de acordo com Vergara (2003) pode ser caracterizado quantos aos meios, como pesquisa bibliográfica, e quanto aos fins como pesquisa é descritiva.

\section{AGRICULTURA FAMILIAR: ASPECTOS CONCEITUAIS E SUA IMPORTÂNCIA ECONÔMICA PARA} BRASIL

\subsection{ASPECTOS CONTEXTUAIS E CONCEITUAIS DA AGRICULTURA FAMILIAR}

Ao se pesquisar a definição de agricultor familiar no Brasil, percebe-se claramente amplitude de contextos e definições a qual ele se submete. O exercício da delimitação do contexto ou ótica de análise se coloca como primeiro obstáculo ao pesquisador para que não haja equívocos nas análises e discussões conceituais. Nesta seção serão examinadas algumas percepções ao se abordar o conceito 
de agricultura familiar, assim como uma definição sintetizada a ser adotada no artigo, sem a pretensão de esgotar a discussão.

É possível segundo Souza (2011), elencar quatro contextos ou perspectivas ao se discutir agricultura familiar no Brasil, sendo eles o empírico, o político, o das políticas públicas e o acadêmico. O primeiro refere-se aos mais diversos agentes que estão diretamente envolvidos com as atividades agropecuárias e por tanto são tratados de forma genérica como agricultores familiares. Essa primeira perspectiva acaba englobando agentes que têm as mais diversificadas relações com a posse e uso da terra.

Já o contexto político satisfaz as necessidades das diferentes organizações representativas de um segmento da agricultura familiar de disputar, na arena pública, os diversos recursos destinados a ela. Além das necessidades de levantar recursos financeiros, os conceitos derivados dessa perspectiva consolidam a posição ideológica, histórica e política de cada organização frente aos indivíduos que ela representa e à própria sociedade. Ainda segundo a autora, o terceiro contexto das políticas públicas ou simplesmente público, refere-se:

\begin{abstract}
"à construção das políticas públicas voltadas para um segmento inicialmente definido a partir da realidade empírica, às vezes de forma imprecisa, e que aos poucos, em um jogo envolvendo o contexto político, acadêmico e da própria política pública, vai se delineando de forma mais clara até alcançar o status de "categoria" elegível a receber determinados benefícios e até a direitos explicitados na legislação" (SOUZA, 2011, p.11).
\end{abstract}

Nessa perspectiva, o termo "agricultor familiar" é cunhado para a formulação de políticas públicas e concessão de benefícios (crédito, assistência técnica, programas de comercialização, dentre outros) que tem diferentes contornos em relação aos demais contextos e uma característica operacional mais acentuada que os demais. Ainda nesse quadro, destaca-se que a principal definição de agricultor familiar é a relacionada aos critérios de elegibilidade para acesso ao PRONAF (Programa Nacional de Fortalecimento da Agricultura Familiar).

Na perspectiva acadêmica o termo agricultura familiar é amplamente discutido em diversas áreas do conhecimento, indo das ciências agrárias às ciências humanas. De acordo com Souza (2011), a partir desse contexto surgem diferentes conceitos de agricultor familiar, principalmente dadas às origens e características socioeconômicas desses indivíduos e aos diferentes sistemas epistemológicos utilizados pelas várias correntes de pensamento e áreas do conhecimento. É nesse plano, sem pretensões de se aprofundar mais ou esgotar o conceito de agricultura familiar frente aos diferentes contextos apresentados, correntes de pensamento e autores, que é possível sintetizar ${ }^{1}$ para fins desse 
artigo a agricultura familiar como aquela em que a gestão, a terra e a maior parte do trabalho no campo advêm de indivíduos que mantêm entre si vínculos familiares.

\subsection{A IMPORTÂNCIA ECONÔMICA DA AGRICULTURA FAMILIAR NO BRASIL}

Nesta seção serão apresentados dados oficiais relativos à agricultura familiar no Brasil. Logo se faz necessário definir o agricultor familiar no contexto das políticas públicas, dado pela lei 11.326/2006. De acordo com a lei, para ser classificado como agricultor familiar é necessário atender os seguintes critérios: (1) não ter, a qualquer título, área maior do que quatro módulos fiscais, (2) utilizar predominantemente mão-de-obra da própria família nas atividades econômicas do seu estabelecimento ou empreendimento, (3) ter percentual mínimo da renda familiar originada de atividades econômicas do seu estabelecimento ou empreendimento, na forma definida pelo Poder Executivo, (4) dirigir seu estabelecimento ou empreendimento com sua família. O mesmo dispositivo legal, ainda ressalva que o Conselho Monetário Nacional (CMN) poderá estabelecer mais critérios e condições a serem atendidas pelos agricultores familiares para fins de concessão de linhas de crédito. A partir da definição legal de agricultor familiar, o Instituto Brasileiro de Geografia e Estatística (IBGE) publicou pela primeira vez, em 2009, a realidade da agricultura familiar no Brasil através do Censo Agropecuário de 2006. Para a delimitação do agricultor familiar o Instituto utilizou o método de exclusão sucessiva e complementar, ou seja, para ser classificado como tal o produtor deveria atender simultaneamente todos os critérios estabelecidos pela lei. Outro esclarecimento oportuno quanto ao Censo agropecuário, é que o mesmo poderá superestimar o público pertencente à agricultura familiar, contudo algo que representa menos de $1 \%$ do total ${ }^{2}$.

De acordo com os dados do Censo Agropecuário de 2006, 84,4\% dos estabelecimentos agropecuários eram de agricultura familiar (Figura 1). Contudo, em relação à área em hectares, os mesmos detinham apenas $24,3 \%$ do total, esses dados que demonstram a alta concentração de terras no país. A primeira informação revela que a agricultura familiar ao contrário do que muitos imaginam constitui esmagadora maioria das propriedades rurais no país, apesar de estarem limitados, pela Lei $11.326 / 2006$, a valores entre 20 e 440 hectares dependendo da região do país ${ }^{3}$. 
Figura 1. Total de Estabelecimentos Agropecuários: participação da agricultura familiar

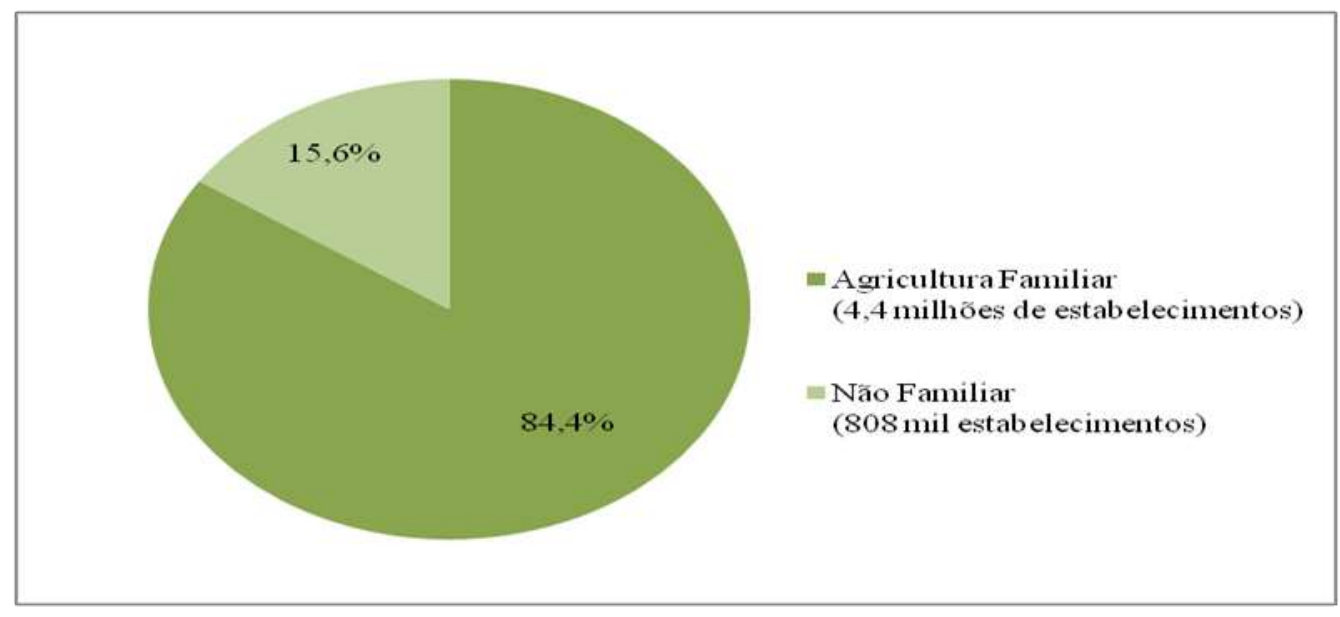

Fonte: Elaboração própria a partir de IBGE (2006)

Outra importante informação extraída do censo diz respeito à geração de emprego e fixação dos homens e mulheres no campo. A agricultura familiar respondeu por 12,3 milhões de pessoas ocupadas no campo, ou seja, 74,4\% de todos os empregos gerados no campo em 2006 (Figura 2). Esse dado demonstra o quanto as propriedades de agricultura familiar são importantes para geração de emprego e fixação, no campo, desses homens e mulheres que através do trabalho da própria família administram e mantêm a propriedade da terra.

Quanto ao valor total da produção dos estabelecimentos, a agricultura familiar respondeu pelo montante de $\mathrm{R} \$ 54,4$ bilhões, correspondente a $38 \%$ do total. Nesse ponto cabe destacar que dos 4,4 milhões de estabelecimentos familiares, cerca de 3,9 milhões declararam algum valor de produção, ou seja, 500 mil agricultores familiares declararam não ter gerado nenhum valor produtivo no período da coleta de dados. Ainda em relação ao valor bruto da produção, é interessante observar que apesar de ocupar apenas $24,3 \%$ da área rural nacional, os agricultores familiares foram responsáveis por $38 \%$ do valor bruto agregado da agropecuária do país em 2006. 
Figura 2. Pessoal Ocupado no Campo: participação da agricultura familiar

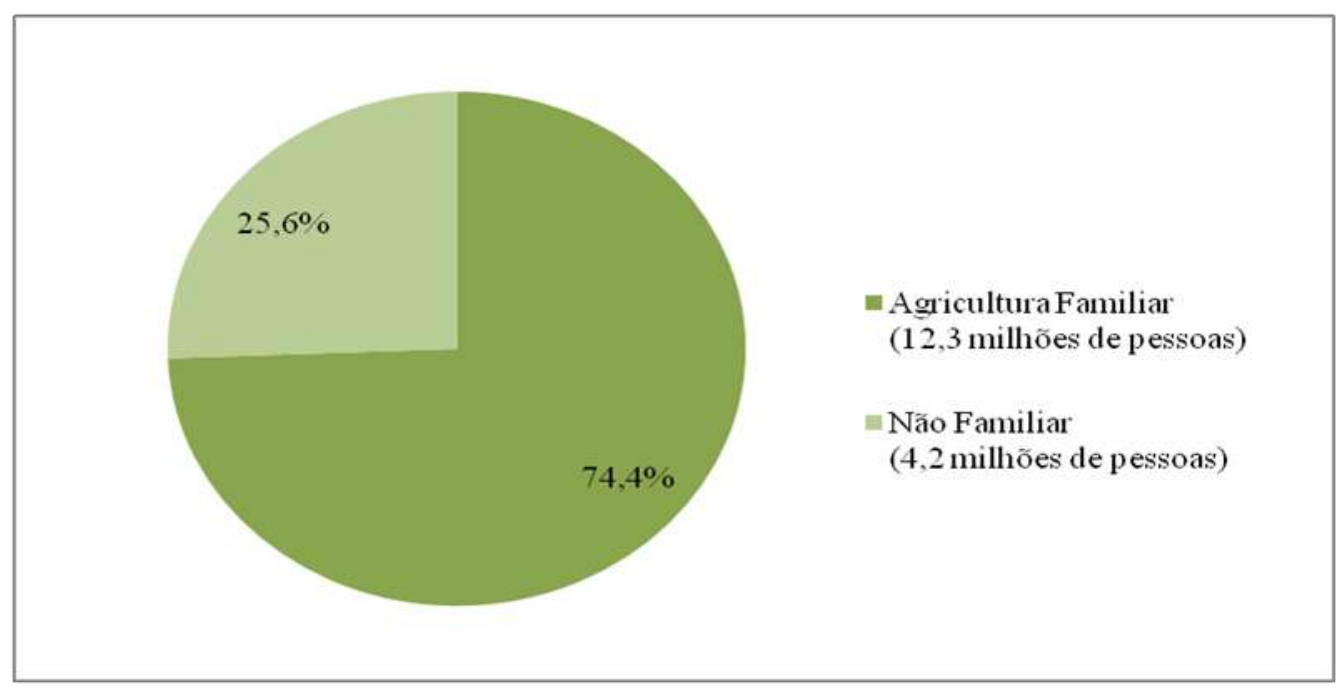

Fonte: Elaboração própria a partir de IBGE (2006)

Outro dado importante do Censo agropecuário de 2006 é o relativo à produção de alimentos básicos e proteína animal pela agricultura familiar para a população brasileira (Figura 3). Sendo esses estabelecimentos responsáveis pela produção, em território nacional, de $87 \%$ da mandioca, $70 \%$ do feijão, 40\% do milho, 34\% do arroz, 58\% do leite, 59\% da Carne suína e 50\% das aves.

Em resumo, esses números expressivos demonstram que mesmo produzindo em uma área menor de terras os estabelecimentos de agricultura familiar foram os principais fornecedores de alimentos básicos e proteínas para o país, no ano de 2006, em comparação aos estabelecimentos não familiares.

Figura 3 Participação da Agricultura Familiar na Produção de Alimentos

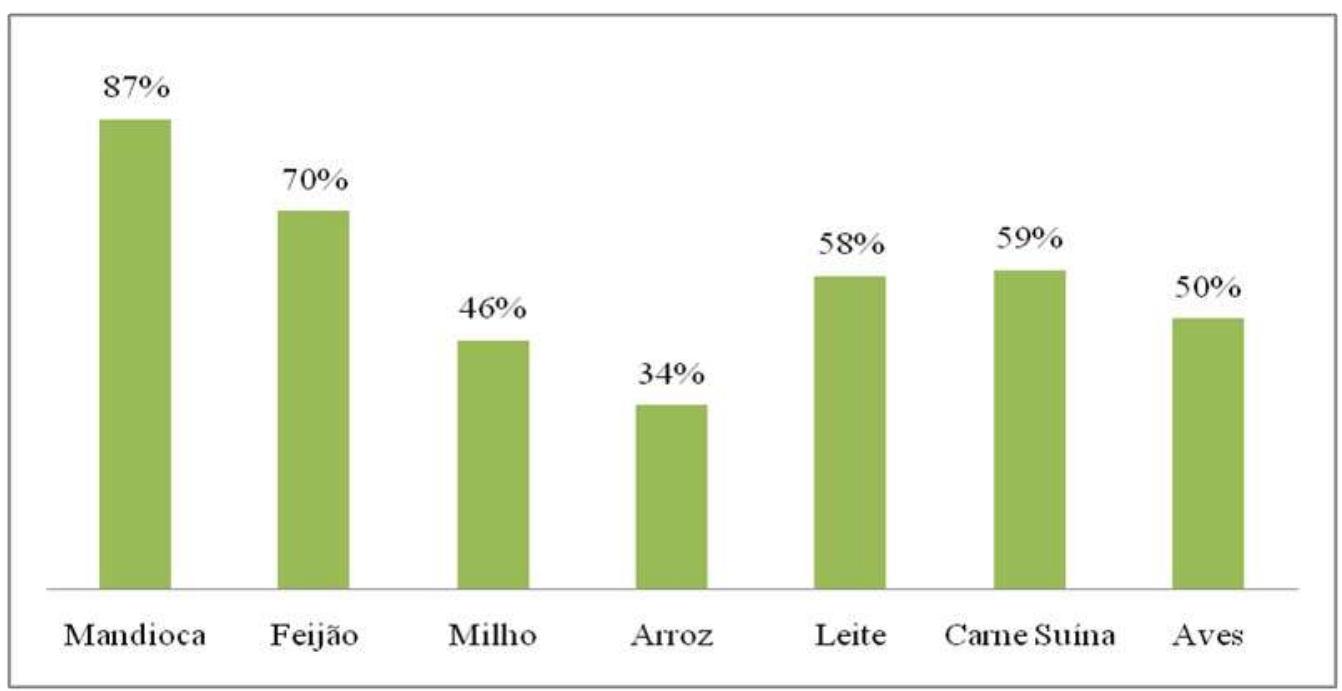

Fonte: Elaboração própria a partir de IBGE (2006) 


\section{A POLÍTICA PÚBLICA NACIONAL DE BIODIESEL}

\subsection{O BIODIESEL}

Sob a perspectiva do consumo de energia, o Mundo aponta para o contínuo aumento da demanda energética, essa tendência coloca a necessidade de se realizar esforços mundiais que propiciem o aumento da oferta e diversificação da matriz energética. Concomitantemente, realizando esforços no sentido de reduzir os impactos ambientais a partir do uso dos combustíveis fósseis tradicionais (petróleo, carvão e gás natural) (Ribeiro e Leal, 2012).

A busca por fontes energéticas alternativas derivam principalmente de um cenário de elevação sistemática do preço do barril de petróleo vivenciado a partir da década de 70 , pela finitude de reservas energéticas de petróleo, e por pressões por parte da sociedade civil organizada face à degradação ambiental decorrente da queima de combustíveis fósseis.

Nesse contexto, surge como alternativa à produção e uso dos combustíveis fósseis tradicionais, o biocombustível. De acordo com Biodieselbr (2012), os biocombustíveis são combustíveis produzidos a partir da biomassa ${ }^{4}$, como cana-de-açúcar, milho, soja, semente de girassol, madeira e celulose, sendo a partir dessas fontes possível a produção de biocombustíveis, como álcool, etanol e biodiesel.

Segundo, Evangelista (2009) um dos conceitos mais utilizados na literatura descreve o biodiesel como um composto de ésteres monoalquílicos de ácidos graxos de cadeia longa, derivados de óleos vegetais, ou de gorduras animais, e que estejam em conformidade com padrões específicos de qualidade. Conforme a Lei 11.097/2005, o biodiesel é um "biocombustível derivado de biomassa renovável para uso em motores a combustão interna com ignição por compressão ou, conforme regulamento, para geração de outro tipo de energia, que possa substituir parcial ou totalmente combustíveis de origem fóssil." (BRASIL, 2005, p.1). Ou seja, o biodiesel nada mais é que um biocombustível para ser utilizado em carros ou caminhões, in natura ou misturado, feito a partir de biomassa, alternativo ao uso do diesel mineral e que por ser biodegradável causa um menor impacto ambiental ${ }^{5}$.

O Biodiesel é encarado como uma ótima alternativa à utilização do diesel fóssil, haja vista que mantém praticamente as mesmas propriedades, além de dispensar adaptação às máquinas que o utilizam (VIANNA, 2006). Holanda (2003) alerta que pode haver necessidade de adaptação em motores de ciclo de diesel, contudo esses não são significantes ou onerosos e destaca que dadas às características físico-químicas semelhantes ao óleo diesel mineral, o biodiesel pode ser utilizado puro ou misturado em quaisquer proporções. 
Segundo Holanda (2003), dada dimensão continental do território brasileiro e suas condições edafoclimáticas, o país tem como poucos no mundo, uma vantajosa condição de exploração em larga escala da biomassa para fins energéticos. Nessa linha o Brasil é reconhecidamente um dos países que detém as condições mais favoráveis de absorver boa parte da demanda global por energia limpa no século XXI.

\subsection{O PROGRAMA NACIONAL DE PRODUÇÃO E USO DE BIODIESEL (PNPB)}

No ano de 2003, o governo brasileiro a partir de um esforço interministerial reuniu-se para discutir a viabilidade do uso do biodiesel como alternativa energética no âmbito nacional, concluindo-se ao final das reuniões ser possível tal ação. Adicionalmente, foi recomendado o desenvolvimento regional e a inclusão social como princípios norteadores para as futuras ações do governo federal quanto à produção e uso do biocombustível. Outra questão levantada no relatório, dizia respeito ao não privilégio de processos produtivos, matérias-primas e escalas de produção em nível industrial (FINCO e DOPPLER, 2011).

A partir das discussões e recomendações realizadas por diferentes setores do governo, em dezembro de 2004, o governo federal lançou oficialmente o Programa Nacional de Produção e Uso de Biodiesel (PNPB). O programa visa de forma sustentável implantar a produção e uso de biodiesel, com enfoque na inclusão social e desenvolvimento regional (Garcez, 2008). Finco e Doppler (2011) destacam de forma oportuna, que o enfoque da inclusão social e desenvolvimento regional do PNPB levam em consideração também aspectos ambientais e culturais das famílias detentoras das propriedades rurais onde a gestão, a terra e a maior parte do trabalho no campo advêm dos seus próprios familiares.

Outros dois objetivos específicos do PNPB, são a garantia de preços competitivos, suprimento e qualidade para o biodiesel além da produção diversificada a partir de oleaginosas. Estes dois objetivos revelam a preocupação da sustentabilidade por parte do programa, na medida em que ao buscar preços competitivos e oferta constante cria condições no mercado para o biodiesel prosperar sem necessidade de recorrentes subsídios governamentais, e a medida que objetiva a diversificação de matérias-primas (óleos vegetais) preconiza a sustentabilidade ambiental.

Em janeiro de 2005, o governo federal lançou o marco legal dos mais importantes do PNPB, a Lei 11.097/2005 (BRASIL, 2005), que introduziu compulsoriamente o biodiesel na matriz energética brasileira e fixou obrigatoriamente em $5 \%$ a mistura de biodiesel ao diesel mineral (B5), com prazo de cumprimento no horizonte de oito anos. Ao estabelecer um prazo intermediário de três anos para o 
cumprimento de parte da meta, segundo Locatelli (2008) o governo criou um mercado inicial com potencial de comercialização de 800 milhões de litros ao ano do biocombustível para o triênio.

A partir da relevância que o PNPB deu na sua criação ao desenvolvimento regional e principalmente à inclusão social, algo que o diferenciou categoricamente em relação ao PRÓ-ÓLEO ${ }^{6}$ e outros programas que o antecederam, o governo federal criou diversos instrumentos diferentes para atingir essa meta, contudo o mais emblemático foi o Selo Combustível Social (SCS) (FINCO e DOPPLER, 2011).

\subsection{O SELO COMBUSTÍVEL SOCIAL (SCS)}

Simultaneamente ao lançamento do PNBP, o governo federal através do Decreto $\mathrm{n}^{\circ} 5.297$, de 06/12/2004 (BRASIL, 2004) instituiu o SCS como instrumento de incentivo à inclusão do agricultor familiar na cadeia produtiva do biodiesel. Um dos critérios para concessão, aos produtores de biodiesel, do selo por parte do Ministério de Desenvolvimento Agrário (MDA) é a compra de parte da matéria-prima proveniente dos estabelecimentos enquadrados no Programa de Nacional de Fortalecimento da Agricultura Familiar (PRONAF) para produção do biocombustível.

As unidades industriais produtoras de biodiesel certificadas com o selo, devem comprar no mínimo 15\% da matéria-prima para produção do biocombustível da agricultura familiar nas regiões Norte e Centro-Oeste e 30\% nas regiões Sul, Sudeste, Nordeste e Semi-Árido. Assim como, para fins de uso, manutenção e concessão do SCS devem celebrar previamente contratos com os agricultores familiares ou suas cooperativas agropecuárias, seguindo condições e critérios mínimos estabelecidos na Instrução Normativa $\mathrm{n}^{\circ} 1$ de 19/02/2009 (Ministério do Desenvolvimento Agrário, 2009), que garantem aos agricultores familiares desde assistência técnica, de responsabilidade do produtor do biodiesel, até garantia de formação do preço ex tante, da matéria prima a ser entregue.

Alguns dos benefícios concedidos às empresas produtoras de biodiesel certificadas com SCS são: facilidades de comercialização ${ }^{7}$ do biocombustível, melhores condições de financiamento junto ao Banco Nacional de Desenvolvimento Econômico e Social (BNDES) e incentivos tributários relativos às contribuições especiais para os programas de financiamento da seguridade social (COFINS), integração social (PIS) e formação do patrimônio do servidor público (PASEP), ver detalhamento dos incentivos no quadro 1. 
Quadro 1. Contribuições Tributárias Federais do Biodiesel no Brasil

\begin{tabular}{|c|c|c|c|c|c|}
\hline Matéria-prima & Região & Tipo de Agricultura & $\begin{array}{c}\text { PIS/PASEP } \\
\text { em } R \$ / \mathbf{m}^{3} \\
\text { (A) }\end{array}$ & $\begin{array}{c}\text { COFINS } \\
\text { em } R \$ \mathbf{m}^{3} \\
\text { (B) }\end{array}$ & $\begin{array}{c}\text { Taxação Total } \\
\text { em } \mathbf{R} \$ \mathbf{m}^{3} \\
(\mathrm{~A}+\mathrm{B})\end{array}$ \\
\hline Qualquer & Qualquer & Qualquer & 31,75 & 146,20 & 177,95 \\
\hline Mamona e dendê & $\mathrm{N} ; \mathrm{NE}$ e SAB & Qualquer & 27,03 & 124,47 & 151,50 \\
\hline Qualquer & Qualquer & Familiar & 12,49 & 57,53 & $70,02 *$ \\
\hline Qualquer & $\mathrm{N} ; \mathrm{NE}$ e SAB & Familiar & 00,00 & 00,00 & $00,00^{*}$ \\
\hline
\end{tabular}

Fonte: Elaborado pelo autor a partir de Garcez e Vianna (2009) e Finco e Doppler (2011)

Nota: * referente às empresa produtoras de biodiesel

$\mathbf{N}=$ Norte, $\mathrm{NE}=$ Nordeste; $\mathrm{SAB}=$ Semi-árido Brasileiro.

A partir desse pacote de benefícios, fica clara a intenção do governo federal em estimular, pelo lado das unidades industriais, a produção de biodiesel através das oleaginosas cultivadas em estabelecimentos em que a gestão, a terra e a maior parte do trabalho no campo advêm de indivíduos que mantêm entre si vínculos familiares. Contudo, principalmente quando analisado o quadro acima se observa a prioridade de incentivos fiscais para as regiões Norte, Nordeste e Semi-árido, onde há isenção total das contribuições tributárias federais para produção do biocombustível. É interessante destacar que tais isenções fiscais para os mesmos tributos são menores que as incidentes sobre a produção de gasolina e diesel mineral, e algo semelhante ao etanol que assim também como o biodiesel é considerado como uma fonte renovável de energia. Segundo relação disponível no sítio do MDA (Ministério do Desenvolvimento Agrário, 2012), até o mês de maio de 2012, haviam no Brasil 39 empresas produtoras de biodiesel com o SCS,

\section{DESENVOLVIMENTO LOCAL SUSTENTÁVEL E A GESTÃO SOCIAL}

Essa seção parte do entendimento que crescimento econômico e desenvolvimento não são sinônimos, contudo que a ocorrência do primeiro é condição necessária, porém não suficiente, para que o segundo se ocorra. Desenvolvimento, segundo Oliveira (2002), deve ser entendido como um processo complexo que envolve mudanças e transformações de ordem econômica, política e, principalmente, humana e social, esse desenvolvimento, sobretudo deve buscar a melhoria da qualidade de vida do homem.

A partir de uma intensificação do debate internacional sobre sustentabilidade, surge o conceito de desenvolvimento sustentável (DS), onde a preocupação com esgotamento dos recursos disponíveis para a sobrevivência do homem, ou seja, do seu próprio ecossistema, toma o papel de protagonista das discussões sobre a concepção de desenvolvimento na modernidade. Para Pires (1998, p.63) “o 
desenvolvimento sustentável expressa mais uma insatisfação com o padrão atual de desenvolvimento do que uma versão acabada de categorias teóricas e práticas de um novo patamar na relação sociedade e natureza".

Nesse contexto, o conceito amplamente difundido de desenvolvimento sustentável surge em 1987, a partir do relatório Brundtland da Comissão das Nações Unidas para o Meio Ambiente, no documento o desenvolvimento sustentável é entendido como aquele que satisfaz as necessidades das gerações presentes, sem comprometer a capacidade das gerações futuras satisfazerem as suas próprias necessidades (Garcez; Vianna, 2009). Em seu livro Caminhos para o Desenvolvimento Sustentável, o ecossocioeconomista Ignacy Sachs faz uma importante contribuição ao refletir o DS sob oito dimensões: social, cultural, ecológica, ambiental, territorial, econômica, política em âmbito nacional e política internacional. (SACHS, 2002). Essa perspectiva do autor alerta que o DS não se restringe somente à questão ambiental, sendo necessário entendê-lo de forma inter-relacionada com as outras sete dimensões.

Ao pensar o desenvolvimento sustentável no âmbito rural, Pereira (2010, p.27), apresenta o desenvolvimento rural sustentável como:

uma estratégia para promover um desenvolvimento que possibilite redução das desigualdades sociais, degradação do meio ambiente, e consequentemente, a verdadeira melhoria na qualidade de vidas das pessoas residentes no meio rural, que devem atuar como agentes do desenvolvimento juntamente com o estado.

Ao enfatizar o papel dos próprios indivíduos na promoção do desenvolvimento a autora remete-se de forma intuitiva à abordagem do desenvolvimento como "local". Segundo Martín (1999) apud Martins (2002) ao se remeter ao termo "local", procura-se apresentar a dimensão das inter-relações pessoais da vida cotidiana, que sobre uma base territorial constroem uma identidade.

Segundo Martins e Caldas (2009) o desenvolvimento local é um tema controverso e pouco estudado no país. Em uma abordagem local do DS, cada indivíduo toma para si o papel de defender e promover a melhoria da qualidade de vida de cada um dos seus pares comunitários, sem comprometer as gerações futuras, transformando-se assim em atores do próprio desenvolvimento local sustentável. Essa idéia do "local" e do indivíduo como agente transformador, pode ser apresentada como uma falência dos modelos tradicionais do desenvolvimento que colocam o Estado como agente principal da promoção do desenvolvimento (MULS, 2008). Contudo, a colocação do último autor não deve retirar ou diminuir a importância que há da participação do Estado no próprio processo de desenvolvimento local. 
O desenvolvimento local sustentável é endógeno, ou seja, nasce de dentro pra fora com a participação protagonista, frente à esfera pública e iniciativa privada, dos agentes locais, que compartilham entre si os benefícios econômicos, sociais e ambientais do mesmo. Nessa lógica, onde a comunidade local é o principal ator social no processo de desenvolvimento, não se deve minimizar a importância das ações e parcerias públicas, privadas e do terceiro setor, pois elas objetivam convergir os interesses e expectativas dos diferentes atores sociais envolvidos no processo.

Martins (2002) apud Tomasetto, Lima e Shikida (2009) destaca oportunamente que, a principal característica do desenvolvimento sustentável local é a forma como se atribuí e garante à comunidade local a função de agente promotor do desenvolvimento, contrapondo-se à posição dessa ser uma simples beneficiária do desenvolvimento exógeno. Justamente por colocar a comunidade local como protagonista do DS, essa abordagem entende que o mesmo não se dá de forma pragmática e homogênea, uma vez que cada comunidade tem características, história e cultura diferentes. Sendo dessa forma, desaconselhável copiar fórmulas de desenvolvimento local sustentável bem sucedidas em outros territórios, até dentro do mesmo país, muito menos importar receitas de desenvolvimento dos países do hemisfério norte.

Martins (2002, p.53) reconhece que a necessidade da persistente participação dos indivíduos, surgimento de um senso crítico e a possível carência de democracia no sistema decisório são as fraquezas que comprometem o processo de desenvolvimento local sustentável, revelando que "estes requisitos são difíceis de serem obtidos, sobretudo quando não estimulados e mesmo sufocados por períodos de pouca ou nenhuma democracia".

Uma possibilidade para contornar tal problema e promover do desenvolvimento local sustentável é a gestão social. Em síntese ${ }^{8}$ :

a gestão social pode ser apresentada como a tomada de decisão coletiva, sem coerção, baseada na inteligibilidade da linguagem, na dialogicidade e no entendimento esclarecido como processo, na transparência como pressuposto e na emancipação enquanto fim último (CANÇADO, TENÓRIO e PEREIRA, 2011, p.697).

É possível dessa forma, concluir que a gestão social é um componente necessário, mas não suficiente, para a promoção do desenvolvimento local sustentável, uma vez que essa forma de gestão reflete características mínimas de indivíduos protagonistas do próprio desenvolvimento e de um Estado preocupado em formular políticas públicas inclusivas feitas de "baixo para cima" com capacidade de atender as especificidades de cada território. Nessa mesma lógica de acordo com Carrion (2012, p. 268), a gestão social "veio para atender a necessidade de coordenar ações de atores que 
historicamente não tinham a tradição de interagirem de forma cooperativa, como o Estado, as organizações sociais, ou terceiro setor e as empresas". Tal cooperação como colocada anteriormente, é de fundamental importância para promoção do desenvolvimento local sustentável.

\section{A POLÍTICA NACIONAL DO BIODIESEL E O DESENVOLVIMENTO LOCAL SUSTENTÁVEL.}

Conceber um programa ou política pública sob a égide da do desenvolvimento e inclusão social, é sem dúvida um aspecto importante para qualquer iniciativa do Estado, contudo não é suficiente para promover mudanças efetivas no seu público alvo. Nesse ponto a política nacional do biodiesel quando analisada sob a ótica dos resultados em relação à inserção na cadeia produtiva do agricultor familiar e da sustentabilidade econômica e ambiental da produção, revela deficiências.

Ao fazer uma análise da competitividade da cadeia produtiva do biodiesel no país, o professor Mario Otávio Batalha revela a existência de uma grande concentração de produção do biocombustível pelo cultivo da soja, segundo o pesquisador, a oleaginosa é a matéria prima responsável pela produção de 80\% do biodiesel brasileiro (AGÊNCIA FAPESP, 2012). Esse panorama revela que a política pública do biodiesel não está sendo eficaz na proposta de diversificar a produção do biocombustível através de outras oleaginosas (dendê, mamona, babaçu e pinhão-manso, etc.) isso compromete tanto a sustentabilidade econômica quanto ambiental da produção, na medida em que qualquer elevação maior no preço da soja pode comprometer ou até inviabilizar a produção. Outro ponto que merece destaque é relativo ao surgimento da monocultura da soja para produção de biodiesel, que pode afetar os ecossistemas locais e falhar na proposta da sustentabilidade ambiental ${ }^{9}$. Nesse mesmo sentido Garcez (2008) alerta para o domínio do cultivo da soja como matéria prima para o biodiesel pode ameaçar as questões sociais e energéticas de sustentabilidade do programa, além de colocar em risco a segurança alimentar, propondo, por exemplo, a criação de incentivos legais para o plantio de oleaginosas em consórcio com alimentos.

Ainda nessa abordagem Batalha, revela que a produção do diesel vegetal é mais cara que a do diesel fóssil o que coloca em risco sua sustentabilidade econômica, e afirma quanto aos custos de produção do biodiesel que

"a escala de produção é pequena, a qualidade é ruim, há restrições tecnológicas, manejo inadequado e alta sazonalidade. Além disso, as famílias ficam dispersas, o que aumenta muito o gasto com transporte e favorece a atuação de atravessadores" (AGÊNCIA FAPESP, 2012, p.1). 
Apesar de Batalha concluir que o programa de biodiesel não conseguiu cumprir a meta social de inclusão do agricultor familiar através de um estudo de caráter tecnicamente economicista (AGÊNCIA FAPESP, 2012), Finco (2010) chega a uma conclusão parecida ao estudar os produtores de pinhão manso e mamona no estado do Tocantins fazendo um estudo de caráter mais multidisciplinar. Em relação à renda, Finco (2010) demonstra que a margem bruta das oleaginosas é menor que o das culturas tradicionais (milho, mandioca e arroz, por exemplo) e que em alguns casos, ela chega a ser negativa. Adicionalmente, o autor, ao pesquisar aproximadamente 130 agricultores familiares, concluí que a inclusão social só ocorreu de forma mais acentuada para os produtores de mamona, sendo que para o pinhão manso o PNPB não foi eficaz.

Ao analisar o PNPB do ponto de vista da sustentabilidade ambiental, Garcez (2008, p.116) conclui que “a política sob análise não dá a devida importância à promoção de práticas agrícolas adequadas e menos intensivas, e não trata da questão do consumo de energia, que é um aspecto importante do desenvolvimento de energia sustentável". Do ponto de do SCS, a autora faz uma crítica à fragilidade legal do mesmo, uma vez que por ser um decreto presidencial o selo pode ser mudado facilmente o que o torna um instrumento instável de inclusão social e desenvolvimento local sustentável. Ainda quanto ao SCS, a mesma faz uma crítica ao selo quanto à inclusão social, "por limitar a participação dos agricultores familiares a meros fornecedores de matéria-prima. A base legal não inclui provisões para a produção de biodiesel por meio de cooperativas de agricultura familiar" (GARCEZ, 2008, p.118) Essas constatações de insucessos quanto à política pública nacional do biodiesel, relativas à geração de renda, inclusão social do agricultor familiar na cadeia produtiva, qualidade do biodiesel produzido e sustentabilidade ambiental e econômica da produção, em partes podem ser computadas a questões econômicas, regionais ou políticas. Mas sem dúvida boa parte delas é proveniente de uma má formulação da política pública nacional em questão. É claro que existem casos de maior sucesso no Brasil quanto a alguns dos pontos levantados anteriormente, como é o caso de alguns municípios da Bahia, Ceará e Minas Gerais onde a iniciativa pública construiu usinas de produção de biodiesel, em que de forma associada e cooperada os agricultores familiares ao invés de produzir somente a matéria prima, produzem o próprio diesel vegetal (LOCATELLI, 2008). Contudo deve-se ponderar até que ponto esses casos são verdadeiras ilhas no território brasileiro.

Sem dúvidas, apesar de alguns instrumentos da política pública nacional de biodiesel como: (1) o SCS, (2) a consulta pública para a elaboração de uma nova instrução normativa para o SCS aberta no sítio do MDA durante trinta dias e (3) a exigência de algum órgão habilitado representativo dos agricultores 
familiares para acompanhar a formalização dos contratos com as empresas, quase nada da formulação e implementação do PNPB tem moldes de uma política pública pautada na gestão social. Isso se constata no trabalho de Locatelli (2008), o autor concluiu, ao fazer uma análise das demandas socioambientais dos movimentos sociais do campo quanto à inclusão dos agricultores familiares no PNPB, que as solicitações da agricultura familiar no âmbito do programa não foram devidamente recepcionadas pelo Estado. O sentimento de falta de diálogo, transparência e descentralização decisória quanto aos rumos do PNPB, também ao que tudo indica ecoa pelas empresas produtoras de biodiesel, conforme a Associação dos produtores de Biodiesel do Brasil - APROBIO (2012) existe um movimento que defende a criação de um novo marco regulatório para o programa, onde se sugere a elaboração do PNPB II.

Quanto ao novo marco regulatório é válida como comparação a afirmação de Carrion (2012, p.270) ao sustentar com propriedade que não se pode "pensar em desenvolvimento e/ou gestão social à sombra de instituições falidas, como partidos políticos e o sistema judiciário". Ainda quanto às reivindicações dos agricultores familiares e empresas, para a gestão social e o desenvolvimento local sustentável "não basta dizer que o espaço é democrático, onde todos têm direito a voz e voto, é necessário que a decisão seja coletiva, livre de coerção e que busque o entendimento, com processos baseados na transparência pública". (OLIVEIRA, CANÇADO, PEREIRA, 2010, p.624). Não se pode perder também as perspectivas do território na formulação e implementação de uma política pública, e ainda que o local e global estejam em escalas diferentes as decisões que se produzem nesse panorama influenciam diretamente no desenvolvimento local sustentável de cada comunidade.

\section{CONSIDERAÇÕES FINAIS}

Ao procurar inserir o agricultor familiar na política pública nacional do biodiesel, o Estado volta a sua atenção a um ator muito importante para a economia e segurança alimentar nacional. É claro que o PNPB é somente uma das várias políticas públicas que entrelaçadas buscam melhorar a qualidade de vida do agricultor familiar, contudo essa é uma ação do Estado que tem importância significativa para transformar a realidade vivida por esses produtores, dada sua envergadura, metas e dimensão de atuação em todo o território brasileiro. A partir desse contexto, esse artigo buscou analisar a capacidade do PNPB em contribuir para a promoção do desenvolvimento local sustentável na agricultura familiar, concluindo que não há indícios que essa política pública tenha sido formulada e/ou implementada nos moldes da gestão social, inferindo dessa forma que o programa não é capaz 
de contribuir para a promoção do desenvolvimento local sustentável, dada que a gestão social é uma condição necessária para que esse gênero de desenvolvimento ocorra.

É claro que esse estudo não defende que o PNPB não esteja promovendo melhorias na qualidade de vida dos agricultores familiares, tão pouco que deva ser extinto, mas sim que para fins de contribuição ao fomento do desenvolvimento local sustentável da agricultura familiar nos moldes como está desenhado, tal programa é insuficiente. Assim como, não se pretende postular que o Estado de forma isolada, através de uma política pública seja capaz de promover o desenvolvimento local sustentável, uma vez que esse depende também da própria comunidade local chamar para si o papel de protagonista do desenvolvimento agindo de forma coordenada e cooperada com o setor público, iniciativa privada e terceiro setor. Mas esse texto sustenta que para a promoção do desenvolvimento local sustentável, se faz necessário um Estado capaz de formular políticas públicas inclusivas e que através da decisão participativa e descentralizada seja capaz de administrar os conflitos sociais de forma neutra e eficiente, ou seja, dentro do modelo de gestão social.

Atualmente, percebe-se que o crescimento da discussão e prática da gestão social, ainda que lento e gradual, está cada vez mais contribuindo para que o indivíduo, de forma cooperada, reivindique soluções para seus problemas locais e participe do processo decisório de forma mais ativa, oportunizando a promoção do desenvolvimento local sustentável, como é o caso das usinas construídas, pelo Estado, na Bahia, Minas Gerais e Ceará oportunizadas pela mobilização de entidades representativas dos agricultores familiares, como apresenta Locatelli (2008). Essa questão de como está ocorrendo a discussão e a prática da gestão social na agricultura familiar brasileira é uma sugestão para trabalhos futuros que envolvam o tema. Também fica como inspiração analisar de qual forma as ações dos demais atores, não só o Estado, envolvidos no ambiente da agricultura familiar, e suas capacidades podem contribuir para fomentar o desenvolvimento local sustentável, pois como bem se sabe não é só o PNPB na sua perspectiva da agricultura familiar que irá promover esse tipo de desenvolvimento.

Por fim, como esse texto não teve a pretensão fazer uma avaliação do PNPB, apesar de levantar argumentos que podem até sustentar essa ideia, mas somente analisar a sua capacidade de contribuir para o fomento do desenvolvimento local sustentável, fica a sugestão para que tal programa possa ser avaliado de uma forma mais completa, desde a sua concepção até sua execução e resultados, de forma qualitativa e/ou quantitativa, sob a ótica da gestão social e do desenvolvimento local sustentável. 


\section{REFERÊNCIAS}

AGÊNCIA FAPESP. O Programa de biodiesel não atingiu a meta social. 2012. Disponível em: https://www.saci.ufscar.br/data/clipping/pdfs/21019_01.pdf. Acesso em: 20 de ago. de 2012.

ASSOCIAÇÃO DOS PRODUTORES DE BIODIESEL DO BRASIL. Mercado. 2012. Disponível em: http://www.aprobio.com.br/mercado.html. Acesso em: 10 de set. 2012.

BIODIESELBR. Sobre os biocombustíveis. Disponível em:

http://www.biodieselbr.com/biodiesel/definicao/biocombustiveis.htm. Acesso em: 02 de ago. de 2012.

BRASIL. Decreto № 5.297 de 06 de Dezembro de 2004. Disponível em:

http://www.planalto.gov.br/ccivil_03/_ato2004-2006/2004/decreto/D5297.htm. Acesso em: 14 de ago. de 2012.

. Lei № 11.097 de 13 de Janeiro de 2005. Disponível em:

https://www2.camara.leg.br/legin/fed/lei/2005/lei-11097-13-janeiro-2005-535383-norma-pl.html. Acesso em: 08 de ago. de 2012.

_. Lei № 11.326 de 24 de Julho de 2006. Disponível em: <http://www.planalto.gov.br/ccivil_03/_ato2004-2006/2006/lei/l11326.htm>. Acesso em 08 de ago. de 2012

CANÇADO, A.C.; TENORIO, F.G.; PEREIRA, J. R. Gestão social: reflexões teóricas e conceituais. Cad. EBAPE.BR, Rio de Janeiro, v. 9, n. 3, Set. 2011. https://doi.org/10.1590/S1679-39512011000300002

CARRION, R. Gestão Social: aspectos teóricos e aplicações. Orgs.: CANÇADO, A.C.; TENORIO, F.G.; SILVA JÚNIOR, J.T. Ijuí: Inijuí, 2012. 456p.

EVANGELISTA, F.J. Inserção de um modelo agro-industrial de pequena escala na cadeia de produção do biodiesel baseado na cultura do girassol e no segmento agrícola familiar do semi-árido potiguar. Campinas, SP, 2009. 138p. Tese (Doutorado em Planejamento de Sistemas Energéticos.) - Faculdade de Engenharia Mecânica, Universidade Estadual de Campinas, 2009.

FINCO, M.V.A. Bioenergy Economics:An Analysis of Oil Seed Farming and Biodiesel Production in the Brazilian Savannah. Hohenheim, ALE, 2010. 251p. Tese (Doutorado em Economia Rural) Departamento de Economia Agrícola e Ciências Sociais nos Trópicos e Sub Trópicos, Universidade de Hohenheim, 2010.

; DOPPLER, W. The Brazilian biodiesel program and regional development: cases from northern Brazil. REDES, Santa Cruz do Sul, v16, n.13, p.215-241, set./dez. 2011. http://dx.doi.org/10.17058/redes.v16i3.1887

.; RIBEIRO, V. S.; BAILIS, R. Biocombustíveis e a economia verde inclusiva: buscando o desenvolvimento regional sustentável na Amazônia legal brasileira. REDES, v. 19, n. 3, p. 130-153, 2014. http://dx.doi.org/10.17058/redes.v19i3.4360 
GARCEZ, C. A. G. Uma Análise da Política Pública do Programa Nacional de Produção e Uso de Biodiesel (PNPB). Brasília, DF, 2008. 171p. Dissertação (Mestrado em Desenvolvimento Sustentável) - Centro de Desenvolvimento Sustentável, Universidade de Brasília, 2008.

.; VIANNA, J. N. S. Brazilian Biodiesel Policy: social and environmental considerations. Energy, v.34, n.5, p.645-654, mai. 2009. https://doi.org/10.1016/j.energy.2008.11.005

HOLANDA, A. O biodiesel e a inclusão social. 2003. Disponível em:

http://www.sfiesc.org.br/artigos/tecnologia/BIODIESEL_2003.pdf. Acesso em: 25 ago. 2012.

INSTITUTO BRASILEIRO DE GEOGRAFIA E ESTATÍSTICA - IBGE. Censo Agropecuário 2006 (resultados preliminares). Rio de Janeiro, IBGE, 2007. Disponível em: http://www.ibge.gov.br/home/estatistica/economia/agropecuaria/censoagro/2006/agropecuario.p df. Acesso em: 02 de ago. de 2012.

INSTITUTO NACIONAL DE COLONIZAÇÃO E REFORMA AGRÁRIA - INCRA. Instrução Especial N 20 de 28 de maio de 1980. Disponível em: https://www.gov.br/incra/pt-br/centrais-deconteudos/legislacao/ie20_1980.pdf. Acesso em: 10 de ago. de 2012.

LOCATELLI, V. A inserção da agricultura familiar no programa nacional de produção e uso de biodiesel e as demandas socioambientais das suas representações. Brasília, DF, 2008. Dissertação (Mestrado em Gestão e Planejamento Ambiental) - Universidade Católica de Brasília, 2008.

MARTINS, S.R.O. Desenvolvimento Local: questões conceituais e metodológicas. Interações, Campo Grande, v.3, n.5, p.51-59, set. 2002. https://doi.org/10.20435/interacoes.v3i5.570

.; CALDAS, E.L. Visões do Desenvolvimento Local: uma análise comparada de experiências brasileiras. Interações, Campo Grande, v.10, n.2, p.207-218, jul./dez. 2009. https://doi.org/10.1590/S1518-70122009000200008

MINISTÉRIO DO DESENVOLVIMENTO AGRÁRIO. Instrução Normativa № 1 de 19 de Fevereiro de 2005. Disponível em: https://www.legisweb.com.br/legislacao/?id=76241. Acesso em: 11 de ago. de 2012.

- Relação das empresas com o selo combustível social. Disponível em: http://www.mda.gov.br/portal/saf/arquivos/view/Atualiza\%C3\%A7\%C3\%A3o_Empresas_SCS_29.05. 2012.pdf. Acesso em: 11 de ago. de 2012.

MULS, L.M. Desenvolvimento Local, Espaço e Território: O Conceito de Capital Social e

a Importância da Formação de Redes entre Organismos e Instituições Locais. Revista Economia, Brasília, v.9, n.1, p.1-21, jan/abr 2008.

OLIVEIRA, G. B. de. Uma discussão sobre o conceito de desenvolvimento. Revista da

FAE. Curitiba, v.5, n.2, p.37-48, mai./ago. 2002.

OLIVEIRA, V.A.R; CANÇADO, A.C.; PEREIRA, J.R. Gestão social e esfera pública: aproximações teóricoconceituais. Cadernos EBAPE.BR. Rio de Janeiro, v.8, n.4, p.613-626, dez. 2010. https://doi.org/10.1590/S1679-39512010000400004 
PERREIRA, F.F. A evolução do conceito de desenvolvimento rural sustentável no estado do Ceará no período de 1995 a 2008. Fortaleza, CE, 2010. 85p. Dissertação (Mestrado em Economia Rural) Universidade Federal do Ceará, 2010.

PIRES, Mauro Oliveira. A trajetória do conceito de desenvolvimento sustentável na transição de paradigmas. IN: DUARTE, Laura M Goulart, BRAGA, Maria L de Santana. (org) Tristes cerrados, sociedade e biodiversidade. Brasília: Paralelo 15, 1998. 300p. p63-92.

RIBEIRO, V. S. Política Pública do Biodiesel e o Desenvolvimento Local Sustentável para a Agricultura Familiar. In: XII Colóquio Internacional sobre o Poder Local. Salvador-BA, 2012. https://www.researchgate.net/publication/340788445_Politica_Publica_do_Biodiesel_e_o_Desenvo Ivimento_Local_Sustentavel_para_a_Agricultura_Familiar

Biodiesel e agricultura familiar no Tocantins: uma análise a partir da teoria dos conjuntos Fuzzy. 2014. 115f. Dissertação (Mestrado em Desenvolvimento Regional) - Universidade Federal do Tocantins, Programa de Pós-Graduação em Desenvolvimento Regional, Palmas, 2014. http://dx.doi.org/10.13140/RG.2.2.12588.26248

; LEAL, J.E.C. A produção de biodiesel e o cultivo da soja na região Mercoeste. In: VII CONNEPI- Congresso Norte Nordeste de Pesquisa e Inovação. Palmas-TO, 2012. https://www.researchgate.net/publication/353741485_A_PRODUCAO_DE_BIODIESEL_E_O_CULTIV O_DE_SOJA_NA_REGIAO_MERCOESTE?_sg=K9uoriEXjApd10sg5j6VWYC8D-CXJ6gFCobvpPynk_dyYUZjAKjqgsKyc8MaBHFiNjJDLcfqMnSB_zCCfyGpy-

DIFqdoXxmx38B_zFP.wW5QSxMwjLjes_x5ealMxsqwRERdRDMzC8fS9cNiUReekVdyLDFt2G1IYoFIFipLdrAZ2BhGhYyekK2IEb1pA

SACHS, I. Caminhos para o desenvolvimento sustentável. Rio de Janeiro: Garamond, 2002.

SOUZA, R.P. Competitividade da produção de leite da agricultura familiar: os limites da exclusão. Campinas, SP, 2011. 247p. Tese (Doutorado em Desenvolvimento Econômico) - Instituto de Economia, Universidade Estadual de Campinas, 2011.

TOMASETTO, M.Z.C.; LIMA, J.F; SHIKIDA, P.F.A. Desenvolvimento local e agricultura familiar: o caso da produção de açúcar mascavo em Capanema - Paraná. Interações, Campo Grande), vol.10, n.1, p.2130, jan./jun. 2009. https://doi.org/10.1590/S1518-70122009000100003

VERGARA, S. C. Projeto e relatórios de pesquisa em administração. São Paulo: Atlas Editora, 2003.

VIANNA, F.C. Análise de Ecoeficiência: Avaliação do Desempenho Econômico-Ambiental do Biodiesel e Petrodiesel. São Paulo, SP, 2006. 183p. Dissertação (Mestrado em Engenharia) - Escola Politécnica, Universidade de São Paulo, 2006. 


\section{NOTAS}

\section{Nota 1}

Este artigo é uma versão de Ribeiro (2012), publicada no 2012 no XII Colóquio Internacional sobre o Poder Local em Salvador-BA. Também é parte integrante da dissertação de mestrado do primeiro autor, Ribeiro (2014) e da publicação Finco, Ribeiro e Bailis (2014).

\section{Nota 2}

A possível superestimação deriva do fato que o conceito de agricultura familiar está relacionado à unidade familiar, enquanto o estabelecimento está relacionado à unidade produtiva. Embora a situação mais frequente seja de uma família estar associada a apenas um estabelecimento, existem casos de famílias com mais de um estabelecimento agropecuário (IBGE, 2007).

\section{Nota 3}

Para maiores informações, vide Instrução Especial N. ${ }^{\circ} 20$ de 28 de maio de 1980 (INSTITUTO NACIONAL DE COLONIZAÇÃO E REFORMA AGRÁRIA,1980).

\section{Nota 4}

Do ponto de vista energético, a biomassa pode ser entendida de forma genérica como todo recurso renovável oriundo de matéria orgânica (de origem animal ou vegetal). Segundo Ribeiro e Leal (2012) é “...um combustível obtido de fontes renováveis, tais como óleos vegetais e gorduras animais, por intermédio de processos químicos como o da transesterificação ou do craqueamento térmico".

\section{Nota 5}

Segundo Holanda (2003, p.20), “O Biodiesel reduz a emissão líquida de $\mathrm{CO}^{2}$ em $78 \%$ quando comparado com o diesel de petróleo. $\mathrm{O} \mathrm{CO}^{2}$ liberado na atmosfera, quando o Biodiesel é queimado, é reciclado pelo crescimento das plantas, que são mais tarde processadas para a produção do combustível".

\section{Nota 6}

De forma embrionária, o governo brasileiro, ainda durante o regime militar no ano de 1975, elaborou o Plano de Produções de Óleos Vegetais para Fins Energéticos, o PRÓ-ÓLEO. Segundo Locatelli (2008), o programa objetivava a produção, a preços competitivos, de um óleo alternativo ao óleo de petróleo, contudo não obteve o êxito desejado e foi extinto o que pode ser explicado pela falta de tecnologia disponível na época para produção.

\section{Nota 7}

O Ministério de Minas e Energia (MME) estabeleceu as orientações para os leilões nacionais de aquisição de biodiesel através da portaria no 483 de 10/03/2005. No leilão nacional de biodiesel, organizado pela Agência Nacional do Petróleo (ANP), 80\% do biodiesel negociado é reservado somente às empresa que detêm o SCS e os $20 \%$ restantes são dedicados a empresas que possuem ou não o SCS (FINCO E DOPPLER, 2011).

\section{Nota 8}

Para não se estender na rica e pertinente discussão sobre o conceito de gestão social, ainda em formação, que claramente não é objetivo desse artigo. Optou-se nesse estudo pela oportuna síntese de Cançado, Tenório e Pereira (2011) acerca da gestão social.

\section{Nota 9}

A cultura da soja necessita de aplicação intensiva de fertilizantes, herbicidas, inseticidas e outros químicos, o que não ocorre, ou ocorre com menor intensidade, com as outras oleaginosas produtoras de biodiesel. 


\section{Capítulo 20}

doi $10.37423 / 210804598$

\section{ELABORAÇÃO E ACEITABILIDADE DE IOGURTE TIPO LÍQUIDO COM ARATICUM (ANNONA CRASSIFLORA)}

AFRA MARIA DO CARMO BANDEIRA DO NASCIMENiñituto Federal de Educação Ciência e Tecnologia do Piauí 
Resumo: Este trabalho refere-se a uma pesquisa experimental desenvolvida no campus Uruçuí e teve como objetivo principal desenvolver iogurte tipo líquido com araticum (Annona crassiflora), procedendo à sua caracterização sensorial. O processamento foi executado no laboratório de alimentos e laticínios do campus, tendo sido as matérias-primas e insumos necessários adquiridos na região de Uruçuí. $O$ iogurte pronto foi submetido à prova sensorial com provadores não treinados.

Palavras-chave: processamento, produto lácteo, aceitabilidade, frutas do cerrado. 


\section{INTRODUÇÃO}

A biodiversidade do Cerrado brasileiro ficou em estágio de latência por muito tempo, desprezando-se do meio científico a riqueza em fauna e em flora dessa região. Os frutos do Cerrado são produtos naturais, saudáveis, ricos em nutrientes, que podem auxiliar inclusive o combate a desnutrição infantil. (OLIVEIRA \& ROCHA, 2008) O consumo das frutas nativas dos cerrados, consagrado pelos índios, sofreu adaptação e foram desenvolvidas técnicas de beneficiamento dessas frutas que resultou em licores, doces, geléias, mingaus, bolos, sucos, sorvetes e aperitivos. (SOARES JÚNIOR, CALIARI, VERA \& MELO, 2007). Assim, o interesse por essas frutas tem atingido diversos segmentos da sociedade, entre os quais se destacam agricultores, industriais, donas-de-casa, comerciantes, instituições de pesquisa e assistência técnica, cooperativas, universidades, órgãos de saúde e de alimentação, entre outros.

O interesse industrial pelas frutas nativas dos cerrados foi intensificado após os anos 40. A mangaba, por exemplo, foi intensivamente explorada durante a Segunda Guerra Mundial, para obtenção de látex. O babaçu e a macaúba foram bastante estudados na década de 70, devido à crise de petróleo, e mostraram grandes possibilidades para utilização em motores de combustão, em substituição ao óleo diesel, a tecnologia do biodiesel. O pequi já foi industrializado, sendo o seu óleo enlatado e comercializado. A polpa e o óleo da macaúba são utilizados na fabricação de sabão de coco. O palmito da guariroba, de sabor amargo, começou a ser comercializado em conserva recentemente, à semelhança do palmito doce. Os sorvetes de cagaita, araticum, pequi e mangaba continuam fazendo sucesso nas sorveterias do Distrito Federal e de Belo Horizonte. (AVIDOS \& FERREIRA, 2003).

Tratando-se de produtos derivados de leite, cabe lembrar que o Brasil é o sexto maior produtor de leite do mundo e apresenta ritmo de crescimento superior à de todos os países que ocupam os primeiros lugares. A cadeia produtiva do leite é uma das mais importantes do complexo agroindustrial brasileiro, estando entre os seis produtos mais importantes da agropecuária brasileira. (CARVALHO et. al., 2002). Pela sua alta qualidade nutricional, o leite tem sido empregado em vários processamentos tecnológicos gerando produtos derivados, tais como queijo, sorvete, doce e iogurte. (BEHMER, 1999).

O iogurte, conforme seu processamento, pode ser classificado em: Tradicional, no qual o processo de fermentação ocorre dentro da própria embalagem, não sofre homogeneização e o resultado é um produto firme, mais ou menos consistente; Batido, o processo de fermentação ocorre em fermentadeiras ou incubadoras com posterior quebra do coágulo; Líquido, o processo de fermentação é realizado em tanques, comercializado em embalagens plásticas tipo garrafa ou do tipo cartonadas. (MUNDIM, 2008). 
Tendo observado esses dois potenciais de elaboração de iogurte e exploração de araticum (Annona crassiflora), o presente trabalho teve por premissa desenvolver um iogurte tipo líquido de araticum em três formulações, que irão variar em concentração da polpa de araticum utilizada, para assim avaliar qual teria melhor aceitabilidade.

\section{METODOLOGIA}

\section{MATÉRIAS-PRIMAS}

Os araticuns (Annona crassiflora) amadurecidos foram obtidos na circunvizinhança da cidade de Uruçuí, região de cerrado do estado do Piauí no período de maio de 2011 . O leite utilizado foi adquirido no comércio local, observando todas as instruções de legislações sobre a qualidade do leite. A cultura necessária para início do processo fermentativo, representada pelo iogurte natural, adquirida em estabelecimento comercial, atentando-se para a temperatura de conservação e prazo de validade, para que isso não viesse interferir no processo de elaboração do iogurte.

Processamento do logurte

Todo o processo foi realizado no Laboratório de Alimentos e Laticínios do Instituto Federal de Educação Ciência e Tecnologia do Piauí, Campus Uruçuí. Por questões estruturais optou-se pelo método caseiro de elaboração de iogurte, que envolve leite, iogurte natural, açúcar e polpa de fruta. O laboratório ao longo de todo o período de processamento manteve-se isolado para evitar risco de contaminação.

Inicialmente, os frutos foram devidamente higienizados em água clorada a 20 ppm, seguido de despolpamento, tendo sido a polpa reservada sob refrigeração até o momento da sua utilização.

O leite líquido foi aquecido na faixa de 80 ㄷ $/ 5 \mathrm{~min}$., com o intuito de reduzir a níveis ínfimos os possíveis micro-organismos presentes, sofrendo posterior resfriamento até $45 \circ \mathrm{C}$, temperatura na qual foi adicionado o iogurte natural e homogeneizado. O recipiente foi imediatamente tampado, para que fosse mantida a temperatura suficiente para a coagulação do leite. Decorridas 6 horas de exposição em temperatura ambiente, o iogurte foi colocado sob refrigeração por mais 4 horas, após essa etapa foi misturada a polpa de araticum nas concentrações de 4\%, 8\% e 12\%, bem como o açúcar necessário, na proporção de $10 \%$ para cada $1 \mathrm{~L}$ de leite. 


\section{ANÁLISE SENSORIAL}

Foi realizada no Laboratório de Alimentos e Laticínios do IFPI, Campus Uruçuí, o corpo de provadores era constituído por alunos e servidores do campus Uruçuí, apresentando ampla faixa etária e de ambos os sexos, os quais receberão orientações específicas sobre os testes antes de serem submetidos a eles.

As amostras foram codificadas em sequência aleatória de três números e servidas em copos de café, cujo conteúdo equivalia a $20 \mathrm{ml}$, em temperatura de geladeira, para aproximar ao máximo da realidade de consumo de iogurtes.

Na ficha do teste o provador conferia uma pontuação " $X$ " para os atributos de cor, aroma, sabor, textura e consistência para cada amostra, de acordo com a escala apresentada, que ia de 1 a 5, onde 1 representava ótimo e 5, péssimo. Ao final do teste ele escolhia, entre as três, a amostra que mais Ihe agradasse.

\section{DESENVOLVIMENTO DA PESQUISA}

\section{RESULTADOS E DISCUSSÃO}

Até o momento foram concluídas somente as análises sensoriais, as físico-químicas estão em andamento em virtude da falta de certos equipamentos e reagentes no campus Uruçuí e mesmo pela sazonalidade do fruto, priorizaram-se as sensoriais. A elaboração do iogurte seguiu todas as normas de higiene previstas pelos órgãos de fiscalização sanitária, visto que era um produto que seria posto para degustação. Os frutos que apresentavam sinais de deterioração foram descartados. O período em que o iogurte foi posto na geladeira antes de ser adicionada a polpa era necessário para interromper o desenvolvimento dos microorganismos, pois se sua multiplicação fosse excessiva isso poderia causar além de transtornos tecnológicos para o produto, poderia ocasionar algum problema de saúde para os provadores.

Os resultados do teste sensorial apontaram para uma melhor apreciação da amostra contendo \% de polpa em relação às demais, em torno de \% dos julgamentos. Observando os parâmetros isoladamente, observou-se que no quesito cor, a amostra contendo $4 \%$ de polpa obteve melhor aceitação em relação às demais; para os aspectos aroma e textura, a amostra de $8 \%$ de polpa foi considerada a mais aceitável dentre as três; e para os parâmetros de sabor e consistência, o maior número de provadores elegeu a amostra com $12 \%$ de polpa. 


\section{CONSIDERAÇÕES FINAIS}

Favor seguir as normas de diagramação aqui expostas, usando este exemplo como base para o seu texto. A submissão do resumo expandido significa que os autores concordam com a publicação deste, a critério da Comissão Editorial, em CD. Além disso, os autores concordam que pela publicação resumo expandido não obterão nenhum ganho, senão a divulgação científica e profissional dos seus trabalhos. Nas referências, seguir as normas da ABNT, conforme o exemplo constante das referências. Após o título da seção haverá um espaço (linha em branco) simples. As considerações finais deverão apresentar os resultados do estudo (finais ou parciais) e não deverá conter citações.

\section{AGRADECIMENTOS}

Agradecemos ao Programa de Bolsas de Iniciação Científica do IFPI, pela ampliação da oportunidade de iniciação à pesquisa para os mais diversos segmentos e campi, pois se sabe que hoje a produção científica é cada vez mais urgente, logo quanto antes nossos alunos puderem ser inseridos nessa realidade melhor para a vida acadêmica deles. 


\section{REFERÊNCIAS}

AVIDOS, M. F. D.; FERREIRA, L. T. Frutos dos cerrados - preservação gera muitos frutos, 2003. Disponível em: <http://www.biotecnologia.com.br/bio15/frutos.pdf>. Acesso em: 18/04/ 2011.

BEHMER, M. L. A. Tecnologia do Leite. 13 ed. São Paulo: Nobel, 1999.

CARVALHO, L. de A.; et. al. Sistema de Produção 2. Goiás: EMBRAPA, 2002. Disponível em: <http://www.cnpgl.embrapa.br/>. Acesso em: 28/04/2011.

INSTITUTO ADOLFO LUTZ. Normas analíticas do Instituto Adolfo Lutz: métodos físicos e químicos para análise de alimentos. V. 1. 3. ed. São Paulo, 1985.

FILHO, M. A. Pesquisadores mapeiam propriedades funcionais de frutas nativas do cerrado. Jornal da Unicamp. Universidade Estadual de Campinas, 2005. Disponível em: <www.unicamp.br/unicamp/unicamp_hoje/.../ju295pg05.pdf>. Acesso em: 19/04/2011.

MUNDIM, S. A. P. Elaboração de logurte Funcional com Leite de Cabra, Saborizado com Frutos do Cerrado e Suplementado com Inulina. Dissertação (Mestrado em Ciências) - Escola de Química. Universidade Federal do Rio de Janeiro, Rio de Janeiro, 2008. Disponível em: $<w w w . e q . u f r j . b r / s i p e q / . . . / i o g u r t e-f u n c i o n a l-c o m-l e i t e-d e-c a b r a . p d f>$. Acesso em: 18/04/2011.

OLIVEIRA, K. A. de M.; et. al. Desenvolvimento de Formulação de logurte de Araticum e Estudo da Aceitação Sensorial. Alimentos e Nutrição, Araraquara. v. 19, n.3, p. 277-281, jul./set. 2008. Disponível em: <serv-bib.fcfar.unesp.br/seer/index.php/alimentos/article/viewFile/631/529>. Acesso em: $18 / 04 / 2011$.

OLIVEIRA, D. L.; ROCHA, C. Alternativas Sustentáveis para a Merenda Escolar com o Uso de Plantas do Cerrado, Promovendo Educação Ambiental. Rev. eletrônica Mestr. Educ. Ambient. ISSN 1517-1256, v. 21, julho a dezembro de 2008. Disponível em: <www.remea.furg.br/edicoes/vol21/art3v21.pdf>. Acesso em: 18/04/2011.

ROCHA, C.; et. al. logurte de Leite de Búfala Sabor Frutos do Cerrado. B.CEPPA, Curitiba, v. 22, n. 1, p. 97-106, jan./jun., 2004. Disponível em: <ojs.c3sl.ufpr.br/ojs2/index.php/alimentos/article/.../1182>. Acesso em: 18/04/2011.

SILVA, M. R.; LACERDA, D. B. C. L.; SANTOS, G. G.; MARTINS, M. D. O. Caracterização química de frutos nativos do cerrado. Ciência Rural, Santa Maria, v.38, n.6, set, 2008. Disponível em: $<w w w . s c i e l o . b r / p d f / c r / v 38 n 6 / a 51 v 38 n 6 . p d f>$. Acesso em: 18/04/2011.

SOARES JÚNIOR, M. S.; CALIARI, M.; VERA, R.; MELO, C. S. Filmes Plásticos e Ácido Ascórbico na Qualidade de Araticum Minimamente Processado. Ciência Rural, Santa Maria, v.37, n.6, p.1779-1785, Nov-dez, 2007. Disponível em: <www.scielo.br/pdf/cr/v37n6/a43v37n6.pdf>. Acesso em: 19/04/2011. 


\section{Capítulo 21}

doi $10.37423 / 210804599$

\section{ECONOMIA DO MEIO AMBIENTE E}

DESENVOLVIMENTO SUSTENTÁVEL: PRINCÍPIOS

E FUNDAMENTOS TEÓRICOS 
Resumo: O mundo moderno tem vivenciado uma crise ambiental sem precedentes. Problemas como escassez de recursos naturais, degradação ambiental, desemprego, fome e miséria invadem todos os países, alguns de forma mais severa e outros de forma moderada. Nesse contexto, e utilizando-se de uma pesquisa bibliográfica, esse artigo discutirá a teoria do chamado desenvolvimento sustentável, partindo inicialmente da discussão sobre economia ambiental e ecológica, bem como os seus desdobramentos teóricos. Além disso, buscar-se-á uma breve análise sobre alguns entraves e possibilidades das principais propostas que envolvem a temática do desenvolvimento sustentável.

Palavras-chave: Desenvolvimento sustentável. Meio ambiente. Economia Ambiental e Ecológica. 


\section{INTRODUÇÃO}

A humanidade tem vivenciado uma crise ambiental sem precedentes. Cenários de escassez de recursos naturais, degradação ambiental, desemprego, fome e miséria fazem parte do cotidiano das pessoas. O modelo econômico utilizado nas últimas décadas por muitos países tem privilegiado o crescimento econômico sem limites e sem preocupações com outras variáveis, como equidade e qualidade de vida, mostra-se ineficiente do ponto de vista sistêmico. Como consequência, faz-se necessário a implementação de um novo paradigma de desenvolvimento, que responda às demandas das gerações presentes sem comprometer as necessidades das gerações futuras.

A construção de um novo modelo de desenvolvimento deve considerar as relações econômicas, sociais e ambientais de forma a proporcionar um desenvolvimento socialmente justo, ambientalmente correto e economicamente viável. Nesse sentido, a proposta conceitual do chamado desenvolvimento sustentável surge como uma alternativa para a concretização dessa nova cosmovisão. 0 desenvolvimento sustentável é mais do que um objetivo a ser alcançado, é um caminho a ser percorrido.

O conceito de desenvolvimento sustentável surgiu no início da década de 1970 com o nome de ecodesenvolvimento ${ }^{1}$ em meio a uma controvertida relação entre crescimento econômico e meio ambiente. O ecodesenvolvimento introduz uma proposta nova, conciliando o progresso técnico e os limites ambientais, reconhecendo que o crescimento econômico, apesar de ser necessário, não é suficiente para a eliminação da pobreza e das disparidades sociais.

Este artigo teórico discutirá a teoria do chamado desenvolvimento sustentável, partindo inicialmente da discussão sobre economia ambiental e ecológica, bem como os seus desdobramentos teóricos. Além disso, buscar-se-á uma breve análise sobre alguns entraves e possibilidades das principais propostas que envolvem a temática do desenvolvimento sustentável.

\section{METODOLOGIA}

O trabalho enquadra-se como pesquisa bibliográfica, com abordagem qualitativa. De acordo com Gil (2002, p.44), “(...) a pesquisa bibliográfica é desenvolvida com base em material já elaborado, constituído principalmente de livros e artigos científicos". A vantagem principal da pesquisa bibliográfica, segundo o autor, é permitir ao pesquisador realizar uma maior cobertura de fenômenos, utilizando-se diversas fontes bibliográficas para corroborar o trabalho. Sua finalidade é colocar o 
pesquisador em contato com o que já se produziu e se registrou a respeito do tema de pesquisa, revelando, como isso, o compromisso da qualidade da pesquisa.

Para Fonseca (2002),

A pesquisa bibliográfica é feita a partir do levantamento de referências teóricas já analisadas, e publicadas por meios escritos e eletrônicos, como livros, artigos científicos, páginas de web sites. Qualquer trabalho científico inicia-se com uma pesquisa bibliográfica, que permite ao pesquisador conhecer o que já se estudou sobre $o$ assunto. Existem, porém, pesquisas científicas que se baseiam unicamente na pesquisa bibliográfica, procurando referências teóricas publicadas com o objetivo de recolher informações ou conhecimentos prévios sobre o problema a respeito do qual se procura a resposta (FONSECA, 2002, p. 32).

Desta forma, foi realizado um levantamento bibliográfico mediante leitura e análise de diversas fontes bibliográfica, como teses, dissertações, artigos publicados em periódicos, e livros, que abordassem a temática pesquisada. Os procedimentos metodológicos, adotados nesta pesquisa, possibilitaram pensamentos reflexivos e o conhecimento crítico acerca do tema de pesquisa proposto.

\section{ECONOMIA AMBIENTAL, ECONOMIA ECOLÓGICA E O DESENVOLVIMENTO SUSTENTÁVEL:}

\section{CONCEITOS E DESDOBRAMENTOS TEÓRICOS}

No debate acadêmico em economia do meio ambiente, esse assunto é discutido a partir de duas correntes principais de interpretação, a saber: economia ambiental (de origem neoclássica) e a chamada economia ecológica.

Na economia ambiental (o mainstream neoclássico) os recursos naturais não representam, no longo prazo, um limite à expansão da economia. Na verdade, conforme Romeiro (2003), esses recursos não apareciam nos estudos, pois os recursos naturais eram considerados fixos. Desta forma, a função de produção ${ }^{2}$ era constituída apenas pelo capital e trabalho, isto é, $Y=f(L, K)$, ou seja, a produção $(Y)$ é função dos fatores trabalho (L) e capital (K), que compreende as máquinas e os equipamentos utilizados no processo produtivo. Binswanger (1999) diz que esse pensamento negligenciava a natureza e funcionava como uma espécie de bolo sem ingredientes, ou seja, para fazer um bolo qualquer, bastaria pegar uma vasilha e uma colher (capital) e começar a mexer (trabalho) por um determinado tempo e esperar o resultado do bolo. Isso demonstrava implicitamente uma visão de infinitude dos recursos naturais. Sendo assim, a economia crescia, segundo pensavam, de forma autônoma e não havia limites naturais a sua expansão, conforme ilustra a figura 1. 
Figura 1 - Símbolo da expansão da economia no longo prazo, sem limites dos recursos naturais

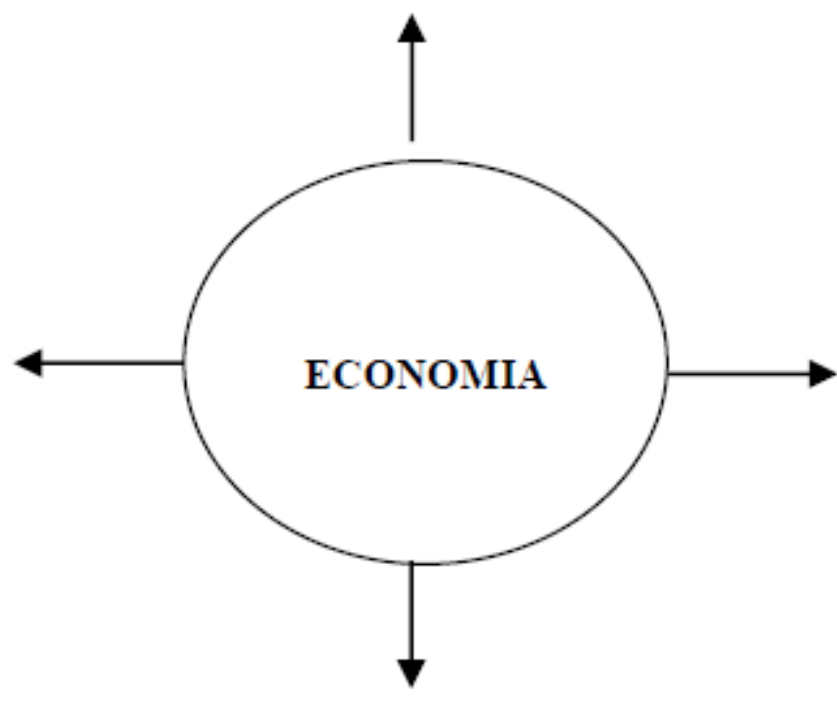

Fonte: adaptado de Binswanger (1999)

Essa visão acerca da não inserção dos recursos naturais na função de produção foi perdendo força com o tempo. O uso cada vez mais intenso de recursos naturais não renováveis Economia do meio ambiente e desenvolvimento sustentável: princípios e fundamentos teóricos e o mau uso dos seus dejetos levaram a uma nova reflexão em torno do meio ambiente, onde a natureza passou a ser tratada como um terceiro fator de produção. Os neoclássicos começaram então a incluir os recursos naturais na função de produção, que passa a ser expressa da seguinte maneira: $Y=f(K, L, R)$, onde $Y$ é o volume de produção, $\mathrm{K}$ é capital (máquinas e equipamentos), L é trabalho e $\mathrm{R}$ os recursos naturais (PYNDICK e RUBINFELD, 2002).

No entanto, esse incremento na função de produção veio na forma de uma espécie de substituibilidade perfeita entre capital, trabalho e recursos naturais. Isto quer dizer que o sistema econômico é extremamente grande para impedir que a escassez de recursos naturais se torne uma restrição a sua expansão, mas apenas uma restrição relativa que seria facilmente superada com o progresso científico e tecnológico. Os recursos naturais (RN) apenas inibem o crescimento da economia. 
Figura 2 - Economia e os Recursos Naturais (RN)

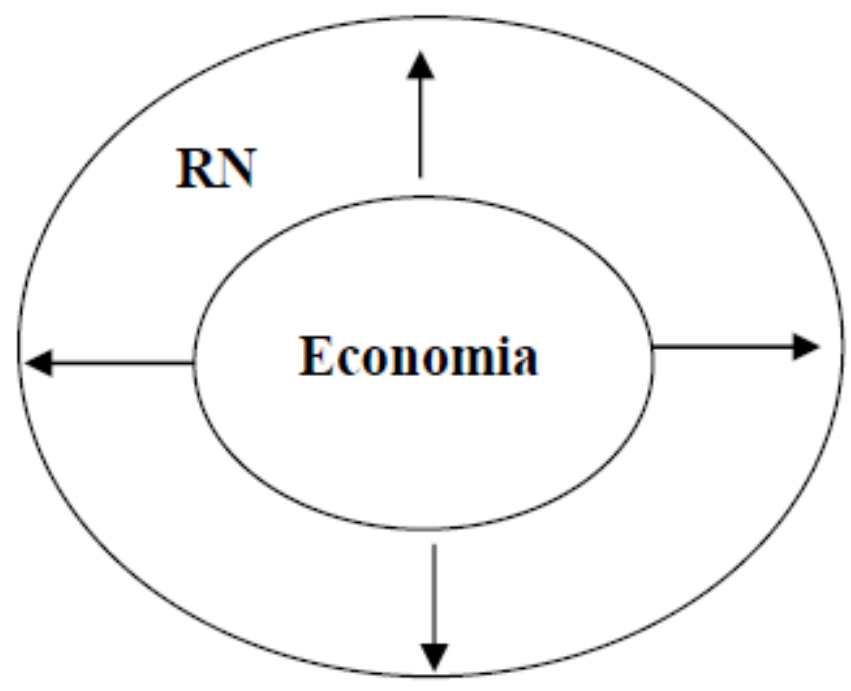

Fonte: adaptado de Romeiro (2003).

Em suma,

Tudo se passa como se o sistema econômico fosse capaz de se mover suavemente de uma base de recursos para outra, à medida que cada uma é esgotada, sendo o progresso científico e tecnológico a variável-chave para garantir que esse processo de substituição não limite o crescimento em longo prazo. (Romeiro, 2003, p.7)

Esse foi o principal argumento para derrubar a teoria do economista Thomas Robert Malthus (17661834), segundo a qual os alimentos crescem no máximo em progressão aritmética e a população em progressão geométrica. Ou seja, a quantidade relativamente fixa de terras existentes no planeta seria insuficiente para o suprimento de alimentos à medida que a população mundial crescesse (HUNT, 1986). Sustenta-se a inviabilidade dessa teoria ao fato de Malthus ignorar a questão do avanço tecnológico como fator de substitubilidade.

Felizmente, Malthus estava enganado (...), avanços tecnológicos modificaram significativamente a produção de alimentos na maioria dos países (inclusive em países em desenvolvimento como a Índia), (...) tais avanços incluem novas variedades de sementes de alto rendimento e alta resistência 'as pragas, melhores fertilizantes e melhores colheitadeiras. (PYNDICK e RUBINFELD, 2002, p.185).

Desta forma, a escassez de recursos naturais seria superada por avanços tecnológicos. Esse pensamento ficou conhecido como o da sustentabilidade fraca (MIKHAILOVA, 2004), por não reconhecer que alguns recursos naturais não podem ser substituídos pela ação humana. Do ponto de vista metodológico, 
A Economia Neoclássica defende, geralmente, o conceito de sustentabilidade fraca. Ela assume que os custos de degradação ambiental podem ser compensados pelos benefícios econômicos. Os indicadores de sustentabilidade fraca são baseados em indicadores econômicos convencionais e podem ser mensurados em unidades monetárias ou em pontos (MIKHAILOVA, 2004, p. 31).

Para a corrente neoclássica, a redução da degradação ambiental seria resolvida por meio de mecanismos de mercado. Assim, se uma determinada matéria-prima que está sendo comercializada ficar escassa, esta escassez elevaria o seu preço e forçaria os fabricantes a buscar inovações para reduzir os seus custos e, desta forma, substituir o recurso natural escasso por outro abundante. Segundo Romeiro (2003), esse pensamento encontrou obstáculos quando se trata dos serviços ambientais que, em geral, não são transacionados no mercado devido a sua natureza, pois se tratam de bens públicos, como ar e água. Portanto, esses recursos naturais não podem ser substituídos.

Os neoclássicos não negam que o processo de desenvolvimento econômico causa, como efeito colateral, a degradação do meio ambiente. Entretanto, esta seria sanada quando a população atingisse certo nível de desenvolvimento socioeconômico, quando ficaria mais sensível e disposta a pagar pela melhoria do meio ambiente.

Além disso, as soluções dos problemas ambientais viriam dos mecanismos de mercado, o que implicaria numa provável privatização de recursos como água e ar e numa internalização dos custos ambientais pelo agente econômico. Este último, no intuito de minimizar o seu custo total, procurará um ponto de equilíbrio entre o que irá gastar para controlar a poluição (custos de controle) e o que irá gastar com o pagamento de taxas por poluir (custo de degradação).

Desta forma, o agente econômico se defrontaria com um trade off (escolha) entre seus custos marginais de controle e os custos marginais da degradação ambiental. O ponto de equilíbrio (onde as curvas se interceptam) é chamado de "poluição ótima". Desta forma, uma política ambiental só teria eficiência se o agente econômico internalizasse os custos da degradação que provoca (ROMEIRO, 2003). 
Figura 3 - Equilíbrio Ambiental

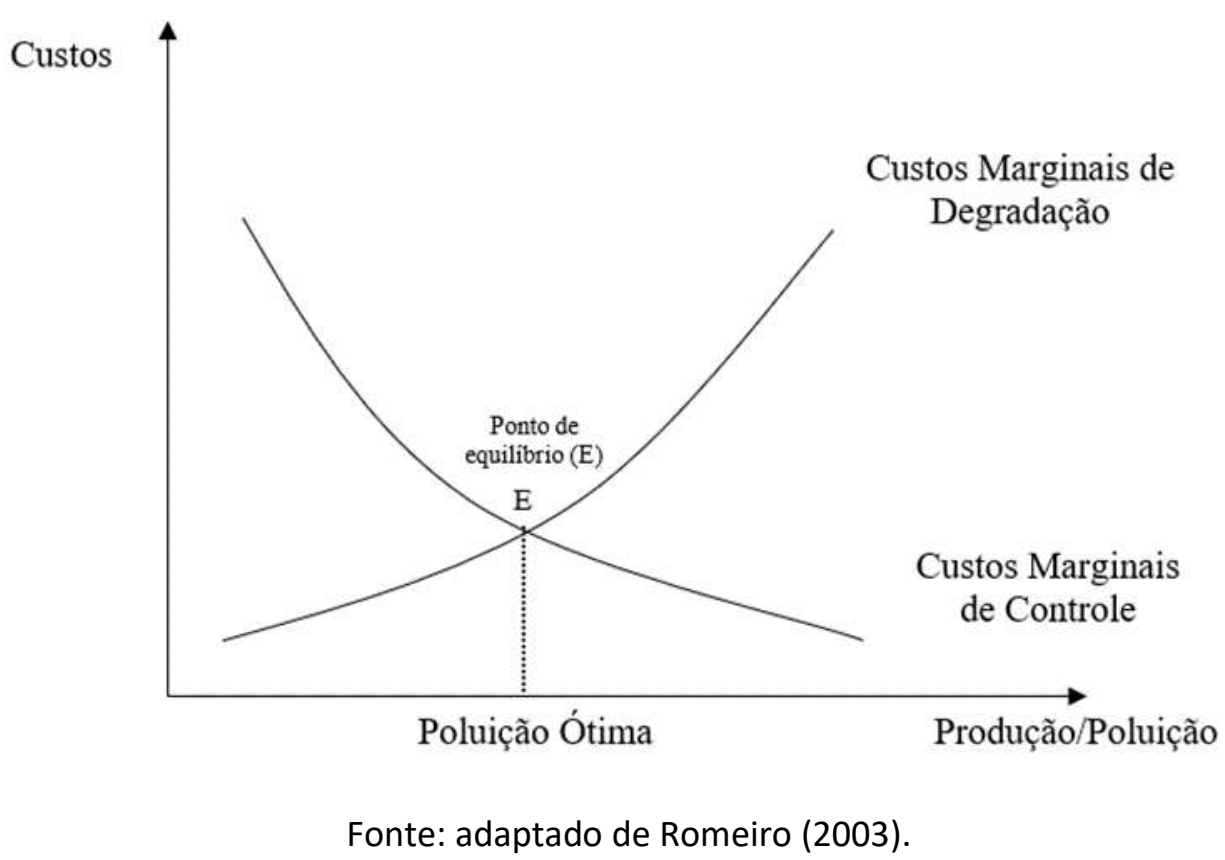

Esse ponto de equilíbrio, que advém da internalização dos custos ambientais pelo agente econômico, chamado de "poluição ótima", é tido como equilíbrio de cunho econômico e não ecológico, pois ecologicamente não pode haver equilíbrio quando a capacidade de assimilação do meio é ultrapassada, uma vez que a poluição permanece.

Discordando em parte da visão da economia ambiental, a segunda corrente de interpretação, a chamada economia ecológica, procura perceber o sistema econômico dentro de um sistema global, que impõe restrição absoluta à sua expansão. Esta abordagem reconhece a importância do progresso científico e tecnológico para aumentar a eficiência na utilização dos recursos naturais renováveis e não-renováveis, que seria estimulada por meio de uma estrutura regulatória baseada em incentivos econômicos (ROMEIRO, 2003).

Segundo essa teoria, no longo prazo a sustentabilidade do sistema econômico não seria possível sem que houvesse uma estabilização dos níveis de consumo per capita compatível com a capacidade do planeta. Para que isso possa ocorrer seria necessário a mobilização da sociedade como um todo, através do Estado ou outra forma de organização coletiva, no sentido de evitar perdas irreversíveis e catastróficas na natureza. O crescimento da economia, aliado aos limites ambientais, é a questão central dessa teoria, que também é chamada de sustentabilidade forte. Esse é o principal ponto de divergência entre a economia ambiental e a ecológica (ROMEIRO, 2003). 
Para Mikhailova (2004, p. 31), “a Economia Ecológica defende o conceito de sustentabilidade forte. Os indicadores que caracterizam a sustentabilidade forte são mensurados em unidades físicas, porque em sua ótica, as perdas ambientais não podem ser compensadas pelos benefícios financeiros".

Sartori et al. (2014, p. 4) sugerem que a sustentabilidade forte "é um paradigma da não substituição, no qual existem sistemas naturais que não podem ser corroídos ou destruídos sem comprometer os interesses as gerações futuras. Para os autores, na sustentabilidade forte é exigido que um subconjunto do capital natural total seja preservado em termos físicos, de modo que suas funções permaneçam intactas.

Entrementes, apesar da economia ecológica reconhecer a importância da conservação dos recursos naturais, ela subestima o potencial produtivo da natureza, especialmente dos ecossistemas tropicais. A produção continua sendo guiada pelas lógicas de mercado e o ambiente, assim como na economia ambiental, é visto como um custo e não como potencial (LEFF, 2001).

As propostas teóricas da economia ecológica exerceram influências na chamada ecologia humana, que tem como base a Teoria Neomalthusiana, na qual o equilíbrio entre economia e meio ambiente se daria através de uma relação entre crescimento populacional, escassez de recursos e limites ecológicos, onde os próprios ecossistemas, através da sua capacidade de suporte, fixariam os limites ao crescimento econômico e demográfico (LEFF, 2001). Além disso, os recursos naturais têm de ser recompensados, sob pena de decadência da própria economia. A figura 4 mostra o esquema de uma economia onde o uso racional dos recursos naturais é imprescindível para se obter uma economia sustentável. 
Figura 4 - Esquema de uma economia moderna e sustentável

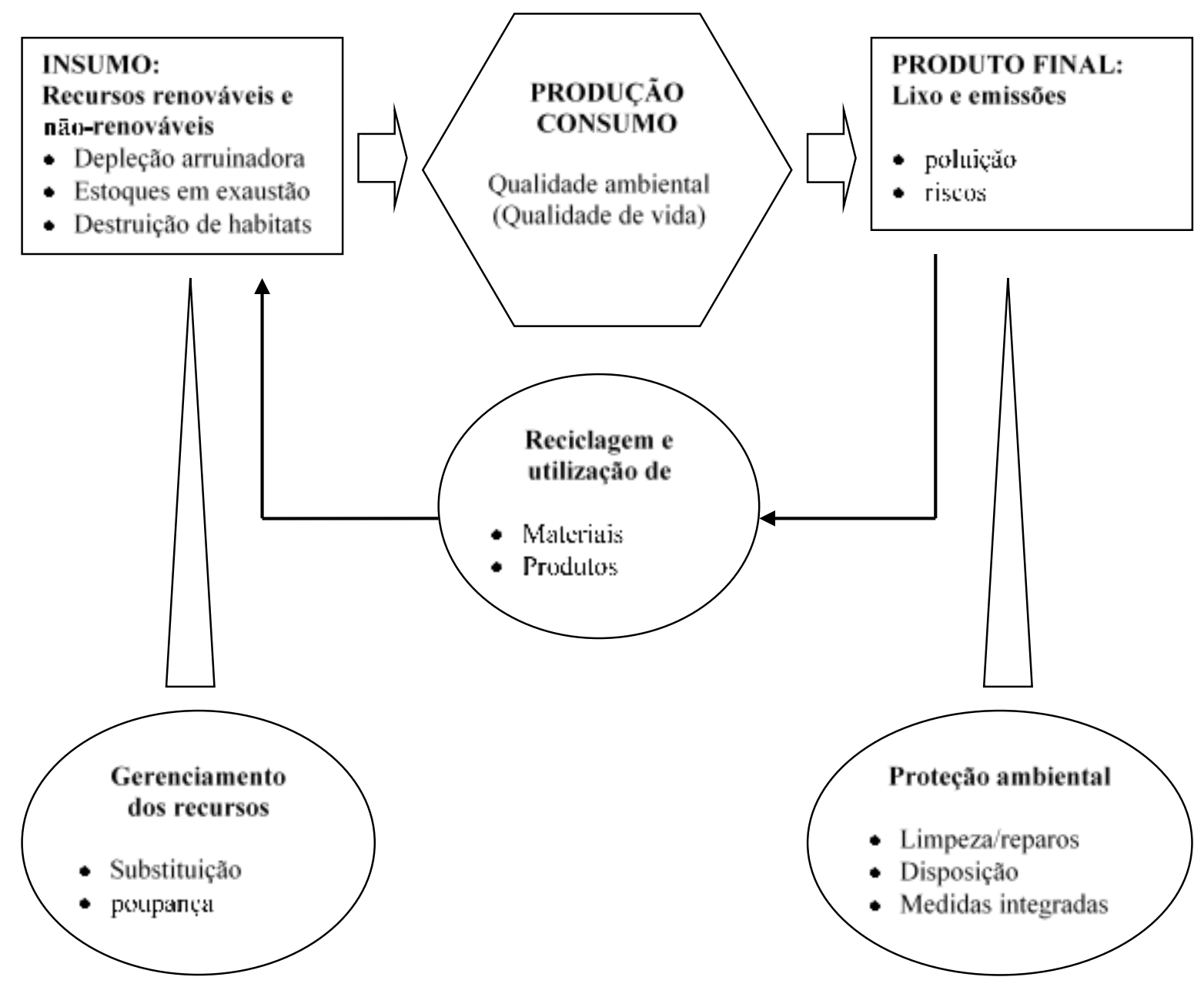

Fonte: Adaptado de Binswanger (1999).

$\mathrm{Na}$ figura 4, todo o processo que vai desde o insumo de recursos naturais, via processo de transformação econômica de produção e consumo, ao produto final, são partes integrantes da economia. Numa economia sustentável, os dejetos da produção, que seriam lançados na natureza sob a forma de lixos, são reintroduzidos na economia na forma de insumo. Para que isso ocorra, são necessárias medidas de proteção ambiental, reciclagem e utilização de produtos e materiais e gerenciamento de recursos. Neste modelo, a economia e a política econômica ganham responsabilidade social mais alta, de modo que não somente o nível de produto social seja garantido, mas também a qualidade do ambiente natural, o que inclui a preservação da qualidade de vida das pessoas (BINSWANGER, 1999).

Essas duas teorias (economia ambiental e economia ecológica) mostram que a problemática ambiental tem sido tratada de diferentes modos no decorrer dos tempos. Apesar das divergências, ambas as teorias apontam que o estudo da relação entre desenvolvimento econômico e o uso dos 
recursos naturais torna-se urgente devido às grandes degradações ambientais que a sociedade está vivenciando. Isso sugere que o pensar em desenvolvimento deve ser acompanhado do pensar em meio ambiente, uma vez que ambos são inseparáveis. Essa relação ou binômio meio ambientedesenvolvimento somente inexiste quando há um ecossistema intocado, que pode existir independentemente do meio ambiente. Isso ocorre porque há ecossistemas que não levam em conta a presença humana e nunca foram explorados ou conhecidos por algum homem. Quando o homem se relaciona com um ecossistema ele cria relações ambientais que alteram o seu entorno (COIMBRA, 2002).

Essa preocupação em harmonizar o desenvolvimento com o meio ambiente deu origem ao chamado desenvolvimento sustentável, que é entendido como "o que tem capacidade de permanecer ao longo do tempo. Em outras palavras: é o desenvolvimento durável, em todas as suas dimensões" (MAGALHÃES, 1998, p. 419).

Entretanto, como relata Leff (2000; 2001), a sustentabilidade possui dois significados. O primeiro é o conhecido como sustentável, no sentido de que implica numa internalização das condições ecológicas de suporte do processo econômico. O segundo significado diz respeito à capacidade de durabilidade do processo econômico. Sendo assim, a sustentabilidade ecológica constitui uma condição de sustentabilidade do processo econômico. Contudo, segundo o autor, o discurso da sustentabilidade objetiva alcançar um crescimento sustentado sem uma justificação rigorosa da capacidade do sistema econômico de internalizar as condições ecológicas e sociais, tais como equidade, justiça e democracia.

Tanto o discurso do desenvolvimento sustentável quanto o da sustentabilidade, entendidos neste trabalho, conforme Leff (2001, p. 20), como sinônimos, tem encontrado dificuldades para o cumprimento dos seus objetivos, pois tem se baseado em mecanismos de mercado.

O discurso da sustentabilidade chegou a afirmar o propósito e a possibilidade de conseguir um crescimento econômico sustentado através dos mecanismos de mercado, sem justificar sua capacidade de internalizar as condições de sustentabilidade ecológica, nem de resolver a tradução dos diversos processos que constituem $\mathrm{o}$ ambiente (tempos ecológicos de produtividade $\mathrm{e}$ regeneração da natureza, valores culturais e humanos, critérios qualitativos que definem a qualidade de vida) em valores e medições do mercado...

Seu intuito não é internalizar as condições ecológicas da produção, mas proclamar o crescimento econômico como um processo sustentável, firmado nos mecanismos do livre mercado como meio eficaz de assegurar o equilíbrio ecológico e a igualdade social. (LEFF, 2001, p.20,27).

Um enfoque mais abrangente é aquele apresentado por Pereira (2000), que enfatiza que o desenvolvimento sustentável deve ser atingido em todas as suas dimensões, ou seja, desenvolvimento 
econômico, comunitário e ecológico. A interação entre eles gera o chamado desenvolvimento sustentável, como mostra a figura 5.

Figura 5 - Desenvolvimento Sustentável

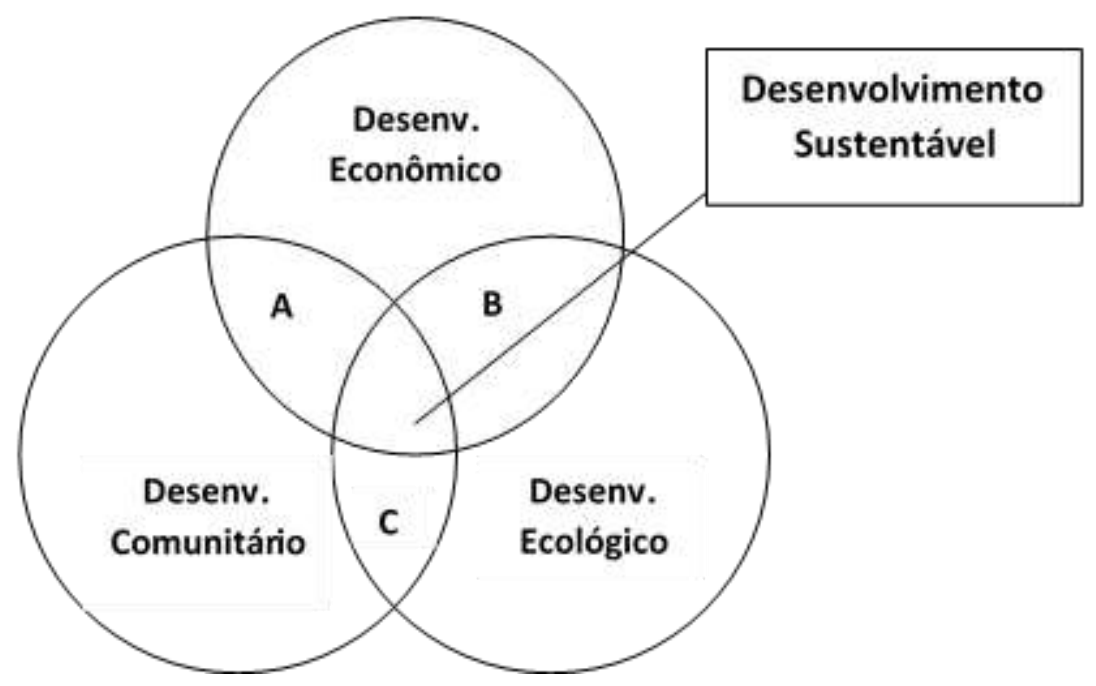

Fonte: ICLEI, 1996 apud Pereira (2000)

Em " $A$ " o desenvolvimento econômico está integrado com o desenvolvimento comunitário, formando o que se chama de desenvolvimento econômico da comunidade. Em " $\mathrm{B}$ " o desenvolvimento econômico está integrado com o desenvolvimento ecológico, gerando o chamado conservacionismo. Já em " $C$ " o desenvolvimento econômico não aparece, a interação fica por conta do desenvolvimento ecológico com o comunitário, dando origem a chamada ecologia profunda. O ponto de interação entre os três tipos de desenvolvimento gera o desenvolvimento sustentável a partir de um envolvimento harmônico entre economia, natureza e comunidade. Pereira $(2000$, p.54) mostra os objetivos de cada dimensão do desenvolvimento sustentável:

Quadro 1 - Objetivos do Desenvolvimento Sustentável

\begin{tabular}{|c|c|}
\hline \multirow{4}{*}{ Desenvolvimento Econômico: } & $\begin{array}{l}\text { - Promover o crescimento sustentado da } \\
\text { economia; }\end{array}$ \\
\hline & - Maximizar os ganhos privados; \\
\hline & - Promover a ampliação dos mercados; \\
\hline & - Externalizar os custos; \\
\hline \multirow{5}{*}{ Desenvolvimento Comunitário: } & - Estimular a auto-suficiência local; \\
\hline & - Satisfazer as necessidades básicas humanas; \\
\hline & - Aumentar a equidade social; \\
\hline & - Estimular o uso de tecnologias apropriadas; \\
\hline & $\begin{array}{l}\text { - Estimular a participação comunitária nas } \\
\text { decisões da comunidade; }\end{array}$ \\
\hline
\end{tabular}




\begin{tabular}{|l|l|}
\hline \multirow{2}{*}{ Desenvolvimento Ecológico: } & $\bullet \begin{array}{l}\text { Respeitar a capacidade de suporte de } \\
\text { natureza; }\end{array}$ \\
\cline { 2 - 2 } & $\bullet \begin{array}{l}\text { Conservar e reciclar produtos para minimizar } \\
\text { o uso dos recursos naturais; }\end{array}$ \\
\cline { 2 - 2 } & $\bullet \quad$ Reduzir desperdícios. \\
\hline
\end{tabular}

Fonte: adaptado de Pereira (2000, p.54).

Já para Magalhães (1998), o desenvolvimento sustentável possuiria quatro dimensões: (I) Econômica; (II) Social; (III) Ambiental; e (IV) Política. A dimensão econômica diz respeito à capacidade de sustentação econômica dos empreendimentos. A social diz respeito à capacidade de incorporar as populações que vivem à margem da sociedade, reduzindo os desequilíbrios sociais; a dimensão ambiental, à necessidade de conservação dos recursos naturais e da capacidade produtiva da base física. Por fim, a dimensão política está relacionada com a estabilidade dos processos decisórios e das políticas de desenvolvimento.

Sachs (1993, p. 37), por sua vez, propõe cinco dimensões de sustentabilidade:

a) Sustentabilidade Social: criação de um processo de desenvolvimento que seja sustentado por outro crescimento baseado numa melhor distribuição de renda e de bens, de modo a reduzir as disparidades socioeconômicas entre ricos e pobres.

b) Sustentabilidade Econômica: relacionada à alocação e gerenciamento mais eficientes dos recursos e de um fluxo constante de investimentos públicos e privados.

c) Sustentabilidade Ecológica: relacionada ao melhor uso dos diversos ecossistemas, no intuito de minimizar possíveis danos, a partir da substituição de combustíveis danosos ao meio ambiente por produtos ou recursos renováveis e/ou abundantes, usados de forma não-agressiva ao meio ambiente. Ela implica na redução dos resíduos e da poluição, através de mecanismo de conservação da energia, recursos e da reciclagem; promoção de incentivos à limitação do consumo de materiais, estimulando a expansão da pesquisa no intuito de desenvolver tecnologias de baixo teor de resíduos e eficientes no uso de recursos para o desenvolvimento urbano, rural e industrial; definição de mecanismos de regulação para uma adequada proteção ambiental.

d) Sustentabilidade Espacial: definição de uma estrutura rural-urbana mais equilibrada e territorialmente melhor distribuída, de forma a reduzir a concentração excessiva nas áreas metropolitanas, impedir a destruição de ecossistemas, estimular a descentralização industrial e proteger a biodiversidade através da criação de reservas naturais e de biosfera. 
e) Sustentabilidade Cultural: estímulo à procura de raízes endógenas de processos de modernização e de sistemas agrícolas integrados, tendo em vista as especificidades do local, ecossistema, cultura e área.

Entretanto, essas cinco dimensões da sustentabilidade proposta por Sachs (1986) não surtirão efeitos na sociedade e na economia se outras dimensões, também relevantes, não forem resolvidas. É o que Camargo (2003) chama de entraves do desenvolvimento sustentável. Segundo o autor, os entraves à sustentabilidade global podem ser agrupados em culturais, científicos, político-econômicos, sociais, ideológicos, psicológicos e filosófico-metafísicos, que serão descritos resumidamente a seguir.

a) Culturais: os principais entraves culturais são os relacionados à maneira segundo a qual os diferentes povos se relacionam com a natureza e utilizam os recursos naturais. Os diferentes valores e crenças contribuem grandemente para esse entrave.

b) Científicos: quanto aos entraves científicos, pode-se destacar, segundo o autor, a ausência de maior conhecimento sobre as inter-relações homem-natureza, a excessiva compartimentação dos diversos campos do conhecimento, a falta de diálogo entre a comunidade científica e a sociedade civil, governos, setores privados e organizações internacionais, a escassa utilização dos princípios e práticas interdisciplinares.

c) Político-econômicos: os entraves político-econômicos podem ser traduzidos como a grande diferença econômica existente entre os países e dentro dos países, no que diz respeito aos níveis de produção, consumo e renda per capita, além do atual estilo de vida consumista existente nos países e da falta de uma visão política para a área socioambiental e da prevalência dos grandes grupos econômicos nos órgãos de representação política e outros.

d) Sociais: o autor apresenta como entraves sociais a pressão decorrente do crescimento populacional, os conflitos étnicos e religiosos, o militarismo e o armamentismo, a violência, baixo nível de escolaridade e outros problemas de exclusão social.

e) Ideológicos: como principais entraves ideológicos encontram-se os fanatismos e os extremismos, as diferentes formas de perceber a vida, as diferenças entre os seres humanos na motivação de se comprometer com projetos globais que excedam sua expectativa de vida, a tendência humana em se opor a idéias novas e outros. 
f) Psicológicos: entre os principais entraves psicológicos estão as dificuldades humanas de se integrar a natureza, a dificuldade de definição da relação homem-natureza e os obstáculos ao ensino sobre preservação ambiental.

g) Filosófico-metafísicos: por fim, os entraves filosófico-metafísicos estão relacionados a dilemas intrapessoais e coletivos sobre temas como a vida e a morte, a natureza humana, a origem e o destino do homem, a existência e a natureza de Deus, quem somos no universo e etc.

Para Camargo (2003), as controvérsias que norteiam a possibilidade de obtenção do desenvolvimento sustentável em âmbito global reforçam a necessidade urgente de uma mudança nas relações homemnatureza e homem-homem. Segundo ele, o desenvolvimento sustentável somente será possível se for gerido por uma nova consciência individual, coletiva e por um novo estágio espiritual.

A busca pelo desenvolvimento sustentável deve, portanto, reunir esforços multilaterais, por meio de ações da sociedade, instituições, empresas e o Estado. A seção seguinte tratará mais sobre isso.

\section{EM BUSCA DO DESENVOLVIMENTO SUSTENTÁVEL}

Conforme já comentado, mais crescimento econômico significa aumento da economia e quanto maior a economia, maior o impacto ecológico. $\mathrm{O}$ aumento da atividade econômica, tendo em vista recursos naturais finitos, implica em aumento do chamado custo de oportunidade de serviços ambientais. Com o crescimento da economia, alguns recursos naturais irão desaparecer. Esse limite ao crescimento revela que é preciso conciliar o desejável (crescimento econômico) com o possível (as fronteiras ecológicas da economia) (CAVALCANTI, 2004).

Mesmo contendo uma proposta conciliadora, os teóricos do desenvolvimento sustentável reconhecem que existem limites para a sua obtenção. A ciência econômica, por exemplo, destaca, como objeto de estudo, que as necessidades humanas são ilimitadas e que os recursos destinados a atender essas necessidades são limitados, escassos. Os limites podem surgir de diversas formas, como sociais, culturais e ambientais. Na mídia e também na literatura, é comum mencionar como limites à sustentabilidade a finitude e a escassez de alguns recursos produtivos, esquecendo-se, muitas vezes, que este assunto é mais complexo do que calcular prazos de validade de alguns elementos da natureza.

Foladori (2001) salienta que os limites à sustentabilidade são provenientes de conflitos sociais. Para demonstrar isso, ele comenta alguns dos principais limites físicos atribuídos à sustentabilidade; trata- 
se dos (I) limites de crescimento da população; (II) limites dos recursos naturais; e III) limites dos resíduos ou detritos.

Os limites do crescimento populacional estão relacionados à forma social de produção adotada, do que propriamente com o aumento da população. É certo que a pobreza, vista como uma das consequências da explosão demográfica, é um problema social. Entretanto, na concepção do autor, não é a pobreza a causa dos problemas ambientais, mas a concentração de riquezas. Além disso, a distribuição geográfica da população também exerce influência. Exemplo disso é a concentração populacional nas grandes cidades, gerada, sobretudo, pelo processo migratório do campo à cidade. A problemática aqui diz respeito, principalmente, aos fatores que causam crescimento populacional e, consequentemente, problemas ambientais.

O cerne da questão está, portanto, na forma de produção. As relações de trabalho, por exemplo, modificam as modalidades de matrimônio e a composição familiar, que são determinantes importantes do ritmo de crescimento populacional. Foladori (2001) apresenta, por exemplo, que na Europa no século XVIII, a constituição familiar mudou drasticamente devido ao advento do trabalho assalariado, pois o salário fez com que os casamentos fossem mais precoces e com mais filhos por famílias. A forma de crescimento populacional pode variar entre as culturas, mas sempre tem relação com a forma social de produção.

Quanto aos limites impostos pelos recursos naturais, o que se leva em consideração não é a finitude do planeta terra em termos naturais físicos, mas como a sociedade gerencia os seus recursos através do desenvolvimento técnico, pois um recurso produtivo, para ser renovável, depende de fatores sociais. Assim,

\footnotetext{
"o que interessa à espécie humana não são os limites físicos absolutos, nem se certos recursos são renováveis em termos absolutos e outros não, mas como determinados recursos se convertem em renováveis ou não renováveis, em função de uma determinada estrutura de classes sociais e do nível de desenvolvimento técnico da sociedade em seu conjunto" (FOLADORI, 2001, p.127).
}

Historicamente, a humanidade vem excluindo do meio natural os recursos ditos renováveis. A percepção dos recursos naturais segundo apenas as suas características materiais não é suficiente para manter um recurso renovável.

Os limites dos resíduos também estariam relacionados, segundo Foladori (2001), prioritariamente, às relações sociais. A poluição, por exemplo, depende em grande medida da consciência do problema. 0 agravamento da poluição levaria, teoricamente, as nações a assinarem acordos internacionais para a 
correção gradativa desse problema, uma vez que a atmosfera seria entendida como um bem coletivo. Entretanto, a história mostra que interesses particulares dos países estão na frente da relação entre a humanidade e a natureza, de sorte que nem mesmo as grandes conferências sobre meio ambiente e desenvolvimento promovidas pelas Nações Unidas têm surtido os efeitos esperados.

A luta pela convivência harmoniosa entre o homem e a natureza ultrapassa os limites impostos por esta, mas depende, primeiramente, da relação homem-homem.

\begin{abstract}
"O ser humano como espécie nunca se defronta com limites físicos, previamente, ocorrem enfrentamentos entre grupos e classes sociais. Não se trata de existir ou não limites físicos; para a prática humana, o problema não é esse, mas de contradições sociais que provocam diferenças de acesso à natureza e que podem conduzir, eventualmente, a catástrofes ambientais. Colocar dessa forma o problema significa considerar que as soluções para as questões ambientais não são técnicas, como seriam se o problema fosse de limites físicos. Ao contrário, as soluções são, em primeira instância, sociais. Somente depois de resolver as contradições sociais, as alternativas técnicas ganham sentido" (Foladori, 2001, p. 137).
\end{abstract}

Desta forma, a resposta às crises ambientais depende, primeiramente, do entendimento e enfrentamento das contradições das relações sociais de produção, pois os desajustes entre o ser humano e a natureza são causados, essencialmente, pela crise das relações sociais entre os seres humanos.

Isto não significa que não existam os problemas ambientais e que para alcançar a sustentabilidade não se deva considerar as questões ambientais físicas, ao contrário, ao contrário, a sustentabilidade só é factível se forem levadas em conta, prioritariamente, as relações sociais, mas sem esquecer as questões que envolvem o ambiente físico.

Um outro fator que exerce papel relevante na promoção do desenvolvimento sustentável é o Estado. Binswanger (1999) comenta que para alcançar o desenvolvimento sustentável é necessário que o Estado elimine os incentivos que institucionalizam a depleção dos recursos naturais e a destruição do meio ambiente. A propriedade da terra, por exemplo, deveria ser melhor definida, a fim de que os proprietários, em vez de ficarem livres para extrair e usar os recursos naturais encontrados sobre e dentro do solo, possam preservar uma parte dessa propriedade.

Além disso, como os países hoje em dia trabalham em cooperação, rompendo as fronteiras geográficas, as regras para se alcançar o desenvolvimento sustentável também devem ser aplicadas no campo da política de comércio internacional, especificamente no âmbito da OMC (Organização 
Mundial do Comércio), que atualmente congrega 149 países-membros. Quanto a essa questão, Jurg Minsch apud Binswanger (1999, p.54) propõe:

a) Integrar os princípios básicos de política ambiental (como o princípio do poluidor-pagador, obrigação de se declarar o conteúdo material dos produtos), nos acordos da OMC;

b) considerar, como subvenção proibida, o chamado dumping ambiental, isto é, os custos de produção baixos provocados por baixos padrões ambientais;

c) observar mecanismos que permitam uma (re)transferência das receitas de tarifas verdes para os países menos desenvolvidos.

Estas opções precisam ser engendradas continuamente, pois a sustentabilidade não é uma meta a ser atingida, mas um processo contínuo. As políticas em busca do desenvolvimento sustentável não devem se limitar a pequenos espaços temporais, mas serem criativas e preocupadas com o longo prazo, atingindo mais de um século de alcance (PROOPS et al., 1999).

Uma das ações relevantes que o Estado realiza é a promoção de políticas que contribuam para a promoção do desenvolvimento sustentável. Essas políticas objetivarão, inicialmente, examinar em detalhe as diferenças existentes entre a tecnologia atualmente utilizada, a estrutura de capital, a demanda final e o estado da natureza no presente e estimativamente no futuro. Segundo Proops et al. (1999), os objetivos são: (I) garantir a reestruturação do estoque de capital, eliminar técnicas ultrapassadas e danosas à natureza e adotar novas técnicas mais eficientes; (II) promover a "renovação" da natureza; e (III) por meio de uma mudança institucional e na educação, adequar os padrões de consumo, tornando-os compatíveis com a tecnologia e com a capacidade de suporte da natureza.

Entretanto, em termos práticos, a operacionalização do desenvolvimento sustentável continua ineficiente. A organização das nações unidas (ONU), por exemplo, entende que o desafio está não somente na teorização do tema, mas também na implementação de medidas práticas, como a implantação da chamada Agenda $21^{4}$. ,

A proposta formulada durante a conferência exortava os países, estados e municípios a elaborarem suas agendas 21 voltadas para o desenvolvimento sustentável de médio e longo prazo. Na prática, a agenda 21 tornou-se essencial para os formuladores de políticas públicas, retirando-se dela conceitos, propostas e ideias para adaptá-las às condições específicas regionais e locais. O desafio maior acabou sendo a tradução dos conceitos e propostas contidos nos 40 capítulos da agenda 21 em ações práticas. 
É certo que para se alcançar a sustentabilidade, no seu sentido mais amplo, alguns desafios devem ser superados, como: eliminação da pobreza, diminuição do consumo, novo modelo de produção, controle da poluição, alternativas energéticas, controle da população, recuperação ambiental, políticas ambientais locais.

Além do mais, não se deve perder de vista o caráter equitativo, onde vários elementos devem compor a agenda da sustentabilidade, alcançando todo o conjunto da sociedade. Conforme mostra a figura 2.6, a proposta do desenvolvimento sustentável tem em vista o compromisso com as gerações futuras, ecossistemas, pobres e com a participação popular.

Figura 6 - Compromisso do desenvolvimento sustentável

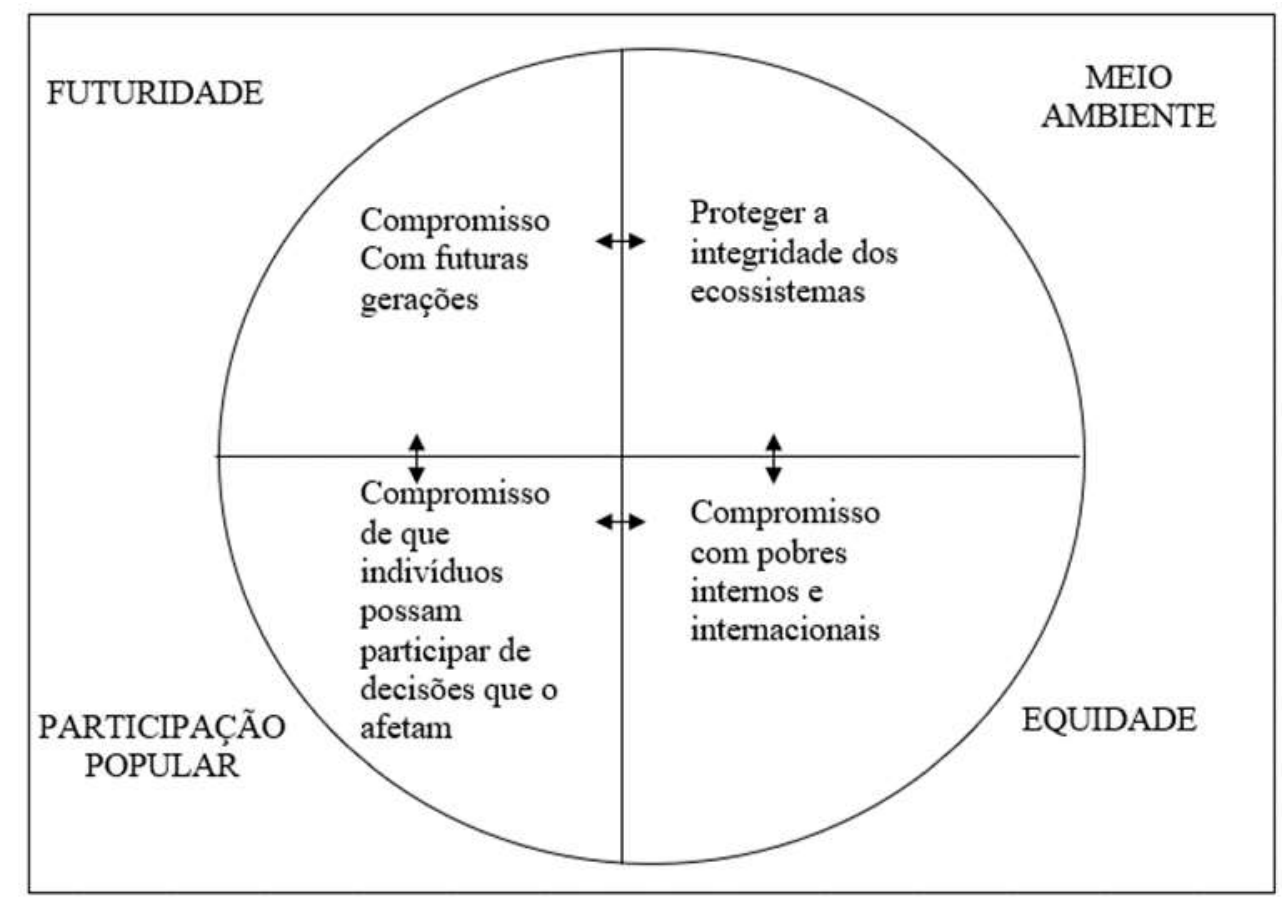

Fonte: Ribeiro (1999)

Não obstante, as políticas de desenvolvimento sustentável, para serem eficazes, precisam contemplar as especificidades locais. Além disso, vários fenômenos presentes na atualidade, como a chamada globalização, devem ser levados em conta na elaboração das agendas públicas. A reflexão em torno das características locais deve ser feita simultaneamente com um pensar global. Assim, a relação entre o global e o local tem ganhado cada vez mais relevância no processo de desenvolvimento local sustentável. 


\section{CONSIDERAÇÕES FINAIS}

Dentro do atual cenário mundial (escassez de recursos naturais, aquecimento global, crises ambientais), a questão da sustentabilidade torna-se palavra-chave na tentativa de pelo menos entender esses novos rumos que a economia mundial está tomando. Sendo assim, pensar em desenvolvimento deve ser acompanhado do pensar em meio ambiente, uma vez que ambos são inseparáveis. Essa relação ou binômio meio ambiente-desenvolvimento somente inexiste quando há um ecossistema intocado, que pode existir independentemente do meio ambiente. Isso ocorre porque há ecossistemas que não levam em conta a presença humana e nunca foram explorados ou conhecidos por algum homem. Quando o homem se relaciona com um ecossistema ele cria relações ambientais que alteram o seu entorno.

Pensar em desenvolvimento e meio ambiente deve ser acompanhado de uma reflexão em torno do que estar acontecendo com a sociedade atual: escassez de recursos naturais, degradação ambiental, desemprego. Tal cenário aponta para uma necessária e urgente mudança nas relações econômicas, sociais e ambientais.

Nesse sentido, a proposta conceitual do desenvolvimento sustentável, serve, no mínimo, para mostrar que a atual estratégia consolidada no capitalismo não se mostra durável, e que novas metodologias deverão fazer parte da agenda capitalista. Estudos apontando os limites institucionais ao desenvolvimento sustentável serão relevantes para engrandecer esse debate, uma vez que as políticas públicas, em interação com os diversos atores sociais, são colunas de sustentação desse modelo de desenvolvimento.

O objetivo desse artigo foi realizar um resgate histórico e teórico dos principais conceitos envolvendo temas como economia ambiental, economia ecológica e desenvolvimento sustentável. Por serem temas em pleno desenvolvimento, novas pesquisas têm sida realizadas e publicadas constantemente no intuito de amadurecer as ideias e propostas contidas nesse trabalho. 


\section{REFERÊNCIAS}

BINSWANGER, Hans Christoph. Fazendo a sustentabilidade funcionar. In: CAVALCANTI, Clóvis (Org.). Meio ambiente, desenvolvimento sustentável e políticas públicas. São Paulo: ed. Cortez/Fundação Joaquim Nabuco, 1999.

CAVALCANTI, Clóvis. Desenvolvimento sustentável e gestão dos recursos naturais: referências conceptuais e de política. In: Educação, ambiente e sociedade: ideias e práticas em debate. Espírito Santo: programa de comunicação ambiental - CST, 2004.

CAMARGO, A. L. B. Sustentabilidade - Entraves globais e reflexões. In: Desenvolvimento Sustentável - dimensões e desafios. Campinas, Papirus, p. 113-124, 2003.

COIMBRA, Ávila. O outro lado do meio ambiente: uma incursão humanista na questão ambiental”. Campinas/SP: Millennium editor, 2002.

CUNHA, L. H. e COELHO, M. C. N. Política e gestão ambiental. In: CUNHA, S. B. e GUERRA, A. J. T. (Orgs). A questão ambiental - diferentes abordagens. Rio de Janeiro, Bertrand Brasil, p. 43-79, 2003.

FOLADORI, Guilhermo. Limites do desenvolvimento sustentável. São Paulo: editora da Unicamp, 2001.

FONSECA, J. J. S. Metodologia da pesquisa científica. Fortaleza: UEC, 2002.

GIL, A. C. Como elaborar projetos de pesquisa. São Paulo: Atlas, 2002.

HUNT, E. K. História do Pensamento Econômico. Rio de Janeiro: Campus, 1986.

LEFF, Henrique. Ecologia, capital e cultura: racionalidade ambiental, democracia participativa e desenvolvimento sustentável". Blumenau: Ed da FURB, 2000.

Vozes, 2001.

Saber Ambiental: Sustentabilidade, racionalidade, complexidade, poder". Petrópolis:

MAGALHÃES, A. Um estudo de desenvolvimento sustentável no nordeste semiárido". In: CAVALCANTI, C (org). Desenvolvimento e natureza - estudos para uma sociedade sustentável. Recife/São Paulo: FUNDAJ/Cortez, 2003.

MIKHAILOVA, Irina. SUSTENTABILIDADE: evolução dos conceitos teóricos e os problemas da mensuração prática. Revista Economia e Desenvolvimento, n. 16, p. 22-41, 2004.

PEREIRA, Paulo Afonso S. Sustentabilidade e Gestão: Ciência, Política e Técnica. In: Rios, Redes e Regiões. Porto Alegre: Ed AGE, p. 19-49, 2000.

PROOPS, John et al. Realizando um mundo sustentável e o papel do sistema político na consecução de uma economia sustentável. In: CAVALCANTI, Clóvis (Org.). Meio ambiente, desenvolvimento sustentável e políticas públicas. São Paulo/Recife: ed. Cortez/Fundação Joaquim Nabuco, 1999.

PYNDICK, Robert S. e RUBINFELD, Daniel L. Microeconomia. 5a ed. São Paulo: Prentice Hall, 2000. 
ROMEIRO, Ademar Ribeiro. Economia ou Economia Política da Sustentabilidade. In: MAY, Peter H (org.) et al. Economia do Meio Ambiente. Rio de Janeiro: ELSEVIER, 2003.

SACHS, Ignacy. Estratégias de transição para o século XXI. In: BURSZTYN, Marcel (org). Para pensar o desenvolvimento sustentável. São Paulo: Ed. Brasiliense, 1993.

SARTORI, S., LATRÔNICO, L., CAMPOS, L. M. S. Sustentabilidade e desenvolvimento sustentável: uma taxonomia no campo da literatura. Ambiente e Sociedade, v. 17, n. 1, p. 1-22, 2014. 


\section{NOTAS}

Nota 1

Atribui-se a autoria do termo ecodesenvolvimento ao economista Ignacy Sachs da Escola de Altos Estudos em Ciências Sociais (EHESS) de Paris.

Nota 2

A função de produção "mostra o produto máximo que uma empresa pode obter para cada combinação especificada de insumos". (Pyndick e Rubinfeld, 2002, p.175)

Nota 3

A esse respeito, consultar Cunha e Coelho (2003, p.43-79)

Nota 4

A Agenda 21 é um documento de 40 capítulos que foi resultado da conferência das Nações Unidas sobre meio ambiente e desenvolvimento, conhecida como ECO 92/Rio 92, realizada na cidade do Rio de Janeiro no ano de 1992. 


\section{Capítulo 22}

doi) $10.37423 / 210804601$

CINZA VEGETAL COMO FONTE ALTERNATIVA DE POTÁSSIO NA NUTRIÇÃO DA CULTURA DE ALFACE (LACTUCA SATIVA)

Ruy Borges da Silva

Roberta de Freitas Souza

FERNANDA BORGES MARTINS
INSTITUTO FEDERAL DE EDUCAÇÃO,

CIÊNCIA E TECNOLOGIA DO TOCANTINS

INSTITUTO FEDERAL DE EDUCAÇÃO, CIENNCIA E TECNOLOGIA DO TOCANTINS UNIVERSIDADE FEDERAL DA PARAÍBA CAMPUS AREIA 
Resumo: No período de outubro a dezembro de 2011, avaliou-se o efeito de doses crescentes de cinza vegetal $\left(0,5,10,15,20\right.$ e 30 t ha $\left.^{-1}\right)$ na produção de alface variedade Crespa Repolhuda. O experimento teve um delineamento inteiramente casualizado com quatro repetições, em solo pobre em matéria orgânica e textura arenosa, tendo sido conduzido no Povoado Santa Tereza, nas imediações do Campus do Instituto Federal de Educação, Ciência e Tecnologia do Tocantins, em Araguatins-TO. A adição de cinza vegetal proporcionou aumentos na produtividade e nos níveis de Potássio (K) do solo. $\mathrm{Na}$ dose de $15 \mathrm{t} \mathrm{ha}^{-1}$ a produtividade estimada foi maior que nos outros tratamentos, e na dose de 30 $\mathrm{t} \mathrm{ha}^{-1}$ a cinza proporcionou o maior incremento de $\mathrm{K}$ no solo, sendo que o aumento de $\mathrm{K}$ foi proporcional à dose aplicada.

Palavras-chave: análise de solo, produtividade, Tocantins. 


\section{INTRODUÇÃO}

Nas últimas décadas, a busca por sistemas de produção mais adaptados e menos dependentes de adubos químicos industrializados tem aumentado devido à preocupação em produzir preservando o meio ambiente (Salmi et al., 2009).

As cinzas provenientes da queima de madeira nos fornos de olaria, quando descartadas de forma concentrada, eutrofiza a camada arável e muda a dinâmica do sistema solo. Quando isso acontece em solos com alta condutividade hidráulica, associado a intensas precipitações como na região de Araguatins, as bases são lixiviadas para os igarapés ou para o lençol freático, gerando problemas ambientais incalculáveis. Por outro lado, o aproveitamento dessas cinzas na agricultura seria duplamente benéfico, pois pode melhorar a produtividade das culturas e minimizar o efeito poluente desse material no ambiente. No entanto, poucos trabalhos podem ser observados nas literaturas disponíveis neste sentido e entre esses, destacam-se os que se dedicam ao uso como corretivo do solo/adubação em espécies florestais (Blanco \& Zambo, 1993). O objetivo deste trabalho é avaliar os efeitos da aplicação de diferentes doses de cinzas vegetal na nutrição e produção da cultura de alface.

\section{MATERIAL E MÉTODOS}

O experimento foi conduzido num Neossolo Quartzarênico (EMBRAPA, 2006), localizado no Povoado Santa Tereza, nas imediações do Campus Araguatins, entre os meses de Outubro e Dezembro de 2011. As análises químicas e físicas do solo (EMBRAPA, 1997) apresentaram os seguintes resultados: 0 a 10 $\mathrm{cm}$ de profundidade de coleta: $\mathrm{pH}$ em água 5,$2 ; \mathrm{P}=10,12 \mathrm{mg} / \mathrm{dm}^{3} ; \mathrm{K}=14 \mathrm{mg} / \mathrm{dm}^{3} ; \mathrm{Ca}=1,2 \mathrm{cmol} / \mathrm{dm}^{3}$; $\mathrm{Mg}=0,2 \mathrm{cmol} / \mathrm{dm} \mathrm{dm}^{3} ; \mathrm{Al}=0,2 \mathrm{cmol} / \mathrm{dm}^{3} ; \mathrm{H}+\mathrm{Al}=2,15 \mathrm{cmol}_{\mathrm{c}} / \mathrm{dm}^{3} ; \mathrm{S}=1,44 \mathrm{cmol} / \mathrm{dm}^{3} ; \mathrm{T}=3,58$ $\mathrm{cmol}_{\mathrm{c}} / \mathrm{dm}^{3} ; \mathrm{V} \%=40,1 \mathrm{cmol} / \mathrm{dm}^{3}$. Na análise da amostra de 10 a $20 \mathrm{~cm}$ o pH em água foi de 4,8; $\mathrm{P}=$ $5,72 \mathrm{mg} / \mathrm{dm}^{3} ; \mathrm{K}=11 \mathrm{mg} / \mathrm{dm}^{3} ; \mathrm{Ca}=0,4 \mathrm{cmol}_{\mathrm{c}} / \mathrm{dm}^{3} ; \mathrm{Mg}=0,1 \mathrm{cmol}_{\mathrm{c}} / \mathrm{dm}^{3} ; \mathrm{Al}=0,6 \mathrm{cmol} / \mathrm{dm}^{3} ; \mathrm{H}+\mathrm{Al}=$ $2,81 \mathrm{cmol}_{\mathrm{c}} / \mathrm{dm}^{3} ; \mathrm{S}=0,53 \mathrm{cmol}_{\mathrm{c}} / \mathrm{dm}^{3} ; \mathrm{T}=3,33 \mathrm{cmol}_{\mathrm{c}} / \mathrm{dm}^{3} ; \mathrm{V} \%=15,84 \mathrm{cmol}_{\mathrm{c}} / \mathrm{dm}^{3}$. Nas duas amostras as percentagens de Areia, Argila e Silte foram a mesma: 90,69\% de areia, 6,59\% de argila e 2,72\% de silte.

Os tratamentos consistiram em aplicação de doses crescentes de cinza vegetal equivalentes a 0, 5, 10, 15, 20 e $30 \mathrm{t} \mathrm{ha}^{-1}$. Os tratamentos foram: T1-0 cinzas, T2-5 t ha-1, T3-10 t ha-1, T4-15 t ha-1, T5- $20 \mathrm{t} \mathrm{ha}^{-}$ ${ }^{1}$ e T6-30 t ha-1. O delineamento experimental utilizado foi o inteiramente casualizado, com seis tratamentos e quatro repetições. A cinza foi incorporada nas parcelas 20 dias antes do transplantio. A cinza vegetal foi fornecida pela Cerâmica Taquari, na cidade de Araguatins-TO. Foi realizada adubação 
química para os nutrientes P e N. O fósforo (P2O5), na forma de Super Simples, foi aplicado na dose de $400 \mathrm{~kg} \mathrm{ha}^{-1}$ e incorporado no solo dos canteiros 5 dias antes do transplantio e o $\mathrm{N}$, na forma de uréia, foi aplicado na dose total de $150 \mathrm{~kg} \mathrm{ha}^{-1}$ em cobertura, divida em três aplicações de $50 \mathrm{~kg} \mathrm{ha}^{-1}$ cada, aos 15, 30 e 40 dias após o transplantio. As doses de P2O5 e $\mathrm{N}$ foram as recomendadas por Fontes (1999).

A variedade de alface plantada foi a Crespa Repolhuda. As mudas foram produzidas em bandejas de isopor e transplantadas para as parcelas aos 34 dias após germinação, quando cada muda apresentou dois pares de folhas permanentes. O espaçamento entre plantas utilizado foi $25 \times 25 \mathrm{~cm}$. Cada parcela teve 2,0 m2 de área com 4 linhas de plantio na qual foram avaliadas as duas linhas centrais para eliminar o efeito de bordas. O número de cabeças de alface avaliadas foi de até 16 por parcela. Para controle de plantas daninhas foram realizadas três capinas em todas as parcelas. A irrigação foi realizada através de um sistema de microaspersão.

Cada parcela recebeu aplicação de adubo orgânico formado por uma mistura de esterco de gado curtido e casca de arroz carbonizada na proporção de 3:1, na dose de 10,0 kg parcela-1 ou $5 \mathrm{~kg} \mathrm{~m}^{-2}$. A aplicação deste composto teve por objetivo melhorar a estrutura física do solo.

Amostras de terra de $0-20 \mathrm{~cm}$ foram coletadas nos canteiros antes do plantio e depois da colheita para caracterização química de macronutrientes segundo metodologia preconizada pela Embrapa (1997). Essas coletas foram realizadas após aplicação da cinza vegetal.

A colheita para avaliação ocorreu aos 45 dias após o transplantio. As plantas foram retiradas com raiz do solo, lavadas e pesadas. As variáveis analisadas foram: peso fresco da cabeça com raiz, peso fresco da cabeça sem raiz e características químicas do solo.

Aos resultados foram aplicados análises de variância (ANOVA), as médias foram comparadas pelo teste de Tukey a $5 \%$ de probabilidade. A análise estatística foi realizada com o auxilio do aplicativo computacional ASSISTAT versão 7.6 beta (Silva \& Azevedo, 2002).

\section{RESULTADOS E DISCUSSÃO}

A aplicação de doses crescentes de cinza vegetal no solo mostrou uma tendência no aumento do peso médio das cabeças frescas com e sem raiz. Sendo que o maior incremento de peso em relação à testemunha ocorreu no tratamento 4, com dose de $15 \mathrm{t} \mathrm{ha}^{-1}$ (tabela 1 ), concordando com os resultados observados por Blanco \& Zambon (1993) onde os maiores pesos médios foram observados nas doses de 10 a 15 t ha-1. Segundo Osaki (1990) apud Blanco \& Zambon (1993) os aumentos de produção até 
essas doses se devem às melhorias nas condições químicas do solo e pelo fato da cinza contribuir para a absorção de outros nutrientes.

Na tabela 1 observa-se que o maior peso médio obtido ocorreu na dose de $15 \mathrm{t} \mathrm{ha}^{-1}$, apresentando um ganho de $17,6 \%$ em relação à testemunha (sem cinza). Nos tratamentos correspondentes às doses de 5 a $15 \mathrm{t} \mathrm{ha}^{-1} \mathrm{o}$ ganho de peso apresentou crescimento proporcional à dose, e nos tratamentos de $20 \mathrm{e}$ $30 \mathrm{t} \mathrm{ha}^{-1}$ observou-se uma pequena diminuição no ganho de peso, podendo isso ter relação com a elevação da concentração salina do solo, e pela grande alcalinidade da cinza vegetal. Mello (1930) apud Blanco \& Zambon (1993) relata que o uso abusivo de cinzas pode prejudicar o sistema radicular das plantas devido a sua alta alcalinidade. Mas ainda assim, o peso médio nas dosagens mais altas (20 e $30 \mathrm{t} \mathrm{ha}^{-1}$ ) foi superior ao peso médio da testemunha.

Tabela 1 - Doses de cinza vegetal aplicada $\left(\mathrm{t} \mathrm{ha}^{-1}\right)$, peso médio da cabeça fresca de alface com e sem raiz (g) e produtividade estimada (t ha-1) de alface variedade Crespa Repolhuda. Araguatins-TO, 2011.

\begin{tabular}{cccc}
\hline $\begin{array}{c}\text { Cinza } \\
\text { Vegetal } \\
\left(\mathrm{t} \mathrm{ha}^{-1}\right)\end{array}$ & $\begin{array}{c}\text { Peso Médio da Cabeça Fresca com } \\
\text { Raiz }\end{array}$ & $\begin{array}{c}\text { Peso Médio da Cabeça Fresca sem } \\
\text { Raiz } \\
(\mathrm{g})\end{array}$ & $\begin{array}{c}\text { Produtividade } \\
\text { Estimada } \\
\left(\mathrm{t} \mathrm{ha}^{-1}\right)\end{array}$ \\
\hline 0 & $188,14 \mathrm{a}$ & $173,00 \mathrm{a}$ & $27,68 \mathrm{a}$ \\
5 & $194,68 \mathrm{a}$ & $179,83 \mathrm{a}$ & $28,77 \mathrm{a}$ \\
10 & $200,49 \mathrm{a}$ & $183,51 \mathrm{a}$ & $29,36 \mathrm{a}$ \\
15 & $221,22 \mathrm{a}$ & $202,62 \mathrm{a}$ & $32,42 \mathrm{a}$ \\
20 & $194,23 \mathrm{a}$ & $179,12 \mathrm{a}$ & $28,66 \mathrm{a}$ \\
30 & $214,84 \mathrm{a}$ & $200,28 \mathrm{a}$ & $32,04 \mathrm{a}$ \\
\hline CV\% & 12,09 & 12,30 & 12,30 \\
\hline
\end{tabular}

CV\% = Coeficiente de Variação em \%; Médias seguidas de mesma letra na coluna não diferem pelo teste de Tukey a $5 \%$ de probabilidade.

O aumento da produtividade foi proporcional ao ganho de peso registrado nos tratamentos, sendo que a maior produtividade ocorreu na dose de 15 t ha-1 (tratamento 4), apresentando um incremento médio na produção de 4,74 t ha-1 em relação á testemunha. No tratamento 5 (20 t ha-1) houve uma queda na produtividade, como também foi observado no peso médio das cabeças, porém, estatisticamente não houve diferença entre as produtividades, como pode ser observado na tabela 1. A aplicação de cinzas no solo proporcionou um aumento expressivo dos teores médios de potássio (K) do solo em cada tratamento. $\mathrm{O}$ aumento foi proporcional à dose aplicada, sendo que no tratamento 6 
(30 $\mathrm{t} \mathrm{ha}^{-1}$ ) o incremento de $\mathrm{K}$ no solo foi de $123,5 \mathrm{mg} \mathrm{dm}-3$ em relação à testemunha na data do transplantio (Figura 1). Os aumentos dos teores de K no solo não foram significativos no teste de Tukey a $5 \%$ de probabilidade, conforme pode ser observado na tabela 2 .

No tratamento 1 (testemunha) podemos observar também que o teor de potássio no solo na data do transplantio, encontrava-se numa faixa considerada muito boa por Alvares et al. (1999), no entanto esse valor foi em consequência da aplicação do composto orgânico (esterco + casca de arroz carbonizada) na dose de $10 \mathrm{~kg}$ por parcela em todos os tratamentos. Na composição do composto orgânico aplicado existia $25 \%$ de casca de arroz carbonizada. A casca de arroz carbonizada é muito rica em potássio (K). Guerrini \& Trigueiro (2004) observaram em seu experimento sobre substratos à base de biossólidos e casca de arroz carbonizada que a casca de arroz aumentou o teor de K2O nos substratos onde foram aplicados, e ainda verificaram que a porcentagem de K2O na casca de arroz carbonizada foi de $0,63 \%$, sendo o potássio o nutriente mais presente.

Após a colheita da alface os níveis de potássio (K) ainda permaneceram numa faixa considerado boa por Alvares et al. (1999). A diminuição dos níveis de K entre o plantio e a colheita se deu pela absorção deste macronutriente pela cultura como também por perdas por lixiviação, pois no período ocorreu elevada precipitação pluviométrica. Segundo Ernani et al. (2007) a lixiviação do potássio é um fenômeno importante em solos com baixa CTC, especialmente em áreas com alta precipitação pluvial, como é o caso do município de Araguatins, onde os solos predominantes apresentam baixos teores de argila, baixa CTC e a incidência de chuva é expressiva. Durante o período do experimento (outubro a dezembro de 2011) a quantidade de chuva acumulada chegou a 336,4 mm (INMET, 2012).

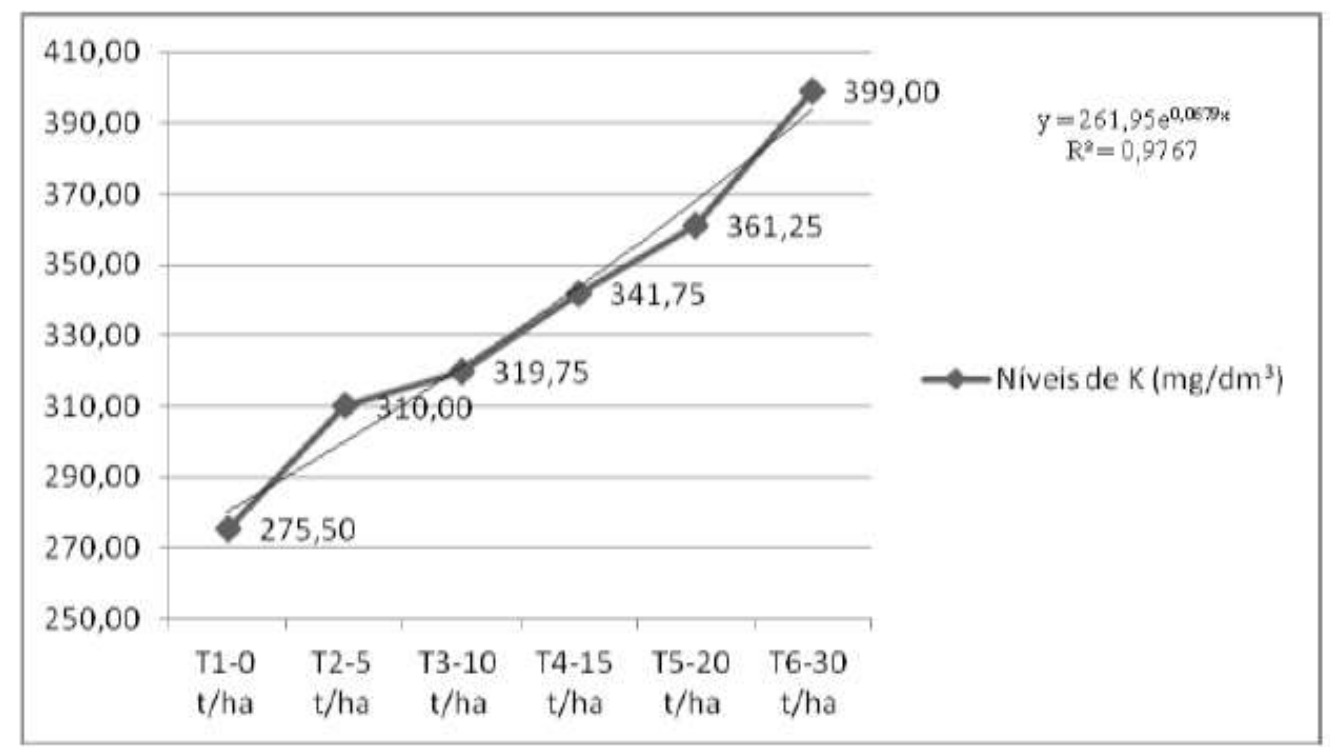

Figura 1 - Níveis de K disponíveis no solo nos respectivos tratamentos. 
Tabela 2 - Doses de cinza vegetal aplicada $\left(\mathrm{t} \mathrm{ha}^{-1}\right)$, níveis de $\mathrm{K}$ disponíveis no solo no plantio e após a colheita de alface variedade Crespa Repolhuda. Araguatins-TO, 2011.

\begin{tabular}{ccc}
$\begin{array}{c}\text { Cinza Vegetal } \\
\left(\mathrm{t} \mathrm{ha}^{-1}\right)\end{array}$ & $\begin{array}{c}\text { Níveis de K disponíveis no solo no plantio } \\
\left(\mathrm{mg} \mathrm{dm}^{-3}\right)\end{array}$ & $\begin{array}{c}\text { Niveis de K disponíveis no solo após a colheita } \\
\left(\mathrm{mg} \mathrm{dm}^{-3}\right)\end{array}$ \\
\hline 0 & $275,50 \mathrm{a}$ & $84,25 \mathrm{a}$ \\
5 & $310,00 \mathrm{a}$ & $95,75 \mathrm{a}$ \\
10 & $319,75 \mathrm{a}$ & $90,25 \mathrm{a}$ \\
15 & $341,75 \mathrm{a}$ & $131,75 \mathrm{a}$ \\
20 & $361,25 \mathrm{a}$ & $105,25 \mathrm{a}$ \\
30 & $399,00 \mathrm{a}$ & $110,33 \mathrm{a}$ \\
\hline $\mathrm{CV} \%$ & 32,07 & 47,48 \\
\hline
\end{tabular}

CV\% = Coeficiente de Variação em \%; Médias seguidas de mesma letra na coluna não diferem pelo teste de Tukey a $5 \%$ de probabilidade.

Neste experimento as variáveis comerciais não puderam ser analisadas devido à cultura ter apresentado estiolamento (alongamento do caule) e aparecimento da inflorescência antecipada. $O$ estiolamento ocorreu devido às condições climáticas do período, como altas temperaturas, alta umidade relativa do ar e alta precipitação pluviométrica. Segundo Tibiriçá et al. 2004, em regiões quentes, ou em época de verão, se a alface é exposta a temperaturas elevadas durante o crescimento vegetativo, ela passa rapidamente para a fase reprodutiva, ocorrendo o estiolamento e, posteriormente, o surgimento da inflorescência, o que desvaloriza a produção comercial ao promover colheitas antecipadas e de qualidade inferior.

Em consequência do estiolamento, todos os tratamentos do experimento foram prejudicados, resultando em alfaces de menor peso comercial, em virtude da rápida passagem do crescimento vegetativo para o reprodutivo. Entretanto, nota-se que ocorre uma tendência a um aumento de matéria fresca da parte aérea com o aumento das doses de cinza vegetal. Este fato demonstra a importância da utilização de cinzas vegetal para a fertilização e correção do solo que será cultivado a cultura.

\section{CONCLUSÕES}

O aumento do peso médio das cabeças de alface e dos teores de potássio (K) no solo foi proporcional às doses de cinza vegetal aplicada. 
De acordo com os resultados, a melhor dose a ser aplicada é a de 15 t ha-1 de cinza vegetal, por ter refletido em maior produtividade da cultura da alface.

Em dosagens acima de 15 t ha-1 é possível ocorrer salinização dos solos, prejudicando a produção da cultura.

\section{AGRADECIMENTOS}

Agradecemos ao IFTO pelo apoio financeiro para execução deste trabalho e pela bolsa de IC concedida. Ao senhor Francisco Vitor por ceder sua propriedade para implantação do experimento. 


\section{REFERÊNCIAS}

ALVARES V., V. H. et al. Interpretação dos resultados das análises de solo. In: RIBEIRO, A. C.; GUIMARÃES, P. T. C.; ALVARES V., V. H. Recomendações para o uso de corretivos e fertilizantes em Minas Gerais: 5 Aproximação. Viçosa: Comissão de Fertilidade do Solo do Estado de Minas Gerais, 1999. cap. 5, p. 25-32.

BLANCO, M. R. D. V.; ZAMBON, N. F. R. A. Cinza vegetal como fonte de nutrientes e corretivos de solo na cultura de alface. Horticultura brasileira, campinas, v. 11. n. 1, maio 1993.

EMBRAPA. Centro Nacional de Pesquisa de Solos. Manual de métodos de análise de solos. 2 ed. Rio de Janeiro, 1997. $212 \mathrm{p}$.

EMBRAPA. Centro Nacional de Pesquisa de Solos. Sistema brasileiro de classificação de solos. 2a ed. Rio de Janeiro: Embrapa solos, 2006. 306 p.

ERNANI, P. R.; ALMEIDA, J. A.; SANTOS, F. C. Potássio. In: NOVAIS, R. F.; ALVAREZ V., V. H.; BARROS, N. F.; FONTES, R. L. F.; CANTARUTTI, R. B.; NEVES, J. C. L. (Ed.) Fertilidade do

solo. Viçosa: SBCS, 2007. cap. 9, p. 552-594.

FONTES, P. C. R. Sugestões de Adubação para Hortaliças: alface. In: RIBEIRO, A. C.; GUIMARÃES, P. T. C.; ALVARES V., V. H. Recomendações para o uso de corretivos e fertilizantes em Minas Gerais: 5o Aproximação. Viçosa: Comissão de Fertilidade do Solo do Estado de Minas Gerais, 1999. p. 177.

GUERRINI, I. A.; TRIGUEIRO, R. M. Atributos físicos e químicos de substratos compostos por biossólidos e casca de arroz carbonizada. Rev. Bras. C. Solo, Viçosa, v. 28, p. 1069-1076, 2004.

INMET. Mapas do Boletim Agroclimatológico. Disponível em:

<http://www.inmet.gov.br/portal/index.php?r=agrometeorologia/boletimAgroclimatologico>. Acesso em: 09 ago. 2012.

SALMI, A. P.; ABBOUD, A. C. S.; GUERRA, J. G. M.; RISSO, I. A. M. Teores de nutrientes na

Biomassa da leguminosa flemingia macropylla In: CONGRESSO BRASILEIRO DE AGROECOLOGIA, 6.; CONGRESSO LATINO AMERICANO DE AGROECOLOGIA, 2., 09 a 12

de novembro de 2009, Curitiba. Agricultura familiar e camponesa: experiências passadas e presentes construindo um futuro sustentável: trabalhos... Curitiba: ABA: SOCLA, 2009. 01 p. 1013-1017.

SILVA, F. de A. S. e.; AZEVEDO, C. A. V. de. Versão do programa computacional Assistat para sistema operacional Windows. R. Bras. de Produtos Agroindustriais, Campina Grande, v. 4, n. 1, p. 71-78, 2002.

TIBIRIÇÁ, A. C. G.; BRITO, A. A. A. de.; BAÊTA, F. C. Produção de alface no verão: estufas como ambiente de cultivo. In: ENCONTRO NACIONAL DE ENGENHARIA DE PRODUÇÃO, 24., 2004,

Florianópolis. Anais... Florianópolis: ENEGEP, 2004, p. 418-425. 